\title{
Ninth Annual Report on Federal Agency Use of Voluntary Consensus Standards and Conformity Assessment
}

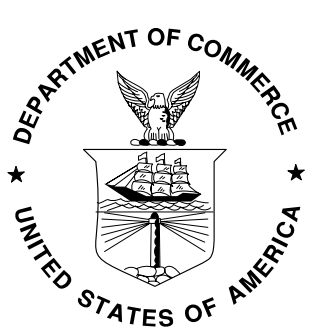

U.S. DEPARTMENT OF COMMERCE Carlos M. Gutierrez, Secretary TECHNOLOGY ADMINISTRATION

Robert C. Cresanti, Under Secretary of Commerce for Technology NATIONAL INSTITUTE OF STANDARDS AND TECHNOLOGY William A. Jeffrey, Director 


\section{Table of Contents}

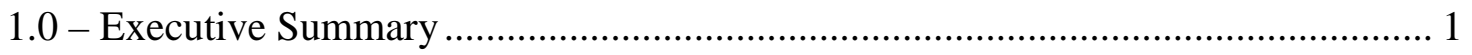

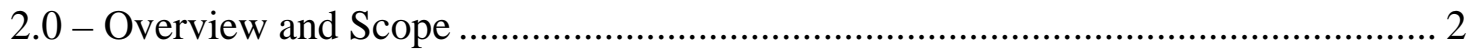

3.0 - Federal Agency Use of Standards ...................................................................... 2

3.1 - Government-Unique Standards Used in Lieu of Voluntary Consensus

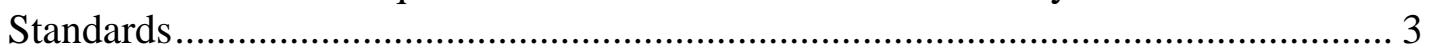

3.2 - Current Federal Agency Use of Voluntary Consensus Standards (VCSs) ........ 5

3.3 - Current Agency Reporting on Voluntary Consensus Standards Substituted for

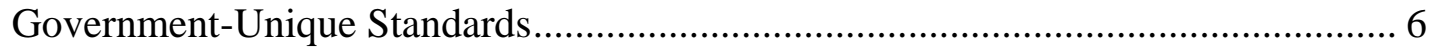

4.0 - Federal Participation in Private Sector Standards Activities ............................... 6

4.1 - Participation Data for FY 2005 .................................................................. 6

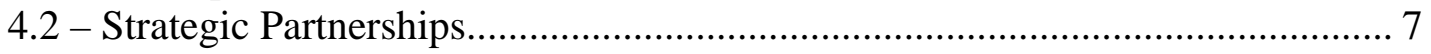

5.0 - Federal Agency Conformity Assessment Activities ......................................... 8

6.0 - Evaluation of the Effectiveness of OMB Circular A-119.................................. 10

7.0 - The Interagency Committee on Standards Policy.......................................... 11

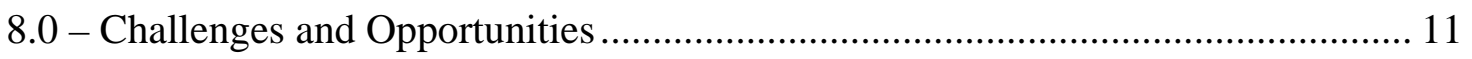

Appendix A - FY 2005 List of Federal Agencies That Report .............................. A-1

Appendix B - FY 2005 Federal Agency Use of Standards and Participation in Private

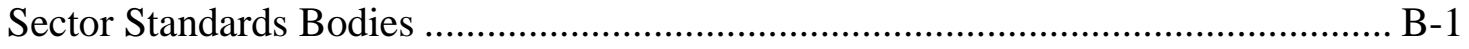

Appendix C -Government-Unique Standards Used in Lieu of Voluntary Consensus Standards

Appendix C.1 - Government-Unique Standards Used in Lieu of Voluntary Consensus Standards Incorporated in FY 2005 C-1

Appendix C.2 -Instances of Government-Unique Standards Used in lieu of Voluntary Consensus Standards Discontinued in FY 2005. 


\section{Summary Report on Federal Agency Use of Private Sector Standards And Conformity Assessment Activities for FY 2005}

\section{0 - Executive Summary}

The U.S. Department of Commerce's National Institute of Standards and Technology (NIST) prepares this summary report for the Office of Management and Budget (OMB) in compliance with OMB Circular A-119 and Public Law 104-113, the National Technology Transfer and Advancement Act (NTTAA). As required by Section 9 of the Circular, this report describes activities related to Federal use of voluntary consensus standards (VCSs) by 26 agencies during FY 2005. The report also summarizes voluntary agency reporting on coordination of conformity assessment activities.

As reported by agencies, the cumulative number of VCSs in use in their regulatory activities in FY 2005 stood at 6,229, a 37\% increase from FY 2004. New uses in FY 2005 totaled 1,670, of which 243 were substitutions for government-unique standards. The significant reported increase in use of VCSs in FY 2005 is primarily the result of continued improvements in the reporting process implemented by DHS, which reported 987 new uses. During the year, four government-unique standards were discontinued and one new one implemented. Since the enactment of the NTTAA there has been a fundamental shift in how the Federal government develops and deploys standards. Since the inception of this report, agencies have adopted and continue to use only a small number of government-unique standards in lieu of voluntary consensus standards. (See Table B-1). The Act has successfully encouraged agencies to first look to voluntary consensus standards to meet their needs rather than to develop government-unique standards.

The Department of Defense (DoD) continues to lead the Federal government in the use of VCSs. Data reported each year since 1997 do not include all nongovernmental standards currently in use by DoD, which launched its efforts to minimize use of governmentunique standards prior to the enactment of the NTTAA. DoD's inventory of private sector standards stood at 9,083 at the close of FY 2005.

The Federal government is a key player in the U.S. private sector voluntary standards system. The 3,954 agency representatives who participated in a total of 409 standards developing organizations in FY 2005 were instrumental in ensuring agency compliance with the NTTAA and the OMB Circular. Even more importantly, government participation means that government users understand both the intent and the content of specific standards. While the number of standards bodies with Federal agency participation continued to decline in FY 2005, the number of agency staff participating in standards activities reached an all-time high.

Reports for FY 2005 show that agencies now recognize or list a wide range of national and international private sector consensus standards as a component of agency guidance or recommendations in key areas. They also make "beyond-regulation" use of voluntary consensus bodies and of conformity assessment programs operated by the private sector. 
Some Federal agencies leverage their partnerships with the private sector in both the standards and conformity assessment realms to address national policy and technology needs. Partnership vehicles include standards panels and joint development of standards strategies and roadmaps in areas ranging from homeland security to health information.

\section{0 - Overview and Scope}

This report fulfills the reporting requirements of Section 12 of the NTTAA and of OMB Circular A-119. It describes Federal agency activities related to the use of private sector standards in regulation, procurement and conformity assessment during FY 2005. In close consultation with OMB, NIST formulates this report based on inputs submitted to NIST by Federal agencies in fulfillment of the requirements of OMB Circular A-119. Section 12 of the Act, enacted on March 7, 1996, directs Federal government agencies to achieve two main goals. First, the Federal government must achieve greater reliance on voluntary consensus standards developed by the private sector. Second, the Federal government must decrease its dependence on government-unique standards developed by and for the Federal government. The NTTAA also directs Federal agency personnel to participate in the activities of voluntary consensus standards developing organizations (SDOs) so that the SDOs remain familiar with the Federal government's position on standards and consider that position in their final standards documents. This provision is intended to help ensure that standards produced in the private sector will be more appropriate, and cost effective, for use by Federal agencies. While these policies have been a part of the Circular for many years, the enactment of the NTTAA served to codify these policies into statute, thereby reinforcing them.

\section{0 - Federal Agency Use of Standards}

The OMB Circular requires that Federal agencies use voluntary consensus standards in lieu of government-unique standards in their regulatory and procurement activities. However, a Federal agency is given the discretion to decide not to use existing voluntary consensus standards if the agency determines that use of such standards would either be inconsistent with applicable laws or otherwise impractical.

According to Section 6 of the OMB Circular:

"Use" means the incorporation of a standard in whole, in part, or by reference for procurement purposes, and the inclusion of a standard in whole, in part, or by reference in regulation(s).

"Impractical" includes circumstances in which such use would fail to serve the agency's program needs; would be infeasible; would be inadequate, ineffectual, inefficient, or inconsistent with agency mission; or would impose more burdens, or would be less useful, than the use of another standard. 
The Circular also directs agencies to establish a process for a continuing review of their use of standards for purposes of updating such use, including substitution of private sector standards for government-unique standards wherever possible.

NIST, through the Interagency Committee on Standards Policy (ICSP), coordinates the efforts of Federal agencies to report their use of standards in a clear and consistent manner and to eliminate confusing interpretations of the term "use" as well as in what has to be reported by Federal agencies. The ICSP established a work group in FY 2005 to: (1) review the reporting procedures for determining the number of private sector standards used by Federal agencies; and (2) establish guidelines as to what agencies should report. The group works with OMB as part of the continuing effort to increase the accuracy and consistency of agency data. The guidance produced by the new work group should help agencies present a more accurate report of the total number of the standards they use and of agency participation in standards activities.

In FY 2005, NIST also conducted its first intra-government training session to clarify agency responsibilities for reporting standards usage under the NTTAA. Approximately 20 representatives of various Federal agencies attended the NTTAA training session. The training included a round-table discussion of issues and problems in reporting agency use of standards. One major issue identified during the FY 2005 session was related to the turnover in agency staff. New staff members who are assigned reporting responsibilities are often unaware of the NTTAA, the Circular, and their agency's duties and responsibilities under both. This lack of awareness has sometimes led to inconsistent, incomplete, or delayed reporting. NIST plans to continue its training efforts for newer ICSP representatives so that the requirements of the NTTAA and the Circular are carried out effectively.

\section{1 - Government-Unique Standards Used in Lieu of Voluntary Consensus Standards}

A major goal of the NTTAA is to reduce the need for Federal government use of government-unique standards. Hence, Section 6 of the Circular requires that Federal agencies report such use and explain the reason(s) why their agencies must use government-unique standards in lieu of private sector standards. However, reporting of such use is limited to only those situations where an applicable private sector standard exists. If there is no applicable private sector standard available to address the agency's needs, then the use of a government-unique standard is not required to be reported. In the past, some agencies have reported the use of government-unique standards in cases where no applicable private sector standard was available. NIST continues to work with the agencies to clarify that no reporting is required in these cases.

Section 12 of the Circular allows Federal agencies to report their use of private sector standards on either a "categorical" or a "transactional" basis. Those agencies that report on a "categorical" basis are not required to list each instance that a government-unique standard is used in lieu of a private sector standard in procurement actions. Agencies that routinely reference private sector or government-unique standards in their numerous 
procurement actions can report such usage on a "categorical" basis if they meet other requirements outlined in the Circular. For example, the agency must maintain a centralized standards management system that identifies how the agency uses both government-unique and private sector standards. The agency must also maintain records on the groups or categories in which the agency uses government-unique standards in lieu of private sector standards. Such agencies are also required to have a system in place to ensure that government-unique standards are developed only when suitable private sector standards are not available for use. At present, only DoD and the National Aeronautics and Space Administration (NASA) consistently report on a "categorical” basis. In those cases when government-unique standards are required because private-sector standards do not exist, use of the government-unique standard is not subject to reporting.

Regulatory agencies must report their standards use on a "transactional” basis because they use far fewer standards in their rulemaking processes than do agencies, such as DoD, that engage in extensive procurement activities. This means that these agencies must report every time that a standard is used, typically by reference in a regulation.

Table 3.1 illustrates the use of government-unique standards (that is, the total number used, by agency and the U.S. Government as a whole, by year) in lieu of voluntary consensus standards since FY 1997, as well as the number of government-unique standards introduced and discontinued in each fiscal year. For FY 2005, the Department of Agriculture (USDA) reported the new use of a government-unique standard. The Government Printing Office (GPO) identified four instances where the use of government-unique standards was previously reported even though no applicable VCS existed. The four are recorded as discontinued. The Department of Interior and GPO reported new government-unique standards in FY 2005; however, they are not in lieu of voluntary consensus standards and therefore not included in the report.

\begin{tabular}{|l|r|r|r|r|r|r|r|r|r|}
\hline \multicolumn{7}{|c|}{ Table 3.1 - Government-unique Standards Used in Lieu of Voluntary } \\
\hline Agency & $\mathbf{1 9 9 7}$ & $\mathbf{1 9 9 8}$ & $\mathbf{1 9 9 9}$ & $\mathbf{2 0 0 0}$ & $\mathbf{2 0 0 1}$ & $\mathbf{2 0 0 2}$ & $\mathbf{2 0 0 3}$ & $\mathbf{2 0 0 4}$ & $\mathbf{2 0 0 5}$ \\
\hline USDA & & & & & & & & & 1 \\
\hline HHS & 3 & 3 & 3 & 3 & 3 & 3 & 3 & 2 & 2 \\
\hline HUD & & & & 2 & 2 & 2 & 2 & 2 & 2 \\
\hline DOL & & & & & 1 & 2 & 4 & 5 & 5 \\
\hline DOT & 1 & 2 & 2 & 2 & 2 & 3 & 3 & 3 & 3 \\
\hline EPA & & 3 & 28 & 29 & 40 & 45 & 50 & 50 & 50 \\
\hline GSA & & & & 3 & 2 & 2 & 3 & 2 & 2 \\
\hline NARA & & & & 1 & 1 & 1 & 1 & 1 & 1 \\
\hline CPSC & & & & 1 & 1 & 1 & 2 & 2 & 2 \\
\hline GPO & & & & 4 & 4 & 4 & 4 & 4 & 0 \\
\hline Total in use & $\mathbf{4}$ & $\mathbf{8}$ & $\mathbf{3 3}$ & $\mathbf{4 5}$ & $\mathbf{5 6}$ & $\mathbf{6 3}$ & $\mathbf{7 2}$ & $\mathbf{7 1}$ & $\mathbf{6 8}$ \\
\hline New Uses & +4 & +4 & +25 & +12 & +12 & +7 & +9 & +1 & +1 \\
\hline Discontinued & & & & & -1 & & & -2 & -4 \\
\hline
\end{tabular}

These changes yield a net total of 68 government-unique standards reported as being used in lieu of voluntary consensus standards during FY 2005. 
A complete listing of the government-unique standards used in lieu of voluntary consensus standards from FY 1997 through FY 2005 is available in Appendix C of this report. The list includes the justification(s) for not using each listed voluntary consensus standard. It should be noted that agency justifications tend to focus on the need for more detailed requirements, higher performance specifications and measurements, and/or the need to accommodate highly specialized technologies not yet adequately addressed by voluntary consensus standards.

\section{2 - Current Federal Agency Use of Voluntary Consensus Standards (VCSs)}

Federal agencies annually report the total number of VCSs they used during the previous fiscal year. For FY 2005, agencies reported a total of 1,670 new uses of VCSs, with a cumulative total number of uses of VCSs reported since 1997 of 6,229. The significant increase in FY 2005 is primarily the result of the improved reporting process implemented by DHS, which reported 987 new uses. Table 3.2 illustrates the upward trend in the total number of VCSs in use by Federal agencies.

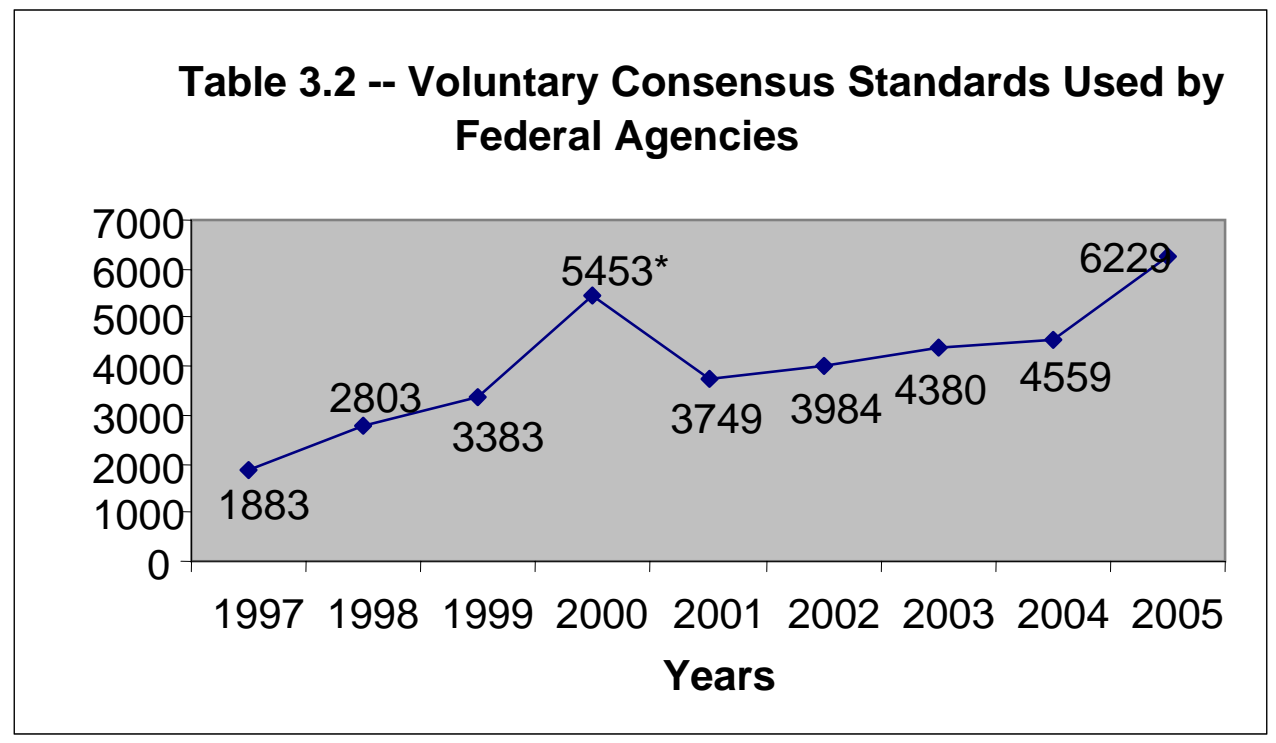

* The increase of VCS usage during FY 2000 was due largely to a reported increase of more than 1500 VCSs used by the Department of Interior. This irregularity is attributable to erroneous interpretations of the term "use” by DOI as described in Section 3.0 of this report. These 1500 VCSs were withdrawn from the inventory for subsequent reporting years.

It should be noted that, since these data include only those standards used since the 1997 onset of agency reporting, the data do not include all non-governmental standards currently in use by DoD, which initiated efforts to minimize use of government-unique standards prior to enactment of the NTTAA. DoD continues to be the leader in the adoption of private sector standards reporting a total inventory of 9,083 private sector standards for FY 2005. 


\section{3 - Current Agency Reporting on Voluntary Consensus Standards Substituted for Government-Unique Standards}

Federal agencies also report annually on the number of voluntary consensus standards they have substituted for government-unique standards during the year. Table 3.3 illustrates the cumulative total number of substitutions each year since FY 1997. In FY 2005, Federal agencies substituted 243 voluntary consensus standards for governmentunique standards. After an intense initial effort to substitute many standards, the trend within the Federal government to make such substitutions is still increasing although at a slower pace.

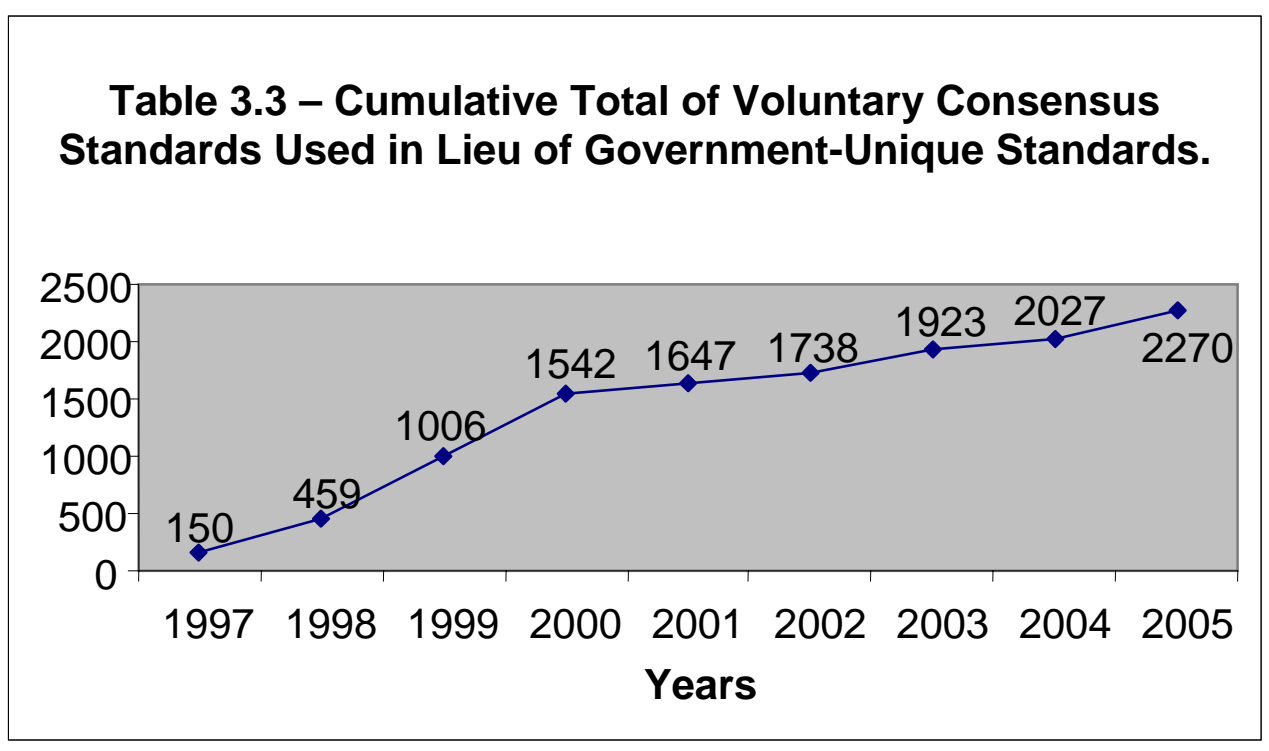

\section{0 - Federal Participation in Private Sector Standards Activities}

OMB Circular A-119 states that Federal agencies "must consult with voluntary consensus standards bodies, both domestic and international, and must participate with such bodies in the development of voluntary consensus standards when consultation and participation is in the public interest and is compatible with their missions, authorities, priorities, and budget resources." The Circular goes on to declare that "agency support provided to a voluntary consensus standards activity must be limited to that which clearly furthers agency and departmental missions, authorities, priorities, and is consistent with budget resources.”

\section{1 - Participation Data for FY 2005}

In FY 2005, agencies reported participation in 409 private sector standards bodies, compared to 431 in FY 2004. The list of organizations includes American National Standards Institute (ANSI)-accredited voluntary consensus standards developers, industry and trade associations, and international organizations. 
Federal agencies are also required by OMB to report the number of Federal employees who participate in private sector standards bodies. This includes not only those who serve on technical standards development committees, subcommittees, or workgroups, but also those who participate in management activities, annual meetings, or seminars. In FY 2005, agencies reported that 3,954 employees participated in private sector standards body activities. This was an increase of 736 participants from FY 2004.

A complete listing of the standards developing organizations in which Federal agencies participated can be viewed in the extended appendices to this report located at http://standards.gov. Data detailing FY 2005 participation for each agency is provided in Appendix B.

\section{2 - Strategic Partnerships}

Today, standards are playing a valuable role in tackling some of the important issues facing the country today. To best address these standards needs, the government and private sector are forming strategic partnerships to develop standards that will reduce costs, improve quality, and provide greater value to all stakeholders.

For example, the development of appropriate standards for addressing health informatics, computer security, and homeland security will provide for common and uniform requirements to help ensure effective and interoperable products.

In support of the President's Health Information Technology Agenda, the Office of the National Coordinator for Health Information Technology in the Department of Health and Human Services has contracted with the American National Standards Institute (ANSI) to organize the Healthcare Information Technology Standards Panel (HITSP). HITSP serves as a cooperative partnership between the public and private sectors for the purpose of achieving a widely accepted and useful set of standards specifically to enable and support widespread interoperability among health related software applications. The HITSP is comprised of a wide range of stakeholders that will assist in the harmonization of the standards needed for the U.S. Nationwide Health Information Network (NHIN).

The General Services Administration's E-Authentication Initiative will provide a trusted and secure standards-based authentication architecture to support Federal E-Government applications and initiatives. Standards will provide a uniform process for establishing electronic identity and eliminate the need for each initiative to develop a redundant solution for the verification of identity and electronic signatures. E-Authentication's distributed architecture will also allow citizens and businesses to use non-government issued credentials to conduct transactions with the government.

Successful implementation of E-Authentication will produce numerous benefits for the public and the Federal government. Citizens and businesses will have a secure, easy-touse and consistent method of proving identity to the government and will be spared the burden of having to keep track of multiple sets of registration information. Federal 
agencies will be able to reduce authentication system development and acquisition costs and reallocate labor resources previously used to develop such systems.

Also, in 2003, ANSI formed the American National Standards Institute's Homeland Security Standards Panel (ANSI-HSSP) which identifies existing consensus standards, or, if none exist, assists the Department of Homeland Security (DHS) and those sectors requesting assistance to accelerate development and adoption of consensus standards critical to homeland security. The ANSI-HSSP promotes a positive, cooperative partnership between the public and private sectors in order to meet the needs of the nation in this critical area.

We expect to see increased public-private partnerships focusing on strategic standards needs in the future as both government and private sector work together to identify standards that are critical to facilitating innovation and global competitiveness, while also protecting public health, safety and the environment. Both OMB Circular A-119 and the NTTAA recognize the valuable contributions that standards make in enabling the government to carry out its responsibilities. Close interaction and cooperation between the public and private sectors are critical to developing and using standards that serve national needs and support innovation and competitiveness.

\section{0 - Federal Agency Conformity Assessment Activities}

The NTTAA requires NIST to coordinate Federal, State, and local standards activities and conformity assessment activities with private sector standards activities and conformity assessment activities, with the goal of eliminating unnecessary duplication and complexity in the development and promulgation of conformity assessment requirements and measures. Federal conformity assessment activities are a means of providing assurance that the products and services regulated or procured by Federal agencies have the required characteristics and/or perform in a specified manner. Agency conformity assessment procedures may include sampling and testing, inspection, accreditation, certification; licensing; product listing; the submission to an agency of manufacturing, operational, and related data for review; manufacturer self-declaration of conformity to agency requirements; mandatory labeling and advertising requirements; establishment of national requirements which are adopted/enforced at state and local government levels; issuance of regulatory guidelines; pre-marketing approval requirements; post-marketing monitoring requirements; and the conduct of environmental impact assessments.

Each agency is responsible for coordinating its conformity assessment activities with those of other cognizant government agencies and with those of the private sector in order to make more productive use of the increasingly limited federal resources available for the conduct of conformity assessment activities and to reduce unnecessary duplication.

This year, agencies reported several examples of using existing public and private sector conformity assessment systems to reduce the duplication of programs and associated 
costs. Examples of ongoing cooperation in conformity assessment activities include the following:

The Department of Health and Human Services (HHS) reported several activities including:

FDA's participation on ongoing conformity assessment activities such as the ANSI Accreditation and International Conformity Assessment Committees and ANSI's Board Committee on Conformity Assessment, as well as American Society for Testing and Materials (ASTM) Committee E-36 on Conformity Assessment allows FDA to ensure that its needs are met while utilizing existing recognition and accreditation criteria.

FDA's Center for Devices and Radiological Health allows a medical device manufacturer to submit a Declaration of Conformity to a "recognized standard" as described in ISO/IEC Guide 22 in its standards recognition program and has developed an MRA with the European Union on mutual recognition of each other's conformity assessment procedures related to manufacture and marketing of medical devices. This reduces costs for manufacturers and decreases the time to market for approved products.

The FDA Office of Regulatory Affairs (FDA/ORA) actively participates in the National Cooperation for Laboratory Accreditation (NACLA), serving as a member of the NACLA Executive Board of Directors and participating in the NACLA Recognition Committee for Accrediting Bodies who apply for mutual recognition. This participation may form the basis for the future accreditation of FDA laboratories.

With the idea of enhancing international credibility and recognition, FDA's Center for Food Safety and Applied Nutrition (CFSAN) is moving towards ISO accreditation of its own laboratories that perform regulatory work.

GSA reported employing a number of conformity assessment activities including direct inspection, testing, supplier and third party testing, and product qualification and listing.

HUD reported that all of its 28 conformity assessment programs under the HUD Building-Products Standards \& Certification Programs are in compliance with ISO guidelines and procedures. Reliance on these standards is consistent with the private sector practices and provides uniformity in the conformity assessment process, whether administered by HUD or by private sector organizations referenced by HUD.

NASA reported that it routinely utilizes other government agencies to assist with its Contract Administration Services, including substantial conformity assessment activities. The Defense Contract and Audit Agency, Defense Contract Management 
Agency, Office of Naval Research, and other activities continue to provide conformity assessment services for NASA Programs.

The Department of Commerce reported that the Nuclear Regulatory Commission (NRC) now accepts accreditation by qualified laboratory accreditation bodies as an acceptable alternative to a supplier audit, commercial-grade survey, or in-process surveillance for the qualification of commercial grade calibration service suppliers. This reduces resource burdens on industry and eliminates costs related to redundant audits. The Department also reported that:

NIST provides technical support for the Inter-American Accreditation Cooperation (IAAC). Such arrangements/agreements are designed to harmonize conformity assessment practices and promote the global acceptance of conformity assessment results from qualified bodies to minimize the need for and cost of redundant conformity assessment activities.

NIST staff worked with the Consumer Product Safety Commission (CPSC) to refine the conformity assessment portion of CPSC's China strategy (to reduce the number of unsafe consumer products imported from China into the United States).

NIST staff provided advice and expertise to the Department of Homeland Security for the design and implementation of a laboratory accreditation program for laboratories that test radiation detectors for homeland security application by federal, state, and local personnel. The laboratory accreditation program, to be carried out by NVLAP, is intended to be the first step towards establishing a comprehensive certification program for radiation detectors.

Federal agencies continue to participate in a variety of conformity assessment activities that are either conducted by private sector organizations or are government-run activities that encourage private sector participation. A number of Federal agencies are working jointly with other agencies and non-governmental organizations in the development of conformity assessment policies and guidelines.

\section{0 - Evaluation of the Effectiveness of OMB Circular A-119}

During FY 2005, the majority of reporting agencies either had no comments on the effectiveness of OMB Circular A-119 or indicated that they found the Circular effective in helping them manage their standards development programs. However, some agencies did provide substantive comments concerning the Circular. Several recommended that consideration be given to simplifying the Circular and its reporting requirements. Agency comments are summarized below.

One department reported that the existing OMB policy concerning participation in VCSs activities is a tool that many agencies could employ to encourage support for VCSs programs. However, that department noted that it is difficult to implement the requirement to collect participant data effectively and recommended that NIST collect 
comprehensive participant data from standards developing organizations, rather than each agency reporting individually.

Another agency recommended obtaining feedback from regulated communities on the use of VCSs, noting that it has received relatively few comments in response to proposed regulations focusing on the use of VCSs.

\section{0 - The Interagency Committee on Standards Policy}

During FY 2005, 54 individuals served on the ICSP including agency Standards Executives, their alternates, NIST support staff, and representation from OMB. The Committee experienced significant turnover in FY 2005, with eight Standards Executive positions vacant at the end of the year. The Department heads of those agencies with vacant Standards Executive positions will be contacted emphasizing the need and importance of filling these positions.

A new organizational member was added to the ICSP in FY 2005: the U.S. Access Board, formerly the Architectural and Transportation Barrier Compliance Board, accepted an invitation to join the ICSP. The Access Board is an independent Federal Board created by Congress in 1973 to address public access for persons with disabilities. The Access Board makes extensive use of voluntary consensus standards.

The ICSP met three times in FY 2005, including one joint meeting with the American National Standards Institute's Government Member Forum. The Committee continues to explore possible future joint meetings with other organizations having related interests.

Some of the issues discussed during the FY 2005 ICSP meetings included:

1. The ANSI/EPA efforts on Environmentally Preferable Purchasing (EPP).

2. The Leadership in Energy and Environmental Design (LEEDs) Green Building Rating System and its use by Federal agencies.

3. Current status of the International Organization for Standardization (ISO) Social Responsibility Working Group and ANSI's Homeland Security Standards Panel.

4. The Department of Energy's information system for managing standards development and participation; i.e., RevCom.

5. Personnel certification in the government sector.

6. Revision and implementation of the U.S. Standards Strategy.

7. Changes in requirements of the ANSI program to accredit standards developing organizations.

\section{0 - Challenges and Opportunities}

Federal agencies continue to experience personnel turnover at all organizational levels due to reorganizations, accelerated or early retirements, and normal attrition. These changes make it difficult for Federal agencies to retain high-level managers who understand the importance of standards and who visibly support standards-related 
activities. Staff turnover has also caused a decrease in "institutional memory" of past standards policies, responsibilities, and practices. To address this issue, NIST recently developed and is now providing training for Federal employees who are engaged in developing standards and using them in regulation or procurement actions. NIST is also creating a handbook for Standards Executives so that they will have readily available the information needed to make decisions about the use of standards.

The availability and dissemination of standards information continues to be a challenge for agencies. The internet portal http://standards.gov created by NIST provides a onestop e-government location for information related to the use of voluntary consensus standards. The website offers background, materials, useful links, and search tools for locating information about the use of standards in government. In FY 2005, NIST updated the inventory of standards referenced in the Code of Federal Regulations (CFR). This inventory allows for the identification of currently used government-unique standards. Identification of these government-unique standards may uncover opportunities for agencies to replace these standards through collaborative efforts with private-sector standards developers. The web site also serves as a forum for providing ongoing, practical guidance, tools, and information needed by agencies to successfully implement the NTTAA. For example, Federal agencies can now use standards.gov to electronically submit their annual reports on standards and conformity assessment activities. The electronic reporting system is designed to reduce paperwork at the agency level, to decrease the level of effort previously needed to organize and analyze agency data, and to facilitate and expedite the preparation of NIST's annual report to OMB.

Sustained high-level Federal agency leadership has been identified as the primary driver of successful NTTAA implementation. Top agency leaders have the ability to direct policy and resources in ways that bring about other desirable outcomes, such as increased Federal participation and collaboration with the private sector. Ensuring that agency Standards Executives have the tools at hand to show how standards and the standards making process contribute to their agency’s mission is a continuing priority.

Finally, there are opportunities for improvement to be made in the methods and data that underpin sound economic analyses of the benefits of greater use of private sector standards and conformity assessment activities. NIST is now laying the groundwork necessary for relevant economic analyses to be conducted across the spectrum of government agencies. As a first step, existing economic analyses of the impact of standards on the economy are being collected as a basis for determining the most relevant factors. The goal is to have the tools and data in place within three to five years to be able to produce the quantitative and objective analyses necessary to demonstrate the utility of voluntary consensus standards for the government.

While there is more work to be done, there have been instances of success where voluntary consensus standards have been used in lieu of government-unique standards. Some examples are:

- By having all of their Army customers in the Midwestern United States buy to only one 
ASTM specification, the Defense Logistics Agency’s Defense Energy Support Center (DESC) was able to accrue savings of \$820,000 in both 2004 and 2005.

- The United States Access Board, coordinating extensively with model building code organizations, revised its Americans with Disabilities Act and Architectural Barriers Act (ABA) Accessibility Guidelines to make them more consistent with model building codes and industry standards such as those from the National Fire Protection Association and the International Code Council. This effort will allow harmonization with model codes and standards, greatly facilitating these two Acts and fostering a better understanding between the building community and the Access Board as to the needs for accessibility.

The Nuclear Regulatory Commission's (NRC) endorsement of Sections III (Construction) and XI (In-service Inspection) of the American Society of Mechanical Engineers (ASME) Boiler and Pressure Vessel Code and Code for Operation and Maintenance of Nuclear Power Plants (In-service Testing of Pumps and Valves) not only saved the Commission valuable time and resources but also encouraged uniform application of requirements, promotion of regulatory efficiency and enhancement of public confidence in the regulatory process.

In a few cases, agencies are able to demonstrate clear economic benefits on a case-bycase basis. The Department of Defense has conducted several case studies that demonstrate a range of positive results from its collaborations with the private sector on standardization issues. Some of DoD's documented benefits include:

- $\quad$ Reduced labor costs to operate and maintain equipment;

- Lower inventory costs;

- Improved safety;

- Improved equipment readiness; and

- Enhanced interchangeability, reliability, and availability of equipment and parts and better equipment performance.

In addition, some Federal agencies are able to point to specific instances where they have benefited from NTTAA implementation in ways that cannot be quantitatively measured. For example, the Environmental Protection Agency (EPA) is making "beyondregulation" use of voluntary consensus bodies and of ANSI. EPA has acknowledged the important role that voluntary consensus organizations play in the development and promulgation of standards for environmentally conscientious products. EPA has partnered with ANSI to educate and train standards organizations on the need for such standards. Together, EPA and ANSI have provided organizations with criteria that can serve as a guideline for use by standards committees working in this area. ANSI has also conducted several workshops and training sessions in cooperation with EPA and posted useful information in this area on ANSI's website.

All these efforts indicate a real and growing reliance on voluntary consensus standards benefiting not only the government, but also businesses and the American public 


\section{Appendix A - FY 2005 List of Federal Agencies That Report}

Agency

Department of Agriculture

Department of Commerce

Department of Defense

Department of Energy

Department of Education

Department of Health and Human Services

Department of Homeland Security

Department of Housing and Urban Development

Department of the Interior

Department of Justice

Department of Labor

Department of State

Department of Transportation

Department of the Treasury

Department of Veterans Affairs

Environmental Protection Agency

Agency for International Development

General Services Administration

National Archives and Records Administration

National Aeronautics and Space Administration

National Science Foundation

Consumer Product Safety Commission

Federal Communications Commission

Federal Trade Commission

Nuclear Regulatory Commission

Government Printing Office
Acronym

USDA

DOC

DoD

DOE

ED

HHS

DHS

HUD

DOI

DOJ

DOL

DOS

DOT

TRES

VA

EPA

USAID

GSA

NARA

NASA

NSF

CPSC

FCC

FTC

NRC

GPO 


\section{Appendix B - FY 2005 Federal Agency Use of Standards and Participation in Private Sector Standards Bodies}

\section{FY 2005 Federal Agency Information On Participation/Adoption Of Private Sector Standards Activities}

\section{Required by OMB Circular A-119}

\begin{tabular}{|c|c|c|c|c|c|c|c|}
\hline Agency & \begin{tabular}{|c} 
Government \\
unique standards \\
used in lieu of \\
voluntary \\
consensus \\
standards \\
\end{tabular} & $\begin{array}{l}\text { Private sector } \\
\text { standards } \\
\text { substituted for } \\
\text { government } \\
\text { unique } \\
\text { standards }\end{array}$ & $\begin{array}{c}\text { Private } \\
\text { sector } \\
\text { standards } \\
\text { used this } \\
\text { year }\end{array}$ & $\begin{array}{l}\text { Employee } \\
\text { participation in } \\
\text { private sector } \\
\text { standards } \\
\text { bodies }\end{array}$ & $\begin{array}{l}\text { Change } \\
\text { from } \\
\text { previous } \\
\text { year }\end{array}$ & $\begin{array}{l}\text { Private sector } \\
\text { standards } \\
\text { bodies with } \\
\text { agency } \\
\text { participation }\end{array}$ & $\begin{array}{l}\text { Change } \\
\text { from } \\
\text { previous } \\
\text { year }\end{array}$ \\
\hline USDA & 1 & 10 & 238 & 52 & -30 & 17 & -18 \\
\hline DOC & 0 & 0 & 0 & 442 & 4 & 98 & 4 \\
\hline DoD & $*$ & 227 & 227 & 1106 & 670 & 118 & -5 \\
\hline DOE & 0 & 0 & 1430 & 761 & 32 & 70 & 5 \\
\hline ED & 0 & 0 & 60 & 4 & 4 & 5 & 5 \\
\hline HHS & 2 & 3 & 945 & 594 & 91 & 114 & -68 \\
\hline DHS & 0 & 0 & 1000 & 160 & 150 & 50 & 43 \\
\hline HUD & 2 & 0 & 300 & 4 & -6 & 4 & -1 \\
\hline DOI & 0 & 2 & 768 & 74 & -195 & 26 & 7 \\
\hline DOJ & 0 & 0 & 0 & 1 & -4 & 0 & -1 \\
\hline DOL & 5 & 0 & 1 & 52 & -2 & 16 & -3 \\
\hline DOS & 0 & 0 & 0 & 8 & 1 & 1 & 0 \\
\hline DOT & 3 & 0 & 381 & 209 & 42 & 47 & 6 \\
\hline TRES & NR & NR & NR & NR & NR & NR & NR \\
\hline VA & 0 & 0 & 0 & 4 & 0 & 20 & 2 \\
\hline EPA & 50 & 0 & 50 & 52 & 7 & 26 & 3 \\
\hline USAID & NR & NR & NR & NR & NR & NR & NR \\
\hline GSA & 2 & 0 & 516 & 22 & -69 & 25 & -1 \\
\hline NARA & 1 & 0 & 89 & 16 & -3 & 10 & 0 \\
\hline NASA & * & 1 & 195 & 172 & 25 & 31 & 1 \\
\hline NSF & 0 & 0 & 0 & 4 & -1 & 4 & -1 \\
\hline CPSC & 2 & 0 & 28 & 28 & -2 & 8 & 0 \\
\hline FCC & 0 & 0 & 0 & 36 & 31 & 13 & 6 \\
\hline FTC & 0 & 0 & 0 & 0 & 0 & 0 & 0 \\
\hline NRC & 0 & 0 & 1 & 153 & 8 & 15 & 2 \\
\hline GPO & 0 & 0 & 0 & 0 & -2 & 0 & -6 \\
\hline Totals & 68 & 243 & 6229 & 3954 & 736 & $* *$ & $* *$ \\
\hline
\end{tabular}

NR: Not Reported

* Agencies reporting on a categorical basis per OMB Circular A-119, Section 12.

** Totals not provided. (Totals would include multiple counting of certain bodies that enjoy simultaneous participation from two or more Federal agencies.) 


\title{
Appendix C -Government-Unique Standards Used in Lieu of Voluntary Consensus Standards
}

\author{
Appendix C.1 - Government-Unique Standards Used in Lieu of Voluntary \\ Consensus Standards Incorporated in FY 2005
}

\section{Agency: Department of Agriculture (USDA) 2005] \\ Voluntary Standard \\ NFPA 1150 - Standard on Fire-Fighting Foam \\ Chemicals for Class A Fuels in Rural, \\ Suburban, and Vegetated Areas.}

Government Standard: USDA Forest Service Specification 5100-307; International Specification for Fire Suppressant Foam for Wild land Fires, Aircraft or Ground Application [Incorporated

\section{Rationale}

Foam fire suppressants contain foaming and wetting agents. The drains from the foam and how well the product clings to the fuel foaming agents affect the accuracy of an aerial drop, how fast the water surfaces. The wetting agents increase the ability of the drained water to penetrate fuels. Foam fire suppressants are supplied as wet concentrates.

This standard was developed with international cooperation for Class A Foam used in wild land fire suppression situations and equipment. This standard was created by the USDA Forest Service in cooperation with the Department of Interior (DOI), the State of California, Department of Forestry and Fire Protection and the Canadian Interagency Forest Fire Center.

The National Fire Protection Association (NFPA) does have a standard for Class A Foam, (NFPA 1150 - Standard on Fire-Fighting Foam Chemicals for Class A Fuels in Rural, Suburban, and Vegetated Areas). The Forest Service has not chosen to utilize NFPA 1150 as it is designed specifically for application by municipal fire agencies in the wild land-urban interface, utilizing apparatus and situations that they are likely to encounter. The Forest Service's GUS for foam products is specific to use by wild land fire equipment and situations that are unique, e.g. helicopter use of foams, remote storage situations, and varied quality of water sources in the wild land settings. The agency feels this standard more accurately reflects the needs and mission of the federal wild land fire suppression agencies. 
Appendix C.2 -Instances of Government-Unique Standards Used in lieu of Voluntary Consensus Standards Discontinued in FY 2005

\section{Agency: Government Printing Office (GPO)}

Government Standard: FED-STD 209 [Incorporated: 2000] [Discontinued: 2005]

Voluntary Standard

Rationale

ISO 14644-1 \& ISO 14644-2

Military and Federal quality assurance standards used and gradually phased out.

Government Standard: MIL-STD 105 [Incorporated: 2000] [Discontinued: 2005]

Voluntary Standard

Rationale

ANSI/ASQC Z1.4

Military and Federal quality assurance standards used and gradually phased out.

Government Standard: MIL-STD 1189 [Incorporated: 2000] [Discontinued: 2005]

Voluntary Standard

Rationale

ANSI/AIM X5-2 \& ANSI X3.182

Military and Federal quality assurance standards used and gradually phased out.

Government Standard: MIL-STD 498 [Incorporated: 2000] [Discontinued: 2005]

Voluntary Standard

IEEE/EIA 12207.0, IEEE/EIA 12207.1, \&

IEEE/EIA 12207.2
Rationale

Military and Federal quality assurance standards used and gradually phased out. 


\title{
Appendix C.3 - Government-Unique Standards Used in Lieu of Voluntary Consensus Standards from FY 1997 through FY 2005
}

\author{
Agency: Consumer Product Safety Commission (CPSC)
}

Government Standard: CPSC CFR Parts 1213, 1500, and 1513 [Incorporated: 2000]

Voluntary Standard

Rationale

ASTM F1427-96

The CPSC rule goes beyond the provisions of the ASTM voluntary standard to provide increased protection to children from the risk of death and serious injury from entrapment.

Government Standard: FR/Vol. 68, No. 75/Friday, April 18, 2003, pp. 19142-19147, Metal-Cored Candlewicks Containing Lead and Candles With Such Wicks [Incorporated: 2003]

Voluntary Standard

Voices of Safety International (VOSI) standard on lead in candle wicks

\section{Rationale}

The U.S. Consumer Product Safety Commission found that the VOSI standard is technically unsound, and thus would not result in the elimination or adequate reduction of the risk, and that substantial compliance with it is unlikely. See FR/Vol. 68, No. 75/Friday, April 18, 2003, pp. 19145-19146, paragraph H2, Voluntary Standards for further information on this finding.

\section{Agency: Department of Labor (DOL) \\ Government Standard: Electric Motor-Drive Equipment Rule [Incorporated: 2001] \\ Voluntary Standard \\ IEEE Standard 242-1986 Recommended Practice for Protection and Coordination of Industrial and Commercial Power Systems (IEEE Buff Book) and NFPA 70 - national Electric Code \\ Rationale \\ The MSHA rule is a design-specific standard. The NFPA and IEEE standards were used as a source for the rule; however, the exact requirements of the rule were tailored to apply specifically to electric circuits and equipment used in the coal mining industry.}

Government Standard: Exit Routes, Emergency Action Plans, and Fire Prevention Plans, 29 CFR 1910, Subpart E [Incorporated: 2003]

Voluntary Standard

Life Safety Code, NFPA 101-2000

\begin{abstract}
Rationale
The OSHA standard addresses only workplace conditions whereas the NFPA Life Safety Code goes beyond workplaces. However, in the final rule OSHA stated that it had evaluated the NFPA Standard 101, Life Safety Code, (NFPA 101-2000) and concluded that it provided comparable safety to the Exit Route Standards. Therefore, the Agency stated that any employer who complied with the NFPA 101-2000 instead of the OSHA Standard for Exit Routes would be in compliance.
\end{abstract}

Government Standard: Fire Protection for Shipyards, 29 CFR Part 1915, Subpart P [Incorporated: 2004]

Voluntary Standard

NFPA 312-2000 Standard for Protection of Vessels During Construction, Repair, and Lay-Up

NFPA 33-2003 Standard for Spray Application Using Flammable or Combustible Materials

\section{Rationale}

Many consensus standards were relied on for various provisions in OSHA's final rule, including 15 consensus standards that are incorporated by reference. However, OSHA and its negotiated rulemaking committee determined that there was no single consensus standard available that covered all the topics in the rule. 


\section{Government Standard: Sanitary Toilets in Coal Mines, 30 CFR 71, Subpart E [Incorporated:}

2003]

\section{Voluntary Standard}

Non-Sewered Waste Disposal Systems--Minimum Requirements, ANSI Z4.3-1987

\section{Rationale}

The ANSI standard was not incorporated by reference because certain design criteria allowed in the ANSI standard, if implemented in an underground coal mine, could present health or safety hazards. For instance, combustion or incinerating toilets could introduce an ignition source which would create a fire hazard. For certain other design criteria found in the ANSI standard, sewage could seep into the groundwater, or overflow caused by rain or runoff could contaminate portions of the mine.

\section{Government Standard: Steel Erection Standards [Incorporated: 2002] \\ Voluntary Standard \\ Rationale}

ANSI A10.13 - Steel Erection; ASME/ANSI B30

Series Cranes Standards
There was no one consensus standard available that covered all of the topics covered by OSHA's final rule.

\section{Agency: Department of Transportation (DOT)}

\section{Government Standard: 63 FR 17976; April 13, 1998 - Product Safety Signs and Labels [Incorporated: 1998]}

\section{Voluntary Standard}

ANSI Z535.4 - ANSI Requirements for Color Coded Header Messages for the Different Levels of Hazard

\section{Rationale}

NHTSA explained in the NPRM that the American National Standard Institute (ANSI) has a standard4 for product safety signs and labels (ANSI Z535.4) that identifies a hierarchy of hazard levels ranging from extremely serious to moderately serious and specifies corresponding hierarchies of signal words, i.e., "danger," "warning," and "caution," and of colors. For the header, the ANSI standard specifies a red background with white text for "danger," an orange background with black text for "warning," and a yellow background with black text for caution."

The ANSI standard specifies that pictograms should be black on white, with occasional uses of color for emphasis, and that message text should be black on white. The agency noted in the NPRM that when it earlier updated the requirements for air bag warning labels to require the addition of color and pictograms, it had chosen not to adopt the colors specified in the ANSI standard. NHTSA chose to use yellow instead of orange in the background of the heading for the air bag warning label, even though the word "warning" was used, because of overwhelming focus group preference for yellow. Only two of the 53 participants preferred orange. Participants generally stated that yellow was more eyecatching than orange. Participants also noted that red (stop) and yellow (caution) had meaning to them, but not orange.

NHTSA asked for comment on three color options for the revised utility vehicle rollover warning label. Proposed label 1 used the ANSI color format with the heading background in orange with the words in black. The remainder of the label had a white background with black text and drawings. Proposed label 2 used a color scheme like the air bag warning labels, which is the same as the ANSI color format except that the background color for the heading in the label is yellow. Proposed label 3 employed the color scheme used in the focus groups - the heading area had a red background with white text. The graphic areas had a yellow background with 
black and white drawings. The text area had a black background with yellow text.

Despite focus group preference for the signal word "danger," the agency proposed the use of the word "warning" as more appropriate to the level of risk. The agency also noted that the word "warning" is used in the air bag warning label.

Recognizing that it might encounter additional conflicts between focus group preferences and the ANSI standard in future rulemakings, NHTSA requested comments in the NPRM on the extent to which any final choice regarding colors and signal words should be guided by the focus group preferences instead of the ANSI standard. NHTSA also requested comments on the broader issue of the circumstances in which it would be appropriate for agency rulemaking decisions to be guided by focus group results or other information when such information is contrary to a voluntary consensus standard such as the ANSI standard.

At this time (February 22, 1999), a final decision is still pending regarding its proposal to upgrade the rollover warning label. As to the general questions it posed in the NPRM, NHTSA recognizes that ANSI's mission differs somewhat from that of the agency's focus groups with respect to the labeling of hazardous situations. ANSI's mission is to develop and maintain a standard for communicating information about a comprehensive hierarchy of hazards, while the focus groups' mission is to design an effective label for a specific hazard. The agency recognizes further that, given the difference in their missions, their conclusions about the appropriate manner of communication might differ on occasion.

Since agency labeling decisions are highly dependent on the facts regarding the specific hazard being addressed, NHTSA anticipates making case-by-case determinations of the extent to which it should follow voluntary standards versus information from focus groups and other sources. NHTSA will rely on its own expertise and judgment in making determinations under the NTTAA and the statutory provisions regarding vehicle safety standards.

\section{Government Standard: Air Bag Warning Label (1997) [Incorporated: 1997] \\ Voluntary Standard \\ Rationale}

ANSI ISO
The Air Bag Warning Label uses yellow as the background color, instead of orange, in accordance with an ANSI standard and uses a graphic developed by Chrysler Corporation to depict the hazards of being too close to an air bag, instead of the graphic recommended by the ISO. These decisions were based on focus group testing sponsored by the agency which strongly indicated that these unique requirements would be far more effective with respect to safety than the industry standards.

\section{Government Standard: Brake Performance, 49 CFR 393.52 - FMCSA's Performance-Based Brake Testers (PBBTs) Requirement [Incorporated: 2002]}

\section{Voluntary Standard}

SAE J667 - Brake Test Code Inertia

Dynamometer (cancelled February 2002)

SAE J1854 - Brake Force Distribution

Performance Guide - Trucks and Buses

\section{Rationale}

FMCSA used government-unique standards in lieu of voluntary consensus standards when it implemented its final rule to allow inspectors to use performance-based brake testers (PBBTs) to check the brakes on large trucks and buses for compliance with federal safety standards and to issue citations when these vehicles 
fail (67 FR 51770, August 9, 2002). The FMCSA evaluated several PBBTs during a round robin test series to assess their functional performance and potential use in law enforcement. The standard, a specific configuration of brake forces and wheel loads on a heavyduty vehicle, was used to evaluate the candidate PBBTs and their operating protocols. The agency's rationale for use of the government-unique standards was to verify that these measurements and new technology could be used by law enforcement as an alternative to stopping distance tests or on-road deceleration tests. PBBTs are expected to save time and their use could increase the number of commercial motor vehicles that can be inspected in a given time. Only PBBTs that meet specifications developed by the FMCSA can be used to determine compliance with the Federal Motor Carrier Safety Regulations. The final rule represents a culmination of agency research that began in the early 1990s.

\section{Agency: Environmental Protection Agency (EPA) \\ Government Standard: 40 CFR 89 - Control of Emissions from New and In-Use Non-Road Compression Ignition Engines [Incorporated: 1999]}

\section{Voluntary Standard}

ISO 8178 - Reciprocating Internal Combustion

Engines, Exhaust Emission Measurement

\section{Rationale}

Procedures would be impractical because they rely too heavily on reference testing conditions. Agency decides instead to continue to rely on procedures outlined in 40 CFR Part 90.

\section{Government Standard: 40 CFR 90 - Control of Emission from Non-Road Spark Ignition Engines at or below 19KV [Incorporated: 1999] \\ Voluntary Standard \\ ISO 8178 - Reciprocating Internal Combustion \\ Engines, Exhaust Emission Measurement \\ Rationale \\ Procedures would be impractical because they rely too heavily on reference testing conditions. Agency decides instead to continue to rely on procedures outlined in 40 CFR Part 90.}

\section{Government Standard: 40 CFR 92 - Control of Air Pollution from Locomotives and Locomotive Engines [Incorporated: 2000] \\ Voluntary Standard \\ ISO 8178 - Reciprocating Internal Combustion \\ Engines, Exhaust Emission Measurement \\ Rationale \\ Procedures would be impractical because they rely too heavily on reference testing conditions. Agency decides instead to continue to rely on procedures outlined in 40 CFR Part 90.}

\section{Government Standard: EPA Method 1 - Traverse Points, Stationary Sources [Incorporated: 1999] \\ Voluntary Standard \\ ASTM D3154-00, Standard Method for Average Velocity in a Duct (Pitot Tube Method) \\ Rationale \\ 1. The standard appears to lack in quality control and quality assurance requirements. It does not include the following: (1) Proof that openings of standard pitot tube have not plugged during the test; (2) if differential pressure gauges other than inclined manometers (e.g., magnehelic gauges) are used, their calibration must be checked after each test series; and (3) the frequency and validity range for calibration of the temperature sensors. 2. They are too general, too broad, or not sufficiently detailed to assure compliance with EPA regulatory requirements.}


ASTM D3154-91 (1995), Standard Method for Average Velocity in a Duct (Pitot Tube Method)
The standard is too general, too broad, or not sufficiently detailed to assure compliance with EPA regulatory requirements.

\section{Government Standard: EPA Method 10 - Carbon Monoxide, NDIR [Incorporated: 1999] \\ Voluntary Standard \\ Rationale}

ASTM D3162 (1994) Standard Test Method for Carbon Monoxide in the Atmosphere (Continuous Measurement by Non-dispersive Infrared Spectrometry)

CAN/CSA Z223.21-M1978, Method for the Measurement of Carbon Monoxide: 3-Method of Analysis by Non-Dispersive Infrared Spectrometry
This ASTM standard, which is stated to be applicable in the range of $0.5-100 \mathrm{ppm} \mathrm{CO}$, does not cover the range of EPA Method 10 (20-1,000 ppm CO) at the upper end (but states that it has a lower limit of sensitivity). Also, ASTM D3162 does not provide a procedure to remove carbon dioxide interference. Therefore, this ASTM standard is not appropriate for combustion source conditions. In terms of non-dispersive infrared instrument performance specifications, ASTM D3162 has much higher maximum allowable rise and fall times (5 minutes) than EPA Method 10 (which has 30 seconds).

1. This standard is lacking in the following areas: (1) Sampling procedures; (2) procedures to correct for the carbon dioxide concentration; (3) instructions to correct the gas volume if $\mathrm{CO} 2$ traps are used; (4) specifications to certify the calibration gases are within 2 percent of the target concentration; (5) mandatory instrument performance characteristics (e.g., rise time, fall time, zero drift, span drift, precision); (6) quantitative specification of the span value maximum as compared to the measured value: The standard specifies that the instruments should be compatible with the concentration of gases to be measured, whereas EPA Method 10 specifies that the instrument span value should be no more than 1.5 times the source performance standard. 2. Is too general, too broad, or not sufficiently detailed to assure compliance with EPA regulatory requirements.

\section{Government Standard: EPA Method 101 - Mercury Emissions, Chlor-Alkali Plants}

(Air) [Incorporated: 2001]

\section{Voluntary Standard}

ASTM D6216-98 - Standard Practice for Opacity Monitor Manufacturers to Certify Conformance with Design and Performance Specifications.

\section{Rationale}

The EPA incorporates ASTM D6216 (manufacturers certification) by reference into EPA Performance Specification 1, Sect. 5 \& 6 in another rulemaking. ASTM D6216 does not address all the requirements specified in PS-1.

\section{Government Standard: EPA Method 101a - Mercury Emissions Sewer/Sludge Incinerator [Incorporated: 2001]}

\section{Voluntary Standard}

ASTM D6216-98 - Standard Practice for Opacity Monitor Manufacturers to Certify Conformance with Design and Performance Specifications.

\section{Rationale}

The EPA incorporates ASTM D6216 (manufacturers certification) by reference into EPA Performance Specification 1, Sect. 5 \& 6 in another rulemaking. ASTM D6216 does not address all the requirements specified in PS-1.

\section{Government Standard: EPA Method 10A - Carbon Monoxide for Certifying CEMS [Incorporated: 2001] \\ Voluntary Standard \\ CAN/CSA Z223.21-M1978, Method for the Measurement of Carbon Monoxide: 3-Method of Analysis by Non-Dispersive Infrared Spectrometry. \\ Rationale \\ 1. It is lacking in the following areas: (1) Sampling procedures; (2) procedures to correct for the carbon dioxide concentration; (3) instructions to correct the gas volume if $\mathrm{CO} 2$ traps are used; (4) specifications to certify the calibration gases are within 2 percent of}


the target concentration; (5) mandatory instrument performance characteristics (e.g., rise time, fall time, zero drift, span drift, precision); (6) quantitative specification of the span value maximum as compared to the measured value: The standard specifies that the instruments should be compatible with the concentration of gases to be measured, whereas EPA Method 10 specifies that the instrument span value should be no more than 1.5 times the source performance standard. 2. Is too general, too broad, or not sufficiently detailed to assure compliance with EPA regulatory requirements.

\section{Government Standard: EPA Method 12 - Inorganic Lead, Stationary Sources [Incorporated: 2001]}

\section{Voluntary Standard}

ASTM D4358-94 (1999), Standard Test Method for Lead and Chromium in Air Particulate Filter Samples of Lead Chromate Type Pigment Dusts by Atomic Absorption Spectroscopy

ASTM E1741-95 (1995), Standard Practice for Preparation of Airborne Particulate Lead Samples Collected During Abatement and Construction Activities for Subsequent Analysis by Atomic Spectrometry

ASTM E1979-98 (1998), Standard Practice for Ultrasonic Extraction of Paint, Dust, Soil, and Air Samples for Subsequent Determination of Lead

\section{Rationale}

These ASTM standards do not require the use of glass fiber filters as in EPA Method 12 and require the use of significantly different digestion procedures that appear to be milder than the EPA Method 12 digestion procedure. For these reasons, these ASTM standards cannot be considered equivalent to EPA Method 12 . Also, the subject ASTM standards do not require the use of hydrogen fluoride (HF) as in EPA Method 29 and, therefore, they cannot be used for the preparation, digestion, and analysis of Method 29 samples. Additionally, Method 29 requires the use of a glass fiber filter, whereas these three ASTM standards require cellulose filters and other probable non-glass fiber media, which cannot be considered equivalent to EPA Method 29.

These ASTM standards do not require the use of glass fiber filters as in EPA Method 12 and require the use of significantly different digestion procedures that appear to be milder than the EPA Method 12 digestion procedure. For these reasons, these ASTM standards cannot be considered equivalent to EPA Method 12. Also, the subject ASTM standards do not require the use of hydrogen fluoride (HF) as in EPA Method 29 and, therefore, they cannot be used for the preparation, digestion, and analysis of Method 29 samples. Additionally, Method 29 requires the use of a glass fiber filter, whereas these three ASTM standards require cellulose filters and other probable non-glass fiber media, which cannot be considered equivalent to EPA Method 29.

These ASTM standards do not require the use of glass fiber filters as in EPA Method 12 and require the use of significantly different digestion procedures that appear to be milder than the EPA Method 12 digestion procedure. For these reasons, these ASTM standards cannot be considered equivalent to EPA Method 12. Also, the subject ASTM standards do not require the use of hydrogen fluoride (HF) as in EPA Method 29 and, therefore, they cannot be used for the preparation, digestion, and analysis of Method 29 samples. Additionally, Method 29 requires the use of a glass fiber filter, whereas these three ASTM standards require cellulose filters and other probable non-glass fiber media, which cannot be considered equivalent to EPA Method 29. 


\section{Government Standard: EPA Method 15 - Hydrogen Sulfide/Carbon Disulfide/Carbon}

Sulfide [Incorporated: 1999]

Voluntary Standard

ASME C00031 or PTC 19-10-1981 - Part 10 Flue and Exhaust Gas Analyses

ASTM D4323-84 (1997) - Standard Test Method for Hydrogen Sulfide in the Atmosphere by Rate of Change of Reflectance

\section{Rationale}

The standard is too broad to be useful in regulatory sense. Covers Methods 3, 6, 7, and 15 with variants.

ASTM D4323 only applies to concentrations of H2S from 1 ppb to 3 ppm without dilution. Many QC items are missing, such as calibration drift and sample line losses. The calibration curve is determined with only one point.

Government Standard: EPA Method 1650 - Organic Halides, Absorbable (AOX) [Incorporated: 1998]

Voluntary Standard

ISO, DIN, SCAN, and Standard Methods (SM 5320)

\begin{abstract}
Rationale
EPA decided to use EPA Method 1650. This Method was developed by drawing on various procedures contained in the methods of voluntary consensus standards bodies and other standards developers, such as ISO, DIN, SCAN, and Standard Methods (SM 5320). However, none of these more narrowly focused voluntary consensus standards contained the standardized quality control and quality control compliance criteria that EPA requires for data verification and validation in its water programs. Therefore, EPA found none of these VCS standing alone to meet EPA's needs.
\end{abstract}

\section{Government Standard: EPA Method 17 - Particle Matter (PM) In Stack Filtration [Incorporated: 1999] \\ Voluntary Standard \\ ASME C00049 \\ ASTM D3685/3685M-95 - Standard Test method for Sampling and Determination of Particle Matter in Stack Gases \\ Rationale \\ EPA looked at this standard for both Pulp and Paper Hazardous Air Pollutant rules and for the Small Municipal Waste Combustion rule. Contains sampling options beyond which would be considered acceptable for Method 5. \\ EPA looked at this standard for both Pulp and Paper Hazardous Air Pollutant rules and for the Small Municipal Waste Combustion rule. Contains sampling options beyond which would be considered acceptable for Method 5.}

\section{Government Standard: EPA Method 18 - VOCIGC [Incorporated: 1999] \\ Voluntary Standard \\ ASTM D6060-96 (in review 2000) - Practice for Sampling of Process Vents with a Portable Gas Chromatography \\ Rationale \\ This standard lacks key quality control and assurance that is required for EPA Method 18. For example: lacks acceptance criteria for calibration, details on using other collection media (e.g. solid sorbents), and reporting/ documentation requirements.}

\section{Government Standard: EPA Method 180.1 - Turbidity Nephelometric [Incorporated: 1999] \\ Voluntary Standard \\ Rationale}

ISO 7027 - Water Quality Determination of Turbidity
EPA has no data upon which to evaluate whether the separate 90 degrees scattered or transmitted light measurement evaluations according to the ISO 7027 method would produce results that are equivalent to results produced by the other methods. 


\section{Government Standard: EPA Method 2 - Velocity and S-type Pitot [Incorporated: 1999] \\ Voluntary Standard \\ Rationale}

ASTM 3796-90 (1998), Standard Practice for Calibration of Type S Pitot Tubes

ASTM D3154-00, Standard Method for Average Velocity in a Duct (Pitot Tube Method)

ASTM D3154-91 (1995), Standard Method for Average Velocity in a Duct (Pitot Tube Method)

ASTM D3464-96 (2001), Standard Test Method Average Velocity in a Duct Using a Thermal Anemometer

ISO 10780:1994, Stationary Source Emissions-Measurement of Velocity and Volume Flowrate of Gas Streams in Ducts
They are too general, too broad, or not sufficiently detailed to assure compliance with EPA regulatory requirements.

1. The standard appears to lack in quality control and quality assurance requirements. It does not include the following: (1) Proof that openings of standard pitot tube have not plugged during the test; (2) if differential pressure gauges other than inclined manometers (e.g., magnehelic gauges) are used, their calibration must be checked after each test series; and (3) the frequency and validity range for calibration of the temperature sensors. 2 . They are too general, too broad, or not sufficiently detailed to assure compliance with EPA regulatory requirements.

It is too general, too broad, or not sufficiently detailed to assure compliance with EPA regulatory requirements.

Applicability specifications are not clearly defined, e.g., range of gas composition, temperature limits. Also, the lack of supporting quality assurance data for the calibration procedures and specifications, and certain variability issues that are not adequately addressed by the standard limit EPA's ability to make a definitive comparison of the method in these areas.

The standard recommends the use of an L-shaped pitot, which historically has not been recommended by EPA. The EPA specifies the S-type design, which has large openings that are less likely to plug up with dust.

\section{Government Standard: EPA Method 21 - Volatile Organic Compound (VOC) Leaks [Incorporated: 2001]}

\section{Voluntary Standard}

ASTM E1211-97 - Standard Practice for Leak Detection and Location Using Surface-Mounted Acoustic Emission Sensors

\section{Rationale}

This standard will detect leaks but not classify the leak as VOC, as in EPA Method 21. In addition, in order to detect the VOC concentration of a known VOC leak, the acoustic signal would need to be calibrated against a primary instrument. Background noise interference in some source situations could also make this standard difficult to use effectively.

\section{Government Standard: EPA Method 23 - Dioxin and Furan (PCDD and PCDF) [Incorporated: 1999]}

\section{Voluntary Standard}

European Committee for Standardization (CEN)

EN 1948-3 (1997), Determination of the Mass

Concentration of PCDD'S/PCDF'S--Part 3:

Identification and Quantification

\section{Rationale}

It is too general, too broad, or not sufficiently detailed to assure compliance with EPA regulatory requirements.

\section{Government Standard: EPA Method 24 - Surface Coatings, Volatile Matter Content [Incorporated: 1998]}

\section{Voluntary Standard}

ISO 11890-1 (2000) part 1, Paints and Varnishes-Determination of Volatile Organic Compound

\section{Rationale}

Measured nonvolatile matter content can vary with experimental factors such as temperature, length of heating period, size of 
(VOC) Content-Difference Method

ISO 11890-2 (2000) Part 2, Paints and Varnishes-Determination of Volatile Organic Compound (VOC) Content-Gas Chromatographic Method weighing dish, and size of sample. The standard ISO 11890-1 allows for different dish weights and sample sizes than the one size (58 millimeters in diameter and sample size of $0.5 \mathrm{gram}$ ) of EPA Method 24. The standard ISO 11890-1 also allows for different oven temperatures and heating times depending on the type of coating, whereas EPA Method 24 requires 60 minutes heating at 110 degrees Celsius at all times. Because the EPA Method 24 test conditions and procedures define volatile matter, ISO $11890-1$ is unacceptable as an alternative because of its different test conditions.

ISO 11890-2 only measures the VOC added to the coating and would not measure any VOC generated from the curing of the coating. The EPA Method 24 does measure cure VOC, which can be significant in some cases, and, therefore, ISO 11890-2 is not an acceptable alternative to this EPA method.

\section{Government Standard: EPA Method 25 - Gaseous Nonmethane Organic Emissions [Incorporated: 2001]}

\section{Voluntary Standard}

EN 12619:1999 Stationary Source Emissions-Determination of the Mass Concentration of Total Gaseous Organic Carbon at Low Concentrations in Flue Gases--Continuous Flame Ionization Detector Method

ISO 14965:2000(E) Air Quality--Determination of Total Nonmethane Organic Compounds-Cryogenic Preconcentration and Direct Flame Ionization Method

\section{Rationale}

The standards do not apply to solvent process vapors in concentrations greater than 40 ppm (EN 12619) and 10 ppm carbon (ISO 14965). Methods whose upper limits are this low are too limited to be useful in measuring source emissions, which are expected to be much higher.

The standards do not apply to solvent process vapors in concentrations greater than 40 ppm (EN 12619) and 10 ppm carbon (ISO 14965). Methods whose upper limits are this low are too limited to be useful in measuring source emissions, which are expected to be much higher.

\section{Government Standard: EPA Method 25A - Gaseous Organic Concentration, Flame Ionization [Incorporated: 2001]}

\section{Voluntary Standard}

EN 12619:1999 Stationary Source Emissions-Determination of the Mass Concentration of Total Gaseous Organic Carbon at Low Concentrations in Flue Gases--Continuous Flame Ionization Detector Method

ISO 14965:2000(E) Air Quality--Determination of Total Nonmethane Organic Compounds-Cryogenic Preconcentration and Direct Flame Ionization Method

\section{Rationale}

The standards do not apply to solvent process vapors in concentrations greater than 40 ppm (EN 12619) and 10 ppm carbon (ISO 14965). Methods whose upper limits are this low are too limited to be useful in measuring source emissions, which are expected to be much higher.

The standards do not apply to solvent process vapors in concentrations greater than 40 ppm (EN 12619) and 10 ppm carbon (ISO 14965). Methods whose upper limits are this low are too limited to be useful in measuring source emissions, which are expected to be much higher.

\section{Government Standard: EPA Method 26 - Hydrogen Chloride, Halides, Halogens Emissions [Incorporated: 1999]}

\section{Voluntary Standard}

EN 1911-1,2,3 (1998), Stationary Source Emissions-- Manual Method of Determination of $\mathrm{HCl}--$ Part 1: Sampling of Gases Ratified European Text--Part 2: Gaseous Compounds Absorption Ratified European Text-- Part 3: Adsorption

\section{Rationale}

Part 3 of this standard cannot be considered equivalent to EPA Method 26 or 26A because the sample absorbing solution (water) would be expected to capture both $\mathrm{HCl}$ and $\mathrm{Cl} 2$ gas, if present, without the ability to distinguish between the two. The EPA Methods 26 and 26A use an acidified absorbing solution to first 


\section{Government Standard: EPA Method 26A - Hydrogen Halide and Halogen, Isokinetic [Incorporated: 1999] \\ Voluntary Standard \\ Rationale}

EN 1911-1,2,3 (1998), Stationary Source Emissions-- Manual Method of Determination of $\mathrm{HCl}-$-Part 1: Sampling of Gases Ratified European Text--Part 2: Gaseous Compounds Absorption Ratified European Text-- Part 3: Adsorption Solutions Analysis and Calculation

\begin{abstract}
Part 3 of this standard cannot be considered equivalent to EPA Method 26 or $26 \mathrm{~A}$ because the sample absorbing solution (water) would be expected to capture both $\mathrm{HCl}$ and $\mathrm{Cl} 2$ gas, if present, without the ability to distinguish between the two. The EPA Methods 26 and 26A use an acidified absorbing solution to first separate $\mathrm{HCl}$ and $\mathrm{Cl} 2$ gas so that they can be selectively absorbed, analyzed, and reported separately. In addition, in EN 1911 the absorption efficiency for $\mathrm{Cl} 2$ gas would be expected to vary as the $\mathrm{pH}$ of the water changed during sampling.
\end{abstract}

\section{Government Standard: EPA Method 28 (Section 10.1) - Wood Heaters, Certificate and Auditing [Incorporated: 2003]}

\section{Voluntary Standard}

ASME Power Test Codes, Supplement on Instruments and Apparatus, part 5, Measurement of Quantity of Materials, Chapter 1, Weighing Scales

ASTM E319-85 (Re-approved 1997), Standard Practice for the Evaluation of Single-Pan Mechanical Balances

\section{Rationale}

It does not specify the number of initial calibration weights to be used nor a specific pretest weight procedure.

This standard is not a complete weighing procedure because it does not include a pretest procedure.

\section{Government Standard: EPA Method 29 - Metals Emissions from Stationary Sources [Incorporated: 2001]}

\section{Voluntary Standard}

ASTM D4358-94 (1999), Standard Test Method for Lead and Chromium in Air Particulate Filter Samples of Lead Chromate Type Pigment Dusts by Atomic Absorption Spectroscopy

ASTM E1741-95 (1995), Standard Practice for Preparation of Airborne Particulate Lead Samples Collected During Abatement and Construction Activities for Subsequent Analysis by Atomic Spectrometry

\section{Rationale}

These ASTM standards do not require the use of glass fiber filters as in EPA Method 12 and require the use of significantly different digestion procedures that appear to be milder than the EPA Method 12 digestion procedure. For these reasons, these ASTM standards cannot be considered equivalent to EPA Method 12. Also, the subject ASTM standards do not require the use of hydrogen fluoride (HF) as in EPA Method 29 and, therefore, they cannot be used for the preparation, digestion, and analysis of Method 29 samples. Additionally, Method 29 requires the use of a glass fiber filter, whereas these three ASTM standards require cellulose filters and other probable non-glass fiber media, which cannot be considered equivalent to EPA Method 29.

These ASTM standards do not require the use of glass fiber filters as in EPA Method 12 and require the use of significantly different digestion procedures that appear to be milder than the EPA Method 12 digestion procedure. For these reasons, these ASTM standards cannot be considered equivalent to EPA Method 12. Also, the subject ASTM standards do not require the use of hydrogen fluoride (HF) as in EPA Method 29 and, therefore, they cannot be used for the preparation, digestion, and analysis of Method 29 samples. Additionally, Method 29 requires the use of a glass fiber filter, 
ASTM E1979-98 (1998), Standard Practice for Ultrasonic Extraction of Paint, Dust, Soil, and Air Samples for Subsequent Determination of Lead

CAN/CSA Z223.26-M1987, Measurement of Total Mercury in Air Cold Vapour Atomic Absorption Spectrophotometeric Method whereas these three ASTM standards require cellulose filters and other probable non-glass fiber media, which cannot be considered equivalent to EPA Method 29.

These ASTM standards do not require the use of glass fiber filters as in EPA Method 12 and require the use of significantly different digestion procedures that appear to be milder than the EPA Method 12 digestion procedure. For these reasons, these ASTM standards cannot be considered equivalent to EPA Method 12. Also, the subject ASTM standards do not require the use of hydrogen fluoride (HF) as in EPA Method 29 and, therefore, they cannot be used for the preparation, digestion, and analysis of Method 29 samples. Additionally, Method 29 requires the use of a glass fiber filter, whereas these three ASTM standards require cellulose filters and other probable non-glass fiber media, which cannot be considered equivalent to EPA Method 29.

It lacks sufficient quality assurance and quality control requirements necessary for EPA compliance assurance requirements.

\section{Government Standard: EPA Method 2C - Velocity and Flow Rate, Standard Pitot [Incorporated: 1999]}

Voluntary Standard

ASTM D3154-00, Standard Method for Average Velocity in a Duct (Pitot Tube Method)

\section{Rationale}

1. The standard appears to lack in quality control and quality assurance requirements. It does not include the following: (1) Proof that openings of standard pitot tube have not plugged during the test; (2) if differential pressure gauges other than inclined manometers (e.g., magnehelic gauges) are used, their calibration must be checked after each test series; and (3) the frequency and validity range for calibration of the temperature sensors. 2 . They are too general, too broad, or not sufficiently detailed to assure compliance with EPA regulatory requirements.

\section{Government Standard: EPA Method 3 - Molecular Weight Carbon Dioxide,}

Oxygen [Incorporated: 1999]

Voluntary Standard

ASME C00031 or PTC 19-10-1981--part 10, "Flue and Exhaust Gas Analyses"

ASTM D3154-00, Standard Method for Average Velocity in a Duct (Pitot Tube Method)

\section{Rationale}

It is too general, too broad, or not sufficiently detailed to assure compliance with EPA regulatory requirements.

1. The standard appears to lack in quality control and quality assurance requirements. It does not include the following: (1) Proof that openings of standard pitot tube have not plugged during the test; (2) if differential pressure gauges other than inclined manometers (e.g., magnehelic gauges) are used, their calibration must be checked after each test series; and (3) the frequency and validity range for calibration of the temperature sensors. 2. They are too general, too broad, or not sufficiently detailed to assure compliance with EPA regulatory requirements. 


\section{Government Standard: EPA Method 306 - Chromium Emissions, Electroplating and Anodizing [Incorporated: 2002]}

Voluntary Standard

ASTM D4358-94 (1999) - Standard Test Method for Lead and Chromium in Air Particulate Filter Samples of Lead Chromate Type Pigment Dusts by Atomic Absorption Spectroscopy

\section{Rationale}

This MACT standard (Petroleum Refineries) only cites Method 29. Therefore, the following EPA comment is only applicable for Method 29 not Method 12 and 306: Method 29 requires the use of hydrofluoric acid (HF) in its process of digestion of the sample. ASTM D4358-94 (1999) does not require the use of HF; therefore, it cannot be used in the preparation, digestion, and analysis of Method 29 samples. Additionally, Method 29 requires the use of a glass fiber filter, whereas the subject ASTM standard requires cellulose filters and other probable non-glass fiber media, and this further negates their use as Method 29 equivalent methods. (Same comment as provided for ASTM E1741 and ASTM E1979).

\section{Government Standard: EPA Method 306a - Chromium Emissions, Electroplating -- Mason Jar [Incorporated: 2002]}

\section{Voluntary Standard}

ASTM D4358-94 (1999) - Standard Test Method for Lead and Chromium in Air Particulate Filter Samples of Lead Chromate Type Pigment Dusts by Atomic Absorption Spectroscopy

\section{Rationale}

This MACT standard (Petroleum Refineries) only cites Method 29. Therefore, the following EPA comment is only applicable for Method 29 not Method 12 and 306: Method 29 requires the use of hydrofluoric acid (HF) in its process of digestion of the sample. ASTM D4358-94 (1999) does not require the use of HF; therefore, it cannot be used in the preparation, digestion, and analysis of Method 29 samples. Additionally, Method 29 requires the use of a glass fiber filter, whereas the subject ASTM standard requires cellulose filters and other probable non-glass fiber media, and this further negates their use as Method 29 equivalent methods. (Same comment as provided for ASTM E1741 and ASTM E1979).

\section{Government Standard: EPA Method 320 - Vapor Phase Organic and Inorganic Emissions, FTIR [Incorporated: 1999]}

Voluntary Standard

ASTM D6348-98, Determination of Gaseous Compounds by Extractive Direct Interface Fourier Transform (FTIR) Spectroscopy

\section{Rationale}

Suggested revisions to ASTM D6348-98 were sent to ASTM by the EPA that, would allow the EPA to accept ASTM D6348-98 as an acceptable alternative. The ASTM Subcommittee D22-03 is currently undertaking a revision of ASTM D6348- 98. Because of this, we are not citing this standard as an acceptable alternative for EPA Method 320 in the final rule today. However, upon successful ASTM balloting and demonstration of technical equivalency with the EPA FTIR methods, the revised ASTM standard could be incorporated by reference for EPA regulatory applicability. In the interim, facilities have the option to request ASTM D6348-98 as an alternative test method under 40 CFR 63.7(f) and 63.8(f) on a caseby-case basis.

\section{Government Standard: EPA Method 3A - Carbon Dioxide and Oxygen Concentrations,}

IAP [Incorporated: 1999]

\section{Voluntary Standard}

ASTM D5835-95, Standard Practice for Sampling

Stationary Source Emissions for Automated Determination of Gas Concentration

\section{Rationale}

1. They lack in detail and quality assurance/quality contro requirements. Specifically, these two standards do not include the following: (1) Sensitivity of the method; (2) acceptable levels of analyzer calibration error; (3) acceptable levels of sampling system 
CAN/CSA Z223.2-M86(1986), Method for the Continuous Measurement of Oxygen, Carbon Dioxide, Carbon Monoxide, Sulphur Dioxide, and Oxides of Nitrogen in Enclosed Combustion Flue Gas Stream

ISO 10396:1993, Stationary Source Emissions: Sampling for the Automated Determination of Gas Concentrations

ISO 12039:2001, Stationary Source Emissions-Determination of Carbon Monoxide, Carbon Dioxide, and Oxygen--Automated Methods bias; (4) zero drift and calibration drift limits, time span, and required testing frequency; (5) a method to test the interference response of the analyzer; (6) procedures to determine the minimum sampling time per run and minimum measurement time; and (7) specifications for data recorders, in terms of resolution (all types) and recording intervals (digital and analog recorders, only). 2. It is too general, too broad, or not sufficiently detailed to assure compliance with EPA regulatory requirements.

1. It does not include quantitative specifications for measurement system performance, most notably the calibration procedures and instrument performance characteristics. The instrument performance characteristics that are provided are nonmandatory and also do not provide the same level of quality assurance as the EPA methods. For example, the zero and span/calibration drift is only checked weekly, whereas the EPA methods requires drift checks after each run. 2. Is too general, too broad, or not sufficiently detailed to assure compliance with EPA regulatory requirements.

1. They lack in detail and quality assurance/quality control requirements. Specifically, these two standards do not include the following: (1) Sensitivity of the method; (2) acceptable levels of analyzer calibration error; (3) acceptable levels of sampling system bias; (4) zero drift and calibration drift limits, time span, and required testing frequency; (5) a method to test the interference response of the analyzer; (6) procedures to determine the minimum sampling time per run and minimum measurement time; and (7) specifications for data recorders, in terms of resolution (all types) and recording intervals (digital and analog recorders, only). 2. Is too general, too broad, or not sufficiently detailed to assure compliance with EPA regulatory requirements.

This ISO standard is similar to EPA Method 3A, but is missing some key features. In terms of sampling, the hardware required by ISO 12039:2001 does not include a 3-way calibration valve assembly or equivalent to block the sample gas flow while calibration gases are introduced. In its calibration procedures, ISO 12039:2001 only specifies a two-point calibration while EPA Method 3A specifies a three-point calibration. Also, ISO 12039:2001 does not specify performance criteria for calibration error, calibration drift, or sampling system bias tests as in the EPA method, although checks of these quality control features are required by the ISO standard.

\section{Government Standard: EPA Method 3B - Oxygen, Carbon Dioxide, Carbon Monoxide, Emission Rate Correction Factor [Incorporated: 1999]}

Voluntary Standard

ASTM D3154-00, Standard Method for Average Velocity in a Duct (Pitot Tube Method)

ASTM D3154-91 (1995), Standard Method for Average Velocity in a Duct (Pitot Tube Method)

\section{Rationale}

1. The standard appears to lack in quality control and quality assurance requirements. It does not include the following: (1) Proof that openings of standard pitot tube have not plugged during the test; (2) if differential pressure gauges other than inclined manometers (e.g., magnehelic gauges) are used, their calibration must be checked after each test series; and (3) the frequency and validity range for calibration of the temperature sensors. 2 . They are too general, too broad, or not sufficiently detailed to assure compliance with EPA regulatory requirements.

It is too general, too broad, or not sufficiently detailed to assure compliance with EPA regulatory requirements. 
Government Standard: EPA Method 4 - Moisture Content in Stack Gases [Incorporated: 1999]

Voluntary Standard

ASTM D3154-00, Standard Method for Average Velocity in a Duct (Pitot Tube Method)

ASTM D3154-91 (1995), Standard Method for Average Velocity in a Duct (Pitot Tube Method)

ASTM E337-84 (1996), Standard Test Method for Measuring Humidity with a Psychrometer (the Measurement of Wet- and Dry-Bulb

Temperatures)

\section{Rationale}

1. The standard appears to lack in quality control and quality assurance requirements. It does not include the following: (1) Proof that openings of standard pitot tube have not plugged during the test; (2) if differential pressure gauges other than inclined manometers (e.g., magnehelic gauges) are used, their calibration must be checked after each test series; and (3) the frequency and validity range for calibration of the temperature sensors. 2 . They are too general, too broad, or not sufficiently detailed to assure compliance with EPA regulatory requirements.

It is too general, too broad, or not sufficiently detailed to assure compliance with EPA regulatory requirements.

They are too general, too broad, or not sufficiently detailed to assure compliance with EPA regulatory requirements.

\section{Government Standard: EPA Method 5 - Particulate Matter, Stationary Sources [Incorporated: 1999]}

\section{Voluntary Standard}

ASME PTC-38-80 R85 or C00049, Determination of the Concentration of Particulate Matter in Gas Streams

ASTM D3685/D3685M-98, Test Methods for Sampling and Determination of Particulate Matter in Stack Gases

ISO 9096:1992, Determination of Concentration and Mass Flow Rate of Particulate Matter in Gas Carrying Ducts-- Manual Gravimetric Method

\section{Rationale}

It lacks sufficient quality assurance and quality control requirements necessary for EPA compliance assurance requirements.

It lacks sufficient quality assurance and quality control requirements necessary for EPA compliance assurance requirements.

It lacks sufficient quality assurance and quality control requirements necessary for EPA compliance assurance requirements.

\section{Government Standard: EPA Method 515.1 - Chlorinated Acids in Water by CC/ECD [Incorporated: 1998 and 2003]}

Voluntary Standard

Standard Methods 6640B

\section{Rationale}

Standard Methods 6640B for acid herbicides was tentatively deemed impractical for EPA's needs because its sample preparation and quality control procedures were not similar enough to EPA Method 515.1 to ensure that there would not be underreporting of acid herbicide contamination. EPA plans to offer to work with the Standard Methods committee to resolve this issue prior to the next publication.

\section{Government Standard: EPA Method 515.4 - Chlorinated Acids in DW by LL Fast CG/ECD [Incorporated: 2003]}

Voluntary Standard

ASTM D5317-98 -- Standard Test Method For Determination of Chlorinated Organic Acid Compounds in Water by Gas Chromatography With an Electron Capture Detector

\section{Rationale}

ASTM D5317-98 specifies acceptance windows for the initial demonstration of proficiency for laboratory fortified blank samples that are as small as 0 percent to as large as 223 percent recovery for picloram, with tighter criteria for other regulated contaminants. 
Therefore, this method permits unacceptably large control limits, which include 0 percent recovery.

Standard Method 6640 B for the chlorinated acids

The use of this voluntary consensus standard would have been impractical due to significant shortcomings in the sample preparation and quality control sections of the method instructions. Section 1b of Method SM 6640 B states that the alkaline wash detailed in section $4 \mathrm{~b} 2$ is optional. The hydrolysis that occurs during this step is essential to the analysis of the esters of many of the analytes. Therefore, this step is necessary and cannot be optional. In addition, the method specifies that the quality control limits for laboratory-fortified blanks are to be based upon plus or minus three times the standard deviation of the mean recovery of the analytes, as determined in each laboratory. Therefore, this method permits unacceptably large control limits, which may include 0 percent recovery.

\section{Government Standard: EPA Method 531.2 - N-Methylcarbamoylozimes/ates, Aqueous In/HPLC [Incorporated: 2003]}

\section{Voluntary Standard}

Standard Method 6610, 20th Edition

Standard Method 6610, 20th Supplemental Edition

\section{Rationale}

Standard Method 6610, 20th Edition has recently been approved for compliance monitoring. Standard Method 6610, 20th Supplemental Edition permits the use of a strong acid, hydrochloric acid ( $\mathrm{HCL})$, as a preservative. The preservatives in all of the other approved EPA and Standard Methods procedures for these analytes are weak acids that adjust the $\mathrm{pH}$ to a specific value based upon the $\mathrm{pKa}$ of the preservative. The use of $\mathrm{HCL}$ would require accurate determinations of the $\mathrm{pH}$ of the sample in the field and could be subject to considerable error and possible changes in $\mathrm{pH}$ upon storage. Although not specifically observed for oxamyl or carbofuran during the development of similar methods, structurally similar pesticides have been shown to degrade over time when kept at $\mathrm{pH}$ 3. Therefore, approval of this method is impractical because it specifies the use of a strong acid (HCL) when positive control of the $\mathrm{pH}$ is critical.

Standard Method 6610, 20th Edition has recently been approved for compliance monitoring. Standard Method 6610, 20th Supplemental Edition permits the use of a strong acid, hydrochloric acid $(\mathrm{HCL})$, as a preservative. The preservatives in all of the other approved EPA and Standard Methods procedures for these analytes are weak acids that adjust the $\mathrm{pH}$ to a specific value based upon the $\mathrm{pKa}$ of the preservative. The use of $\mathrm{HCL}$ would require accurate determinations of the $\mathrm{pH}$ of the sample in the field and could be subject to considerable error and possible changes in $\mathrm{pH}$ upon storage. Although not specifically observed for oxamyl or carbofuran during the development of similar methods, structurally similar pesticides have been shown to degrade over time when kept at $\mathrm{pH}$ 3. Therefore, approval of this method is impractical because it specifies the use of a strong acid $(\mathrm{HCL})$ when positive control of the $\mathrm{pH}$ is critical.

\section{Government Standard: EPA Method 5i - Low Level Particulate Matter, Stationary Sources [Incorporated: 2001] \\ Voluntary Standard \\ Rationale}

ASTM D6331-98
This standard does not have paired trains as specified in method 5 and does not include some quality control procedures specified in 
the EPA method and which are appropriate to use in this rule.

\section{Government Standard: EPA Method 6 - Sulphur Dioxide Emissions [Incorporated: 1999] \\ Voluntary Standard \\ ASME C00031 or PTC 19-10-1981 - Part 10 Flue \\ and Exhaust Gas Analyses \\ Rationale \\ They are too broad to be useful in regulatory sense. Covers Methods 3, 6, 7, and 15 with variants.}

ISO 11632:1998 - Stationary Source Emissions Determination of the Mass Concentration of Sulfur Dioxide - Ion Chromatography

ISO 7934:1998 - Stationary Source Emissions Determination of the Mass Concentration of Sulfur Dioxide - Hydrogen Peroxide/Barium Perchlorate/ Thorin Method
This standard is only applicable to sources with $30 \mathrm{mg} / \mathrm{m} 3 \mathrm{SO} 2$ or more. In addition, this method does not separate SO3 from SO2 as does EPA Method 6; therefore, this method is not valid if more than a negligible amount of $\mathrm{SO} 3$ is present. Also, does not address ammonia interferences.

\section{Government Standard: EPA Method 6c - Sulphur Dioxide Emissions Stationary by IAP [Incorporated: 1999]}

\section{Voluntary Standard}

ASTM D5835-95 - Standard Practice for Sampling

Stationary Source Emissions for Automated

Determination of Gas Concentration

CAN/CSA Z223.2-M86 - (1986) Method for the Continuous Measurement of Oxygen, Carbon Dioxide, Carbon Monoxide, Sulphur Dioxide, and Oxides of Nitrogen in Enclosed Combustion Flue Gas Streams

ISO 10396:1993 - Stationary Source Emissions: Sampling for the Automated Determination of Gas Concentrations

\section{Rationale}

Similar to Methods 3a, 6c, 7e, 10, ALT 004, CTM 022, the standard lacks in detail and quality assurance and quality control requirements; very similar to ISO 10396.

It is too general. This standard lacks in detail and quality assurance/quality control requirements. Appendices with valid quality control information are not a required part of this method.

It duplicates Method 3a, 6c, 7e, 10, ALT 004, CTM 022 and lacks in detail and quality assurance plus quality control requirements. Similar to ASTM D5835.

\section{Government Standard: EPA Method 7 - Nitrogen Oxide Emissions Stationary Sources [Incorporated: 1999]}

Voluntary Standard

ASME C00031 or PTC 19-10-1981 - Part 10 Flue and Exhaust Gas Analyses

\section{Rationale}

It is too broad to be useful in regulatory sense. Covers Methods 3 , 6,7 , and 15 with variants.

\section{Government Standard: EPA Method 7e - Nitrogen Oxide, Instrumental [Incorporated: 1999] \\ Voluntary Standard \\ ASTM D5835-95 - Standard Practice for Sampling \\ Stationary Source Emissions for Automated \\ Determination of Gas Concentration \\ CAN/CSA Z223.2-M86 - (1986) Method for the Continuous Measurement of Oxygen, Carbon Dioxide, Carbon Monoxide, Sulphur Dioxide, and \\ Rationale \\ Similar to Methods 3a, 6c, 7e, 10, ALT 004, CTM 022, It lacks in detail and quality assurance and quality control requirements; very similar to ISO 10396. \\ It is too general. This standard lacks in detail and quality assurance/quality control requirements. Appendices with valid quality control information are not a required part of this method.} Oxides of Nitrogen in Enclosed Combustion Flue Gas Streams 
ISO 10396:1993 - Stationary Source Emissions: Sampling for the Automated Determination of Gas Concentrations
It duplicates Method 3a, 6c, 7e, 10, ALT 004, CTM 022 and lacks in detail and quality assurance plus quality control requirements; similar to ASTM D5835.

\section{Government Standard: EPA Method ALT 004 [Incorporated: 2002] \\ Voluntary Standard \\ Rationale}

ASTM D5835-95 - Standard Practice for Sampling

Stationary Source Emissions for Automated

Determination of Gas Concentration

ISO 10396:1993 - Stationary Source Emissions:

Sampling for the Automated Determination of Gas

Concentrations
Similar to Methods 3a, 6c, 7e, 10, ALT 004, CTM 022, it lacks in detail and quality assurance and quality control requirements; very similar to ISO 10396.

It duplicates Method 3a, 6c, 7e, 10, ALT 004, CTM 022 and lacks in detail and quality assurance plus quality control requirements; similar to ASTM D5835.

\section{Government Standard: EPA Method CTM 022 [Incorporated: 2002] \\ Voluntary Standard \\ Rationale}

ASTM D5835-95 - Standard Practice for Sampling

Stationary Source Emissions for Automated

Determination of Gas Concentration

ISO 10396:1993 - Stationary Source Emissions: Sampling for the Automated Determination of Gas Concentrations
Similar to Methods 3a, 6c, 7e, 10, ALT 004, CTM 022, it lacks in detail and quality assurance and quality control requirements; very similar to ISO 10396.

It duplicates Method 3a, 6c, 7e, 10, ALT 004, CTM 022 and lacks in detail and quality assurance plus quality control requirements; similar to ASTM D5835.

\section{Government Standard: EPA Method GG - (Title not found in index) [Incorporated: 2003] Voluntary Standard \\ Rationale}

ASTM D3031-81 - Method of Test for Total Sulfur in Natural Gas (Hyrogenation), Withdrawn

This method has been deleted from the final rule because it was discontinued by the ASTM in 1990 with no replacement. If the total sulfur content of the fuel being fired in the turbine is less than 0.4 weight percent, we are adding a provision that the following methods may be used to measure the sulfur content of the fuel: ASTM D4084-82 or 94, D5504-01, D6228-98, or the Gas Processors Association Method 2377-86. This provision is consistent with the provision in 40 CFR 60.13(j)(1) allowing alternatives to reference method tests to determine relative accuracy of CEMS for sources with emission rates demonstrated to be less than 50 percent of the applicable standard.

\section{Government Standard: EPA Performance Specification 1 [Incorporated 2001] \\ Voluntary Standard \\ ASTM D6216-98 -Standard Procedure for Opacity Monitor Manufacturers to Certify Conformance with Design and Performance Specifications \\ Rationale \\ EPA incorporates ASTM D6216 (manufacturers certification) by reference into EPA Performance Specification 1, Sections 5 and 6 in another rulemaking. ASTM D6216 does not address all the requirements specified in $\mathrm{PS}-1$.}

\section{Government Standard: EPA Performance Specification 2 (sulfur dioxide portion only) [Incorporated: 2001] (nitrogen oxide portion only) [Incorporated: 2001] \\ Voluntary Standard \\ Rationale}

ISO 7935:1992, Stationary Source Emissions--

Determination of the Mass Concentration of Sulfur Dioxide--Performance Characteristics of
It is too general, too broad, or not sufficiently detailed to assure compliance with EPA regulatory requirements. 


\section{Voluntary Standard}

ISO 10849:1996, Determination of the Mass

Concentration of Nitrogen Oxides--Performance

\section{Rationale}

It is too general, too broad, or not sufficiently detailed to assure compliance with EPA regulatory requirements.

\section{Government Standard: EPA Performance Specifications 11 - Particulate Matter Continuous Monitoring System [Incorporated: 1999]}

\section{Voluntary Standard}

ISO 10155:1995 - Stationary source emissions. Automated monitoring of mass concentration of particles - Performance characteristics, test methods and specifications.

\section{Rationale}

This international standard is only applicable on a site specific basis by direct correlation with the manual method ISO 9096 (which does not produce particulate matter measurements like EPA Method 5). This appears to be a PM CEMS performance specification similar to EPA Performance Specification 11, but does not contain detailed RATA procedures. Also, EPA doesn't have a final performance specification to compare this to.

\section{Government Standard: GLI Method 2 [Incorporated: 1999]}

\section{Voluntary Standard}

ISO 7027 - Water Quality Determination of Turbidity

\section{Rationale}

EPA has no data upon which to evaluate whether the separate 90 degrees scattered or transmitted light measurement evaluations according to the ISO 7027 method would produce results that are equivalent to results produced by the other methods.

\section{Government Standard: Standard Method 2130B [Incorporated: 1999]}

\section{Voluntary Standard}

ISO 7027 - Water Quality Determination of Turbidity

\section{Rationale}

EPA has no data upon which to evaluate whether the separate 90 degrees scattered or transmitted light measurement evaluations according to the ISO 7027 method would produce results that are equivalent to results produced by the other methods.

\section{Government Standard: SW846-6010b Voluntary Standard \\ ASTM C1111-98 (1998) - Standard Test Method for Determining Elements in Waste Streams by Inductively Coupled Plasma-Atomic Emission Spectrometers}

ASTM D6349-99 (1999) - Standard Test Method for Determining Major and Minor Elements in Coal, Coke, and Solid Residues from Combustion of Coal and Coke by Inductively Coupled PlasmaAtomic Emission Spectrometers

\section{corporated: 2002]}

\section{Rationale}

This standard lacks details for instrument operation QA/QC, such as optimizing plasma operating conditions; upper limit of linear dynamic range; spectral interference correction; and calibration procedures, which include initial and continuous calibration verifications. Also lacks internal standard and method of standard addition options for samples with interferences.

This standard lacks details for instrument operation QA/QC, such as optimizing plasma operating conditions, upper limit of linear dynamic range, spectral interference correction, and calibration procedures, that include initial and continuous calibration verifications. Also lacks details for standard preparation, and internal standard and method of standard addition options for samples with interferences. 
Agency: Government Printing Office (GPO)

Government Standard: FED-STD 209 [Incorporated: 2000] [Discontinued: 2005]

Voluntary Standard

ISO $14644-1$ \& ISO 14644-2

\section{Rationale}

Military and Federal quality assurance standards used and gradually phased out.

Government Standard: MIL-STD 105 [Incorporated: 2000] [Discontinued: 2005]

Voluntary Standard

ANSI/ASQC Z1.4
Rationale

Military and Federal quality assurance standards used and gradually phased out.

Government Standard: MIL-STD 1189 [Incorporated: 2000] [Discontinued: 2005]

Voluntary Standard

ANSI/AIM X5-2 \& ANSI X3.182
Rationale

Military and Federal quality assurance standards used and gradually phased out.

Government Standard: MIL-STD 498 [Incorporated: 2000] [Discontinued: 2005]

Voluntary Standard

IEEE/EIA 12207.0, IEEE/EIA 12207.1, \& IEEE/EIA

12207.2

\section{Rationale}

Military and Federal quality assurance standards used and gradually phased out.

\section{Agency: General Services Administration (GSA)}

Government Standard: FF-L-2740 Locks, Combination [Incorporated: 1999] [Discontinued: 2002]; AA-D-600B and AA-V-2737, Door Vault Security and Modular Vault Systems [Incorported: 2000] [Discontinued: 2001]

Voluntary Standard

UL 608/UL 768

\section{Rationale}

The government standards were justified for protection of National security information.

\section{Government Standard: Federal Specification KKK-A-1822E - Federal Specification for} Ambulances [Incorporated: 2000]

Voluntary Standard

ASTM F2020 - Standard Practice for Design, Construction, and Procurement of Emergency Medical Services Ambulances

\section{Rationale}

The ASTM Standard Practice for Design, Construction, and Procurement of Emergency Medical Services (EMSS) Ambulances (ASTM F2020) is not practical for use, and therefore GSA uses the Federal Specification for Ambulances (KKK-A-1822E). GSA has determined the ASTM document is not practical for use for the following reasons:

1) GSA has determined that ASTM F2020 contains specific practices that are technically and economically impractical to use for the acquisition of commercial based vehicles because the document is financially burdensome and technically ineffective. Specifically at issue is the ASTM Standard Specification for Medical 
Oxygen Delivery Systems for EMS Ground Vehicles, F1949-99 which is inclusive to ASTM F2020.

2) GSA has determined that ASTM F2020 is impractical because it is defined as a standard practice which is ambiguous and an ineffective substitution for specifications or requirements for use in GSA contract documents. ASTM F1949-99, a Standard Specification for Medical Oxygen Delivery Systems for EMS Ground Vehicles is included in ASTM F2020. ASTM F1949-99 is defined as a "standard specification".

3) GSA has determined that ASTM F2020 is impractical because ASTM International does not provide interpretations and written guidance to their publications which is inadequate and less useful. ASTM members may only offer personal opinions. ASTM offers no mechanism to support timely resolution of conflicts between contractor and procurement organizations on technical subject matter. GSA provides interpretations, clarifications and engineering determinations when required. This is one of the most important concerns presented by the Ambulance Manufacturers Division (AMD).

4) The AMD has determined through consensus that it is impractical to replace the Federal Specification for Ambulances, KKK-A-1822E with the ASTM Standard Practice, F2020. GSA initiated a survey to collect public responses from a wide range of constituent users of the Federal Ambulance Specification. The National Association of Emergency Medical Technicians (NAEMT), the International Association of Fire Chiefs (IAFC), the National Association of State EMS Directors (NASEMSD) and the National Association of EMS Physicians universally accept and support the continued use of the Federal Specification. The AMD and constituent users have determined that it is impractical to replace the Federal Specification for Ambulances, KKK-A-1822E with the ASTM Standard Practice, F2020 because rule promulgation is burdensome and costly. Staff and administration resources would need to be diverted in each state EMS office to implement the change in statutes, public health codes, rules and regulations.

5) GSA has determined that ASTM F2020 is impractical because it is burdensome to GSA procurement efforts. While the current ASTM document recites many of the requirements from the Federal Specification, a future ASTM document would likely have diverging requirements unacceptable to the Government. This was verified by a member of the ASTM F2020 subcommittee at the September 4, 2003 meeting of the Federal Interagency Committee on Emergency Medical Services.

\section{Government Standard: MIL-G-9954 - Glass Beads for Cleaning and Peening [Incorporated: 2003]}

Voluntary Standard

SAE/AMS 2431 - Peening Media, General

Requirements

\section{Rationale}

This government-unique standard contains specific size \& performance required for Air Force critical applications that are not present in the voluntary standards. 
Government Standard: Federal Specification A-A-1925 - Shield, Expansion (Nail Anchors) [Incorporated: 2000] [Discontinued: 2004]

Voluntary Standard

Not applicable

\section{Rationale}

Upon subsequent review, it was determined that this is not a government-unique standard. Rather, it is described by the Defense Logistics Agency, the originator of the document, as a Commercial Item Description (CID), and it does not replace the applicable test method standard ASTM E488.

\section{Agency: Department of Health and Human Services (HHS)}

Government Standard: FDA Guidelines on Asceptic Processing (2004) [Incorporated: 1997]

Voluntary Standard

ISO 13408-1 Asceptic Processing of Health Care Products, Part 1, General Requirements

\section{Rationale}

FDA is not using the ISO standard because the applicability of these requirements is limited to only portions of aseptically manufactured biologics and does not include filtration, freezedrying, sterilization in place, cleaning in place, or barrier-isolator technology. There are also significant issues related to aseptically produced bulk drug substance that are not included in the document.

\section{Government Standard: National Standard Format [Incorporated: 1997] [Discontinued: 2004] Voluntary Standard \\ Rationale \\ The NSF was used widely across the health care payment industry and has become a defacto national standard. However, the Centers for Medicare and Medicaid Services (CMS) directed their contractors to discontinue use of the NSF standard and replace it with ANSI X12 837 by the beginning of FY 2003.}

\section{Government Standard: FR Notice dated June 17, 1994 Tentative Final Monograph for Health Care Antiseptic Drug Products; Proposed Rule [Incorporated: 1997] \\ Voluntary Standard \\ ASTM Standard E1115 - Test Method for \\ Evaluation of Surgical Hand Scrub Formulations \\ Rationale \\ Sensitivity and bias of the ASTM Standard has not been established.}

ASTM Standard E1173-93 - Standard Test Method of an Evaluation of Preoperative, Precatheterization, or Pre-injection Skin Preparations

ASTM Standard E1174-00 - Standard Test method for the Evaluation of the Effectiveness of Health Care Personnel or Consumer Handwash Formulations
Sensitivity and bias of the ASTM Standard has not been established.

Sensitivity and bias of the ASTM Standard has not been established. 


\section{Agency: Department of Housing and Urban Development (HUD)}

Government Standard: 24 CFR 200.935 - 24 CFR 200.955 - Administrator qualifications and procedures for HUD building products and certification programs [Incorporated: 2000]

Voluntary Standard

ANSI A119.1 N - Recreation Vehicles

\section{Rationale}

HUD Building-Product Standards \& Certification Programs. HUD was required by legislation to "establish Federal construction and safety standards for manufactured homes and to authorize manufactured home safety research and development". HUD uses VC together with program administrators who are qualified to validate manufacturers' certifications that particular building products or materials meet applicable HUD standards. VCS without conformity assessments would not provide assurances that the products conform to HUD requirements. HUD retained a private consensus body (NFPA) to update and modernize the Manufactured Home Standards. At the conclusion of the development process, NFPA will submit the revised standard to HUD for regulatory adoption.

\section{Government Standard: 24 CFR 3280 - Manufactured Home Construction and Safety Standards [Incorporated: 2000]}

Voluntary Standard

NFPA 501, Standard on Manufactured Housing

\section{Rationale}

HUD-Unique Manufactured Home Construction \& Safety Standards. HUD was required by legislation to "establish Federal Manufactured Housing Construction and Safety Standards that comport with the purposes of the National Manufacturing Housing and Construction Safety Standards Act. As a result of recent changes in the Act, HUD is now required to consider recommendations for revising the standards that are developed by the Manufactured Housing Consensus Committee (MHCC) through its consensus standards development process. While the NFPA 501 standard has served as the basis for a number of the revisions recommended by the MHCC to the Secretary, the MHCC has modified or did not accept other provisions of the NFPA 501 standard because those requirements did not fully conform to all purposes of the Act.

\section{Agency: National Archives and Records Administration (NARA) \\ Government Standard: NARA data standard [Incorporated: 2000] \\ Voluntary Standard \\ Archives, Personal Papers, and Manuscripts (APPM); \\ Rationale \\ These voluntary standards do not meet the precise needs of the agency.}

General International Standard Archival

Description (ISAD(G));

International Standard Archival Authority Record

for Corporate Bodies, Persons, and Families

(ISAAR(CPF));

Encoded Archival Description (EAD);

Machine Readable Cataloging (MARC) 


\section{Agency: Department of Agriculture (USDA) \\ Government Standard: USDA Forest Service Specification 5100-307; International Specification for Fire Suppressant Foam for Wild land Fires, Aircraft or Ground Application [Incorporated: 2005]}

\section{Voluntary Standard}

NFPA 1150 - Standard on Fire-Fighting Foam Chemicals for Class A Fuels in Rural, Suburban, and Vegetated Areas.

\section{Rationale}

Foam fire suppressants contain foaming and wetting agents. The foaming agents affect the accuracy of an aerial drop, how fast the water drains from the foam and how well the product clings to the fuel surfaces. The wetting agents increase the ability of the drained water to penetrate fuels. Foam fire suppressants are supplied as wet concentrates.

This standard was developed with international cooperation for Class A Foam used in wild land fire suppression situations and equipment. This standard was created by the USDA Forest Service in cooperation with the Department of Interior (DOI), the State of California, Department of Forestry and Fire Protection and the Canadian Interagency Forest Fire Center.

The National Fire Protection Association (NFPA) does have a standard for Class A Foam, (NFPA 1150 - Standard on FireFighting Foam Chemicals for Class A Fuels in Rural, Suburban, and Vegetated Areas). The Forest Service has not chosen to utilize NFPA 1150 as it is designed specifically for application by municipal fire agencies in the wild land-urban interface, utilizing apparatus and situations that they are likely to encounter. The Forest Service's GUS for foam products is specific to use by wild land fire equipment and situations that are unique, e.g. helicopter use of foams, remote storage situations, and varied quality of water sources in the wild land settings. The agency feels this standard more accurately reflects the needs and mission of the federal wild land fire suppression agencies. 


\section{Addendum to the \\ Ninth Annual Report on Federal \\ Agency Use of Voluntary Consensus Standards and Conformity Assessment}




\section{Table of Contents for Supplemental Appendices}

\section{Note: Appendices $A, B$, and $C$ are contained in the full report to the Office of}

Management and Budget

Appendix D - Individual, Unabridged Departmental Reports.......................................D-1

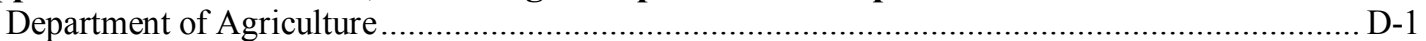

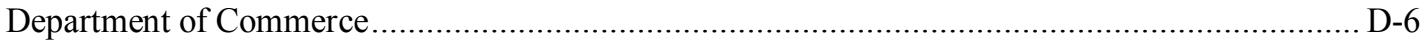

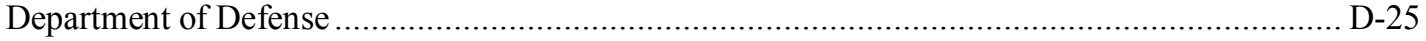

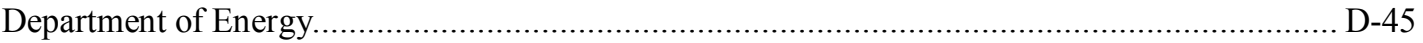

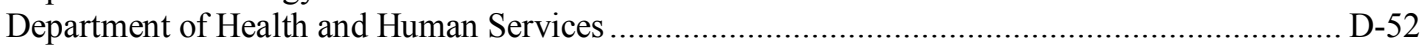

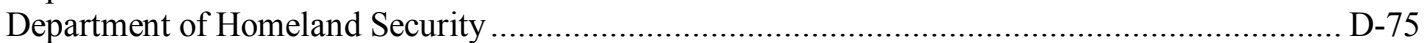

Department of Housing and Urban Development ……...................................................... D-80

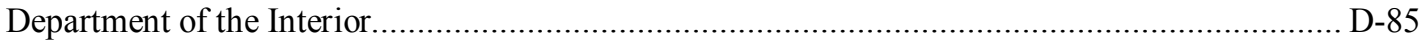

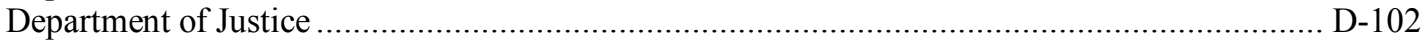

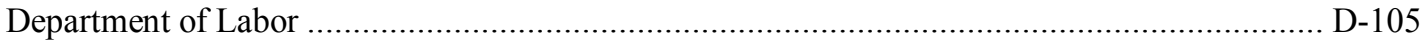

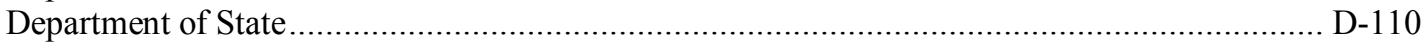

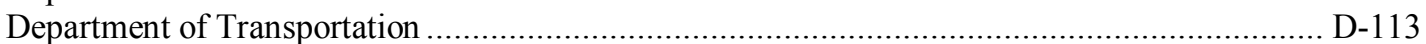

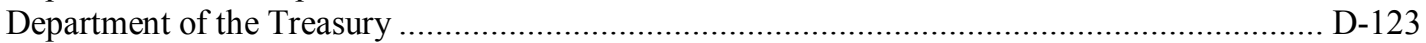

Appendix E - Individual, Unabridged Commission and other Agency Reports..............E-1

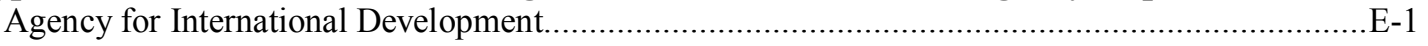

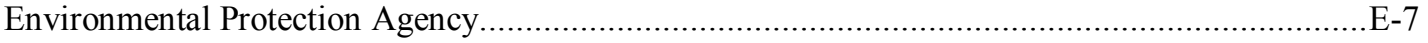

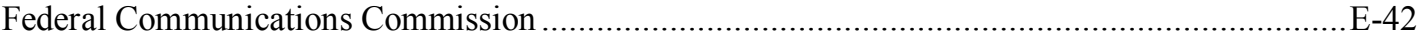

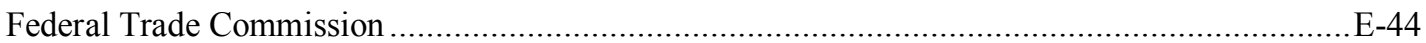

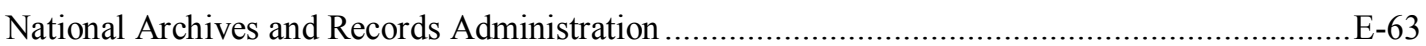

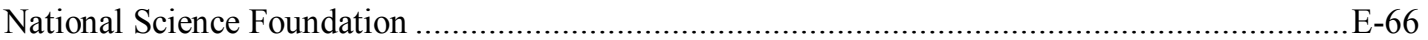

Appendix F - Federal Agency Activities Related to Use of Private Sector Standards.... F-1

Appendix G - The Interagency Committee on Standards Policy (ICSP)........................ G-1

Appendix H - Publications Related to the National Technology Transfer and Advancement Act (NTTAA) and Office of Management and Budget (OMB) Circular A- 


\section{Appendix D - Individual, Unabridged Departmental Reports}

Note: This appendix contains the unabridged reports submitted to NIST by the Cabinet level Departments as they were submitted to NIST.

\section{Department of Agriculture}

1. Please describe the importance of standards in the achievement of your agency's mission, how your agency uses standards to deliver its primary services in support of its mission, and provide any examples or case studies of standards success:

The United States Department of Agriculture follows various voluntary consensus standards adopted by voluntary consensus standards bodies such as the International Organization for Standardization (ISO). The benefits of utilizing consistent standards are significant. For example, conforming to the international standards adopted by ISO has allowed USDA to interface more readily with other industry partners within and outside of the United States. They agree on specifications and criteria to be applied consistently in the classification of materials, in the manufacture and supply of products, in testing and analysis, with sharing data, in terminology and in the provision of services. In this way, the standards provide a reference framework, or a common technological language, between USDA and USDA stakeholders that facilitates trade and the transfer of technology. In utilizing these standards, the time and cost spent in translating and converting data are significantly reduced. Using and conforming to standards, embracing widely accepted methods, promotes credibility and acceptance of the USDA.

2. Please list the government-unique standards your agency used in lieu of voluntary consensus standards during FY 2005: 1

1. Government Unique Standard: Name: WILDLAND FIRE FOAM Number: USDA Forest Service Specification 5100-307; July, 2000 Title: International Specification for Fire Suppressant Foam for Wild land Fires, Aircraft or Ground Application) (Incorporated: 2005)

Voluntary Standard 
NFPA 1150 - Standard on Fire-Fighting Foam Chemicals for Class A Fuels in Rural, Suburban, and Vegetated Areas.

Rationale

Foam fire suppressants contain foaming and wetting agents. The foaming agents affect the accuracy of an aerial drop, how fast the water drains from the foam and how well the product clings to the fuel surfaces. The wetting agents increase the ability of the drained water to penetrate fuels. Foam fire suppressants are supplied as wet concentrates.

This standard was developed with international cooperation for Class A Foam used in wildland fire suppression situations and equipment. Standard created by the USDA Forest Service in cooperation with the Department of Interior (DOI), the State of California, Department of Forestry and Fire Protection and the Canadian Interagency Forest Fire Center.

The National Fire Protection Association (NFPA) does have a standard for Class A Foam, (NFPA 1150 - Standard on Fire-Fighting Foam Chemicals for Class A Fuels in Rural, Suburban, and Vegetated Areas). The Forest Service has not chosen to utilize NFPA 1150 as it is designed specifically for application by municipal fire agencies in the wildland-urban interface, utilizing apparatus and situations that they are likely to encounter. The Forest Service's GUS for foam products is specific to use by wildland fire equipment and situations that are unique, e.g. helicopter use of foams, remote storage situations, and varied quality of water sources in the wildland settings. The agency feels this standard more accurately reflects the needs and mission of the federal wildland fire suppression agencies.

3. Please list the Voluntary Consensus Standards (VCS) your agency substituted for Government Unique Standards (GUS) in FY 2005 as a result of review under Section 15(b)(7) of OMB Circular A-119: 10

Voluntary Standard

Government Standard

A Guide to Writing the Security Features User's Guide USDA/RD Standard for Trusted Systems, NCSC-TG-026, September 1991, NATIONAL COMPUTER SECURITY CENTER, Library No. 
5-237,294 Version 1

American National Standards Institute (ANSI) USDA/RD Standard

Accredited Standards Committee (ASC) X12 -

Approved Format Transaction Set 203 Quarterly

Status Reporting

American National Standards Institute (ANSI)

USDA/RD Standard

Accredited Standards Committee (ASC) X12 -

Approved Format Transaction Set 264 Monthly

Default Status Reporting

ANSI Standard for Structured Query Language (SQL) USDA/FNS Standard

COM / DCOM Security Standards

USDA/RD Standard

Guide to Understanding Trusted Facility

USDA/RD Standard

Management, NCSC-TG-015, June 1989, National

Computer Security Center, Library No. S-231, 429

Guidelines for Writing Trusted Facility Manuals, NCSC-TG-016, Oct. 1992, NATIONAL COMPUTER SECURITY CENTER, Library No. S239,639 Version 1. ISO/BS 17799 Audit Checklist (6/08/2003), BS USDA/RD Standard 7799.2:

J2EE Architectural Standards

USDA/RD Standard

Unified Modeling Language (UML) Standards for

USDA/RD Standard

Documentation, Version 2

4. Please provide the total number of Voluntary Consensus Standards your agency used during FY 2005: Optional: If possible, also please provide the total number of Nonconsensus Standards that are developed in the private sector your agency used during FY 2005. In addition, please provide your agency's rationale for using the Nonconsensus Standards that are developed in the private sector counted in this question.

Voluntary Consensus Standards: 238

Other Technical Standards: 0

Rationale: N/A 
5. Please enter the Voluntary Consensus Standards Bodies (VCSB) in which your agency participated in during FY 2005: 17

\begin{tabular}{|c|c|}
\hline Voluntary Consensus Standards Body & Acronym \\
\hline $\begin{array}{l}\text { American Association of Textile Chemists and } \\
\text { Colorists }\end{array}$ & AATCC \\
\hline American National Standards Institute & ANSI \\
\hline American Society for Testing and Materials & ASTM \\
\hline $\begin{array}{l}\text { Association of Official Analytical Chemists } \\
\text { International }\end{array}$ & $\mathrm{AOACl}$ \\
\hline Codex & CODEX \\
\hline $\begin{array}{l}\text { Industry-wide Cooperative Meat Identification } \\
\text { Standards Committee }\end{array}$ & ICMISC \\
\hline International Dairy Federation & IDF \\
\hline International Organization for Standardization & ISO \\
\hline $\begin{array}{l}\text { International Organization for } \\
\text { Standardization/International Electrotechnical } \\
\text { Commission }\end{array}$ & ISO/IEC \\
\hline International Seed Testing Association & ISTA \\
\hline National Cooperation for Laboratory Accreditation & NACLA \\
\hline National Fire Protection Association & NFPA \\
\hline National Information Standards Organization & NISO \\
\hline $\begin{array}{l}\text { Organization for Economic Cooperation and } \\
\text { Development }\end{array}$ & OECD \\
\hline Project Management Institute & PMI \\
\hline The Open Group & TOG \\
\hline $\begin{array}{l}\text { United Nations Economic Commission for Europe WP } \\
.29 / \text { GRSP }\end{array}$ & UNECE \\
\hline
\end{tabular}

6. Please provide the total number of your agency's representatives who participated in voluntary consensus standards activities during FY 2005 and the total number of activities these agency representatives participated in: $\mathbf{5 2}$ 
7. Please provide any conformity assessment activities (as described in "Guidance on Federal Conformity Assessment Activities" found in the Federal Register, Volume 65, Number 155, dated August 10, 2000) in which your agency was involved in FY 2005.

72

8. Please provide an evaluation of the effectiveness of Circular A-119 policy and recommendations for any changes:

The OMB Circular A-119 policy is sufficient.

9. Please provide any other comments you would like to share on behalf of your agency.

No additional comments.

10. Please use this box to provide any additional comments on how your agency currently reports its use of voluntary consensus standards:

No additional comments

10-1. Removed [This question has been deprecated for 2005]

10-2. Removed [This question has been deprecated for 2005]

10-3. Removed [This question has been deprecated for 2005]

10-4. Does your agency report standards that it uses for guidance purposes (as opposed compliance purposes)? (a) Yes; (b) No; (c) Not applicable; Yes

10-5. Does your agency report use of standards from non-ANSI accredited standards developers, industry consortia groups, or both? (a) non-ANSI Accredited; (b) Consortia; (c) Both; (d) Neither; or (e) Not applicable; C

10-6. Does your agency have a schedule for periodically reviewing its use of standards for purposes of updating such use? (a) Yes; (b) No; Yes

10-7. How often does your agency review its standards for purposes of updating such use? [enter the number of years]: 1 


\section{Department of Commerce}

Title: Department of Commerce (DOC) Fiscal Year 2005 Agency Report

1. Please describe the importance of standards in the achievement of your agency's mission, how your agency uses standards to deliver its primary services in support of its mission, and provide any examples or case studies of standards success:

Standards have been an integral part of the mission of the National Institute of Standards and Technology, U.S. Department of Commerce, since its establishment in 1901. NIST staff contribute to the development of voluntary consensus standards by providing laboratory research for technical content and participating in standards developing committees. This participation supports NIST's mission to promote U.S. innovation and industrial competitiveness.

Reducing Standards-Related Barriers to Trade

Since 2003 when Secretary Evans launched the Standards Initiative, NIST has launched Notify U.S. (described below) as a direct reply to the need for an early warning system that would give the U.S private sector and other interested stakeholders the opportunity to learn about proposed foreign technical regulations that might impact their areas of export. Furthermore, NIST has also promoted the use of U.S. technical standards in global markets through its Standards in Trade Program. Since 2003 NIST has held 12 SIT workshops working with many private sector stakeholders to deliver a coherent and influential message about the U.S. standardization system.

The National Center for Standards and Certification Information ( $\mathrm{NCSCl}$ ) is the U.S. source for standards and standards-related information at home and abroad. The Center provides information on U.S., foreign, regional, and international voluntary standards, mandatory government regulations, and conformity assessment procedures for nonagricultural products. Resources include an extensive collection of reference materials, including U.S. military and other Federal Government specifications, U.S. industry and national standards, international standards, and selected foreign national standards. $\mathrm{NCSCI}$ responds to requests for specialized standards information, provides 
contact points for translations of foreign standards and regulations, and disseminates information to U.S. industry concerning proposed foreign regulations and general standards issues.

In fulfillment of U.S. obligations under the World Trade Organization (WTO) Agreement on Technical Barriers to Trade (TBT) and the North American Free Trade Agreement (NAFTA), NCSCI serves as the U.S. national Inquiry Point and national Notification Authority. Signatories to the WTO TBT Agreement are required to notify the WTO Secretariat in Geneva of proposed technical regulations that could affect world trade and provide a 60-day comment period for review and comment by other WTO Members. On July 1, 2005, NCSCI launched a web-based email subscription service, Notify U.S., to disseminate WTO summary notifications at no charge to U.S. entities (citizens, industries, organizations). Notify U.S. provides industry with an opportunity to review and comment on proposed foreign technical regulations that can affect their businesses and their access to international markets. $\mathrm{NCSCI}$ acquires the full texts of the proposed technical regulations from the relevant foreign inquiry points and distributes them via Notify U.S. to interested U.S. industries. Further details regarding Notify U.S. can be viewed at www.nist.gov/notifyus.

In 2005, NCSCI staff handled over 12,250 requests for standards and technical barriers to trade information. $\mathrm{NCSCl}$ developed and hosted a 5-day workshop in June 2005 on operation of a WTO TBT Inquiry Point for eighteen inquiry point staff from the Caribbean Community (Caricom) member nations. $\mathrm{NCSCl}$ staff led planning for the annual observance of World Standards Day in October 2005 jointly with the American National Standards Institute (ANSI).

$\mathrm{NCSCl}$ is the U.S. member of the International Organization for Standardization (ISO) Information Network (ISONET). NCSCI networks with other national standards organizations to exchange standards-related information and share access to foreign trade-related standards, technical regulations, and conformity assessment procedures.

The Standards in Trade (SIT) program is a major activity of the Global Standards and Information Group (GSIG) in the NIST Standards Services Division (SSD). The workshops are designed to provide timely information to foreign 
standards officials on U.S. practices in standards and conformity assessment. Participants are introduced to U.S. technology and principles in metrology, standards development and application, and conformity assessment systems. The workshop agenda includes briefing panels on strategies to enhance trade between the United States and the invited countries.

NIST works closely with the private sector including small and medium sized companies to develop a one week program offering a comprehensive overview of the roles of the U.S. government, private sector, and regional and international organizations involved in standards development and conformity assessment practices that impact trade. SIT offers an excellent opportunity where U.S. stakeholders, including small and medium sized enterprises, make professional contacts of great value when trying to get their products exported to countries where standards related requirements have to be met. As mentioned about since 2003 when Secretary Evans launched the Standards Initiative, NIST has organized 12 SIT workshops. The upcoming 2006 workshops are:

1. Electrical Safety for the Americas

2. Iraq Construction Sector, and

3. Building and Construction for the Middle East.

More detailed information about the SIT program can be found at http: / /ts.nist.gov/ts/htdocs/210/gsig/sitdescr.htm.

2. Please list the government-unique standards your agency used in lieu of voluntary consensus standards during FY 2005: 0

3. Please list the Voluntary Consensus Standards (VCS) your agency substituted for Government Unique Standards (GUS) in FY 2005 as a result of review under Section 15(b)(7) of OMB Circular A-119: 0

4. Please provide the total number of Voluntary Consensus Standards your agency used during FY 2005: Optional: If possible, also please provide the total number of Non- 
consensus Standards that are developed in the private sector your agency used during FY 2005. In addition, please provide your agency's rationale for using the Non-

consensus Standards that are developed in the private sector counted in this question.

Voluntary Consensus Standards: 0

Other Technical Standards: 0

Rationale:

5. Please enter the Voluntary Consensus Standards Bodies (VCSB) in which your agency participated in during FY 2005: 98

Voluntary Consensus Standards Body

Acoustical Society of America

Air Conditioning \& Refrigeration Institute

Alliance for Telecommunications Industry Solutions

American Association of Physicists in Medicine

American Concrete Institute

American Dental Association

American Gas Association

American Institute of Aeronautics and Astronautics

American National Standards Institute

American Nuclear Society

American Society for Testing and Materials

American Society of Civil Engineers

American Society of Heating, Refrigerating, and Air

Conditioning Engineers

American Society of Mechanical Engineers

American Society of Quality Control

American Vacuum Society

American Welding Society

Association for Information and Image Management
Acronym

ASA

ACRI

ATIS

AAPM

$\mathrm{ACl}$

ADA

AGA

AIAA

ANSI

ANS

ASTM

ASCE

ASHRAE

ASME

ASQC

AVS

AWS

AlIM 
Association of Biomolecular Research Facilities

Basic Linear Algebra Subprograms Technical Forum

Biometrics Application Programming Interface

British Standards Institution

Canadian General Standards Board

Clinical and Laboratory Standards Institute

Codex

Committee on Data for Science and Technology

Common Criteria Management Committee

Consumer Electronics Association

Council on Ionizing Radiation Measurements and

Standards

Council on Optical Radiation Measurements

Electronic Industries Alliance

Engineering Sciences Data Unit International

Illuminating Engineering Society of North America

Industrial Truck Association

Institute for Interconnecting and Packaging

Electronic Circuits

Institute of Electrical and Electronic Engineers

Inter-American Accreditation Cooperation

Inter-American Metrology System

International Association for the Properties of Water

and Steam

International Atomic Energy Agency

International Bureau of Weights and Measures

International Cartographic Association

International Civil Aviation Organization

International Code Council

International Commission for Illumination

International Commission on Radiation Units and
ABRF

BLAS

BioAPI

BSI

CGSB

CSLI

CODEX

CODATA

CCMC

CEA

CIRMS

CORM

EIA

ESDU

IES

ITA

IPEC

IEEE

IAAC

SIM

IAPWS

IAEA

BIPM

ICA

ICAO

ICC

CIE

ICRU 
Measurements, Inc.

InterNational Committee for Information Technology INCITS

Standards

International Committee for Weights and Measures CIPM

International Council for Science ICSU

International Earth Rotation and Reference Systems IERS

Service

International Electrotechnical Commission IEC

International Federation on Information Processing IFIP

International Hydrographic Organization IHO

International Imaging Industry Association IIIA

International Organization for Legal Metrology OIML

International Organization for Standardization ISO

International Organization for ISO/IEC

Standardization/International Electrotechnical

Commission

International Telecommunication Union

ITU

International Union of Laboratories and Experts in

RILEM/CIB

Materials, System and Structures/International

Council for Research and Innovation in Building and

Construction

International Union of Laboratories and Experts in

RILEM

Materials, Systems and Structures

International Union of Pure and Applied Chemistry IUPAC

Internet Engineering Task Force IETF

Internet Software Consortium ISC

JANNAF - Interagency Propulion Committee JANNF

Java Grande Forum JGF

Joint Electron Device Engineering Council JEDEC

National Academy of Sciences NAS

National Conference of Standards Laboratories NCSL

National Conference on Weights and Measures NCWM 
National Council of Radiation Protection and

NCRPM

Measurements

National Fire Protection Association NFPA

National Fluid Power Association NFPA

North American Open Math Initiative NAOMI

Open Applications Group OAGi

Open DeviceNet Vendor Association ODVA

Open Geospatial Consortium OGC

Open Management Group OMG

Optical Internetworking Forum OIF

Optical Society of America $\quad$ OSA

Optical Storage Technology Association OSTA

Optics and Electro-Optics Standards Council OEOSC

Organization for the Advancement of Structured OASIS

Information Systems

Pan-American Standards Commission COPANT

Robotics Industry Association RIA

Semiconductor Equipment and Materials SEMI

International

Simulation Interoperability Standards Organization SISO

Society of Automotive Engineers SAE

Society of Motion Picture and Television Engineers SMPTE

Standards Engineering Society SES

Telecommunications Industry Association TIA

The Instrumentation, Systems, and Automation ISAS

Society

U.S. Product Data Association US PRO

Underwriters Laboratories UL

Versailles Project on Advanced Materials and VAMAS

Standards

Video Electronics Standards Association VESA 
World Intellectual Property Organization

World Meteorological Organization

World Wide Web Consortium
WIPO

WMO

W3C

6. Please provide the total number of your agency's representatives who participated in voluntary consensus standards activities during FY 2005 and the total number of activities these agency representatives participated in: $\mathbf{4 4 2}$

7. Please provide any conformity assessment activities (as described in "Guidance on Federal Conformity Assessment Activities" found in the Federal Register, Volume 65, Number 155, dated August 10, 2000) in which your agency was involved in FY 2005.

National Voluntary Laboratory Accreditation Program (NVLAP)

The National Voluntary Laboratory Accreditation Program (NVLAP) provides third-party accreditation to testing and calibration laboratories. NVLAP's accreditation programs are established in response to Congressional mandates or administrative actions by the Federal Government or from requests by private-sector organizations. NVLAP is in full conformance with the standards of the International Organization for Standardization (ISO) and the International Electrotechnical Commission (IEC), including ISO/IEC 17025 and Guide 58 (ISO/IEC 17011 as of January 1, 2006). NVLAP identifies its laboratories in its NVLAP-Accredited Laboratories Directory which is published online at www.nist.gov/nvlap. NVLAP is a signatory to the International Laboratory Accreditation Cooperation (ILAC), the Asia-Pacific Laboratory Accreditation Cooperation (APLAC), and the National Cooperation for Laboratory Accreditation (NACLA) Mutual Recognition Arrangements. By participating in these Cooperations, NVLAP facilitates the mutual recognition of accredited test and measurement results of its signatory partners, reducing the need redundant testing and lower costs to customers.

National Voluntary Conformity Assessment System Evaluation (NVCASE) Program

The National Voluntary Conformity Assessment System Evaluation (NVCASE)

Program enables U.S. industry to satisfy mandated foreign technical requirements using the results of U.S.-based conformity assessment programs 
that perform technical evaluations comparable in their rigor to practices in the receiving country. Under this program, the Department of Commerce, acting through the National Institute of Standards and Technology, evaluates U.S.based conformity assessment bodies in order to be able to give assurances to a foreign government that qualifying bodies meet that government's requirements and can provide results that are acceptable to that government. The program provides a technically-based U.S. approval process for U.S. industry to gain foreign market access; the acceptability of conformity assessment results to the relevant foreign government will be a matter for agreement between the two governments. Additional information about the NVCASE Program can be found at http://ts.nist.gov/ts/htdocs/210/gsig/nvcase.htm.

Conformity Assessment Activities under Mutual Recognition Agreements/Arrangement (MRAs)

The United States and the European Community Mutual Recognition Agreement (US - EU MRA) is a multi-sector bilateral government-to-government agreement between the United States and the 25 Member States of the European Union. Under this MRA, NIST is responsible for designating organizations in the US Conformity Assessment Bodies (CABs) for three product sectors: 1) Electromagnetic Compatibility (EMC), 2) Telecommunications, and 3) Recreational Craft. After a lengthy review process, CABs that meet certain criteria are formally recognized and may operate as a CAB as described in the U.S. - EU MRA and the specific technical regulations of the EU governing the appropriate product sectors. . The U.S.-EU MRA is an important regulatory and trade agreement which provides greater market access in a timelier manner for U.S. manufacturers exporting to Europe and European manufacturers exporting to the United States. Further information can be obtained at http: / /ts.nist.gov/ts/htdocs/210/gsig/mra.htm.

The Asia-Pacific Economic Cooperation (APEC) Mutual Recognition Arrangement for Conformity Assessment of Telecommunications Equipment is intended to streamline the Conformity Assessment Procedures for a wide range of telecommunications and telecommunications-related equipment and hereby to facilitate trade among the parties. It provides for the mutual recognition by 
the importing parties of CABs and mutual acceptance of the results of testing and equipment certification procedures undertaken by those bodies in assessing conformity of equipment to the importing Parties' own Technical Regulations.

Under Phase-I of the APEC Mutual Recognition Arrangement, NIST-designated CABs are able to produce test data in their facilities that are accepted as evidence that the tested product satisfies an APEC economy's appropriate technical requirements. CABs operating under Phase-II of the MRA are able to approve products as being in compliance with the technical and administrative requirements of the importing economy. The general and specific requirements that must be met in order to be nominated as a CAB under the APEC Tel MRA, as well as the text of the MRA, can be found at www.ts.nist.gov/mra.

The Inter-American Telecommunication Commission (CITEL) Mutual Recognition Agreement is almost identical to the APEC Tel MRA in purpose and structure. The goal of the CITEL MRA is to facilitate trade among the 34 Member States of the Organization of American States. The conformity assessment activities under this Agreement have yet to become operational. When operational, NIST will serve as the Designating Authority of U.S. CABs. In the meantime, NIST continues to work towards implementation of the Agreement. More information on the CITEL Agreement can be found on http: / /ts.nist.gov/ts/htdocs/210/gsig/mra.htm.

NIST Committee Participation in Conformity Assessment Activities

NIST's Standards Services Division (NIST/SSD) participates in the American National Standards Institute's (ANSI) International Conformity Assessment Committee (ICAC). This committee serves as the U.S. Technical Advisory Group (TAG) to ISO's Council Committee on Conformity Assessment (CASCO). SSD staff is also active on CASCO's ad hoc Regulators Interface group.

NIST/SSD is a member of ANSI's Conformity Assessment Policy Committee (CAPC), which is the primary focal point for developing, coordinating, and maintaining ANSI's policies and accreditation activities. The committee makes policy recommendations to the ANSI Board related to conformity assessment and provides oversight for ANSI's conformity assessment programs. 
NIST/SSD participates in the U.S Technical Advisory Group (TAG) to ISO Technical Committee 176, as well as several ISO TC 176 Working Groups. ISO TC 176 is the ISO committee responsible for the development and maintenance of the ISO 9000 standards series. SSD staff also chair the American Society for Quality (ASQ) Z-1 Subcommittee on Quality, the U.S. committee responsible for adoption of the ISO 9000 series and other generic quality system standards as U.S. national standards.

In the International Electrotechnical Commission (IEC) area, NIST/SSD personnel serve on the U.S. National Committee to the IECEE (IEC System for Conformity Testing and Certification of Electrical Equipment). The latter is a worldwide scheme that allows manufacturers to obtain a test certificate from an approved U.S. National Certification Body (NCB) and to use that test report to obtain certification marks in other participating countries.

Additionally, NIST provides technical support to the Standards Related Measures (SRM) Committee under the North American Free Trade Agreement (NAFTA). The SRM Committee serves as a forum for the resolution of standards and conformity assessment issues that impact trade among the three NAFTA partners. NIST also provides technical support for the Interamerican Accreditation Cooperation (IAAC). Such arrangements/agreements are designed to harmonize conformity assessment practices and promote the global acceptance of conformity assessment results from qualified bodies to minimize the need for and cost of redundant conformity assessments.

NIST/SSD staff are also working with the Consumer Product Safety Commission (CPSC) to refine the conformity assessment portion of CPSC's China strategy (to reduce the number of unsafe consumer products imported from China into the United States), as well as with the U.S. Department of Homeland Security on its conformity assessment related efforts.

Finally, NIST/SSD has published a number of directories and reports on conformity assessment-related issues. NIST/SSD also maintains a Web site (http://ts.nist.gov) that provides a one-stop-shopping source for information on various conformity assessment issues. 
8. Please provide an evaluation of the effectiveness of Circular A-119 policy and recommendations for any changes:

None at this time.

9. Please provide any other comments you would like to share on behalf of your agency.

DOC BUREAUS (EXCLUDING NIST) - SUMMARY OF STANDARDS-RELATED ACTIVITIES (2005)

International Trade Administration (ITA) - The ITA participates in seven CODEX committees and one ICAO committee. This year, ITA's work in standards furthered international civil aviation and processed food safety standards adoption and acceptance worldwide.

National Oceanic and Atmospheric Administration (NOAA) - Standardization of data acquisition and data management practices are vital to the mission at NOAA. NOAA seeks to establish voluntary standards with selected industrial associations, academia, and national organizations of state and local governments (e.g., the American Association of State Climatologists), as well as through participation in professional societies (e.g., American Meteorological Society). All NOAA line organizations participate in standards development activities. In general, standards used in many NOAA activities are established in conjunction with other federal agencies (e.g., DOD, Federal Aviation Administration, U.S. Department of Agriculture, and the Federal Geographic Data Committee) either through joint participation in international organizations such as the World Meteorological Organization, or by means of bilateral and multilateral agreements with other nations. These standardization activities apply to all phases of environmental data acquisition, processing, and distribution.

National Telecommunications and Information Administration (NTIA) - The NTIA contributes to the development and application of national and international telecommunication standards by participating and holding leadership roles in various voluntary standards committees at the national and international levels 
(e.g., Telecommunications Industry Association, International

Telecommunication Union). These standards enhance the quality and reliability of the domestic telecommunications infrastructure, promote healthy competition in telecommunications products and services, and expand international trade opportunities for U.S. telecommunications firms.

United States Patent and Trademark Office (USPTO) - The USPTO participates and contributes to the resolution of identified requirements for international standards, primarily through the Standing Committee on Information Technologies of the World Intellectual Property Organization. USPTO staff also participates in standardization activities of the International Patent Classification Union.

Bureau of the Census - DOC's Bureau of the Census is active in the development of standards and specifications for: (1) the capture and storage of geographic information in computer-readable formats along with metadata documenting the characteristics of those data; and (2) the definitions of statistical, economic, and geographic terms. The Census Bureau participates in the following groups: Federal Geographic Data Committee -- various subcommittees and working groups; ANSI/NCITS-L1 Geographic Information Systems; ISO Technical Committee 211; Ad hoc Baseline Committee on the U.S. International Boundary; U.S.G.S. Spatial Data Transfer Standards (SDTS) Technical Review Board; International Cartographic Association, Commission on National and Regional Atlases; U.S.G.S. National Atlas of the United States Steering Committee; and the Open GIS Consortium (OGC).

Commercial Law Development Program (CLDP) - CLDP provides consultative and training support to developing and transitional nations that are working to enhance their economic growth by improving the legal environment for doing business in their countries. CLDP staff provided the following standards-related assistance in FY2005:

- The Coordination of SPS Procedures Workshop in Bulgaria, which brought together SPS representatives from all of the Stability Pact countries and observer UNMIK/Kosovo, to determine problems and procedural impediments to efficient implementation of SPS measures within the Stability Pact region.

- The establishment of three Stability Pact wide regional working groups to 
cover the areas of food safety, animal health, and plant health with the goals of exchanging information on legislative and regulatory requirements and establishing procedures for dealing with pest and disease outbreaks in the Southeast Europe region.

- The inaugural SPS Working Group Meetings in Chisinau, Moldova determined procedures to bring about the timely exchange of legislative and regulatory requirements and sector specific procedures for dealing with pest and disease outbreaks. Experts from USDA, the Codex Alimentarius of the United Nations Food and Agriculture Organization (FAO/Codex), the World Organization for Animal Health (OIE), and the International Plant Protection Convention (IPPC) provide ongoing advice to the working groups.

- Consultations in the U.S. on American agribusiness standards, and quality control processes surrounding agricultural products, for a mixed delegation of Moroccan agribusiness executives and government officials.

- Consultations in the U.S. on American electric and electronic standards for a mixed delegation of Moroccan executives and government officials.

- Program management meetings of standards focus groups in Morocco for the evaluation of previous consultations for auto parts, agribusiness and electronic/electric industries, and the planning of requested standards consultations for the leather industry.

- Leather standards consultation in the U.S. for Moroccan Ministry of Commerce officials and leather industry representatives on standards and technical regulations surrounding U.S. imports of leather products.

\section{OTHER NIST STANDARDS ACTIVITIES}

Federal Information Processing Standards (FIPS) - FY2005

Under the Federal Information Security Management Act (FISMA), TITLE III of the E-Government Act of 2002, the Secretary of Commerce approves standards and guidelines that are developed by NIST for federal computer systems. This includes standards and guidelines needed to ensure the cost-effective security and privacy of sensitive information in federal computer systems. These standards and guidelines are issued by NIST as FIPS for use government wide. FIPS are issued when there are compelling federal government requirements such as for security and interoperability and there are no acceptable industry 
standards or solutions. When FIPS are considered necessary, NIST announces proposed FIPS in the Federal Register for public review and comment.

During FY2005, NIST made the following FIPS announcements:

On January 12, 2005, NIST announced in a Federal Register Notice it plans to develop Federal Information Processing Standard (FIPS) 140-3, which will supersede FIPS 140-2, Security Requirements for Cryptographic Modules On February 8, 2005, NIST announced in a Federal Register Notice that the Secretary of Commerce has approved the withdrawal of seventeen (17) Federal Information Processing Standards (FIPS) Publications. These FIPS are being withdrawn because they are obsolete, or have not been updated to adopt current voluntary industry standards, current federal data standards, or current good practices for information security. This situation preserves obsolete standards for agency use. Some of these FIPS adopt voluntary industry standards. Federal agencies and departments are directed by the National Technology Transfer and Advancement Act of 1995 (Public Law104-113) to use technical standards that are developed in voluntary consensus standards bodies. Consequently, FIPS that duplicate voluntary industry standards are no longer needed.

Additionally, the Secretary of Commerce approved the withdrawal of FIPS 46-3, Data Encryption Standard (DES); FIPS 74, Guidelines for Implementing and Using the NBS Data Encryption Standard; and FIPS 81, DES Modes of Operation. These FIPS are withdrawn because FIPS 46-3, DES, no longer provides the security that is needed to protect Federal government information. FIPS 74 and 81 are associated standards that provide for the implementation and operation of the DES. Federal government organizations are now encouraged to use FIPS 197, Advanced Encryption Standard (AES), which was approved for Federal government use in November 2001.

In July of 2005, NIST proposed to withdraw ten (10) Federal Information Processing Standards (FIPS) from the FIPS series. The standards proposed for withdrawal include FIPS 161-2, FIPS 183, FIPS 184, FIPS 192 and 192-1, which adopt voluntary industry standards for Federal government use. These FIPS are obsolete because they have not been updated to reference current or revised voluntary industry standards. In addition, FIPS 4-2, FIPS 5-2, FIPS 6-4, and FIPS 
10-4, adopt specifications or data standards that are developed and maintained by other Federal government agencies or by voluntary industry standards organizations. These FIPS have not been updated to reflect the changes and modifications that have been made by the organizations that develop and maintain the specifications and data representations. FIPS 113, Computer Data Authentication, specifies an algorithm for generating and verifying a Message Authentication Code (MAC). Since the algorithm is based on the Data Encryption Standard, which has been recommended for withdrawal, NIST plans to recommend the use of newer techniques for data authentication based on more secure algorithms.

On April 8, 2005 The Secretary of Commerce approved the FIPS 201, Standard for Personal Identity Verification of Federal Employees and Contractors, and has made it compulsory and binding on Federal agencies for use in issuing a secure and reliable form of personal identification to employees and contractors. The standard does not apply to personal identification associated with national security systems as defined by 44 U.S.C.

The National Institute of Standards and Technology (NIST) announced the release of draft Federal Information Processing Standards (FIPS) Publication 200, Minimum Security Requirements for Federal Information and Information Systems for public comment. Draft FIPS Publication 200 is one of a series of security standards and guidelines that NIST is developing to help federal agencies implement their responsibilities under the Federal Information Security Management Act (FISMA). The FISMA requires that all federal agencies develop, document and implement agency-wide information security programs to protect federal information and information systems. Draft FIPS Publication 200, which will be used with other publications already issued by NIST, specifies minimum security requirements for federal information and information systems and a risk-based process for selecting the security controls necessary to satisfy the minimum requirements.

Telemedicine Standards

The mission of the American Telemedicine Association (ATA) is to promote access to medical care by consumers and health professionals via information and telecommunications technology. An important element of this mission is to 
advance the use of telemedicine through the development or identification of technology, clinical, and administrative standards related to the ongoing delivery of health and medical care. Telemedicine allows patients to gain access to healthcare professionals, electronically regardless of their location. It can provide faster, more affordable healthcare services, especially when telemedicine is integrated into the entire health and medical care a patient receives via the traditional in-person environment.

Working to accomplish this mission, the NIST's Information Technology Laboratory and ATA are working together to define a portfolio of standards and guidelines to enable the development and advancement of the use of telemedicine. In particular, NIST and the ATA have conducted a series of workshops to identify standards needed to provide ocular care through telecommunications technology. In particular, this effort focused on teleretinal imaging for the assessment of diabetic retinopathy (e.g., taking images of the eye and evaluating those images to diagnose and treat diabetic retinopathy). This is a mature areas of telemedicine for which there is strong need for a standards portfolio to guide administrators, clinicians, and others involved in ocular telehealth. NIST provided leadership in defining the strategy and subsequent process for establishing the portfolio and as well as expertise in defining the technical (i.e., IT related) standards for diabetic retinopathy. NIST led and hosted the first workshop on technical standards.

The result of these workshops is a consensus-based document that includes the identification of appropriate technical standards, clinical protocols, and administrative arrangements. It will be promulgated as an ATA Technical Standard and be published in the ATA Journal. As a Technical Standard, it will be used to advance the use of telemedicine in fields related to ophthalmology, optometry, and optical engineering.

The next steps are to expand upon this work to help the industry (e.g., eye care practitioners, ophthalmologists, lab technicians, and screening and imaging equipment vendors) use the standard and develop measurements to ensure correct implementation and interoperability. Additionally, the process by which this diabetic retinopathy portfolio of standards was developed will be documented and used as a guide in the development of additional portfolios for 
other medical disciplines.

Homeland Security Standards

The Chief of the Standards Services Division of NIST serves as co-Chair on the American National Standards Institute's Homeland Security Standards Panel (ANSI-HSSP). The mission of the HSSP is to identify existing consensus standards, or, if none exist, assist the Department of Homeland Security (DHS) and those sectors requesting assistance to accelerate development and adoption of consensus standards critical to homeland security. The ANSI-HSSP promotes a positive, cooperative partnership between the public and private sectors in order to meet the needs of the nation in this critical area.

At the Plenary Meeting of the ANSI HSSP held September 29-30, 2005, Dr. Charles McQueary, Under Secretary, DHS Standards \& Technology (S\&T) Directorate stated, "Standards are the vital underpinnings of homeland security efforts to develop the technologies we need to prepare for, protect against and respond to all manner of high-consequence events. The availability of standards helps us condition the marketplace for the protective technologies we need to safeguard the nation."

The event brought together more than 150 professionals, experts and leaders from the homeland security standards and conformity assessment community to review progress that has been made and areas to be further explored.

Michelle O'Neill, Acting Under Secretary for Technology, Department of Commerce further highlighted the importance of standards and work of the ANSI-HSSP in addressing the needs for homeland security standards.

"Over the past 3 years, members of the Panel and volunteer workshop participants have identified existing standards related to homeland security priorities, catalogued standards projects under way or planned and determined gaps where security standards are needed. This work has been crucial to focus the U.S. standards system's resources on the most pressing needs in security related standards."

10. Please use this box to provide any additional comments on how your agency currently reports its use of voluntary consensus standards: 
10-1. Removed [This question has been deprecated for 2005]

10-2. Removed [This question has been deprecated for 2005]

10-3. Removed [This question has been deprecated for 2005]

10-4. Does your agency report standards that it uses for guidance purposes (as opposed compliance purposes)? (a) Yes; (b) No; (c) Not applicable; No

10-5. Does your agency report use of standards from non-ANSI accredited standards developers, industry consortia groups, or both? (a) non-ANSI Accredited; (b) Consortia; (c) Both; (d) Neither; or (e) Not applicable; E

10-5. Does your agency have a schedule for periodically reviewing its use of standards for purposes of updating such use? (a) Yes; (b) No; No

10-5. How often does your agency review its standards for purposes of updating such use? [enter the number of years]: 0 


\section{Department of Defense}

Title: Department of Defense (DoD) Fiscal Year 2005 Agency Report

1. Please describe the importance of standards in the achievement of your agency's mission, how your agency uses standards to deliver its primary services in support of its mission, and provide any examples or case studies of standards success:

Supporting the warfighter is the main mission of the Department of Defense(DoD). This support can range from acquiring weapons systems to training personnel for a multitude of functions to providing food and shelter for our troops in combat zones. Standards play a vital role in ensuring appropiate goods and services get to the warfigher in a timely,cost effective fashion.Using standards achieves cost benefits by creating an acquisiton environment which allows for larger economical buys, reduces development and maintenance costs, and lessens the need for stockpiling large amounts of inventory. The Department has found relying on different types of acqusition documents such as military-unique standards and non-government standards enhances the possbility for technology insertion in weapons systems, ensures a high reliability in parts and systems, levels the manufacturer's playing field, thereby, increasing competition, and also reduces development costs. For many years, DoD has been focusing on replacing military unique standardization documents in commodity areas having commercial application in an effort to promote the intergration of commercial and military manufacturig facilities and provide freedom of choice in selecting items which meet warfigher requirements.DoD's reliance on non-government standards as acquisition vehicles whenever practical continues to be a strong and cost effective policy.

The following DoD case studies illustrate how standards and standardization have contibuted to providing the warfighter with equipment and services in a timely and cost consciencous manner.

AN/PRC-12 Survival Radio - Downed military pilots use a survival radio to signal their location to rescuers. The AN/PRC-112C operates only in line-of-sight conditions and lacks geo-positioning information thus recovering downed pilots can be very difficult.Also, many of the parts in this piece of equipment are obsolete.The Army has devised a method to sustain and support the AN/PRC-12 
Survival Radio by retrofitting existent radios with commercial circuitry and batteries. This initiative has designed out obsolescence, decreased power consumption and designed in commercial batteries,compressed development cycle tiem, improved reliability and reduced acquisition costs.

Joint Precision Approach and Landing System (JPALS) - In the early 1990's, DoD recognized the need to develop an improved landing navigation system that would be rapidly deployable, operate in adverse weather and adverse terrain, be survivable and maintainable, and be interoperable with other military and civilian sector systems. To solve this problem, DoD initiated a formal research program. JPALS is a joint military program, with the Air Force as the lead for developing the land-based solutions and the Navy as the lead for a shipboard solution. The team evaluated 27 different technology alternatives against five key functional objectives and four operational environments. Only one technology - Differential Global Positioning System (DGPS) technology satisfied all objectives in all operational environments. As a result, military and civil aviation communities will realize many benefits from the work of the JPALS team. The key benefits are increased safety, reduced cost, improved operations and enhanced interoperability.

Joint Tactical Radio System(JTRS)- Combat communication has been a problem largely because each military tactical radio had a dedicated function. Consequently, a warfighter needing to communicate with a dozen different functional activities might require a dozen different radios. Legacy radios are hardware based, and most use proprietary designs and components. Logistics support is complex, and upgrades to add new capabilities or to overcome technical limitations are costly, significantly increasing system life-cycle costs. The JTRS Team decided that the key to the solution was a software defined radio that relies on state-of-the-art object-oriented technology and used a standard open architecture. As a result, DoD now has a common tactical radio system that dramatically increases the capability of the warfighters to communicate with one another - independent of echelon, locations, or situations - greatly improving the probability of victory and most certainly saving many lives.

Acoustic-Rapid Commercial Off-the-Shelf Insertion (A-RCI)- The use of modern 
Commercial Off-the-Shelf (COTS) processors and commercial software languages in $\mathrm{A}-\mathrm{RCl}$ opens the door to easier future upgrades of sonar systems. Because $\mathrm{A}-\mathrm{RCl}$ is designed to use commercial open standards, the Navy can select from a number of available components. The software design also makes upgrading easier by its use of middleware to handle hardware specific aspects of design instead of hardware-specific application code. This approach eliminates the traditional problem of block obsolescence and the need to buy large quantities of expensive spares to support a long equipment lifetime. The Navy will benefit from A-RCl in five key ways: improved sonar performance, increased number of modernized submarines, increased commonality across sonar systems, faster introduction of improvements, lower development, acquisition, and support costs.

All of DoD's case studies can be located on the Defense Standardization Program Office website -

http://dsp.dla.mil/case-abstracts.htm.

2. Please list the government-unique standards your agency used in lieu of voluntary consensus standards during FY 2005:

This agency reports voluntary consensus standards usage on a category basis

3. Please list the Voluntary Consensus Standards (VCS) your agency substituted for Government Unique Standards (GUS) in FY 2005 as a result of review under Section 15(b)(7) of OMB Circular A-119: 227

Voluntary Standard

PIA-PS70098

SAE- AS5809

SAE-25427

SAE-AMS-T-9047

SAE-AMS5617

SAE-AS15002

SAE-AS15004

SAE-AS15005

\section{Government Standard}

MS70098

MIL-C-5809

MIL-C-25427

MIL-T-9047

MIL-S-83311

MS15002

MS15004

MS15005 


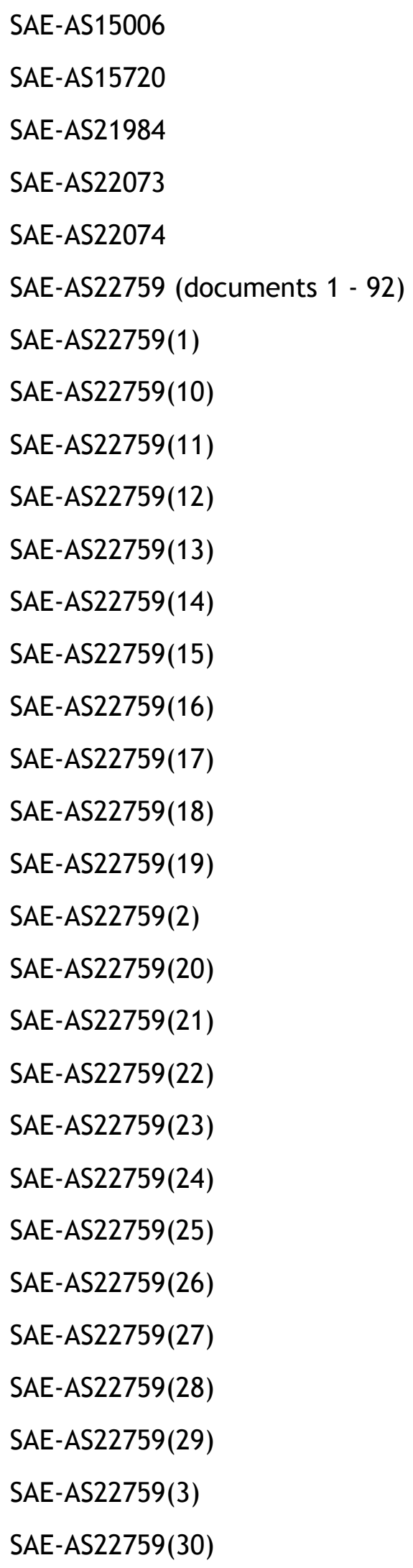

MS15006

MS15720

MS21984

MS22073

MS22074

MIL-W-22759 (documents 1-92)

MIL-W-22759(1)

MIL-W-22759(10)

MIL-W-22759(11)

MIL-W-22759(12)

MIL-W-22759(13)

MIL-W-22759(14)

MIL-W-22759(15)

MIL-W-22759(16)

MIL-W-22759(17)

MIL-W-22759(18)

MIL-W-22759(19)

MIL-W-22759(2)

MIL-W-22759(20)

MIL-W-22759(21)

MIL-W-22759(22)

MIL-W-22759(23)

MIL-W-22759(24)

MIL-W-22759(25)

MIL-W-22759(26)

MIL-W-22759(27)

MIL-W-22759(28)

MIL-W-22759(29)

MIL-W-22759(3)

MIL-W-22759(30) 


\begin{tabular}{|c|c|}
\hline SAE-AS22759(31) & MIL-W-22759(31) \\
\hline SAE-AS22759(32) & MIL-W-22759(32) \\
\hline SAE-AS22759(33) & MIL-W-22759(33) \\
\hline SAE-AS22759(34) & MIL-W-22759(34) \\
\hline SAE-AS22759(35) & MIL-W-22759(35) \\
\hline SAE-AS22759(36) & MIL-W-22759(36) \\
\hline SAE-AS22759(37) & MIL-W-22759(37) \\
\hline SAE-AS22759(38) & MIL-W-22759(38) \\
\hline SAE-AS22759(39) & MIL-W-22759(39) \\
\hline SAE-AS22759(4) & MIL-W-22759(4) \\
\hline SAE-AS22759(40) & MIL-W-22759(40) \\
\hline SAE-AS22759(41) & MIL-W-22759(41) \\
\hline SAE-AS22759(42) & MIL-W-22759(42) \\
\hline SAE-AS22759(43) & MIL-W-22759(43) \\
\hline SAE-AS22759(44) & MIL-W-22759(44) \\
\hline SAE-AS22759(45) & MIL-W-22759(45) \\
\hline SAE-AS22759(46) & MIL-W-22759(46) \\
\hline SAE-AS22759(47) & MIL-W-22759(47) \\
\hline SAE-AS22759(48) & MIL-W-22759(48) \\
\hline SAE-AS22759(49) & MIL-W-22759(49) \\
\hline SAE-AS22759(5) & MIL-W-22759(5) \\
\hline SAE-AS22759(50) & MIL-W-22759(50) \\
\hline SAE-AS22759(51) & MIL-W-22759(51) \\
\hline SAE-AS22759(52) & MIL-W-22759(52) \\
\hline SAE-AS22759(53) & MIL-W-22759(53) \\
\hline SAE-AS22759(54) & MIL-W-22759(54) \\
\hline SAE-AS22759(55) & MIL-W-22759(55) \\
\hline SAE-AS22759(56) & MIL-W-22759(56) \\
\hline SAE-AS22759(57) & MIL-W-22759(57) \\
\hline SAE-AS22759(58) & MIL-W-22759(58) \\
\hline
\end{tabular}




\begin{tabular}{|c|c|}
\hline SAE-AS22759(59) & MIL-W-22759(59) \\
\hline SAE-AS22759(6) & MIL-W-22759(6) \\
\hline SAE-AS22759(60) & MIL-W-22759(60) \\
\hline SAE-AS22759(61) & MIL-W-22759(61) \\
\hline SAE-AS22759(62) & MIL-W-22759(62) \\
\hline SAE-AS22759(63) & MIL-W-22759(63) \\
\hline SAE-AS22759(64) & MIL-W-22759(64) \\
\hline SAE-AS22759(65) & MIL-W-22759(65) \\
\hline SAE-AS22759(66) & MIL-W-22759(66) \\
\hline SAE-AS22759(67) & MIL-W-22759(67) \\
\hline SAE-AS22759(68) & MIL-W-22759(68) \\
\hline SAE-AS22759(69) & MIL-W-22759(69) \\
\hline SAE-AS22759(7) & MIL-W-22759(7) \\
\hline SAE-AS22759(70) & MIL-W-22759(70) \\
\hline SAE-AS22759(71) & MIL-W-22759(71) \\
\hline SAE-AS22759(72) & MIL-W-22759(72) \\
\hline SAE-AS22759(73) & MIL-W-22759(73) \\
\hline SAE-AS22759(74) & MIL-W-22759(74) \\
\hline SAE-AS22759(75) & MIL-W-22759(75) \\
\hline SAE-AS22759(76) & MIL-W-22759(76) \\
\hline SAE-AS22759(77) & MIL-W-22759(77) \\
\hline SAE-AS22759(78) & MIL-W-22759(78) \\
\hline SAE-AS22759(79) & MIL-W-22759(79) \\
\hline SAE-AS22759(8) & MIL-W-22759(8) \\
\hline SAE-AS22759(80) & MIL-W-22759(80) \\
\hline SAE-AS22759(81) & MIL-W-22759(81) \\
\hline SAE-AS22759(82) & MIL-W-22759(82) \\
\hline SAE-AS22759(83) & MIL-W-22759(83) \\
\hline SAE-AS22759(84) & MIL-W-22759(84) \\
\hline SAE-AS22759(85) & MIL-W-22759(85) \\
\hline
\end{tabular}




\begin{tabular}{|c|c|}
\hline SAE-AS22759(86) & MIL-W-22759(86) \\
\hline SAE-AS22759(87) & MIL-W-22759(87) \\
\hline SAE-AS22759(88) & MIL-W-22759(88) \\
\hline SAE-AS22759(89) & MIL-W-22759(89) \\
\hline SAE-AS22759(9) & MIL-W-22759(9) \\
\hline SAE-AS22759(90) & MIL-W-22759(90) \\
\hline SAE-AS22759(91) & MIL-W-22759(91) \\
\hline SAE-AS22759(92) & MIL-W-22759(92) \\
\hline SAE-AS24333 & MS24333 \\
\hline SAE-AS24334 & MS24334 \\
\hline SAE-AS24335 & MS24335 \\
\hline SAE-AS25244 & MS25244 \\
\hline SAE-AS25337 & MS25337 \\
\hline SAE-AS25361 & MS25361 \\
\hline SAE-AS26574 & MS26574 \\
\hline SAE-AS39029(1) & MIL-C-39029(1) \\
\hline SAE-AS39029(10) & MIL-C-39029(10) \\
\hline SAE-AS39029(100) & MIL-C-39029(100) \\
\hline SAE-AS39029(101) & MIL-C-39029(101) \\
\hline SAE-AS39029(102) & MIL-C-39029(102) \\
\hline SAE-AS39029(103) & MIL-C-39029(103) \\
\hline SAE-AS39029(104) & MIL-C-39029(104) \\
\hline SAE-AS39029(105) & MIL-C-39029(105) \\
\hline SAE-AS39029(106) & MIL-C-39029(106) \\
\hline SAE-AS39029(107) & MIL-C-39029(107) \\
\hline SAE-AS39029(108) & MIL-C-39029(108) \\
\hline SAE-AS39029(109) & MIL-C-39029(109) \\
\hline SAE-AS39029(11) & MIL-C-39029(11) \\
\hline SAE-AS39029(12) & MIL-C-39029(12) \\
\hline SAE-AS39029(13) & MIL-C-39029(13) \\
\hline
\end{tabular}


SAE-AS39029(14)

SAE-AS39029(15)

SAE-AS39029(16)

SAE-AS39029(17)

SAE-AS39029(18)

SAE-AS39029(19)

SAE-AS39029(2)

SAE-AS39029(20)

SAE-AS39029(21)

SAE-AS39029(22)

SAE-AS39029(23)

SAE-AS39029(24)

SAE-AS39029(25)

SAE-AS39029(26)

SAE-AS39029(27)

SAE-AS39029(28)

SAE-AS39029(29)

SAE-AS39029(3)

SAE-AS39029(30)

SAE-AS39029(31)

SAE-AS39029(32)

SAE-AS39029(33)

SAE-AS39029(34)

SAE-AS39029(35)

SAE-AS39029(36)

SAE-AS39029(37)

SAE-AS39029(38)

SAE-AS39029(39)

SAE-AS39029(4)

SAE-AS39029(40)
MIL-C-39029(14)

MIL-C-39029(15)

MIL-C-39029(16)

MIL-C-39029(17)

MIL-C-39029(18)

MIL-C-39029(19)

MIL-C-39029(2)

MIL-C-39029(20)

MIL-C-39029(21)

MIL-C-39029(22)

MIL-C-39029(23)

MIL-C-39029(24)

MIL-C-39029(25)

MIL-C-39029(26)

MIL-C-39029(27)

MIL-C-39029(28)

MIL-C-39029(29)

MIL-C-39029(3)

MIL-C-39029(30)

MIL-C-39029(31)

MIL-C-39029(32)

MIL-C-39029(33)

MIL-C-39029(34)

MIL-C-39029(35)

MIL-C-39029(36)

MIL-C-39029(37)

MIL-C-39029(38)

MIL-C-39029(39)

MIL-C-39029(4)

MIL-C-39029(40) 
SAE-AS39029(41)

SAE-AS39029(42)

SAE-AS39029(43)

SAE-AS39029(44)

SAE-AS39029(45)

SAE-AS39029(46)

SAE-AS39029(47)

SAE-AS39029(48)

SAE-AS39029(49)

SAE-AS39029(5)

SAE-AS39029(50)

SAE-AS39029(51)

SAE-AS39029(52)

SAE-AS39029(53)

SAE-AS39029(54)

SAE-AS39029(55)

SAE-AS39029(56)

SAE-AS39029(57)

SAE-AS39029(58)

SAE-AS39029(59)

SAE-AS39029(6)

SAE-AS39029(60)

SAE-AS39029(61)

SAE-AS39029(62)

SAE-AS39029(63)

SAE-AS39029(64)

SAE-AS39029(65)

SAE-AS39029(66)

SAE-AS39029(67)

SAE-AS39029(68)
MIL-C-39029(41)

MIL-C-39029(42)

MIL-C-39029(43)

MIL-C-39029(4)

MIL-C-39029(45)

MIL-C-39029(46)

MIL-C-39029(47)

MIL-C-39029(48)

MIL-C-39029(49)

MIL-C-39029(5)

MIL-C-39029(50)

MIL-C-39029(51)

MIL-C-39029(52)

MIL-C-39029(53)

MIL-C-39029(54)

MIL-C-39029(55)

MIL-C-39029(56)

MIL-C-39029(57)

MIL-C-39029(58)

MIL-C-39029(59)

MIL-C-39029(6)

MIL-C-39029(60)

MIL-C-39029(61)

MIL-C-39029(62)

MIL-C-39029(63)

MIL-C-39029(64)

MIL-C-39029(65)

MIL-C-39029(66)

MIL-C-39029(67)

MIL-C-39029(68) 


\begin{tabular}{|c|c|}
\hline SAE-AS39029(69) & MIL-C-39029(69) \\
\hline SAE-AS39029(7) & MIL-C-39029(7) \\
\hline SAE-AS39029(70) & MIL-C-39029(70) \\
\hline SAE-AS39029(71) & MIL-C-39029(71) \\
\hline SAE-AS39029(72) & MIL-C-39029(72) \\
\hline SAE-AS39029(73) & MIL-C-39029(73) \\
\hline SAE-AS39029(74) & MIL-C-39029(64) \\
\hline SAE-AS39029(75) & MIL-C-39029(75) \\
\hline SAE-AS39029(76) & MIL-C-39029(76) \\
\hline SAE-AS39029(77) & MIL-W-22759(77) \\
\hline SAE-AS39029(78) & MIL-C-39029(78) \\
\hline SAE-AS39029(79) & MIL-C-39029(79) \\
\hline SAE-AS39029(8) & MIL-C-39029(8) \\
\hline SAE-AS39029(80) & MIL-C-39029(80) \\
\hline SAE-AS39029(81) & MIL-C-39029(81) \\
\hline SAE-AS39029(82) & MIL-C-39029(82) \\
\hline SAE-AS39029(83) & MIL-C-39029(83) \\
\hline SAE-AS39029(84) & MIL-C-39029(84) \\
\hline SAE-AS39029(85) & MIL-C-39029(85) \\
\hline SAE-AS39029(86) & MIL-C-39029(86) \\
\hline SAE-AS39029(87) & MIL-C-39029(87) \\
\hline SAE-AS39029(88) & MIL-C-39029(88) \\
\hline SAE-AS39029(89) & MIL-C-39029(89) \\
\hline SAE-AS39029(9) & MIL-C-39029(9) \\
\hline SAE-AS39029(90) & MIL-C-39029(90) \\
\hline SAE-AS39029(91) & MIL-C-39029(91) \\
\hline SAE-AS39029(92) & MIL-C-39029(92) \\
\hline SAE-AS39029(93) & MIL-C-39029(93) \\
\hline SAE-AS39029(94) & MIL-C-39029(94) \\
\hline SAE-AS39029(95) & MIL-C-39029(95) \\
\hline
\end{tabular}


SAE-AS39029(96)

SAE-AS39029(97)

SAE-AS39029(98)

SAE-AS39029(99)

SAE-AS39029(documents 1 -109)

SAE-AS7195

SAE-AS7365

SAE-AS8102

SAE-J2360
MIL-C-39029(96)

MIL-C-39029(97)

MIL-C-39029(98)

MIL-C-39029(99)

MIL-C-39029(documents 1-109)

MIL-H-7195

MIL-H-7365

MIL-C-8102

MIL-PRF-2105E

4. Please provide the total number of Voluntary Consensus Standards your agency used during FY 2005: Optional: If possible, also please provide the total number of Nonconsensus Standards that are developed in the private sector your agency used during FY 2005. In addition, please provide your agency's rationale for using the Nonconsensus Standards that are developed in the private sector counted in this question.

Voluntary Consensus Standards: 9083

Other Technical Standards: 248

Rationale: The Department relies on all categories of non-government standards to meet mission essential requirements. Specifically, due to the prevalence of consortium standards in the information arena, the Defense Informatio Systems Agency relies on this type document to meet requirements. The number of Other Technical Standards used during FY2005 is an approximation. The Department does not officially collect this information.

5. Please enter the Voluntary Consensus Standards Bodies (VCSB) in which your agency participated in during FY 2005: 118

Voluntary Consensus Standards Body

Aerospace Industries Association of America

Air Conditioning \& Refrigeration Institute

Air Movement and Control Association $\underline{\text { Acronym }}$

AIA

ACRI

AMCA 
Alliance for Telecommunications Industry Solutions

ATIS

Aluminum Association

American Architectural Manufacturers Association

AAMA

American Association of State Highway and Transportation Officials

AASHTO

American Association of Textile Chemists and Colorists

AATCC

American Bearing Manufacturers Association

ABMA

American Boat and Yacht Council

ABYC

American Concrete Institute

$\mathrm{ACl}$

American Conference of Governmental Industrial Hygienists

ACGIH

American Dental Association

ADA

American Gas Association

AGA

American Gear Manufacturers Association

AGMA

American Hardboard Association

AHA

American Industrial Hygiene Association

AlHA

American Institute of Aeronautics and Astronautics

AIAA

American Institute of Steel Construction

AISC

American Institute of Timber Construction

AITC

American National Metric Council

ANMC

American National Standards Institute

ANSI

American Petroleum Institute

API

American Railway Engineering \& Maintenance-of-Way Association

AREMA

American Society for Nondestructive Testing

ASNT

American Society for Testing and Materials

ASTM

American Society of Cinematographers

ASC

American Society of Civil Engineers

ASCE

American Society of Heating, Refrigerating, and Air-Conditioning

ASHRAE

Engineers

American Society of Mechanical Engineers

ASME

American Society of Quality Control

ASQC

American Society of Sanitary Engineering

ASSE

American Water Works Association

AWWA 
American Welding Society $\quad$ AWS

American Wood Preservers Association AWPA

APA The Engineering Wood Association APA

Association for Automatic Indentification \& Mobility AIM

Association for the Advancement of Medical Instrumentation AAMI

British Standards Institute BSI

Builders Hardware Manufacturers Association BHMA

Building Officials and Code Administrators International BOCA

Canadian General Standards Board CGSB

Cast Iron Soil Pipe Institute $\quad$ CISPI

Compressed Gas Association CGA

Construction Specifications Institute CSI

Cooling Technology Institute $\quad$ CTI

Cordage Institute $\quad \mathrm{Cl}$

Data Interchange Standards Association, Inc. DISAI

Deep Foundations Institute DFI

Deutsches Institut fur Nomung - German Institute for Standardization DIN

Electronic Commerce Code Management Association ECCMA

Electronic Components Assemblies \& Materials Association ECAMA

Electronic Industries Alliance EIA

Electrostatic Discharge Association EDA

FM Global FMG

Government Electronics \& Information Technology Association GEITA

Graphic Communications Association GCA

Gypsum Association GYP

Hardwood Plywood \& Veneer Association HPVA

High Frequency Industry Association HFIA

Human Factors and Ergonomics Society, Inc. HFESI

Illuminating Engineering Society of North America IES

Information Technology Industry Council ITI 
Institute for Interconnecting and Packaging Electronic Circuits IPEC Institute of Clean Air Companies ICAC

Institute of Electrical and Electronic Engineers IEEE

Institute of Environmental Sciences \& Technology IEST

Insulated Cable Engineers Association ICEA

International Association of Plumbing and Mechanical Officials IAPMO

InterNational Committee for Information Technology Standards INCITS

International Electrotechnical Commission IEC

International Organization for Standardization ISO

International Telecommunication Union ITU

Internet Engineering Task Force IETF

Joint Electron Device Engineering Council JEDEC

Machinery Informaiton Management Open Systems MIMOSA

Magnetic Materials Producers Association MMPA

Manufacturers Standardization Society of the Valve and Fittings MSSVFI

Industry

Master Painters Institute MPI

National Association of Corrosion Engineers International NACE

National Association of Relay Manufacturers NARM

National Conference of Standards Laboratories $\quad$ NCSL

National Electrical Manufacturers Association NEMA

National Fire Protection Association NFPA

National Fluid Power Association NFPA

National Information Standards Organization NISO

National Institute of Building Sciences NIBS

National Petroleum Management Association NPMA

NSF International NSF

Optics and Electro-Optics Standards Council OEO

Parachute Industry Association PIA

Pipe Fabrication Institiute PFI

Plastic Pipe Institute $\quad$ PPI 
Plumbing and Draining Institute PDI

Plumbing-Heating-Cooling Contractors Association PHCCA

Quarter-Inch Cartridge Drive Standards, Inc. QCDS

Rack Manufacturers Institute RMI

Resistance Welders Manufacturers Association RWMA

$\begin{array}{ll}\text { Rubber Manufacturers Association } & \text { RMA }\end{array}$

Scientific Apparatus Makers Association SAMA

Sheet Metal \& Air Conditioning Contractors National Association SHACCNA

Simulation Interoperability Standards Organization SISO

Society for Protective Coatings $\quad$ SPC

Society of Allied Weight Engineers SAWE

Society of Automotive Engineers SAE

Standards Engineering Society SES

Steel Door Institute $\quad$ SDI

Steel Founders Society of America SFSA

Telecommunications Industry Association $\quad$ TIA

The Instrumentation, Systems, and Automation Society ISAS

The Open Group TOG

The Soap and Detergent Association SDA

The Tire and Rim Association, Inc. TRAl

Truck Trailer Manufacturers Association TTMA

UN Centre for Trade Facilitation \& Electronic Business $\quad$ UCTFEB

Underwriters Laboratories UL

Window and Door Manufacturers Association WDMA

World Wide Web Consortium W3C

6. Please provide the total number of your agency's representatives who participated in voluntary consensus standards activities during FY 2005 and the total number of activities these agency representatives participated in: 1106 
7. Please provide any conformity assessment activities (as described in "Guidance on Federal Conformity Assessment Activities" found in the Federal Register, Volume 65, Number 155, dated August 10, 2000) in which your agency was involved in FY 2005.

The Department does not collect this information.

8. Please provide an evaluation of the effectiveness of Circular A-119 policy and recommendations for any changes:

The exisiting OMB policy concerning participation in voluntary consenus standards activities is perhaps a tool that many agencies need to employ to support voluntary standards programs. Since Department employees participated in the development of voluntary consensus standards prior to development of Circular A-119 it is questionable whether the policy has had any major impact on increasing support for the voluntary consensus standard initiative.

The Dapartment questions the accuracy of the data collected related to participant information. Therefore, it is very possible the figures regarding the number of employees participating in voluntary consenus standards activies is highly distorted and presents a false impression to Congress. Furthermore, the participant data is particularly difficult to collect and the return on investment is questionable.

9. Please provide any other comments you would like to share on behalf of your agency.

The Department suggests the ICSP A-119 subcommittee review the mission, objectives, goals of the report and ascertain information that would provide Congress with a clear understanding of the government's role in voluntary consensus standards activities.

10. Please use this box to provide any additional comments on how your agency currently reports its use of voluntary consensus standards:

The information provided by the voluntary consensus standards bodies regarding participant activities is highly suspect. After reviewing the collected information it was discovered the listings included the names of participants 
who had retired from government service and no longer lived in the area, therefore, it would be assumed they could not be involved in extensive committee work.

Also, it is suggested that the database provide a means of printing the input prior to submittal.

10-1. Removed [This question was deprecated in 2005]

10-2. Removed [This question was deprecated in 2005]

10-3. Removed [This question was deprecated in 2005]

10-4. Does your agency report standards that it uses for guidance purposes (as opposed compliance purposes)? (a) Yes; (b) No; (c) Not applicable; No

10-5. Does your agency report use of standards from non-ANSI accredited standards developers, industry consortia groups, or both? (a) non-ANSI Accredited; (b) Consortia; (c) Both; (d) Neither; or (e) Not applicable; C

10-6. Does your agency have a schedule for periodically reviewing its use of standards for purposes of updating such use? (a) Yes; (b) No; Yes

10-7. How often does your agency review its standards for purposes of updating such use? [enter the number of years]: 5 


\section{Department of Education}

1. Please describe the importance of standards in the achievement of your agency's mission, how your agency uses standards to deliver its primary services in support of its mission, and provide any examples or case studies of standards success:

The National Center for Education Statistics (NCES), the principal statistical agency within the U.S. Department of Education uses standards to provide high quality, reliable, useful, and informative statistical information to public policy decision makers and to the general public. In particular, the standards that NCES follows are intended for use by NCES staff and contractors to guide them in their data collection, analysis, and dissemination activities. These standards are also intended to present a clear statement for data users regarding how data should be collected in NCES surveys, and the limits of acceptable applications and use. Beyond these immediate uses, NCES hope that other organizations involved in similar public endeavors will find the contents of some of NCES standards useful in their work. (Source: NCES Statistical Support Standards: NCES 2003-601)

The Department of Education also uses standards in the implementation of Information Technology for the Department which ultimately enhances the delivery of Department Education services to citizens. The Department of Education uses Information Technology Standards to implement common enabling services and infrastructure services. These Information Technology standards used in the Department of Education's Enterprise Architecture also fulfill OMB's requirement for a Standards Profile. (Source: Department of Education Enterprise Standards and Guidelines Technology Standards Profile, Volume I: Enterprise Standards Profile Version 1.0)

2. Please list the government-unique standards your agency used in lieu of voluntary consensus standards during FY 2005: 0

3. Please list the Voluntary Consensus Standards (VCS) your agency substituted for Government Unique Standards (GUS) in FY 2005 as a result of review under Section 15(b)(7) of OMB Circular A-119: 0 
4. Please provide the total number of Voluntary Consensus Standards your agency used during FY 2005: Optional: If possible, also please provide the total number of Nonconsensus Standards that are developed in the private sector your agency used during FY 2005. In addition, please provide your agency's rationale for using the Nonconsensus Standards that are developed in the private sector counted in this question.

Voluntary Consensus Standards: 60

Other Technical Standards: 0

Rationale: Not Applicable.

5. Please enter the Voluntary Consensus Standards Bodies (VCSB) in which your agency participated in during FY 2005: 5

\begin{tabular}{ll} 
Voluntary Consensus Standards Body & $\underline{\text { Acronym }}$ \\
\hline National Forum on Education Statistics & NCES Forum \\
Post Secondary Electronic Standards Organization PESC \\
School Interoperability Framework Association & SIFA \\
Semantic Interoperability Community of Practice & SICOP \\
XML Community of Practice & xmICOP
\end{tabular}

6. Please provide the total number of your agency's representatives who participated in voluntary consensus standards activities during FY 2005 and the total number of activities these agency representatives participated in: $\mathbf{4}$

7. Please provide any conformity assessment activities (as described in "Guidance on Federal Conformity Assessment Activities" found in the Federal Register, Volume 65, Number 155, dated August 10, 2000) in which your agency was involved in FY 2005.

None

8. Please provide an evaluation of the effectiveness of Circular A-119 policy and recommendations for any changes:

No Comments. 
9. Please provide any other comments you would like to share on behalf of your agency.

No Comments.

10. Please use this box to provide any additional comments on how your agency currently reports its use of voluntary consensus standards:

10-1. Removed [This question has been deprecated for 2005]

10-2. Removed [This question has been deprecated for 2005]

\section{0-3. Removed [This question has been deprecated for 2005]}

10-4. Does your agency report standards that it uses for guidance purposes (as opposed compliance purposes)? (a) Yes; (b) No; (c) Not applicable; Yes

10-5. Does your agency report use of standards from non-ANSI accredited standards developers, industry consortia groups, or both? (a) non-ANSI Accredited; (b) Consortia; (c) Both; (d) Neither; or (e) Not applicable; C

10-6. Does your agency have a schedule for periodically reviewing its use of standards for purposes of updating such use? (a) Yes; (b) No; Yes

10-7. How often does your agency review its standards for purposes of updating such use? [enter the number of years]: 1 


\section{Department of Energy}

1. Please describe the importance of standards in the achievement of your agency's mission, how your agency uses standards to deliver its primary services in support of its mission, and provide any examples or case studies of standards success:

DOE uses VCSs extensively in managing, operating, and regulating our diverse sites, laboratories, operations, facilities, and activities - over a range that includes nuclear weapons and materials production, energy research, energy efficiency, oil storage, hydroelectric power, accelerator operations, nuclear facility decommissioning, and fusion experiments. VCSs are consulted, referenced and applied in mission-related design, procurement, construction, operations, maintenance, emergency operations, and decommissioning efforts; in environment, safety and health management; in DOE research and development activities; in security and safeguards programs; and in overall business operations and management.

Other areas where DOE and its contractors use VCSs at DOE facilities and activities that may not be fully documented and reported include:

1) writing procedures;

2) establishing safety criteria (e.g., for worker job task analyses, fire protection, nuclear criticality safety, nuclear facility safety); and

3) citing supporting references in internal DOE Technical Standards.

\section{Examples/Case Studies:}

1. The Department of Energy (DOE) has historically used voluntary consensus standards (VCS) promulgated by the National Fire Protection Association (NFPA) in the development and implementation of fire safety and emergency response programs at its sites. DOE and its predecessor agencies (AEC, ERDA) have done so for a number of reasons. NFPA is universally recognized for the diverse expertise of the members of its technical committees. (DOE and its contractor employees are widely represented within these committees.) The scope of fire safety issues with the Department is vast. Attempting to address these issues 
solely with internal directives would be cost prohibitive. NFPA codes and standards, through the "Equivalency" principle, allows for the flexible and cost-effective implementation of requirements. DOE has saved literally hundreds of thousands of dollars in the inspection and testing of fire protection systems through the adaptation of this principle, as delineated in NFPA Standards 25 (superscript 1) and 72 (superscript 2), to site circumstances.

1 Inspection, Testing and Maintenance of Water-Based Fire Protection Systems

2 National Fire Alarm Code

2. This is not a specific case, however it is important to mention that because of DOE's use of VCSs, local contractors performing work for the Department's National Labs have been more successful when bidding for jobs than if DOE used only internally generated standards. We feel that VCSs are responsible because they provide more universally accepted approaches to getting work completed.

2. Please list the government-unique standards your agency used in lieu of voluntary consensus standards during FY 2005: 0

3. Please list the Voluntary Consensus Standards (VCS) your agency substituted for Government Unique Standards (GUS) in FY 2005 as a result of review under Section 15(b)(7) of OMB Circular A-119: 0

4. Please provide the total number of Voluntary Consensus Standards your agency used during FY 2005: Optional: If possible, also please provide the total number of Nonconsensus Standards that are developed in the private sector your agency used during FY 2005. In addition, please provide your agency's rationale for using the Nonconsensus Standards that are developed in the private sector counted in this question.

Voluntary Consensus Standards: 1430

Other Technical Standards: 0 
Rationale: This reflects an increase of 105 additional standards being used this year (2005).

5. Please enter the Voluntary Consensus Standards Bodies (VCSB) in which your agency participated in during FY 2005: 70

\begin{tabular}{|c|c|}
\hline Voluntary Consensus Standards Body & Acronym \\
\hline $\begin{array}{l}\text { Air Movement and Control Association International, } \\
\text { Inc. }\end{array}$ & AMCA \\
\hline Air-Conditioning \& Refrigeration Institute & ARI \\
\hline American Architectural Manufacturers Association & AAMA \\
\hline $\begin{array}{l}\text { American Association of State Highway and } \\
\text { Transportation Officials }\end{array}$ & AASHTO \\
\hline American Concrete Institute & $\mathrm{ACl}$ \\
\hline American Industrial Hygiene Association & AlHA \\
\hline American Institute of Steel Construction & AISC \\
\hline American Iron and Steel Institute & AISI \\
\hline American Medical Association & AMA \\
\hline American National Standards Institute & ANSI \\
\hline American Nuclear Society & ANS \\
\hline American Petroleum Institute & API \\
\hline American Public Health Association & APHA \\
\hline $\begin{array}{l}\text { American Railway Engineering \& Maintenance-of- } \\
\text { Way Association }\end{array}$ & AREMA \\
\hline American Society for Nondestructive Testing & ASNT \\
\hline American Society for Quality & ASQ \\
\hline American Society for Testing and Materials & ASTM \\
\hline American Society of Civil Engineers & ASCE \\
\hline $\begin{array}{l}\text { American Society of Heating, Refrigerating, and Air- } \\
\text { Conditioning Engineers }\end{array}$ & ASHRAE \\
\hline American Society of Mechanical Engineers & ASME \\
\hline American Water Works Association & AWWA \\
\hline
\end{tabular}


American Welding Society AWS

Association for Information and Image Management AllM

Association for the Advancement of Cost Engineering AACE Int.

Building Officials and Code Administrators BOCA

International, Inc.

Ceilings and Interior Systems Construction CISCA

Association

Compressed Gas Association CGA

Construction Safety Association of Ontario CSAO

Cooling Tower Institute $\quad$ CTI

Crane Manufacturing Association of America CMAA

Electronic Industries Alliance EIA

Institute of Electrical and Electronic Engineers IEEE

Institute of Makers of Explosives IME

Institute of Transportation Engineers ITE

Instrumentation, Systems, and Automation Society ISA

Insulated Steel Door Systems Institute ISDSI

International Air Transport Association IATA

International Association of Plumbing and Mechanical IAPMO

Officials

International Atomic Energy Agency IAEA

International Civil Aviation Organization ICAO

International Commission on Radiation Protection ICRP

International Commission on Radiation Units and ICRU

Measurements, Inc.

International Conference of Building Officials ICBO

International Electrotechnical Commission IEC

International Organization for Standardization ISO

Metal Lath/Steel Framing Association, A Division of MLSFA

NAAMM

National Association of Architectural Metal NAAMM 


\begin{tabular}{|c|c|}
\hline National Conference of Standards Laboratories & NCSL \\
\hline $\begin{array}{l}\text { National Council on Radiation Protection and } \\
\text { Measurements }\end{array}$ & NCRP \\
\hline National Electrical Manufacturers Association & NEMA \\
\hline National Electrical Safety Code & NESC \\
\hline National Fire Protection Association & NFPA \\
\hline National Information Standards Organization & NISO \\
\hline National Safety Council & NSC \\
\hline National Window and Door Association & NWDA \\
\hline Post-Tensioning Institute & PTI \\
\hline Precast/Prestressed Concrete Institute & $\mathrm{PCl}$ \\
\hline Resilient Floor Covering Institute & $\mathrm{RFCl}$ \\
\hline Scaffolding, Shoring, and Forming Institute, Inc. & SSFI \\
\hline Screen Manufacturers Association & SMA \\
\hline $\begin{array}{l}\text { Sheet Metal and Air Conditioning Contractors' } \\
\text { National Association }\end{array}$ & SMACNA \\
\hline Single Ply Roofing Institute & SPRI \\
\hline Society of Automotive Engineers & SAE \\
\hline Society of Fire Protection Engineers & SFPE \\
\hline Southern Building Code Congress International, Inc. & $\mathrm{SBCCl}$ \\
\hline Steel Door Institute & SDI \\
\hline Steel Joist Institute & SJI \\
\hline Steel Window Institute & SWI \\
\hline Underwriters Laboratories & UL \\
\hline Water Environment Federation & WEF \\
\hline
\end{tabular}

6. Please provide the total number of your agency's representatives who participated in voluntary consensus standards activities during FY 2005 and the total number of activities these agency representatives participated in: $\mathbf{7 6 1}$ 
7. Please provide any conformity assessment activities (as described in "Guidance on Federal Conformity Assessment Activities" found in the Federal Register, Volume 65, Number 155, dated August 10, 2000) in which your agency was involved in FY 2005.

This number is unchanged from previous years.

8. Please provide an evaluation of the effectiveness of Circular A-119 policy and recommendations for any changes:

OMB A-119 continues to be adequate.

9. Please provide any other comments you would like to share on behalf of your agency.

Because of declining budgets, it has become increasingly difficult to fund VCS participation by DOE and contractor personnel. As a result, it becomes less likely that the Department's needs are adequately addressed during VCS development/revision, particularly those that relate to important international standards.

10. Please use this box to provide any additional comments on how your agency currently reports its use of voluntary consensus standards:

\section{7 continued.}

Periodically as needed but no less than every 5 years.

10-1. Removed [This question has been deprecated for 2005]

10-2. Removed [This question has been deprecated for 2005]

10-3. Removed [This question has been deprecated for 2005]

10-4. Does your agency report standards that it uses for guidance purposes (as opposed compliance purposes)? (a) Yes; (b) No; (c) Not applicable; Yes

10-5. Does your agency report use of standards from non-ANSI accredited standards developers, industry consortia groups, or both? (a) non-ANSI Accredited; (b) Consortia; (c) Both; (d) Neither; or (e) Not applicable; B 
10-6. Does your agency have a schedule for periodically reviewing its use of standards for purposes of updating such use? (a) Yes; (b) No; Yes

10-7. How often does your agency review its standards for purposes of updating such use? [enter the number of years]: 5 


\section{Department of Health and Human Services}

Title: Department of Health and Human Services (HHS) Fiscal Year 2005 Agency Report

1. Please describe the importance of standards in the achievement of your agency's mission, how your agency uses standards to deliver its primary services in support of its mission, and provide any examples or case studies of standards success:

As noted below, the individual agencies of DHHS believe the use of nongovernment standards, both voluntary consensus standards and non-consensus but non-government unique standards, are integral to the success of their missions.

Food and Drug Administration

The central purpose for FDA involvement in the development and use of standards is to assist the agency in fulfilling its domestic public health and regulatory missions. The agency participates widely in the development of standards, both domestic and international, and adopts or uses standards when this action enhances its ability to protect consumers and increases the effectiveness or efficiency of its regulatory efforts. Further, using standards, especially international ones, is a means to facilitate the harmonization of FDA regulatory requirements with those of foreign governments, and thus to improve domestic and global public health protection. Therefore, FDA encourages participation in the development of standards as a useful adjunct to regulatory controls.

FDA has been involved in standards activities for more than twenty years. In January 1977 the agency promulgated a final regulation now found at 21 CFR 10.95 covering participation by FDA employees in standards development activities outside the agency. This regulation encourages FDA participation in standards activities that are in the public interest, and specifies the circumstances under which FDA employees can participate in various types of standards bodies. The agency built upon that rule with a final policy statement published in the Federal Register on October 11, 1995, entitled International Harmonization; Policy on Standards. It provides the agency's overall policy on 
development and use of standards for all product areas regulated by the agency.

For FDA, voluntary consensus standards are most relevant for medical devices, where they are used extensively in the agency's regulatory work and where the majority of the agency's standards activities are centered. In the areas of human and veterinary pharmaceuticals, biological products and foods, voluntary consensus are generally not available nor being developed. Here FDA works within other national and international organizations such as the World Health Organization (WHO), the Food and Agriculture Organization (FAO), the Organization for Economic Cooperation and Development (OECD), the United States Pharmacopeia, and the International Conference on Harmonization of Technical Requirements for Registration of Pharmaceuticals for Human Use $(\mathrm{ICH})$ to develop appropriate standards.

\section{FDA/CDRH Success Story}

The FDA Center for Devices and Radiological Health (CDRH) is the world leader in the development of standards for safety of implants in the MR environment. Since it was convened in May, 1998, ASTM Committee F04, Medical and Surgical Devices and Materials, Subcommittee 15, Test Methods, has hosted a Task Force 11 (ASTM F04.15.11) on Magnetic Resonance (MR) compatibility of implant materials and medical devices in the MR environment. Led by Dr. Terry Woods, FDA/CDRH, this Task Force has written and published 5 standards addressing the safety of implants in the MR environment. The four standard test methods address the 4 principal issues that can affect the safety of a medical device in the MR environment. They are: ASTM F2052-02 Standard Test Method for Measurement of Magnetically Induced Displacement Force on Medical Devices in the Magnetic Resonance Environment, ASTM F2119-01 Standard Test Method for Evaluation of MR Image Artifacts from Passive Implants, ASTM F2182-02a Standard Test Method for Measurement of Measurement of Radio Frequency Induced Heating Near Passive Implants During Magnetic Resonance Imaging, and ASTM F2213-04 Standard Test Method for Measurement of Magnetically Induced Torque on Medical Devices in the Magnetic Resonance Environment. The fifth standard, ASTM Standard Practice for Marking Medical Devices and Other Items for Safety in the Magnetic Resonance Environment (ASTM F2503-05), was published in August, 2005. The 
symbols and the associated MR safety terminology defined in the standard practice have been urgently needed by the MR community. Within two days of being notified that ASTM F2503 had been published, Dr. Woods was contacted by members of the MR community congratulating her on the publication and thanking her for leading this vital effort. This group included Johnson \& Johnson, Medtronic, Guidant, the University of Southern California, the Institute for Magnetic Resonance Safety, Education, and Research, Brigham \& Women's Hospital, the Mayo Clinic, the University of Pittsburgh Medical Center, ECRI, the UK's Medicines and Healthcare products Regulatory Agency, and the major consultants in the area of MR safety. The ASTM MR standards are the first and only published standards that define general test methods to address safety and compatibility of medical devices in the MR environment. They provide invaluable assistance to device manufacturers and to FDA reviewers in the determination of device safety in the MR environment.

\section{FDA/CBER Success Story}

Standards developed by FDA Center for Biologics Evaluation and Research (CBER) or through interactions with various standard development bodies, including voluntary consensus standard organizations and or industry consortia can provide benefit to stakeholders in multiple ways. CBER interactions with these organizations have resulted in development of several standards that affect various aspects (e.g., clinical, product, pharmacology/ toxicology clinical, statistical, inspectional, IT) for products CBER regulates and ultimately facilitate development, approval and improvements in new products, and appropriate regulation including compliance activities with existing products. Typically standards provide a generally acceptable path that developers and manufacturers can follow in product development and approval. However, the option almost always remains for developers and manufacturers to adapt general standards to specific products and/or to follow a more acceptable approach.

Establishment and use of standards result in benefits to CBER that include: international standards that can be used by multiple regulatory regions; following our legal mandate to facilitate harmonization on an international level; often better utilization of limited internal resources; more direct participation by various stakeholders in development of standards 
CBER also has created unique opportunities to develop standards, by participating in standards development in a unique collaborative effort with service or material donations from multiple organizations including academic and corporate institutions. For example, CBER organized an Adenovirus Reference Materials Working Group that developed an adenoviral virus reference material and adenoviral virus associated reference material. The reference material is used to define the particle and infectious units for adenovirus vectors used in gene therapy thus facilitating advancement in this developing field and helping to assure patient safety.

The FDA Center for Food Safety and Applied Nutrition (CFSAN) staff participate in the activities of the Codex Alimentarius Commission of the FAO and the WHO. CFSAN experts are actively involved in Codex Alimentarius activities and in activities of methods validation organizations on which Codex Alimentarius relies, such as ISO, the Association of Official Analytical Chemists (AOAC), and the International Dairy Federation (IDF). CFSAN has provided the U.S. Delegate or Alternate Delegate to $80 \%$ (17 out of 21 ) of the technical committees and task forces and also provided technical experts to assist on the work of developing more that 90 Codex standards and guidelines. Voluntary consensus standards have limited relevance to food and veterinary medicine products. However, since the standards activities of multilateral organizations such as the WHO, FAO, the World Trade Organization (WTO) and the OECD are important in these areas, CFSAN is actively engaged in standards and policy development with these organizations. CFSAN is also engaged in standards review in the International Organization for Standardization in Microbiology.

International/Treaty Standards-Related Activities - FDA takes part in a variety of international standards activities that fall under treaty organizations, and thus are not reportable under the provisions of Circular A-119. These standards activities are nonetheless important to the agency in fulfilling its public health regulatory mission. Some of these are referred to above, i.e. WHO, FAO, and OECD.

FDA/CFSAN Success Story 
3-A Sanitary Standards, Inc.: Milk Safety Team (MST) standardizes FDA Office of Regulatory Affairs' (FDA/ORA) Regional Milk Specialists (RMS) who conduct check-ratings (audits) of Interstate Milk Shippers and State Regulatory Agency enforcement activities as they relate to the National Conference on Interstate Milk Shippers (NCIMS) Grade “A” National Milk Safety Program. During this field standardization exercise, MST and the RMS evaluate pieces of dairy processing equipment in relationship to meeting 3-A Sanitary Standards and Accepted Practices for dairy equipment sanitary design and cleanability in relationship to the Grade “A” Pasteurized Milk Ordinance (PMO).

The FDA/ORA RMS routinely conduct audits of these IMS Listed Shippers (dairy plants) of which one segment of the audit is to evaluate dairy processing equipment utilized in the plant for conformity to 3-A Sanitary Standards and Accepted Practices and the PMO.

This program has enhanced public health protection by:

o verifying conformity of equipment to consensus-based sanitary standards; o improving the quality and safety of milk and milk products processed on acceptably designed equipment; and o ready acceptance by both Regulatory Agencies and the dairy industry.

Grade “A” Pasteurized Milk Ordinance: The Grade “A” Pasteurized Milk Ordinance (PMO) is the national sanitary model ordinance for the production and processing of Grade " $A$ " milk and milk products. It is uniformly applied by all 50 States and Puerto Rico under the National Conference on Interstate Milk Shippers (NCIMS) Grade “A” Milk Safety Program. This model ordinance is incorporated by reference in Federal specifications for procurement of milk and milk products; is used as the sanitary regulation for milk and milk products served on interstate carriers; and is recognized by the Public Health Agencies, the milk industry, and many others as the national standard for milk sanitation. The Grade "A" PMO adopted and uniformly applied will continue to provide effective public health protection without being unduly burdensome to either Regulatory Agencies or the dairy industry. It represents a "grass-roots" consensus of current knowledge and experience and as such represents a 
practical and equitable milk sanitation standard for the nation. This model ordinance has been developed over the last 50 years as a compliment to the federal GMP's.

Agency for Healthcare Research and Quality -

AHRQ funds and participates with the National Quality Forum (NQF) in the endorsement of standards for performance measures of quality among various providers. This effort brings all stakeholders together to make a determination founded in a membership-driven NTAA-compliant consensus process. In 2003, AHRQ incorporated NQF standards in its National Quality Report that was mandated by Congress and is in clearance within HHS. The AHRQ Director has a permanent seat on the Board of Directors of NQF and participates in the endorsement of the consensus driven standards (measures) through a voting process. AHRQ provides support to NQF.

AHRQ is a member and supports the meetings of the ANSI Health Informatics Standards Board, a board that coordinates the U.S. standards developing organizations for health information exchange. Other federal agencies, professional health organizations, and vendors are members. Duplication and overlap of health data standards domains and other issues are voluntarily resolved through ANSI HISB.

AHRQ is a member and supports the meetings of the U.S. Technical Advisory Group to ISO Technical Committee 215, Health Informatics. The U.S. TAG formulates and reaches consensus on the U.S. position on health data issues taken at ISO TC 215 meetings.

AHRQ supported the Institute of Medicine's letter report recommending eight functions be included in the definition of an electronic health record. These functions were used by Health Level 7 to produce a balloted standard on the functional definition of an EHR in September 2003. The ballot has reached consensus in 2004 and is beginning to be used by clinical information software vendors to disclose their support of specific functions defined in these standards. 
AHRQ participates as a liaison to the National Committee on Vital and Health Statistics (NCVHS), an advisory committee that advises the Secretary of HHS on health information policy. NCVHS recommended adoption of four ANSI standards to the Secretary for use in federal health program information exchange. On February 21, 2003, the Secretary adopted 5 messaging standards. In FY 2004, NCVHS will recommend a core set of terminology standards to the Secretary for adoption. The Secretary adopted 15 more clinical data standards in the Spring 2004 for federal government sector use.

AHRQ participates in one of the administration's 24 e-Government initiativesthe Consolidated Health Informatics (CHI) initiative. In 2003, CHI recommended four messaging standards and one terminology standard to the Secretary of HHS for adoption. He adopted all five. $\mathrm{CHI}$ is working selecting voluntary consensus standards for a total of 24 domain areas.

AHRQ supported the founding of the Health Level 7 Special Interest Group on Patient Safety to begin the process of developing standards for reporting patient safety events across the nation in a uniform format.

AHRQ supports ASTM's Continuity of Care standard for health information to be exchanged among providers and given to patients following an office visit. AHRQ devoted $\$ 10$ million of its $\$ 300$ million budget in 2004 to the development and implementation of health care data standards to improve patient safety and quality of care. This includes funding FDA's development of an electronic structured product labeling system, an electronic product listing of all products approved by FDA for sale in the US, a coding system for all drug components-active and inactive ingredients, and improvements in the National Drug Code; and funding for transmission of this information in electronic form to the National Library of Medicine (NLM). Additionally, AHRQ funded NLM to develop a system to post this information on its DailyMed web site quarterly and to map selected terminologies (ICD, CPT, MedDRA, others) to SNOMED. Also AHRQ funded NIST and CMS to develop web-based, publicly available systems for displaying the landscape of standards developing activities in the US and the data components of specific data standards. AHRQ is studying how patient safety event data reported by 24 states may use existing American National Standards and what ANS standards need to be developed to make this 
information more uniform and accurate.

\section{Centers for Disease Control}

The Agency is very involved in the voluntary standards process and has been for a number of years. See http://www.cdc.gov/phin/ for an example of a current system using voluntary consensus standards. Additionally, this years report asks, for the first time, about information regarding Other Technical Standards. $C D C$ has been requesting the ability to provide this information for several years. The Public Health Surveillance System in the US is a true Federal, State and Local partnership driven by many consensus processes with a variety of partner organizations such as the Council of State and Territorial Epidemiologists (CSTE), Association of State and Local Territorial Health Officials (ASTHO), Association of Public Health Laboratories (APHL), National Association for Public Health Statistics and Information System (NAPHSIS), National Association of Health Data Organizations (NADHO), etc. These partnerships result in guidelines or local laws invoked at the state and local level to provide uniform and professional public health surveillance and reporting system in the US. The notification of this change came while many of the CDC Personnel involved in these activities were focused on emergency response deployments in the Gulf States and other then a mention in this report, full details will be delayed. It is estimated that the number of people involved in these activities greatly exceeds that of those involved with the more formal VCS process.

\section{Centers for Medicare and Medicaid Services}

CMS is participating with the National Quality Forum (NQF) in the endorsement of standards for performing measures of quality among providers. This effort brings all stakeholders together to make a determination founded in a membership-driven NTAA-compliant consensus process. The NQF endorsed quality measures for nursing home quality and hospitals in FY 2003. In FY 2004, CMS submitted measures to the NQF for endorsement in the home health and ambulatory settings. CMS incorporated NQF endorsed quality measures into its demonstrations, public reporting or quality improvement activities. 
The CMS Administrator has a permanent seat on the Board of Directors of the NQF and participates through an appointed designee. As a dues paying member of the NQF, CMS also participates on the Purchaser Council.

The Consolidated Health Initiative $(\mathrm{CHI})$ as one of 24 critically important EGovernment (eGov) initiatives, that will provide the federal health enterprise with one of the essential components needed to enable federal agencies to build interoperable health data systems: clinical health data and messaging standards. Standards will enable this large enterprise to exchange comparable health data across the wide range of federal activities. Three federal departments lead the initiative: Department of Health and Human Services (DHHS), Department of Defense (DoD), and Department of Veterans Affairs (VA). To date, the $\mathrm{CHI}$ work has led to the adoption of eleven sets of standards covering twenty healthcare specific domains. This wide spread adoption of standards marks the first time the entire federal health enterprise has committed to use the same vocabularies to enable exchange of health information.

Within CMS, the implementation of the $\mathrm{CHI}$ standards requires a multicomponent effort that cuts across various CMS business processes. The Office of Information Services' (OIS) Enterprise Architecture (EA) organization will employ a standardized implementation methodology for incorporating the $\mathrm{CHI}$ adopted standards across the framework architecture to facilitate CMS' implementation of the $\mathrm{CHI}$ standards. The EA group will integrate the $\mathrm{CHI}$ adopted standards into the data and information infrastructures and will identify potential business functions and areas where the $\mathrm{CHI}$ clinical messaging and vocabulary standards may apply.

CHI's initial portfolio identified 24 domain/subject areas requiring data and messaging standards. To date, 20 domains/sub-domains have adopted standards. (Government only standards are highlighted)

They are:

Domain Area Outcome

Laboratory Results Names LOINC adopted 
Messaging Standards: Patient care including scheduling, medical record and image management, patient administration, observation reporting, financial management, public health notification, and patient care HL7 adopted Messaging Standards: Retail pharmacy transactions NCPDP SCRIPT adopted

Messaging Standards: Connectivity IEEE 1073 adopted Messaging Standards: Image information to workstations DICOM adopted Medications Set of federal terminologies adopted including:

- Food and Drug Administration's names and codes for ingredients, manufactured dosage forms, drug products, and medication packages (FDA Ingredient Names \& UNII Code; CDER Standard, NDC codes)

- National Library of Medicine's RxNORM

- Veterans Administration's National Drug File Reference Terminology (NDF-RT) for specific drug classifications

- LOINC SPL for label section headers

- HL7 Gender, Race \& Ethnicity for special populations

Demographics HL7 adopted

Immunizations HL7 adopted

Clinical Encounters HL7 adopted

Units HL7 adopted

Interventions and Procedures:

A. Non-laboratory

SNOMED CT adopted

Interventions and Procedures:

B. Laboratory test names LOINC adopted

Lab Result Contents SNOMED CT adopted

Diagnoses and Problems SNOMED CT adopted

Anatomy SNOMED CT and NCI Thesaurus adopted

Nursing SNOMED CT adopted

Text-based Reports HL7 clinical document architecture

Genes Human genome nomenclature adopted (HGNC)

Chemicals EPA's substance registry system

Financial and Payment HIPAA transactions and code sets

History and Physical No standard ready for adoption. Follow-up recommendations provided. 
Population Health

Multimedia

Medical Devices and Supplies

Disability

Proteins

Physiology

Examples of case studies of standards successes include:

- Significant savings of electronic claims versus paper claims

- Ended Medicare claim contingency on October 1, 2005

- MREP developed; enables ending the contingency for remittance legacy formats.

National Institutes of Health/National Cancer Institute

The Nanotechnology Characterization Laboratory $(\mathrm{NCL})$ is part of the National Cancer Institute $(\mathrm{NCl})$, which is part of the National Institutes of Health $(\mathrm{NIH})$. The intent of the NCL is to accelerate the transition of basic nanotechnology research into clinical applications. It seeks to establish and standardize an analytical cascade for nanomaterial characterization and to facilitate clinical development and regulatory review of nanomaterials. The use of voluntary consensus standards (VCS) is, and will continue to be, critical in this endeavor. $\mathrm{NCL}$ is therefore taking a lead role in developing standard protocols for characterization of nanoparticles, which then enable appropriate assessment of the biological activity of these products.

2. Please list the government-unique standards your agency used in lieu of voluntary consensus standards during FY 2005: 2

1. Government Unique Standard: FDA Guidelines on Asceptic Processing (2004) (Incorporated: 2004)

Voluntary Standard

ISO 13408-1 Asceptic Process ing of Health Care Products, Part 1, General Requirements 
Rationale

FDA is not using the ISO standard because the applicability of these requirements is limited to only portions of aseptically manufactured biologics and does not include filtration, freeze-drying, sterilization in place, cleaning in place, or barrier-isolator technology. There are also significant issues related to aseptically produced bulk drug substance that are not included in the document

2. Government Unique Standard: FR Notice dated June 17, 1994 Tentative Final Monograph for Health Care Antiseptic Drug Products; Proposed Rule (Incorporated: 1997)

Voluntary Standard

ASTM Standard E1115 - Test Method for Evaluation of Surgical Hand Scrub

Formulations

Rationale

Sensitivity and bias of the ASTM Standard has not been established.

Voluntary Standard

ASTM Standard E1173-93 - Standard Test Method of an Evaluation of

Preoperative, precatheterization, or Preinjection Skin Preparations

Rationale

Sensitivity and bias of the ASTM Standard has not been established.

Voluntary Standard

ASTM Standard E1174-00 - Standard Test method for the Evaluation of the Effectiveness of Health Care Personnel or Consumer Handwash Formulations Rationale

Sensitivity and bias of the ASTM Standard has not been established.

3. Please list the Voluntary Consensus Standards (VCS) your agency substituted for Government Unique Standards (GUS) in FY 2005 as a result of review under Section 15(b)(7) of OMB Circular A-119: 3

\section{Voluntary Standard}

HL 7 Annotated ECG Waveform Data Standard

\section{Government Standard}

FDA Guidance 21 CFR Part 
HL 7 Structured Product Labeling

Voluntary Product Accessibility Template (VPAT)
FDA Guidance 21 CFR Part 314

CMS Section 508 Checklist

4. Please provide the total number of Voluntary Consensus Standards your agency used during FY 2005: Optional: If possible, also please provide the total number of Nonconsensus Standards that are developed in the private sector your agency used during FY 2005. In addition, please provide your agency's rationale for using the Nonconsensus Standards that are developed in the private sector counted in this question.

Voluntary Consensus Standards: 945

Other Technical Standards: 0

Rationale: The number reported here as Voluntary Consensus standards is only an estimate of the total number of VCS and non-consensus standards used by DHHS Agencies. The proportion of these that are non-consensus standards is unknown. While the data provided elsewhere in this report indicate considerable involvement with voluntary consensus standard setting organizations, they are not reflective of the total DHHS involvement with standard setting organizations. A large number of DHHS standards setting activities are with groups which do not meet OMB's definition of a voluntary consensus standards body: United States Pharmacopeia (USP), International Conference on Harmonization (ICH), Organization for Economic Cooperation and Development (OECD) and the World Health Organization (WHO), etc. For example, the primary standards setting organization for FDA/CDER is the United States Pharmacopeia (USP). The Food, Drug and Cosmetic Act recognizes USP and mandates FDA's involvement with the USP. OMB Circular No. A-119 states that its definition of standard does not include a standard created under other legal authority, such as those contained in the United States Pharmacopeia and the National Formulary. FDA is also active with organizations such as Codex Alimentarius, $\mathrm{ICH}$, VICH, CHIC, etc.. These groups do not qualify as a voluntary standard setting organizations since they are treaty or government-to-government organizations. FDA also manages many products through the standards developed by their trade organizations. These 
are only a few examples of the types of organizations, manufacturer associations, comodity groups and professional societies with whom DHHS Agencies interact to develop standards. Last, and by no means least, due to the lack of a true consensus process, the WHO does not meet the criteria for a voluntary consensus standard body.

5. Please enter the Voluntary Consensus Standards Bodies (VCSB) in which your agency participated in during FY 2005: 114

\section{Voluntary Consensus Standards Body}

3-A Sanitary Standards, Inc

Accredited Standards Committee X12

Acoustical Society of America

Adeno Associated Virus Reference Standard Working

Group

American Academy of Pediatrics

American Association for Clinical Chemistry

American Association of Blood Banks

American Association of Physicists in Medicine

American Association of Tissue Banks

American Chemical Society

American College of Surgeons

American Conference of Governmental Industrial

Hygienists

American Industrial Hygiene Association

American Institute of Ultrasound Manufacturers

American National Standards Institute

American Red Cross

American Society for Blood and Marrow

Transplantation

American Society for Reproductive Medicine

American Society for Testing and Materials

International

\section{Acronym}

3-ASS

X12

ASA

AAVSWG

AACP

AACC

AABB

AAPM

AATB

ACS

ACOS

ACGIH

AlHA

AIUM

ANSI

ARC

ASBMTT

ASRM

ASTMI 
American Society of Agricultrial Engineers

American Society of Agricultural and Biological

ASABE

Engineers

American Society of Heating, Refrigerating, and Air- ASHRAE

Conditioning Engineers

American Society of Mechanical Engineers

ASME

Association for Assessment and Accreditation of

AAALAC

Laboratory Animal Care International

Association for Electronic Health Care Transactions

AFEHCT

Association for the Advancement of Medical

AAMI

Instrumentation

Association of Food and Drug Officials

AFDO

Association of Official Analytical Chemists

$\mathrm{AOACl}$

International

Baking Industry Sanitary Standards Committee

BISSC

Clinical and Laboratory Standards Institute

CLSI

Clinical Data Interchange Standards Consortium

CDISC

Codex Alimentarius

CODEX

College of American Pathologists

CAP

Conference for Food Protection

CFP

Congress of International Organizations of Medical

CIOMS

Sciences

Consolidated Health Informatics

$\mathrm{CHI}$

Cosmetic Ingredient Review

CIR

Cosmetic Toiletry and Fragrance Association

CTFA

Council on lonizing Radiation Measurements and

CIRMS

Standards

Designated Standards Maintenance Organizations

DSMO

Board

European Directorate for Quality of Medicines

EDQM

External RNA Controls Consortium

ERCC

Eye Bank Association of AMerica

EBAA 
foundation for Accrediation of Cellular Therapies

FACS

Fresh Produce Association of America FPA

$\begin{array}{ll}\text { Health Level Seven } & \text { HL7 }\end{array}$

Healthcare Information and Management Systems HIMSS

Society

Independent Cosmetic Manufacturers and ICMAD

Distributers

Industrial Safety and Equipment Association ISEA

Institute of Electrical and Electronic Engineers IEEE

International Association for Food Protection IAFP

International Association of Cancer Registrars IACR

International Blood Group Reference Laboratory IBRGL

International Commission for Illumination CIE

International Commission on Harmonization of $\quad \mathrm{VICH}$

Technical Requirements for Registration of

Pharmaceuticals for Veterinary Use

International Committee for Cosmetic Harmonization CHIC

and International Cooperation

International Conference on the Harmonization of $\quad \mathrm{ICH}$

Technical Requirements for Registration of

Pharmaceuticals for Human Use

International Coordinating Committee on the ICCVAM

Validation of Alternative Methods

International Dairy Foods Association IDFA

International Electrotechnical Commission IEC

International Organization for Standardization ISO

International Organization for Standardization in ISOB

Microbiology

International Organization for ISO/IEC

Standardization/International Electrotechnical

Commission

International Regulatory Alternatives Group IRAG 


\begin{tabular}{|c|c|}
\hline International Society for Analytical Cytology & ISAC \\
\hline International Society for Blood Transfusion & ISBT \\
\hline International Society for Cardiovascular Surgery & ISCVS \\
\hline International Society for Cell Therapy & ISCT \\
\hline International Society for Measurement and Control & ISA \\
\hline International Society of Oncology Pharmacy & ISOPP \\
\hline Practitioners & \\
\hline International Society on Thrombosis and Homeostasis & S ISTH \\
\hline International Union Against Cancer & UICC \\
\hline International Union of Pure and Applied Chemistry & IUPAC \\
\hline Interstate Shellfish Sanitation Conference & ISSC \\
\hline Joint FAO/WHO Expert Committee on Food Additives & JECFA \\
\hline Logical Observation Identifier Names and Codes & LOINC \\
\hline National Cancer Registrar Assciation & NCRA \\
\hline National Center for Vital and Health Statistics & NCVHS \\
\hline National Committee on Vital and Health Statistics & NCVHS \\
\hline National Conference for Interstate Milk Shipments & NCIMS \\
\hline National Cooperation for Laboratory Accreditation & NACLA \\
\hline National Coordinating Council for Cancer & NCCCS \\
\hline Surveillance & \\
\hline National Council for Prescription Drug Program & NCPDP \\
\hline National Council of Radiation Protection and & NCRPM \\
\hline Measurements & \\
\hline National Dialog on Cancer & NDC \\
\hline National Electrical Manufacturers Association & NEMA \\
\hline National Environmental Health Association & NEHA \\
\hline National Fire Protection Association & NFPA \\
\hline National Institute for Biological Sciences and & NIBSC \\
\hline Controls & \\
\hline National Marow Doner Program & NMDP \\
\hline National Sanitary Foundation International & \\
\hline
\end{tabular}




\begin{tabular}{|c|c|}
\hline National Skill Standards Board & NSSB \\
\hline National Uniform Billing Committee & NUBC \\
\hline National Uniform Claim Committee & NUCC \\
\hline $\begin{array}{l}\text { North American Association of Central Cancer } \\
\text { Registries }\end{array}$ & NAACCR \\
\hline $\begin{array}{l}\text { Organization for Economic Cooperation and } \\
\text { Development }\end{array}$ & OECD \\
\hline $\begin{array}{l}\text { Organization for the Advancement of Structured } \\
\text { Information Standards }\end{array}$ & OASIS \\
\hline Pan American Health Organization & PAHO \\
\hline Pasteurized Milk Ordinance & PMO \\
\hline Portable Sanitation Association International & PSIA \\
\hline Produce Marketing Association & PMA \\
\hline $\begin{array}{l}\text { Rehabilitation Engineering and Assistive Technology } \\
\text { Society of North America }\end{array}$ & RESNA \\
\hline Research Institute for Fragrance Materials & RIFM \\
\hline Society of Automotive Engineers & SAE \\
\hline Society of Cosmetic Chemists & SCC \\
\hline Standard for Exchange of Nonclinical Data & SEND \\
\hline Strategic National Implementation Process & SNIP \\
\hline U.S. Adopted Names Council & USANC \\
\hline Underwriters Laboratories & UL \\
\hline United Fresh Furit and Vegetable Association & UFFVA \\
\hline United States Adopted Names & USAN \\
\hline United States Pharmacopoeia & USP \\
\hline Workgroup for Electronic Data Interchange & WEDI \\
\hline World Health Organization & WHO \\
\hline
\end{tabular}

6. Please provide the total number of your agency's representatives who participated in voluntary consensus standards activities during FY 2005 and the total number of activities these agency representatives participated in: 594 
7. Please provide any conformity assessment activities (as described in "Guidance on Federal Conformity Assessment Activities" found in the Federal Register, Volume 65, Number 155, dated August 10, 2000) in which your agency was involved in FY 2005.

\section{U.S. Food and Drug Administration -}

FDA inspects manufacturers of regulated products (pharmaceuticals, veterinary drugs, medical devices, biologicals) for compliance with current Good Manufacturing Practice (cGMP)and/or Quality System (QSR)Regulations requirements. FDA inspects laboratories that provide pivotal animal studies for drug approvals for compliance with Good Laboratory Practice (GLP). FDA participates on the ANSI Accreditation Committee, the ANSI International Conformity Assessment Committee, ANSI Board Committee on Conformity Assessment, and ASTM Committee E-36 on Conformity Assessment. Within FDA, the Center for Devices and Radiological Health allows a medical device manufacturer to submit a Declaration of Conformity to a "recognized standard" as described in ISO/IEC Guide 22 in its standards recognition program and has developed an MRA with the European Union on mutual recognition of each other's conformity assessment procedures related to manufacture and marketing of medical devices. The FDA Office of Regulatory Affairs (FDA/ORA) actively participates with the National Cooperation for Laboratory Accreditation (NACLA), serving as a member of the NACLA Executive Board of Directors and and participating in the NACLA Recognition Committee for Accrediting Bodies who apply for mutual recognition. Other FDA officials participate with NACLA in the evaluation of accrediting bodies under ISO/IEC 58 and ISO/IEC 17025 and sit on NACLA technical committees.

CDER - The conformity assessment activities in which the Center has been involved as described in the Federal Register, Vol. 65, No. 155, Thursday, August 10, 2000, Guidance on Federal Conformity Assessment Activities, and the 9/7/00 NIST document “Information on Voluntary Reporting on Federal Conformity Assessment Activities for the Agency Annual Report.

CFSAN - Conformity Assessment Activity participation included:

a. Grade A Milk Laboratory Certification Program - The Grade A Milk safety laboratory certification program relies on on-site 
inspection as well as annual proficiency testing Evaluation forms developed through common agreement by all parties are used to review records, facilities, and analysts' performance of tests. The proficiencies cover the range of testing for which the laboratories are certified and the results are evaluated statistically. This program has enhanced public health protection by: o verifying analysts' abilities to perform testing successfully; o improving the quality of the work performed by the analysts, analysts' knowledge , and the credibility of results;

o more rapidly and accurately identifying pathogens leading to earlier and more successful treatment; and o keeping drugs out of the milk supply.

With the idea of enhancing international credibility and recognition, CFSAN is moving towards ISO accreditation of its own laboratories that perform regulatory work.

b. Retail food managers' certification program - Via participation in the Conference for Food Protection (CFP), CFSA was involved in a certification / accreditation program. The CFP now owns copyrighted Food Manager Certification Standards which are administered by ANSI under contract with the CFP. An FDA employee sits on an ANSI/CFP accreditation committee to ensure those Standards are administered, consistent with CFP's intent. This is the culmination of over 20 years of work to arrive at legally defensible national standards to which all the stakeholders have agreed; meaningful certification; a basis for reciprocity among the 3000 + regulatory agencies in the U.S.; a single process for industry; and a straightforward method of fulfilling the FDA model Food Code.

Centers for Medicare and Medicaid Services

Sampled remittances ( 835 transactions) generated by Medicare Part A contractors to determine the use of Claim Adjustment Reason Code 'A7'. This code value represents a forced-balance situation with the claim and should be rarely used.

a. Before $=75 \%$ out of balance

b. After $=47 \%$ out of balance 
Project continues; next sampling will be taken in January 2006 for 1st quarter results.

8. Please provide an evaluation of the effectiveness of Circular A-119 policy and recommendations for any changes:

Food and Drug Administration

U.S. Food and Drug Administration - The policy and recommendations contained in Circular A-119 are consistent with FDA's framework for standards management as announced in the Federal Register on October 11, 1995, and enhanced by the Food and Drug Administration Modernization Act (FDAMA). Resource constraints oblige the agency to focus attention on the highest priority activities and to strive to make its participation in those activities very effective. FDA participates in several hundred standards development activities (the exact number is not known as there is not established procedure to gather this information) within 165 voluntary consensus standards bodies.

\section{Centers for Disease Control}

CDC's major issue with prior OMB A-119 reporting revolved around our inability to report the majority of our work with partner organizations that are not SDOs. This has been corrected this year, but knowledge came too late to effectively organize any data collection mechanism. Collecting this information will be a major resource burden for the Agency as all essentially all CDC programs are involved. In light of our difficulty in collecting present data, we realize the information content will better reflect our work, but will still question completeness.

9. Please provide any other comments you would like to share on behalf of your agency.

Agency for Healthcare Research and Quality

Agency for Healthcare Research and Quality - AHRQ has supported voluntary consensus standards development and processes for many years because 
uniform information exchange can lead to better research data having more powerful findings and because informatics tools can better access the knowledge to improve patient safety, quality of care, the cost of care, and access to care. In 2004 AHRQ increased its pace of support for health data standards and code sets by $\$ 10$ million.

\section{Centers for Disease Control}

The notification for this year's NTTAA Report came while many of the CDC Personnel involved in these activities were focused on emergency response deployments in the Gulf States. Full details will be delayed until next year's report.

Federal recognition of VCS is increasing, but Agency recognition is still weak. Until the importance is elevated so that it is part of the planning process involving the Agency Director full advantage of the VCS process will not be obtained. Likewise, complete reporting will remain out-of-reach. At CDC a good example may be seen by the level of reporting by our National Institute for Occupational Safety and Health (NIOSH) which works effectively though numerous partnerships, with a large outreach to the VCS community and good tracking of VCS work. A similar situation does not exist in most other areas of CDC.

\section{Center for Medicare and Medicaid Services}

An evaluation period is planned for carriers during FY 2006 to assess remittances that are out of balance.

National Institutes of Health/National Cancer Institute

NCL is actively involved in the development of new standards for characterization of nanotechnology products for medical use. It must interact with national and international agencies. Considerable effort is being put into evaluating existing standards for applicability and developing new protocols when needed. $\mathrm{NCL}$ is part of one agency $(\mathrm{NCl})$, but its "products" must be approved by a different agency (FDA). It cannot select which VCS are 
acceptable and which GUS must be used, but must follow the regulations of the FDA centers involved. It does hope to promote the development of standards that will be acceptable to the FDA and will aid in the commercialization of nanotechnology products.

10. Please use this box to provide any additional comments on how your agency currently reports its use of voluntary consensus standards:

10-1. Removed [This question has been deprecated for 2005]

10-2. Removed [This question has been deprecated for 2005]

10-3. Removed [This question has been deprecated for 2005]

10-4. Does your agency report standards that it uses for guidance purposes (as opposed compliance purposes)? (a) Yes; (b) No; (c) Not applicable; Yes

10-5. Does your agency report use of standards from non-ANSI accredited standards developers, industry consortia groups, or both? (a) non-ANSI Accredited; (b) Consortia; (c) Both; (d) Neither; or (e) Not applicable; C

10-5. Does your agency have a schedule for periodically reviewing its use of standards for purposes of updating such use? (a) Yes; (b) No; No

10-5. How often does your agency review its standards for purposes of updating such use? [enter the number of years]: 0

Title: Department of Health and Human Services (HHS) Fiscal Year 2005 Agency Report 


\section{Department of Homeland Security}

Title: Department of Homeland Security (DHS) Fiscal Year 2005 Agency Report

1. Please describe the importance of standards in the achievement of your agency's mission, how your agency uses standards to deliver its primary services in support of its mission, and provide any examples or case studies of standards success:

The U.S. Department of Homeland Security is committed to developing and adopting nationally and internationally recognized standards as a means to improve homeland, air and maritime safety, marine environmental protection, and to promote an internationally competitive U.S. maritime industry. One of the goals of our Standards program is to develop a comprehensive set of nationally recognized, internationally compatible standards through active participation in national standards organizations. While the adoption of industry standards enables the Homeland Security Department to fulfill its regulatory functions more efficiently, this capability would be useless without the existence of meaningful standards. Recognizing this reality early on, the Coast Guard aggressively pursued membership on a full range of standardsorganizations. Today the Coast Guard supports at least 30 non-government organizations and actively participate on over 100 standards-committees. This active participation enables us to raise genuine issues of public safety and preservation of the marine environment. Additionally, where industry has not established suitable safety requirements, we catalyze their development. Becoming an integral part in this process has enabled the Coast Guard to avoid drafting unnecessarily detailed regulations and in some cases avoiding regulation completely. It has also helped us to evolve from a regulatory process which reacts to disaster to a more orderly process which recognizes technical innovation and progressive ideas aimed at preventing disaster.

To date we have adopted over 450 industry standards, saving over 25,000 pages of federal regulations and the associated regulation maintenance, while specifying standards already familiar to the industry regulated. We estimate that our participation on standards committees saves us over $\$ 1.5 \mathrm{M}$ annually and increases our inspection and technical force 100 times. 
2. Please list the government-unique standards your agency used in lieu of voluntary consensus standards during FY 2005: 0

3. Please list the Voluntary Consensus Standards (VCS) your agency substituted for Government Unique Standards (GUS) in FY 2005 as a result of review under Section 15(b)(7) of OMB Circular A-119: 0

4. Please provide the total number of Voluntary Consensus Standards your agency used during FY 2005: Optional: If possible, also please provide the total number of Nonconsensus Standards that are developed in the private sector your agency used during FY 2005. In addition, please provide your agency's rationale for using the Nonconsensus Standards that are developed in the private sector counted in this question.

Voluntary Consensus Standards: 1000

Other Technical Standards: 0

Rationale:

5. Please enter the Voluntary Consensus Standards Bodies (VCSB) in which your agency participated in during FY 2005: 50

\begin{tabular}{|c|c|}
\hline Voluntary Consensus Standards Body & Acronym \\
\hline 3rd Generation Partnership Project & 3GPP \\
\hline 3rd Generation Partnership Project 2 & 3GPP2 \\
\hline Alliance for Telecommunications Industry Solutions & ATIS \\
\hline $\begin{array}{l}\text { American Association for Budget and Program } \\
\text { Analysis }\end{array}$ & AABPA \\
\hline $\begin{array}{l}\text { American Association of State Highway and } \\
\text { Transportation Officials }\end{array}$ & AASHTO \\
\hline American Boat and Yacht Council & $A B Y C$ \\
\hline American Bureau of Shipping & --SELECT-- \\
\hline American National Standards Institute & ANSI \\
\hline $\begin{array}{l}\text { American Railway Engineering \& Maintenance-of- } \\
\text { Way Association }\end{array}$ & AREMA \\
\hline
\end{tabular}


American Society for Testing and Materials

ASTM

American Society of Civil Engineers ASCE

American Society of Heating, Refrigerating, and Air- ASHRAE

Conditioning Engineers

American Society of Mechanical Engineers

ASME

American Society of Naval Engineers

ASNE

American Towing Tank Conference

--SELECT--

American Welding Society

AWS

Association of Diving Contractors International

--SELECT--

Chlorine Institute

--SELECT--

Compressed Gas Association

CGA

Council on lonizing Radiation Measurements and

CIRMS

Standards

Electronic Industries Alliance

EIA

Health Physics Society

HPS

Human Factors Society

HFS

Institute of Electrical and Electronic Engineers

IEEE

Instrumentation Society of America

--SELECT--

International Association of Drilling Contractors

IADC

International Association of Lighthouse Authorities

--SELECT--

International Atomic Energy Agency

IAEA

International Civil Aviation Organization

ICAO

International Electrotechnical Commission

IEC

International Organization for Standardization

ISO

International Radio Consultative Committee

IRCC

International Ship and Offshore Structures Congress

International Telecommunication Union -

ISOSC

ITU-T

Telecommunication Standardization Sector

Internet Engineering Task Force IETF

Joint Aeronautical Commander's Group

--SELECT--

Marine Technology Society

MTS 


$\begin{array}{ll}\text { National Cargo Bureau, Inc } & \text { NCB } \\ \text { National Committee for Information Technology } & \text { NCITS } \\ \text { Standards } & \\ \text { National Council of Radiation Protection and } & \text { NCRPM } \\ \text { Measurements } & \\ \text { National Defense Industrial Association } & \text { NDIA } \\ \text { National Fire Protection Association } & \text { NFPA } \\ \text { National Marine Electronics Association } & \text {--SELECT-- } \\ \text { National Marine Manufacturers Association } & ? \\ \text { National Sanitation Foundation } & ? \\ \text { Radio Technical Commission for Maritime Services } & \text { RTCM } \\ \text { Society of Naval Architects and Marine Engineers } & \text { SNAME } \\ \text { Telecommunications Industry Association } & \text { TIA } \\ \text { Telemanagement Forum } & \text { TMF } \\ \text { Underwriters Laboratories } & \text { UL }\end{array}$

6. Please provide the total number of your agency's representatives who participated in voluntary consensus standards activities during FY 2005 and the total number of activities these agency representatives participated in: 160

7. Please provide any conformity assessment activities (as described in "Guidance on Federal Conformity Assessment Activities" found in the Federal Register, Volume 65, Number 155, dated August 10, 2000) in which your agency was involved in FY 2005.

TSL's Trace Certification Program created pursuant to ATSA Act of 2001 and registered to ISO-9001:2000

8. Please provide an evaluation of the effectiveness of Circular A-119 policy and recommendations for any changes:

The USCG encourages government-wide use of risk-based methodologies in standards development and assessments. The Coast Guard uses risk-based methodologies to determine the level and degree of standardization needed. Using risk-based methods in a top down systems engineering approach we can 
determine the relative safety hazards and determine the effective level of standardization needed. Using risk-based methods on specially designed cargo vessels, we saved over $\$ 2 m$ per vessel.

9. Please provide any other comments you would like to share on behalf of your agency.

none

10. Please use this box to provide any additional comments on how your agency currently reports its use of voluntary consensus standards:

haphazardly by component

10-1. Removed [This question has been deprecated for 2005]

10-2. Removed [This question has been deprecated for 2005]

\section{0-3. Removed [This question has been deprecated for 2005]}

10-4. Does your agency report standards that it uses for guidance purposes (as opposed compliance purposes)? (a) Yes; (b) No; (c) Not applicable; Yes

10-5. Does your agency report use of standards from non-ANSI accredited standards developers, industry consortia groups, or both? (a) non-ANSI Accredited; (b) Consortia; (c) Both; (d) Neither; or (e) Not applicable; C

10-5. Does your agency have a schedule for periodically reviewing its use of standards for purposes of updating such use? (a) Yes; (b) No; Yes

10-5. How often does your agency review its standards for purposes of updating such use? [enter the number of years]: $\mathbf{5}$ 


\section{Department of Housing and Urban Development}

Title: Department of Housing and Urban Development (HUD) Fiscal Year 2005 Agency Report

1. Please describe the importance of standards in the achievement of your agency's mission, how your agency uses standards to deliver its primary services in support of its mission, and provide any examples or case studies of standards success:

Standards are of significant value in the accomplishment of the HUD mission. Because the HUD housing and community development mission closely parallels other construction and coummunity development activities in America's cities, counties and states, HUD relies on the use of standards common to both activities such as local, regional or national construction codes.

HUD has been successful (and welcomed) in recent efforts to participate in the development of national model construction codes. During the 2005 International Code Council hearings, HUD testified on code change proposals regarding rehabilitation codes and accessibility. This involvement was well received by the other participants at the hearings.

Based on a recent Office of Policy Development \& Research (PD\&R) assessment of HUD's own Minimum Property Standards (MPS) and Technical Suitability of Products (TSP) program, discussions continue to determine the future of the MPS and TSP program. This major study recommends that the Department extend its reliance on voluntary standard in two ways. First, the study recommends that HUD totally abandon the MPS for single-family housing in all aspects totally relying on the model codes, especially the ICC \& IRC codes and remove all remaining references to the MPS in HUD regulations. This would clarify the decision by HUD regarding not issuing construction standards. Second the study recommends that HUD abandon its own "Technical Suitability of Products" program relying instead on the National Evaluation Service to review al innovative or other products that do not meet the prescriptive standards of the model codes. This study is under review by the assistant Secretary for Housing. If adopted, this will strengthen HUD's reliance on the voluntary and private consensus process in lieu of HUD developed standards 
and criteria.

Work continues on the development of a revision to the HUD Manufactured Home Construction and Safety Standards (24 CFR 3280) being developed through a concensus process with NFPA. This will remain a Government Unique Standard.

2. Please list the government-unique standards your agency used in lieu of voluntary consensus standards during FY 2005: 2

1. Government Unique Standard: 24 CFR 200.935 - Administrator qualifications and procedures for HUD building products and certififcation programs (Incorporated: 2000)

Voluntary Standard

ANSI A119.1 N - Recreation Vehicles

Rationale

HUD Building-Product Standards \& Certification Programs. HUD was required by legislation to "establish Federal construction and safety standards for manufactured homes and to authorize manufactured home safety research and development". Recently, HUD retained a private consensus body (NFPA) to update and modernize the Manufactured Home Standards. At the conclusion of the development process, NFPA will submit the revised standard to HUD for regulatory adoption.

2. Government Unique Standard: 24 CFR 3280 - Manufactured Home Construction and Safety Standards (Incorporated: 2000)

Voluntary Standard

ANSI A119.1 - Recreation Vehicles and NFPA 501C - Standard on Recreational Vehicles

Rationale

HUD-Unique Manufactured Home Construction \& Safety Standards. HUD was required by legislation to "establish Federal construction and safety 
standards for manufactured homes and to authorize manufactured home safety research and development". Recently, HUD retained a private consensus body (NFPA) to update and modernize the Manufactured Home Standards. At the conclusion of the development process, NFPA will submit the revised standard to HUD for regulatory adoption.

3. Please list the Voluntary Consensus Standards (VCS) your agency substituted for Government Unique Standards (GUS) in FY 2005 as a result of review under Section 15(b)(7) of OMB Circular A-119: 0

4. Please provide the total number of Voluntary Consensus Standards your agency used during FY 2005: Optional: If possible, also please provide the total number of Nonconsensus Standards that are developed in the private sector your agency used during FY 2005. In addition, please provide your agency's rationale for using the Nonconsensus Standards that are developed in the private sector counted in this question.

Voluntary Consensus Standards: 300

Other Technical Standards: 0

Rationale: Because of the nature of the HUD work, the value of VCS used in 2005 is an estimate. Most of these standards are used in the execution of the HUD mission by HUD contractors and grantees. No known Other Technical Standards were identified on an agency-wide survey conducted during the year.

5. Please enter the Voluntary Consensus Standards Bodies (VCSB) in which your agency participated in during FY 2005: 4

\begin{tabular}{|c|c|}
\hline Voluntary Consensus Standards Body & Acronym \\
\hline American Society for Testing and Mater & ASTM \\
\hline Federal Geographic Data Committee & FGDC \\
\hline International Code Council & ICC \\
\hline National Fire Protection Association & NFPA \\
\hline
\end{tabular}


6. Please provide the total number of your agency's representatives who participated in voluntary consensus standards activities during FY 2005 and the total number of activities these agency representatives participated in: $\mathbf{4}$

7. Please provide any conformity assessment activities (as described in "Guidance on Federal Conformity Assessment Activities" found in the Federal Register, Volume 65, Number 155, dated August 10, 2000) in which your agency was involved in FY 2005.

All of HUD's 25 conformity assessment (CA) programs, under the HUD BuildingProducts Standards \& Certification Programs, are in compliance with the ISO guidelines \& procedures. These are the same standards used by ANSI and other nationally recognized third-party certification agencies.

8. Please provide an evaluation of the effectiveness of Circular A-119 policy and recommendations for any changes:

This policy continues to be effective in replacing Federal Standards with publicly developed standards. This has resulted in more up-to-date and technically accurate standards. Circular A-119 might use stronger language to encourage agencies to be more active in determining which standards are applicable to the agency activities and when standards are identified, motivate the agency to be more assertive in enforcing their use.

9. Please provide any other comments you would like to share on behalf of your agency.

N/A

10. Please use this box to provide any additional comments on how your agency currently reports its use of voluntary consensus standards:

$\mathrm{n} / \mathrm{a}$

10-1. Removed [This question has been deprecated for 2005]

10-2. Removed [This question has been deprecated for 2005]

10-3. Removed [This question has been deprecated for 2005] 
10-4. Does your agency report standards that it uses for guidance purposes (as opposed compliance purposes)? (a) Yes; (b) No; (c) Not applicable; No

10-5. Does your agency report use of standards from non-ANSI accredited standards developers, industry consortia groups, or both? (a) non-ANSI Accredited; (b) Consortia; (c) Both; (d) Neither; or (e) Not applicable; C

10-5. Does your agency have a schedule for periodically reviewing its use of standards for purposes of updating such use? (a) Yes; (b) No; No

10-5. How often does your agency review its standards for purposes of updating such use? [enter the number of years]: 0 


\section{Department of the Interior}

1. Please describe the importance of standards in the achievement of your agency's mission, how your agency uses standards to deliver its primary services in support of its mission, and provide any examples or case studies of standards success:

DOI consists of 8 bureaus. The following is a response from Fish and Wildlife Service (FWS):

The FWS is using data standards to increase the quality and compatibility of its data and to increase opportunities to share data with clients, cooperators, partners, and the general public. Standards are developed, reviewed, and adopted according to a formal process. This process is described in detail at http://www.fws.gov/stand/standards/process_www.html.

The FWS recognizes the importance of using technical standards, in general, and Voluntary Consensus Standards (VCS), in particular, to accomplish a variety of mission-related goals and objectives. The following are examples and outcomes:

* To date, over 50 data standards have been formally adopted for Service-wide use and implementation, and several other standards are in progress. A data steward is identified for each standard, and this person is responsible for maintaining both the content of the data standard and any applicable source data that is linked from the standard's web page. A complist of the FWS data standards is available at http://www.fws.gov/stand/.

* The FWS is the nation's leading wetlands conservation and restoration agency within the federal government. For the past decade, FWS national wetlands standards have been widely used within and outside of the government for wetlands classification, mapping and data reporting purposes (i.e., nonregulatory purposes).

* The FWS has adopted the Department of the Interior's Certification and Accreditation Guide, November 2004, which provides a standardized approach for the certification and accreditation (C\&A) of all Interior IT systems. The guide complies with OMB, NIST, and other applicable Federal and Departmental laws, policies, and regulations. 
* The FWS Analytical Control Facility (ACF), Division of Environmental Quality (DEQ), uses the ANSI Z87.1 Standard (product standard) for personal protective equipment. The ACF also uses the Hazardous Material Information System (HMIS) (industry standard) for proposed labeling of hazardous chemical being used in the laboratory. Use of these standards ensures the safety of employees who provide analytical support on wildlife refuge investigations in support of the FWS mission.

* The Coastal Barrier Resources Act program utilizes data standards in its execution of the Digital Mapping Pilot Project as directed by the Coastal Barrier Resources Reauthorization Act of 2000 (P.L. 106-514 Sec. 6(b)(4)). This pilot project supports the Service's mission goal of resource protection through the strategy of improving the information base, information management, and technical assistance.

* The FWS Endangered Species Program primarily uses Government Standards as published in ITIS (Integrated Taxonomix Information System) to maintain consistent nomenclature when referring to listed or candidate species, and published by the Convention on International Trade in Endangered Species of Wild Fauna and Flora (CITES) standard when referring to foreign species protected under the CITIES international agreement between Governments. It is extremely important that FWS adheres to these nomenclature standards to ensure consistency in reporting activities related to T\&E species and to ensure there is no confusion on the part of the public sector and other Federal government entities.

FWS Outcomes:

* The implementation and use of adopted FWS data standards has resulted in less duplication of effort and a significant improvement in the ability to share and exchange data among FWS systems and with other DOI bureaus, in particular the U.S. Geological Survey (USGS).

* The Department of the Interior developed the C\&A Guide in response to the E-Government Act (Public Law 107-347), Title III, Federal Information Security Management Act (FISMA), which emphasizes the need to organizations to develop, documents, and implement organization-wide programs to provide 
information security for the information systems that support operations and assets. The FWS has officially adopted this policy and is working to incorporate its requirements in all IT systems.

* Standards implementation promotes uniform acquisition and production of nationally consistent wetlands data, resulting in significant cost/time savings; improved collaboration and cooperation with the public and/or private sectors; helps avoid duplication of private sector activities; promotes innovation and application of better technology; and increased goodwill for the Federal government.

* Use of both the ANSI Z87.1 and HMIS standards results in improved safety and less lost time/cost due to fewer injuries in the laboratory.

The following is a response from DOl's Bureau of Land Management (BLM)

* The BLM's mission statement is to "sustain the health, diversity, and productivity of the public lands for the use and enjoyment of present and future generations". To that end, the BLM maintains relationships with the stakeholders and neighbors of the public lands and uses standards to provide common understanding and meaning behind its land management decisions. The BLM has developed and populated a Corporate Metadata Repository for bureau-wide information systems that maintains the definitions and metadata for the data elements and themes used by the BLM. This allows for greater collaboration internally with the various resources programs and externally, with the interest groups and citizen advisory panels to allow for greater cooperation. The BLM recently designated an oversight committee composed chiefly of data stewards and managers to ensure that the CMR meets the business requirements of the BLM.

Response from DOl's Bureau of Reclamation (BOR): Industry standards are incorporated into Regional Construction Specifications when possible. General Contractor's are more familiar with industry standards and therefore, usage should result in more economic bid packages.

Standards are used in the management of construction contracts. Most 
construction specifications reference one or more set of standards, and Construction Services personnel must be familiar with the standards in order to ensure contract compliance. Contractors are more familiar with voluntary consensus standards and their use allows improved collaboration and cooperation with the private sector as well as the successful completion of construction contracts resulting in properly functioning facilities.

The regulatory and consensus industry standards are critical to establishing the scientific basis for the engineering controls, administrative controls, exposure assessments, medical surveillance and personal protective equipment necessary to protect personnel, contractors and the public from safety and health hazards in Reclamation.

The use of standards is the basal requirement for the accurate communication of technical concepts. The use of standards is vital to ensure the results of facility inspections; the descriptions of potential concerns; both the development and results of investigation; the entire evaluation and design process; the creation of understandable contract specification; and the assurance of contract quality and control. Without the use of a well thought out standards system all technical language would be open to interpretation and the likely of ensuring a facility's continued safe and productive function would be compromised.

The geotechnical community has a vast array of nomenclature; sampling and testing methodology, sampling and testing procedures; and reporting and documentation alternatives from which to choose. Reclamation has selected specific sources, in some cases creating these sources, to ensure a thorough understanding of Reclamation data. This has allowed Reclamation personnel to communicate and work effective with other Reclamation staff and representatives from other governmental agencies and the public with maximum efficiency and minimal misunderstanding.

Reclamation relies on consensus standards for geospatial activities related to metadata for data documentation, maintenance, and data transfer; and also data acquisition and development. Voluntary Consensus Standards (VCS) through ISO, the Federal Geographic Data Committee (FGDC), ASTM, as well as 
state and local agencies have reduced the cost of geospatial data acquisition and development. Costs to coordinate efforts have risen in respect to the increased activity, but are expected to drop as standards are adopted by all agencies over the next 5 years.

Response from DOI's Minerals Management Service (MMS):

The Minerals Management Service's mission is to manage the minerals resources on the Outer Continental Shelf and Federal and Indian minerals revenues to enhance public and trust benefits, promote responsible use, and realize fair value. In support of this mission, we have adopted the use of voluntary consensus standards to promote improved collaboration and cooperation with the private sector and industries we regulate and apply innovative and improved technology.

In addition, the BLM participates in federal standards bodies, including the Federal Geographic Data Committee (FGDC). While the membership is from federal agencies, the standards that are developed are often elevated to the American National Standards Institute (ANSI) and to the International Standards Organization (ISO) and will, therefore, receive wider review. BLM's participation in the North American Weeds Management Association, which includes representatives from Canada and Mexico, as well as State and local representatives. The result has been the development of standards that can be used in both a commercial sense (e.g., cropland management) as well as providing an integrated approach to weed control.

Response from DOI's U.S. Geological Survey (USGS):

The nature of USGS scientific research and monitoring makes the use of voluntary consensus standards a required tool. Our science programs collaborate with partners and cooperators in the public and private sectors locally, nationally, and internationally. Thus, agreement on the use of standards is essential to our mission.

The USGS National Geospatial Programs Office (NGPO) hosts the Federal Geographic Data Committee (FGDC) Secretariat. OMB Circular A-16 establishes the FGDC as the interagency coordinating body for developing the National Spatial Data Infrastructure (NSDI) as the "technology, policies, standards, 
human resources, and related activities necessary to acquire process, distribute, use, maintain, and preserve spatial data."

The NSDI Clearinghouse Network is an online community of distributed data providers who publish metadata that describe their geospatial data. Users may search metadata records published on the NSDI Clearinghouse Network to find geospatial data and evaluate the fitness for use. If a user finds already existing geospatial data that meets their needs through the NSDI Clearinghouse Network, they do not have to create their own data, which results in time and costs savings. The NSDI Clearinghouse Network uses the search and retrieval protocol in ANSI Z39.50-1995 (ISO 23950).

Metadata records published on the NSDI Clearinghouse Network are prepared following the FGDC Digital Content Standard for Geospatial Metadata ("FGDC CSDGM). FGDC CSDGM was developed when there were no equivalent voluntary consensus content standards for geospatial metadata and is the foundation for many other countries' geospatial metadata standards. ISO 19115, Geographic information -- Metada, adopted by the American National Standards Institute, mirrors much of the content found in the FGDC CSDGM. FGDC also contributes greatly to the US implementation of ISO 19115 and ISO 19139 metadata XML Schema and coordinating development of a North American profile with the Canadian Standards Board. FGDC has also supported development of a standalone crosswalk application to convert FGDC CSDGM to ISO 19139 Metadata Schema. The benefit of the crosswalk is that it will maintain the value of existing metadata assets.

DOI Bureau of Reclamation (BOR) response: Industry standards are incorporated into Regional Construction Specifications when possible. General Contractor's are more familiar with industry standards and therefore, usage should result in more economic bid packages.

Standards are used in the management of construction contracts. Most construction specifications reference one or more set of standards, and Construction Services personnel must be familiar with the standards in order to ensure contract compliance. Contractors are more familiar with voluntary consensus standards and their use allows improved collaboration and 
cooperation with the private sector as well as the successful completion of construction contracts resulting in properly functioning facilities.

The regulatory and consensus industry standards are critical to establishing the scientific basis for the engineering controls, administrative controls, exposure assessments, medical surveillance and personal protective equipment necessary to protect personnel, contractors and the public from safety and health hazards in Reclamation.

The use of standards is the basal requirement for the accurate communication of technical concepts. The use of standards is vital to ensure the results of facility inspections; the descriptions of potential concerns; both the development and results of investigation; the entire evaluation and design process; the creation of understandable contract specification; and the assurance of contract quality and control. Without the use of a well thought out standards system all technical language would be open to interpretation and the likely of ensuring a facility's continued safe and productive function would be compromised.

The geotechnical community has a vast array of nomenclature; sampling and testing methodology, sampling and testing procedures; and reporting and documentation alternatives from which to choose. Reclamation has selected specific sources, in some cases creating these sources, to ensure a thorough understanding of Reclamation data. This has allowed Reclamation personnel to communicate and work effective with other Reclamation staff and representatives from other governmental agencies and the public with maximum efficiency and minimal misunderstanding.

Reclamation relies on consensus standards for geospatial activities related to metadata for data documentation, maintenance, and data transfer; and also data acquisition and development. Voluntary Consensus Standards (VCS) through ISO, the Federal Geographic Data Committee (FGDC), ASTM, as well as state and local agencies have reduced the cost of geospatial data acquisition and development. Costs to coordinate efforts have risen in respect to the increased activity, but are expected to drop as standards are adopted by all agencies over the next 5 years. 
DOI Minerals Management Service (MMS) response: The MMS's mission is to manage the minerals resources on the Outer Continental Shelf and Federal and Indian minerals revenues to enhance public and trust benefits, promote responsible use, and realize fair value. In support of this mission, we have adopted the use of voluntary consensus standards to promote improved collaboration and cooperation with the private sector and industries we regulate and apply innovative and improved technology.

2. Please list the government-unique standards your agency used in lieu of voluntary consensus standards during FY 2005: 1

1. Government Unique Standard: 1. FWS Geospatial Metadata Standard (adopts the Content Standard for Digital Geospatial Metadata (CSDGM), Version 2.0 FGDC-STD-001-1998. 2. Nomenclature of Endangered and Threatened Wildlife and Plants (FWS Data Set Standard, Working Draft); proposed standard to adopt the Service's official list of scientific names, common names, and taxonomic group names for all species of wildlife and plants t (Incorporated: 2005)

Voluntary Standard

1. International Organization for Standardization (ISO, ISO 19115:2003, Published Standard on Geographic Information - Metadata

2. Convention on International Trade in Endangered Species (CITES)of Wild Fauna and Flora, Checklist of CITES Species; provides the official alphabetical list of CITES species, their scientific synonyms, their common names in English, French, and Spanish, etc.

3.

Rationale

1. The Federal Geographic Committee (FGDC) developed the Content Standard for Digital Geospatial Metada (CSDGM) in response to Executive Order 12906, which require3d all Federal agencies to document spatial data in a consistent manner to facilitate sharing data and to reduce duplication of 
effort. The FWS officially adopted the FGDC CSDGM, Version 2.0, in August 1998. ISO 19115, an abstract standard, specified general content for the metadata, but does not specify format for the metadata. The FGDC is working to harmonize the ISO 19115 metadata standard with the CSDGM Version 2.0.

2. Different Service programs maintain species lists in compliance with several conservation laws and treaties, including the Endangered Species Act, Migratory Bird Treaty Act, Lacey Act, and Convention on International Trade in Endangered Species (CITES). In other words, there is no single species list that meets the needs of all Service programs. The list of scientific and common names for this data set is published in the Code of Federal Regulations (CFR), Title 50--Wildlife and Fisheries, Part 17-Endangered and Threatened Wildlife and Plants. These values, along with the associated species and population codes, are contained in the Service's official Threatened and Endangered Species System (TESS) database.

3. Service personnel must comply with the adopted FWS data standard unless it conflicts with their primary responsibilities. for example, the FWS International Affairs Program is responsible for implementing CITE, a treaty with 153 member countries. In this capacity, the FWS is bound by resolution to use the ISO country codes in its permit numbers rather than the FIPS codes to ensure consistency in reporting.

3. Please list the Voluntary Consensus Standards (VCS) your agency substituted for Government Unique Standards (GUS) in FY 2005 as a result of review under Section 15(b)(7) of OMB Circular A-119: 2

\section{Voluntary Standard}

CITES of Wild Fauna and Flora Nomenclature

\section{Government Standard}

FWS Data Set Standard:

Nomenclature of

Endangered and Threatened

Wildlife and Plants (working draft)

ISO 3166-1:1977, Codes for the Representation of
FWS Data Element 
Names of Countries and their Subdivisions - Part I: Standard: Geopolitical Country Codes Entity Name and Code (adopts FIPS PUB 10-4)

4. Please provide the total number of Voluntary Consensus Standards your agency used during FY 2005: Optional: If possible, also please provide the total number of Nonconsensus Standards that are developed in the private sector your agency used during FY 2005. In addition, please provide your agency's rationale for using the Nonconsensus Standards that are developed in the private sector counted in this question.

Voluntary Consensus Standards: 768

Other Technical Standards: 65

Rationale: No suitable Voluntary Consensus Standard was available for use at the time these standards were adopted.

5. Please enter the Voluntary Consensus Standards Bodies (VCSB) in which your agency participated in during FY 2005: 26

\begin{tabular}{ll} 
Voluntary Consensus Standards Body & Acronym \\
\hline Advisory Committee for water Information & ACWI \\
American Concrete Institute & ACI \\
American Institute of Steel Construction & AISC \\
American National Standards Institute & ANSI \\
American Petroleum Institute & API \\
American Society for Photogrammetry and Remote & ASPRS \\
Sensing & \\
American Society for Testing and Materials & ASTM \\
American Society of Civil Engineers & ASCE \\
American Society of Mechanical Engineers & ASME \\
American Water Works Association & AWWA \\
American Welding Society & AWS \\
Convention on International Trade in Endangered & CITES
\end{tabular}




$\begin{array}{ll}\begin{array}{l}\text { Species of Wild Fauna and Flora (CITES) } \\ \text { Cultural Resources Standards with State Historic }\end{array} & \text { SHPO } \\ \text { Preservation Offices } & \\ \text { Federal Geographic Data Committee } & \text { FGDC } \\ \text { Ground Water Protection Council } & \text { GWPC } \\ \text { Institute of Electrical and Electronic Engineers } & \text { IEEE } \\ \text { International Air Transport Association (IATA) } & \text { IATA } \\ \text { International Organization for Standardization } & \text { ISO } \\ \text { National Association of Corrosion Engineers } & \text { NACE } \\ \text { National Environmental Methods Index } & \text { NEMI } \\ \text { National Water-Quality Monitoring Council } & \text { NWQMC } \\ \text { North American Weeds Management Association } & \text { NAWMA } \\ \text { Open Geospatial Consortium } & \text { OGC } \\ \text { Petrotechnical Open Standards Consortium, Inc. } & \text { POSC } \\ \text { The National Digital Orthophoto Program } & \text { NDOP } \\ \text { Urban and Regional Information Systems Association } & \text { URISA }\end{array}$

6. Please provide the total number of your agency's representatives who participated in voluntary consensus standards activities during FY 2005 and the total number of activities these agency representatives participated in: $\mathbf{7 4}$

7. Please provide any conformity assessment activities (as described in "Guidance on Federal Conformity Assessment Activities" found in the Federal Register, Volume 65, Number 155, dated August 10, 2000) in which your agency was involved in FY 2005.

DOI - Fish and Wildlife Service (FWS) Activities:

1. FWS Information Technology Bulletin (ITB) 2005-001, Adoption of the Department of the Interior Certification Accreditation Guide, Version 1.1, July 10, 2003: The Department's OCIO issued the Department of the Interior Certification and Accreditation (C\&A) Guide to provide a standardized approach for the C\&A of all Interior IT systems. The guide complies with OMB, NIST and other applicable Federal and Departmental laws, policies and regulations. The FWS officially adopted this policy in FY 2005 (November 2004) and is working to incorporate its requirements in all IT systems. Utilizing the $\mathrm{C}^{\wedge} \mathrm{A}$ methodology 
defined in this guide will result in a standardized IT security C\&A program across Interior.

2. FWS representatives actively participate in the FGDC Coordination Group, associated National Spatial Data Infrastructure (NSDI) activities, and the Geospatial One-Stop (GOS) initiative. A subgroup of the FGDC Standards Work group is working on a process to develop/approve VCS that are consistent with OMB Circular A-119. One major objective of GOS is to develop geospatial standards and web services for multiple mapping applications by identifying common data requirements and structured use of VCS.

DOI- Bureau of Land Management (BLM) Activities:

1. Interagency trails Data Standards:

The BLM is one of three major national land management agencies that have established data standards for trails information. The membership in this standards working group included the National Park Service (NPS), the BLM, the US Forest Service (USFS), and representatives from trails organizations. Over 150 participants have furnished comments on the Trails standards and the final standards will be used in the Recreation.gov effort, of the Presidential EGovernment initiatives.

\section{National Digital Elevation Program (NDEP)}

The NDEP was established to promote the exchange of accurate digital land elevation data among government, private, and nonprofit sectors and the academic community and to establish standards and guidance that will benefit all users. The NDEP is composed of agencies from the Department of the Interior, Commerce, and Agriculture, as well as the National Imagery and Mapping Agency, National Aeronautics and Space Administration, US Army Corp of Engineers, and the Federal emergency Management Agency, and representation from state governments through the National States Geographic Information Council.

\section{Pacific Northwest Regional Geospatial Information Council (PNW-RGIC)}

The BLM participates in voluntary standards that are developed by PNW-RGIC, which includes the BLM, the US Forest Service, and state natural resource partners, particularly in the area of hydrology, fisheries, and related 
categories. The standards are adopted by the land management agencies for cooperative forest management.

DOI Bureau of Reclamation (BOR) Activities:

Geospatial data acquired by or provided by BOR's mid pacific region is reviewed for compliance with relevant FGDC and ISO standards for metadata. Data developed by the Region for land cover analysis is done in coordination with other Federal and State agencies to ensure compliance with FGDC standards on vegetation and land cover. The MP region continues to work toward integrating standards into the daily business efforts. many of the developed geospatial databases preceded the current standards.

DOI MMS: Is a member of the FGDC with representation on the Standards working Group and subcommittees developing standards for geospatial data.

8. Please provide an evaluation of the effectiveness of Circular A-119 policy and recommendations for any changes:

DOI BLM - It is difficult to apply policy retroactively and it is not clear what policy implementation documents have been released from NIST or from OMB directing agencies to conform to the NTTAA. It might be useful to solicit comments during the year on proposals for strengthening the NTTAA and suggestions for what types of cooperative activities might be appropriate so that the agencies can get involved in cooperative efforts to develop consensus standards as well as their adoption.

DOI USGS: Since its issuance, Circular A-119 has worked in a straightforward manner to encourage the use of voluntary consensus standards. we have no recommendations for changes to the Circular.

DOI MMS: As a direct result of OMB Circular A-119, MMS continues to increase our presence in voluntary standards groups -- both domestic and international. we believe that A-119 continues to work in a straightforward manner to encourage the use of voluntary consensus standards. The MMS has not requested any exemptions, nor are we contemplating making such a request. We have no recommendations for changes to the Circular. 
9. Please provide any other comments you would like to share on behalf of your agency.

Comments from DOI - Fish and Wildlife Service (FWS):

To improve the quality of responses, future request for annual reports should include the following:

1. Clear guidance on what type of technical standards should be reported. For example:

(a) Question 1 - respondents are asked to describe the importance and use of "standards" in general, while the Help Text asks for examples and beneficial outcomes of VCS in particular. It is not clear if respondents should report success stories on the use of all technical standards - or only those that pertain to the use of VCS.

(b) Question 3 - respondents are asked to list the VCS substituted for GUS, but it is not clear where respondents list NEW VCS that do not meet this criterion. (c) Question 4 asks for the total NUMBER of VCS AND Other Technical Standards -- document titles are not requested. Without titles, respondents can not identify or track the "new or discontinued uses" that occurred during the previous reporting year.

2. The NIST and/or OMB should identify high priority VCS for implementation by Federal agencies, especially standards that pertain to E-Gov initiative and IT security requirements.

3. Definitions and good examples of VCS and GUS, as well as a list of bona fide organizations (standards bodies) that develop both types of standards. Previous reports identify Federal organizations as VCS bodies (e.g., FGDC and NIST).

4. The URL for NIST Standards.gov web site (http://standards.gov/) should be provided to all agencies/bureaus for links to the Act, OMB Circular A-119, standards web sites, and NTTAA reports to OMB for previous years.

5. A digital version o the NTTAA questions in a format that is usable to respondents for distribution and data entry proposed (i.e., a form in Word or PDB that can be used for data entry). 
6. Agency bureaus (e.g., DOI's FWS, USGS, etc) should be given access to the NIST Agency Reporting Tool for the purpose of entering their own information. The current procedure is both cumbersome and inefficient and puts the burden of reporting on one person.

7. Better guidance and quality control (on information received) is needed to obtain accurate data from all Federal agencies.

Reply from the DOI BLM:

1. The current report is difficult to categorize in terms of efforts of federal agencies to engage in cooperative efforts with non-governmental organizations in order to develop standards. This seems to be a very worthwhile endeavor but does not seem to be emphasized in any of the OMB Circular A-119 reporting.

DOI USGS: USGS would be interested in a NIST -- sponsored online forum to discuss the interpretation of NTTAA and OMB Circular A-119.

DOI BOR: Reclamation needs to continue to resurrect portions of the Design Standards that were sunset during the previous administration.

The use of voluntary consensus standards is extremely important in accomplishment of Reclamation's activities which are supported by construction contracts. The standards are accessible and generally familiar to contractors.

Reclamation is in the process of developing an enterprise approach with other bureaus in the Department of Interior (DOI) through the DOI Enterprise Geographic Information Management (EGIM) team. These efforts extend to geospatial data and services. Utilization of the Technical Resources Model (TRM), associated Enterprise License Agreements (ELA), Services Reference Model (SRM), Data Reference Model (DRM), and integration of the Geospatial Blue Print the support for implementing standards is becoming more effective within the MP Region. These positively impact not only hardware and software acquisition, but are impacting geospatial data development. Standardization in data structures and services implemented and used in geospatial data development have the potential to reduce redundancy, loss of data, 
inappropriate and appropriate use of geospatial data and services. The standardization process can be augmented and improved upon through the assistance and greater involvement by voluntary standard organizations. These organizations have an established framework for review of proposed standards with formal procedures for evaluation and review of existing standards. Greater participation with these organizations by both Reclamation and DOI staff should provide rapid development of appropriate standards for geospatial data structures and services. Having OPM request this level of participation from the DOI Bureaus will help support the participation, integration and utilization of standards that have the potential to save the federal government time, effort, and funding in all Bureaus.

10. Please use this box to provide any additional comments on how your agency currently reports its use of voluntary consensus standards:

Annual review of VCS; at least quarterly (4 times per year) for FWS standards, including all VCS and Government Unique Standards associated with adopted FWS standards.

The BLM requested a review by the data stewards as to the data standards that are published in the metadata repository. The BLM also reviews new IT projects to determine what new data standards might be proposed and will direct the proponents to any existing standards to ensure that no duplication or redundant standards are allowed.

10-1. Removed [This question has been deprecated for 2005]

10-2. Removed [This question has been deprecated for 2005]

\section{0-3. Removed [This question has been deprecated for 2005]}

10-4. Does your agency report standards that it uses for guidance purposes (as opposed compliance purposes)? (a) Yes; (b) No; (c) Not applicable; Yes

10-5. Does your agency report use of standards from non-ANSI accredited standards developers, industry consortia groups, or both? (a) non-ANSI Accredited; (b) Consortia; (c) Both; (d) Neither; or (e) Not applicable; C 
10-6. Does your agency have a schedule for periodically reviewing its use of standards for purposes of updating such use? (a) Yes; (b) No; Yes

10-7. How often does your agency review its standards for purposes of updating such use? [enter the number of years]: 5 


\section{Department of Justice}

1. Please describe the importance of standards in the achievement of your agency's mission, how your agency uses standards to deliver its primary services in support of its mission, and provide any examples or case studies of standards success:

The Department, in its primary mission roles, does not specify products requiring voluntary consensus standards. Because of the nature of the Departments missions, DOJ participates in the development of government standards for law enforcement information representation. The Department developed the National Information Exchange Model (NIEM) as a critical standard to facilitate the Law Enforcement Information Sharing Program. NIEM serves as a government standard for information that lacks voluntary consensus standards.

2. Please list the government-unique standards your agency used in lieu of voluntary consensus standards during FY 2005: 0

3. Please list the Voluntary Consensus Standards (VCS) your agency substituted for Government Unique Standards (GUS) in FY 2005 as a result of review under Section 15(b)(7) of OMB Circular A-119: 0

4. Please provide the total number of Voluntary Consensus Standards your agency used during FY 2005: Optional: If possible, also please provide the total number of Nonconsensus Standards that are developed in the private sector your agency used during FY 2005. In addition, please provide your agency's rationale for using the Nonconsensus Standards that are developed in the private sector counted in this question.

Voluntary Consensus Standards: 0

Other Technical Standards: 0

Rationale:

5. Please enter the Voluntary Consensus Standards Bodies (VCSB) in which your agency participated in during FY 2005: 0 
6. Please provide the total number of your agency's representatives who participated in voluntary consensus standards activities during FY 2005 and the total number of activities these agency representatives participated in: 1

7. Please provide any conformity assessment activities (as described in "Guidance on Federal Conformity Assessment Activities" found in the Federal Register, Volume 65, Number 155, dated August 10, 2000) in which your agency was involved in FY 2005.

$\mathrm{n} / \mathrm{a}$

8. Please provide an evaluation of the effectiveness of Circular A-119 policy and recommendations for any changes:

The Department of Justice offers no recommended changes to Circular A-119.

9. Please provide any other comments you would like to share on behalf of your agency.

none

10. Please use this box to provide any additional comments on how your agency currently reports its use of voluntary consensus standards:

10-1. Removed [This question has been deprecated for 2005]

10-2. Removed [This question has been deprecated for 2005]

\section{0-3. Removed [This question has been deprecated for 2005]}

10-4. Does your agency report standards that it uses for guidance purposes (as opposed compliance purposes)? (a) Yes; (b) No; (c) Not applicable; C

10-5. Does your agency report use of standards from non-ANSI accredited standards developers, industry consortia groups, or both? (a) non-ANSI Accredited; (b) Consortia; (c) Both; (d) Neither; or (e) Not applicable; D

10-6. Does your agency have a schedule for periodically reviewing its use of standards for purposes of updating such use? (a) Yes; (b) No; No 
10-7. How often does your agency review its standards for purposes of updating such use? [enter the number of years]: 0 


\section{Department of Labor}

1. Please describe the importance of standards in the achievement of your agency's mission, how your agency uses standards to deliver its primary services in support of its mission, and provide any examples or case studies of standards success:

The DOL develops and promulgates safety and health standards which are the minimum requirements for the protection of workers in the United States. DOL consults, and routinely relies on Voluntary Consensus Standards (VCS) whenever a Federal standard is written or updated. Since the VCS are on a shorter review cycle than Federal standards, the VCS provide a more current view of industry standards and practices than the Agency can efficiently or economically achieve.

Furthermore, safety compliance officers use VCS during inspections and investigation when there are no Federal standards that apply to a certain circumstance.

2. Please list the government-unique standards your agency used in lieu of voluntary consensus standards during FY 2005: 5

1. Government Unique Standard: Electric Motor-Drive Equipment Rule (Incorporated: 2001)

Voluntary Standard

IEEE Standard 242-1986 Recommended Practice for Protection and Coordination of Industrial and Commercial Power Systems (IEEE Buff Book) and NFPA 70 - national Electric Code

Rationale

The MSHA rule is a design-specific standards. The NFPA and IEEE standards were used as a source for the rule; however, the exact requirements of the rule were tailored to apply specifically to electric circuits and equipment used in the coal mining industry. 
2. Government Unique Standard: Exit Routes, Emergency Action Plans, and Fire Prevention Plans, 29 CFR 1910, Subpart E (Incorporated: 2003)

Voluntary Standard

Life Safety Code, NFPA 101-2000

Rationale

The OSHA standard addresses only workplace conditions whereas the NFPA Life Safety Code goes beyond workplaces. However, in the final rule OSHA stated that it had evaluated the NFPA Standard 101, Life Safety Code, (NFPA 101-2000) and concluded that it provided comparable safety to the Exit Route Standards. Therefore, the Agency stated that any employer who complied with the NFPA 101-2000 instead of the OSHA Standard for Exit Routes would be in compliance.

3. Government Unique Standard: Fire Protection for Shipyards, 29 CFR Part 1915, Subpart P (Incorporated: 2004)

Voluntary Standard

NFPA 312-2000 Standard for Protection of Vessels During Construction, Repair, and Lay-Up

NFPA 33-2003 Standard for Spray Application Using Flammable or Combustible Materials

Rationale

Many consensus standards were relied on for various provisions in OSHA's final rule, including 15 consensus standards that are incorporated by reference. However, OSHA and its negotiated rulemaking committee determined that there was no, one consensus standard available that covered all the topics in the rule.

4. Government Unique Standard: Sanitary Toilets in Coal Mines, 30 CFR 71, Subpart E (Incorporated: 2003) 
Voluntary Standard

Non-Sewered Waste Disposal Systems--Minimum Requirements, ANSI Z4.31987

Rationale

The ANSI standard was not incorporated by reference because certain design criteria allowed in the ANSI standard, if implemented in an underground coal mine, could present health or safety hazards. For instance, combustion or incinerating toilets could introduce an ignition source which would create a fire hazard. For certain other design criteria found in the ANSI standard, sewage could seep into the groundwater, or overflow caused by rain or runoff could contaminate portions of the mine.

5. Government Unique Standard: Steel Erection Standards (Incorporated: 2002)

Voluntary Standard

ANSI A10.13 - Steel Erection; ASME/ANSI B30 Series Cranes Standards Rationale

Many consensus standards were relied upon for various provisions in the final rule, but there was no one consensus standard available that covered all of the topics covered by OSHA's final rule.

3. Please list the Voluntary Consensus Standards (VCS) your agency substituted for Government Unique Standards (GUS) in FY 2005 as a result of review under Section 15(b)(7) of OMB Circular A-119: 0

4. Please provide the total number of Voluntary Consensus Standards your agency used during FY 2005: Optional: If possible, also please provide the total number of Nonconsensus Standards that are developed in the private sector your agency used during FY 2005. In addition, please provide your agency's rationale for using the Nonconsensus Standards that are developed in the private sector counted in this question.

Voluntary Consensus Standards: 1

Other Technical Standards: 0 
Rationale: MSHA published one final rule that used VCS. Rule: 30CFR part 57 Diesel Particulate Exposure of Underground Metal and Nonmetal Miners. VCS: ANSI Z-88.2-1969 American National Standards Practices for Respiratory Protection, 1969.

5. Please enter the Voluntary Consensus Standards Bodies (VCSB) in which your agency participated in during FY 2005: 16

\begin{tabular}{ll} 
Voluntary Consensus Standards Body & Acronym \\
\cline { 2 - 2 } Acoustical Society of America & ASA \\
American Industrial Hygiene Association & AIHA \\
American Ladder Institute & ALI \\
American National Standards Institute & ANSI \\
American Society of Mechanical Engineers & ASME \\
American Society of Safety Engineers & ASSE \\
American Society of Testing and Materials & ASTM \\
American Welding Society & AWS \\
Association for Machine Technology & AMT \\
Institute of Electrical and Electronic Engineers IEEE \\
International Electrotechnical Commission & IEC \\
International Organization for Standardization & ISO \\
National Fire Protection Association & NFPA \\
National Safety Council & NSC \\
Society of Automotive Engineers & SAE \\
Underwriters Laboratories & UL
\end{tabular}

6. Please provide the total number of your agency's representatives who participated in voluntary consensus standards activities during FY 2005 and the total number of activities these agency representatives participated in: $\mathbf{5 2}$

7. Please provide any conformity assessment activities (as described in "Guidance on Federal Conformity Assessment Activities" found in the Federal Register, Volume 65, Number 155, dated August 10, 2000) in which your agency was involved in FY 2005. 
No comment at this time.

8. Please provide an evaluation of the effectiveness of Circular A-119 policy and recommendations for any changes:

No comment at this time.

9. Please provide any other comments you would like to share on behalf of your agency.

No comment at this time.

10. Please use this box to provide any additional comments on how your agency currently reports its use of voluntary consensus standards:

10-1. Removed [This question has been deprecated for 2005]

10-2. Removed [This question has been deprecated for 2005]

10-3. Removed [This question has been deprecated for 2005]

10-4. Does your agency report standards that it uses for guidance purposes (as opposed compliance purposes)? (a) Yes; (b) No; (c) Not applicable; No

10-5. Does your agency report use of standards from non-ANSI accredited standards developers, industry consortia groups, or both? (a) non-ANSI Accredited; (b) Consortia; (c) Both; (d) Neither; or (e) Not applicable; D

10-6. Does your agency have a schedule for periodically reviewing its use of standards for purposes of updating such use? (a) Yes; (b) No; No

10-7. How often does your agency review its standards for purposes of updating such use? [enter the number of years]: 0 


\section{Department of State}

1. Please describe the importance of standards in the achievement of your agency's mission, how your agency uses standards to deliver its primary services in support of its mission, and provide any examples or case studies of standards success:

The Department of State represents the U.S. at the International Telecommunication Union (ITU) where international telecommunication standards are agreed. This role is performed by the Bureau of Economic \& Business Affairs, International Communications \& Information Policy. The Department of State coordinates this work internally in the Government with other Agencies such as the FCC, Dept of Commerce/NTIA, and Dept of Homeland Security/NCS, and externally with US industry through the International Telecommunication Advisory Committee, a Federal Advisory Committee.

2. Please list the government-unique standards your agency used in lieu of voluntary consensus standards during FY 2005: 0

3. Please list the Voluntary Consensus Standards (VCS) your agency substituted for Government Unique Standards (GUS) in FY 2005 as a result of review under Section 15(b)(7) of OMB Circular A-119: 0

4. Please provide the total number of Voluntary Consensus Standards your agency used during FY 2005: Optional: If possible, also please provide the total number of Nonconsensus Standards that are developed in the private sector your agency used during FY 2005. In addition, please provide your agency's rationale for using the Nonconsensus Standards that are developed in the private sector counted in this question.

Voluntary Consensus Standards: 0

Other Technical Standards: 0

Rationale:

5. Please enter the Voluntary Consensus Standards Bodies (VCSB) in which your agency participated in during FY 2005: 1 


\section{Voluntary Consensus Standards Body Acronym}

International Telecommunication Union ITU

6. Please provide the total number of your agency's representatives who participated in voluntary consensus standards activities during FY 2005 and the total number of activities these agency representatives participated in: $\mathbf{8}$

7. Please provide any conformity assessment activities (as described in "Guidance on Federal Conformity Assessment Activities" found in the Federal Register, Volume 65, Number 155, dated August 10, 2000) in which your agency was involved in FY 2005.

We do not get involved with conformity testing directly. There have been cases in which the delegations we lead to ITU have addressed conformity testing.

8. Please provide an evaluation of the effectiveness of Circular A-119 policy and recommendations for any changes:

No comment.

9. Please provide any other comments you would like to share on behalf of your agency.

No comment.

10. Please use this box to provide any additional comments on how your agency currently reports its use of voluntary consensus standards:

We are reporting only our involvement in the international telecommunications standards development process not the procurement practices of the Department. The number 5 above is only a place holder.

10-1. Removed [This question has been deprecated for 2005]

10-2. Removed [This question has been deprecated for 2005]

10-3. Removed [This question has been deprecated for 2005] 
10-4. Does your agency report standards that it uses for guidance purposes (as opposed compliance purposes)? (a) Yes; (b) No; (c) Not applicable; C

10-5. Does your agency report use of standards from non-ANSI accredited standards developers, industry consortia groups, or both? (a) non-ANSI Accredited; (b) Consortia; (c) Both; (d) Neither; or (e) Not applicable; E

10-6. Does your agency have a schedule for periodically reviewing its use of standards for purposes of updating such use? (a) Yes; (b) No; No

10-7. How often does your agency review its standards for purposes of updating such use? [enter the number of years]: 5 


\section{Department of Transportation}

1. Please describe the importance of standards in the achievement of your agency's mission, how your agency uses standards to deliver its primary services in support of its mission, and provide any examples or case studies of standards success:

The U.S. Department of Transportation (DOT) and its operating administrations rely upon an active consensus rulemaking program to support the Department's primary mission, transportation safety. In addition, DOT relies upon a consensus process with various stakeholders to advance transportation technology and operational innovations, and to improve the state of transportation practice in all modes of transportation, in support of the Department's strategic objectives: safety, mobility, global connectivity, environmental stewardship, and security. Voluntary consensus standards, and the technical interchanges that occur during the process of developing and revising codes and standards, are a foundational element for meeting DOT's objectives.

Among several case studies of standards success in 2005, two stand out:

1) Federal Transit Administration (FTA): FTA works directly with the transit industry and with related Standards Development Organizations to develop voluntary consensus standards that increase safety of transit systems and provide capital and operating cost savings. The goal in developing voluntary consensus standards is to give transit agencies the information that they need to make wise decisions about what technology to use, what data to collect, and what information to provide to their customers.

The transit industry developed a business case that identified the benefits of using standards. Those identified benefits include: safety improvements, reduction of manufacturing costs, reduction of operating costs, advancement of trade policy by providing standards that can guide markets outside the United States, and significant return on investments. For new vehicle procurement alone, senior transit vehicle manufacturing executives estimated that procurement costs can be reduced as much as five percent by using standards. Assuming a constant rate of procurement investment over the next 
ten years, industry wide savings could amount to $\$ 2.64$ billion.

2) Federal Motor Carrier Safety Administration (FMCSA): FMCSA uses standards in its safety regulations concerning the operation of commercial motor vehicles. An example of FMCSA's use voluntary consensus standards is incorporation-by-reference (49 CFR Part 393, Subpart I) of private-sector manufacturing standards for cargo securing devices such as chain, wire rope, synthetic webbing, steel strapping, and cordage. FMCSA first adopted voluntary consensus standards for cargo securing devices in 1994 in response to a petition for rulemaking from the Commercial Vehicle Safety Alliance, an organization of Federal, State, and Provincial agencies in the United States, Canada and Mexico responsible for commercial motor vehicle safety. FMCSA subsequently updated its incorporations-by-reference in its 2002 final rule on cargo securing. The 2002 final rule is the result of a multi-year program to work with government agencies and the private sector to develop uniform cargo securing regulations throughout North America, including the uniform incorporation of voluntary consensus standards regarding cargo securing devices. The new cargo securing rules have generally been regarded by interested parties (the States and industry groups) as a significant enhancement of FMCSA's cargo securing standards.

2. Please list the government-unique standards your agency used in lieu of voluntary consensus standards during FY 2005: 3

1. Government Unique Standard: 63 FR 17976; April 13, 1998 - Product Safety Signs and Labels (Incorporated: 1998)

Voluntary Standard

ANSI Z535.4 - ANSI Requirements for Color Coded Header Messages for the Different Levels of Hazard

Rationale

NHTSA explained in the NPRM that the American National Standard Institute (ANSI) has a standard4 for product safety signs and labels (ANSI Z535.4) that identifies a hierarchy of hazard levels ranging from extremely serious to moderately serious and specifies corresponding hierarchies of signal words, 
i.e., "danger," "warning," and "caution," and of colors. For the header, the ANSI standard specifies a red background with white text for "danger," an orange background with black text for "warning," and a yellow background with black text for caution."

The ANSI standard specifies that pictograms should be black on white, with occasional uses of color for emphasis, and that message text should be black on white. The agency noted in the NPRM that when it earlier updated the requirements for air bag warning labels to require the addition of color and pictograms, it had chosen not to adopt the colors specified in the ANSI standard. NHTSA chose to use yellow instead of orange in the background of the heading for the air bag warning label, even though the word "warning" was used, because of overwhelming focus group preference for yellow. Only two of the 53 participants preferred orange. Participants generally stated that yellow was more eye-catching than orange. Participants also noted that red (stop) and yellow (caution) had meaning to them, but not orange.

NHTSA asked for comment on three color options for the revised utility vehicle rollover warning label. Proposed label 1 used the ANSI color format with the heading background in orange with the words in black. The remainder of the label had a white background with black text and drawings. Proposed label 2 used a color scheme like the air bag warning labels, which is the same as the ANSI color format except that the background color for the heading in the label is yellow. Proposed label 3 employed the color scheme used in the focus groups - the heading area had a red background with white text. The graphic areas had a yellow background with black and white drawings. The text area had a black background with yellow text.

Despite focus group preference for the signal word "danger," the agency proposed the use of the word "warning" as more appropriate to the level of risk. The agency also noted that the word "warning" is used in the air bag warning label.

Recognizing that it might encounter additional conflicts between focus group preferences and the ANSI standard in future rulemakings, NHTSA requested 
comments in the NPRM on the extent to which any final choice regarding colors and signal words should be guided by the focus group preferences instead of the ANSI standard. NHTSA also requested comments on the broader issue of the circumstances in which it would be appropriate for agency rulemaking decisions to be guided by focus group results or other information when such information is contrary to a voluntary consensus standard such as the ANSI standard.

At this time (February 22, 1999), a final decision is still pending regarding its proposal to upgrade the rollover warning label. As to the general questions it posed in the NPRM, NHTSA recognizes that ANSI's mission differs somewhat from that of the agency's focus groups with respect to the labeling of hazardous situations. ANSI's mission is to develop and maintain a standard for communicating information about a comprehensive hierarchy of hazards, while the focus groups' mission is to design an effective label for a specific hazard. The agency recognizes further that, given the difference in their missions, their conclusions about the appropriate manner of communication might differ on occasion.

Since agency labeling decisions are highly dependent on the facts regarding the specific hazard being addressed, NHTSA anticipates making case-by-case determinations of the extent to which it should follow voluntary standards versus information from focus groups and other sources. NHTSA will rely on its own expertise and judgment in making determinations under the NTTAA and the statutory provisions regarding vehicle safety standards.

2. Government Unique Standard: Air Bag Warning Label (1997) (Incorporated: 1997)

Voluntary Standard

ANSI ISO

Rationale

The Air Bag Warning Label uses yellow as the background color, instead of orange, in accordance with an ANSI standard and uses a graphic developed 
by Chrysler Corporation to depict the hazards of being too close to an air bag, instead of the graphic recommended by the ISO. These decisions were based on focus group testing sponsored by the agency which strongly indicated that these unique requirements would be far more effective with respect to safety than the industry standards.

3. Government Unique Standard: Brake Performance, 49 CFR 393.52 - FMCSA's Performance-Based Brake Testers (PBBTs) Requirement (Incorporated: 2002)

Voluntary Standard

SAE J667 - Brake Test Code Inertia Dynamometer (cancelled February 2002)

SAE J1854 - Brake Force Distribution Performance Guide - Trucks and Buses Rationale

FMCSA used government-unique standards in lieu of voluntary consensus standards when it implemented its final rule to allow inspectors to use performance-based brake testers (PBBTs) to check the brakes on large trucks and buses for compliance with federal safety standards and to issue citations when these vehicles fail (67 FR 51770, August 9, 2002). The FMCSA evaluated several PBBTs during a round robin test series to assess their functional performance and potential use in law enforcement. The standard, a specific configuration of brake forces and wheel loads on a heavy-duty vehicle, was used to evaluate the candidate PBBTs and their operating protocols. The agency's rationale for use of the government-unique standards was to verify that these measurements and new technology could be used by law enforcement as an alternative to stopping distance tests or on-road deceleration tests. PBBTs are expected to save time and their use could increase the number of commercial motor vehicles that can be inspected in a given time. Only PBBTs that meet specifications developed by the FMCSA can be used to determine compliance with the Federal Motor Carrier Safety Regulations. The final rule represents a culmination of agency research that began in the early 1990 s. 
3. Please list the Voluntary Consensus Standards (VCS) your agency substituted for Government Unique Standards (GUS) in FY 2005 as a result of review under Section 15(b)(7) of OMB Circular A-119: 0

4. Please provide the total number of Voluntary Consensus Standards your agency used during FY 2005: Optional: If possible, also please provide the total number of Nonconsensus Standards that are developed in the private sector your agency used during FY 2005. In addition, please provide your agency's rationale for using the Nonconsensus Standards that are developed in the private sector counted in this question.

Voluntary Consensus Standards: $\mathbf{3 8 1}$

Other Technical Standards: 0

Rationale:

5. Please enter the Voluntary Consensus Standards Bodies (VCSB) in which your agency participated in during FY 2005: 47

\section{Voluntary Consensus Standards Body}

Aerospace Industries Association of America

American Association of Motor Vehicle

Administrators

American Association of State Highway and

Transportation Officials

American Gas Association

American Institute of Aeronautics and Astronautics

American National Standards Institute

American Petroleum Institute

American Public Transportation Association

American Pyrotechnics Association

American Railway Engineering \& Maintenance-of-

Way Association

American Society for Nondestructive Testing

American Society for Testing and Materials

\section{Acronym}

AIA

AAMVA

AASHTO

AGA

AIAA

ANSI

API

APTA

APA

AREMA

ASNT

ASTM 


\begin{tabular}{|c|c|}
\hline American Society of Civil Engineers & ASCE \\
\hline American Society of Mechanical Engineers & ASME \\
\hline American Trucking Associations & ATA \\
\hline Association of American Railroads & AAR \\
\hline Association of Public Health Laboratories & APHL \\
\hline Canadian General Standards Board & CGSB \\
\hline Canadian Standards Association & CSA \\
\hline Chlorine Institute & $\mathrm{Cl}$ \\
\hline Commercial Vehicle Safety Alliance & CVSA \\
\hline Compressed Gas Association & CGA \\
\hline Gas Technology Institute & GTI \\
\hline Institute of Electrical and Electronic Engineers & IEEE \\
\hline Institute of Transportation Engineers & ITE \\
\hline Intelligent Transportation Society of America & ITS America \\
\hline International Atomic Energy Agency & IAEA \\
\hline International Civil Aviation Organization & ICAO \\
\hline International Commission on Occupational Health & $\mathrm{ICOH}$ \\
\hline International Maritime Organization & IMO \\
\hline International Organization for Standardization & ISO \\
\hline $\begin{array}{l}\text { Manufacturers Standardization Society of the Valve } \\
\text { and Fittings Industry }\end{array}$ & MSSVFI \\
\hline NAFTA Land Transportation Standards Subcommittee & NAFTA \\
\hline $\begin{array}{l}\text { National Association of Corrosion Engineers } \\
\text { International }\end{array}$ & NACE \\
\hline $\begin{array}{l}\text { National Board of Boiler and Pressure Vessel } \\
\text { Inspectors }\end{array}$ & NBBPVI \\
\hline $\begin{array}{l}\text { National Committee on Uniform Traffic Control } \\
\text { Devices }\end{array}$ & NCUTCD \\
\hline National Electrical Manufacturers Association & NEMA \\
\hline National Fire Protection Association & NFPA \\
\hline North American Transport of Dangerous Goods & NATDGS \\
\hline
\end{tabular}


Standards

Organization for Economic Cooperation and $\quad$ OECD

Development

Recreation Vehicle Industry Association RVIA

Rehabilitation Engineering and Assistive Technology RESNA

Society of North America

Society of Automotive Engineers SAE

Transportation Research Board TRB

Truck Trailer Manufacturers Association TTMA

United Nations Committee on the Transport of UNTDG

Dangerous Goods

United Nations Economic Commission for Europe WP UNECE $.29 /$ GRSP

6. Please provide the total number of your agency's representatives who participated in voluntary consensus standards activities during FY 2005 and the total number of activities these agency representatives participated in: 209

7. Please provide any conformity assessment activities (as described in "Guidance on Federal Conformity Assessment Activities" found in the Federal Register, Volume 65, Number 155, dated August 10, 2000) in which your agency was involved in FY 2005.

Federal Railroad Administration (FRA): Under 15 CFR Part 287.4(i): FRA's conformity assessment activities are visible internationally through expanded efforts in the area of safe, uniform international transport of hazardous materials by participation in the Canadian General Standards Board Tank Car Committee and the ASME Transportation Pressure Vessel Committee, as well as continuing to participate in the North American Transport of Dangerous Goods Standard (NATDGS) Working Group and the AAR Tank Car Committee.

Under 15 CFR Part 287.4(j): Participation in the voluntary consensus standards bodies listed above as well as in numerous committees and sub-committees of those bodies gives FRA access to the developmental stages of private sector conformity assessment standards to ensure that the agency viewpoint is considered in the development of these standards. 
8. Please provide an evaluation of the effectiveness of Circular A-119 policy and recommendations for any changes:

DOT believes that Circular A-119 is working effectively. The use of voluntary standards saves time and money for regulatory agencies, and for regulated entities and industries. Due to the effective implementation of the standardsrelated sections of the National Technology Transfer and Advancement Act (NTTAA), there is a low volume of government-unique standards being used in lieu of voluntary consensus standards, especially when compared with the status when NTTAA was passed in 1996.

DOT recommends that OMB Circular A-119 be amended to require NTTAA reporting on an exception basis only (only report instances of governmentunique standards being used in lieu of voluntary consensus standards).

9. Please provide any other comments you would like to share on behalf of your agency.

DOT offers no additional comments.

10. Please use this box to provide any additional comments on how your agency currently reports its use of voluntary consensus standards:

The DOT operating administrations have pursued different approaches to the management of voluntary consensus standards with their sets of modal stakeholders. Document review, including standards included or incorporated by reference, normally occurs no less frequently than every five years.

Standards referenced in the Code of Federal Regulations are periodically reviewed as part of the Section 610 reviews, and as a part of the continuing rulemaking process, including petitions for rulemaking. Some operating administrations also have an internal regulatory effectiveness review function, which provides a further opportunity to review both voluntary consensus and agency-unique standards. These avenues allow for both ad-hoc and periodic reviews. 
Standards incorporated into regulations for purposes of international harmonization are generally reviewed and updated every two years.

10-1. Removed [This question has been deprecated for 2005]

10-2. Removed [This question has been deprecated for 2005]

10-3. Removed [This question has been deprecated for 2005]

10-4. Does your agency report standards that it uses for guidance purposes (as opposed compliance purposes)? (a) Yes; (b) No; (c) Not applicable; Yes

10-5. Does your agency report use of standards from non-ANSI accredited standards developers, industry consortia groups, or both? (a) non-ANSI Accredited; (b) Consortia; (c) Both; (d) Neither; or (e) Not applicable; C

10-6. Does your agency have a schedule for periodically reviewing its use of standards for purposes of updating such use? (a) Yes; (b) No; Yes

10-7. How often does your agency review its standards for purposes of updating such use? [enter the number of years]: 5 


\section{Department of the Treasury}

No report submitted. 


\section{Department of Veterans Affairs}

1. Please describe the importance of standards in the achievement of your agency's mission, how your agency uses standards to deliver its primary services in support of its mission, and provide any examples or case studies of standards success:

As a Federal Agency our mission is to promote healthcare to our Nations Veterans. With the use of Standards it allows the Department to reduce cost, for services provided, and maintains compliance with guidelines in support of the Department's mission. The Department of Veterans Affairs enforces participation in Standards compliance which eliminates the research process, increase of manpower, and the necessity for development of Governmentunique standards which affects the Departments allocated budget resources.

2. Please list the government-unique standards your agency used in lieu of voluntary consensus standards during FY 2005: 0

3. Please list the Voluntary Consensus Standards (VCS) your agency substituted for Government Unique Standards (GUS) in FY 2005 as a result of review under Section 15(b)(7) of OMB Circular A-119: 0

4. Please provide the total number of Voluntary Consensus Standards your agency used during FY 2005: Optional: If possible, also please provide the total number of Nonconsensus Standards that are developed in the private sector your agency used during FY 2005. In addition, please provide your agency's rationale for using the Nonconsensus Standards that are developed in the private sector counted in this question.

Voluntary Consensus Standards: 0

Other Technical Standards: 0

Rationale:

5. Please enter the Voluntary Consensus Standards Bodies (VCSB) in which your agency participated in during FY 2005: 20 


\begin{tabular}{|c|c|}
\hline American Industrial Hygiene Association & AlHA \\
\hline American Institute of Timber Construction & AITC \\
\hline American National Metric Council & ANMC \\
\hline American National Standards Institute & ANSI \\
\hline American Society for Testing and Materials & ASTM \\
\hline $\begin{array}{l}\text { American Society of Heating, Refrigerating, and Air- } \\
\text { Conditioning Engineers }\end{array}$ & ASHRAE \\
\hline American Society of Mechanical Engineers & ASME \\
\hline American Society of Safety Engineers & ASSE \\
\hline Builders Hardware Manufacturers Association & BHMA \\
\hline Federal Facilities Council & FFC \\
\hline $\begin{array}{l}\text { Government Electronics \& Information Technology } \\
\text { Association }\end{array}$ & GEITA \\
\hline $\begin{array}{l}\text { Joint Commission on Accreditation of Healthcare } \\
\text { Organizations }\end{array}$ & JCAHO \\
\hline NAFTA Land Transportation Standards Subcommittee & NAFTA \\
\hline National Center for Vital and Health Statistics & NCVHS \\
\hline $\begin{array}{l}\text { National Committee for Information Technology } \\
\text { Standards }\end{array}$ & NCITS \\
\hline National Fire Protection Association & NFPA \\
\hline National Institute for Occupational Safety and Health & $\mathrm{NIOSH}$ \\
\hline National Institute of Building Sciences & NIBS \\
\hline National Petroleum Management Association & NPMA \\
\hline Society of Toxicological Pathologists & STP \\
\hline
\end{tabular}

6. Please provide the total number of your agency's representatives who participated in voluntary consensus standards activities during FY 2005 and the total number of activities these agency representatives participated in: 4

7. Please provide any conformity assessment activities (as described in "Guidance on Federal Conformity Assessment Activities" found in the Federal Register, Volume 65, Number 155, dated August 10, 2000) in which your agency was involved in FY 2005. 
The VA does not engage in conformity assessments activities. VA strives to use industry based standards and commercial off-the-shelf products.

8. Please provide an evaluation of the effectiveness of Circular A-119 policy and recommendations for any changes:

The Department of Veterans Affairs has no comment or recommendations for changes at this time.

9. Please provide any other comments you would like to share on behalf of your agency.

The Department of Veterans Affairs has no comments at this time.

10. Please use this box to provide any additional comments on how your agency currently reports its use of voluntary consensus standards:

The Veterans Health Administration accepts and conforms to standards developed by the Joint Commission on Accreditation of Healthcare Organization (JCAHO) for Veterans Affairs (VA) healthcare facilities. Voluntary consensus standard requirements are utilized in the regulatory, contractual and grants determinations executed by the Veterans Health Administration.

10-1. Removed [This question has been deprecated for 2005]

10-2. Removed [This question has been deprecated for 2005]

10-3. Removed [This question has been deprecated for 2005]

10-4. Does your agency report standards that it uses for guidance purposes (as opposed compliance purposes)? (a) Yes; (b) No; (c) Not applicable; Yes

10-5. Does your agency report use of standards from non-ANSI accredited standards developers, industry consortia groups, or both? (a) non-ANSI Accredited; (b) Consortia; (c) Both; (d) Neither; or (e) Not applicable; A

10-6. Does your agency have a schedule for periodically reviewing its use of standards for purposes of updating such use? (a) Yes; (b) No; Yes 
10-7. How often does your agency review its standards for purposes of updating such use? [enter the number of years]: 1 


\section{Appendix E - Individual, Unabridged Commission and other Agency Reports}

Note: This appendix contains the unabridged Commission and other agency reports as they were submitted to NIST.

\section{$\underline{\text { Agency for International Development }}$}

No report submitted. 


\section{Consumer Product Safety Commission}

1. Please describe the importance of standards in the achievement of your agency's mission, how your agency uses standards to deliver its primary services in support of its mission, and provide any examples or case studies of standards success:

The U.S. Consumer Product Safety Commission is responsible for protecting the American public from unreasonable risks of injury and death from 15,000 types of consumer products. Since its inception in 1973, the Commission has promoted the development of voluntary product safety standards to help it accomplish this mission. From 1990 through 2005, the Commission supported the development of 304 completed voluntary consensus safety standards while issuing 35 mandatory standards, a nearly nine-to-one ratio.

An example of the importance of voluntary safety standards in the achievement of the Commission's mission is found in the case of baby walkers. Baby walkers used to account for more injuries than any other type of nursery product. In 1992 an estimated 25,700 children younger than 15 months of age were treated in U.S. hospital emergency rooms for baby walker injuries, most related to falls down stairs. CPSC staff worked with ASTM and the baby walker industry and a new ASTM safety standard was published in 1997. This standard called for "gripping strips" under the walker base to stop the walker at the edge of a step. By 2003, the estimated number of baby walker injuries treated in hospital emergency rooms had dropped dramatically from 25,700 to 3,200 , an $88 \%$ reduction.

2. Please list the government-unique standards your agency used in lieu of voluntary consensus standards during FY 2005: 2

1. Government Unique Standard: CPSC CFR Parts 1213, 1500, and 1513 (Incorporated: 2000)

Voluntary Standard

ASTM F1427-96

Rationale 
The CPSC rule goes beyond the provisions of the ASTM voluntary standard to provide increased protection to children from the risk of death and serious injury from entrapment.

2. Government Unique Standard: FR/Vol. 68, No. 75/Friday, April 18, 2003, pp. 19142-19147, Metal-Cored Candlewicks Containing Lead and Candles With Such Wicks (Incorporated: 2003)

Voluntary Standard

Voices of Safety International (VOSI) standard on lead in candle wicks Rationale

The U.S. Consumer Product Safety Commission found that the VOSI standard is technically unsound, and thus would not result in the elimination or adequate reduction of the risk, and that substantial compliance with it is unlikely. See FR/Vol. 68, No. 75/Friday, April 18, 2003, pp. 19145-19146, paragraph H2, Voluntary Standards for further information on this finding.

3. Please list the Voluntary Consensus Standards (VCS) your agency substituted for Government Unique Standards (GUS) in FY 2005 as a result of review under Section 15(b)(7) of OMB Circular A-119: 0

4. Please provide the total number of Voluntary Consensus Standards your agency used during FY 2005: Optional: If possible, also please provide the total number of Nonconsensus Standards that are developed in the private sector your agency used during FY 2005. In addition, please provide your agency's rationale for using the Nonconsensus Standards that are developed in the private sector counted in this question.

Voluntary Consensus Standards: 28

Other Technical Standards: 0

Rationale:

5. Please enter the Voluntary Consensus Standards Bodies (VCSB) in which your agency participated in during FY 2005: 8 
Voluntary Consensus Standards Body

American National Standards Institute

American Society for Testing and Materials

American Society of Mechanical Engineers

Canadian Standards Association

International 2-Up ATV Manufacturers Association I2AMA

National Fire Protection Association NFPA

Specialty Vehicle Institute of America

Underwriters Laboratories

\section{Acronym}

ANSI

ASTM

ASME

CSA

SVIA

UL

6. Please provide the total number of your agency's representatives who participated in voluntary consensus standards activities during FY 2005 and the total number of activities these agency representatives participated in: $\mathbf{2 8}$

7. Please provide any conformity assessment activities (as described in "Guidance on Federal Conformity Assessment Activities" found in the Federal Register, Volume 65, Number 155, dated August 10, 2000) in which your agency was involved in FY 2005.

None

8. Please provide an evaluation of the effectiveness of Circular A-119 policy and recommendations for any changes:

During FY 2005, the Commission efforts to enhance voluntary safety standards development was complemented by the overall Federal policy set forth in the Circular. There are no recommendations for changes in the Circular at this time.

9. Please provide any other comments you would like to share on behalf of your agency.

The U.S. Consumer Product Safety Act (CPSA), as amended, requires the Commission to defer to issued voluntary standards, rather than promulgate mandatory standards, when the voluntary standards will eliminate or adequately reduce the risk of injury addressed and it is likely that there will be 
substantial compliance with the voluntary standards. In addition, the Commission is required, after any notice or advance notice of proposed rulemaking, to provide technical and administrative assistance to persons or groups who propose to develop or modify an appropriate voluntary standard. Additionally, the Commission is encouraged to provide technical and administrative assistance to groups developing product safety standards and test methods, taking into account Commission resources and priorities.

Since its inception in 1973, the Commission has promoted the development of voluntary product safety standards. Policy statements in support of voluntary standards were published by the CPSC in 1975 and 1978. These policy statements were updated in 1988 (16 U.S.C. 1031), and a staff directive in implementation of portions of these policy statements was promulgated in 1989 and updated in October 2001. Since the principles set forth in the OMB Circular A-119 were published, the Commission has consistently supported them.

10. Please use this box to provide any additional comments on how your agency currently reports its use of voluntary consensus standards:

With regard to items 10.6 and 10.7 , the Commission staff reviews approximately four standards per year. The Commission reports on it voluntary consensus standards activities in its annual Performance and Accountability Report.

10-1. Removed [This question has been deprecated for 2005]

10-2. Removed [This question has been deprecated for 2005]

10-3. Removed [This question has been deprecated for 2005]

10-4. Does your agency report standards that it uses for guidance purposes (as opposed compliance purposes)? (a) Yes; (b) No; (c) Not applicable; No

10-5. Does your agency report use of standards from non-ANSI accredited standards developers, industry consortia groups, or both? (a) non-ANSI Accredited; (b) Consortia; (c) Both; (d) Neither; or (e) Not applicable; A 
10-6. Does your agency have a schedule for periodically reviewing its use of standards for purposes of updating such use? (a) Yes; (b) No; Yes

10-7. How often does your agency review its standards for purposes of updating such use? [enter the number of years]: 1 


\section{Environmental Protection Agency}

1. Please describe the importance of standards in the achievement of your agency's mission, how your agency uses standards to deliver its primary services in support of its mission, and provide any examples or case studies of standards success:

Standards are important to EPA in both our regulatory and our voluntary programs.

Analytical test methods, particularly, are important for many EPA regulations. In any given year over half of the Agency's regulations include a section on how to sample or measure materials, emissions or other things in order to determine conformance to the overall requirements of the regulation. In some cases the test methods used are ones that were developed by EPA technical experts with input from experts of the regulated community. The regulated community sometimes prefers the use of these methods precisely because they are designed with specific regulations in mind. Other times, the use of test methods developed through voluntary consensus bodies are more useful to both the purpose of the individual regulatory action and more acceptable to the regulated community. Generally (but not always) the latter is true where advances in technology or testing equipment is a significant factor in determining conformance to the regulation. EPA test methods are compiled within the Code of Federal Regulations and thus are publicly available.

EPA has a wide range of non-regulatory programs that foster pollution prevention, energy conservation, public-private partnerships and beyondcompliance activities that all add up to greater environmental protection and improved human health. Voluntary standards play a key role in such programs as Environmentally Preferable Purchasing, Energy Star, Environmental Management for Federal Facilities and Green Buildings. Our employees participate in a wide range of private sector standards activities and work with counterparts from industry, education, non-government organizations and consumer groups to help develop voluntary standards for things such as environmentally safe cleaning products and recyclable electronic products. Standards organizations and industry not only welcome EPA participation but seek out our experts so that standards which underpin U.S. manufacturing and 
products, and are sold world-wide, benefit from an environmental perspective that often helps cost-savings as well as the other legs of sustainability.

EPA is pleased to be an active member of the American National Standards Institute (ANSI), our U.S. National Standards Body and gateway to the International Organization for Standardization and the International Electrotechnical Commission. Through ANSI, EPA is an active member and leader in standards panels for nanotechnology and homeland security. Likewise EPA is proud to participate in the U.S. based international standards bodies such as ASTM, IEEE and ASME to name only a very few. Our standards activities and associations all serve to help the Agency meet it's goals and obligations to provide the best for environmental protection and human health.

2. Please list the government-unique standards your agency used in lieu of voluntary consensus standards during FY 2005: 50

1. Government Unique Standard: 40 CFR 89 - Control of Emissions from New and In-Use Non-Road Compression Ignition Engines (Incorporated: 1999)

Voluntary Standard

ISO 8178 - Reciprocating Internal Combustion Engines, Exhaust Emission Measurement

Rationale

Procedures would be impractical because they rely too heavily on reference testing conditions. Agency decides instead to continue to rely on procedures outlined in 40 CFR Part 90.

2. Government Unique Standard: 40 CFR 90 - Control of Emission from NonRoad Spark Ignition Engines at or below 19KV (Incorporated: 1999)

Voluntary Standard

ISO 8178 - Reciprocating Internal Combustion Engines, Exhaust Emission Measurement

Rationale 
Procedures would be impractical because they rely too heavily on reference testing conditions. Agency decides instead to continue to rely on procedures outlined in 40 CFR Part 90.

3. Government Unique Standard: 40 CFR 92 - Control of Air Pollution from Locomotives and Locomotive Engines (Incorporated: 1999)

Voluntary Standard

ISO 8178 - Reciprocating Internal Combustion Engines, Exhaust Emission Measurement

Rationale

Procedures would be impractical because they rely too heavily on reference testing conditions. Agency decides instead to continue to rely on procedures outlined in 40 CFR Part 90.

4. Government Unique Standard: EPA Method 1 - Traverse Points, Stationary Sources (Incorporated: 2001)

Voluntary Standard

ASTM D3154-00, Standard Method for Average Velocity in a Duct (Pitot Tube Method)

Rationale

1. The standard appears to lack in quality control and quality assurance requirements. It does not include the following: (1) Proof that openings of standard pitot tube have not plugged during the test; (2) if differential pressure gauges other than inclined manometers (e.g., magnehelic gauges) are used, their calibration must be checked after each test series; and (3) the frequency and validity range for calibration of the temperature sensors.

2. They are too general, too broad, or not sufficiently detailed to assure compliance with EPA regulatory requirements.

Voluntary Standard

ASTM D3154-91 (1995), Standard Method for Average Velocity in a Duct (Pitot Tube Method)

Rationale 
Is too general, too broad, or not sufficiently detailed to assure compliance with EPA regulatory requirements.

5. Government Unique Standard: EPA Method 10 - Carbon Monoxide, NDIR (Incorporated: 1999)

Voluntary Standard

ASTM D3162 (1994) Standard Test Method for Carbon Monoxide in the Atmosphere (Continuous Measurement by Non-dispersive Infrared Spectrometry)

Rationale

This ASTM standard, which is stated to be applicable in the range of $0.5-100$ ppm CO, does not cover the range of EPA Method 10 (20-1,000 ppm CO) at the upper end (but states that it has a lower limit of sensitivity). Also, ASTM D3162 does not provide a procedure to remove carbon dioxide interference. Therefore, this ASTM standard is not appropriate for combustion source conditions. In terms of non-dispersive infrared instrument performance specifications, ASTM D3162 has much higher maximum allowable rise and fall times (5 minutes) than EPA Method 10 (which has 30 seconds).

Voluntary Standard

CAN/CSA Z223.21-M1978, Method for the Measurement of Carbon Monoxide: 3-Method of Analysis by Non-Dispersive Infrared Spectrometry Rationale

1. This standard is lacking in the following areas: (1) Sampling procedures;

(2) procedures to correct for the carbon dioxide concentration; (3) instructions to correct the gas volume if $\mathrm{CO} 2$ traps are used; (4) specifications to certify the calibration gases are within 2 percent of the target concentration; (5) mandatory instrument performance characteristics (e.g., rise time, fall time, zero drift, span drift, precision); (6) quantitative specification of the span value maximum as compared to the measured value: The standard specifies that the instruments should be compatible with the concentration of gases to be measured, whereas EPA Method 10 specifies that the instrument span value should be no more than 1.5 times the source 
performance standard. 2. Is too general, too broad, or not sufficiently detailed to assure compliance with EPA regulatory requirements.

6. Government Unique Standard: EPA Method 101 - Mercury Emissions, ChlorAlkali Plants (Air) (Incorporated: 2001)

Voluntary Standard

ASTM D6216-98 - Standard Practice for Opacity Monitor Manufacturers to Certify Conformance with Design and Performance Specifications.

Rationale

The EPA is incorporating ASTM D6216 (manufacturers certification) by reference into EPA Performance Specification 1, Sect. 5 \& 6 in another rulemaking. ASTM D6216 does not address all the requirements specified in PS-1.

7. Government Unique Standard: EPA Method 101a - Mercury Emissions Sewer/Sludge Incinerator (Incorporated: 2001)

Voluntary Standard

ASTM D6216-98 - Standard Practice for Opacity Monitor Manufacturers to Certify Conformance with Design and Performance Specifications.

Rationale

The EPA is incorporating ASTM D6216 (manufacturers certification) by reference into EPA Performance Specification 1, Sect. 5 \& 6 in another rulemaking. ASTM D6216 does not address all the requirements specified in PS-1.

8. Government Unique Standard: EPA Method 10A - Carbon Monoxide for Certifying CEMS (Incorporated: 2001)

Voluntary Standard

CAN/CSA Z223.21-M1978, Method for the Measurement of Carbon Monoxide:

3-Method of Analysis by Non-Dispersive Infrared Spectrometry. 
Rationale

1. It is lacking in the following areas: (1) Sampling procedures; (2)

procedures to correct for the carbon dioxide concentration; (3) instructions

to correct the gas volume if $\mathrm{CO} 2$ traps are used; (4) specifications to certify the calibration gases are within 2 percent of the target concentration; (5) mandatory instrument performance characteristics (e.g., rise time, fall time, zero drift, span drift, precision); (6) quantitative specification of the span value maximum as compared to the measured value: The standard specifies that the instruments should be compatible with the concentration of gases to be measured, whereas EPA Method 10 specifies that the instrument span value should be no more than 1.5 times the source performance standard. 2 . Is too general, too broad, or not sufficiently detailed to assure compliance with EPA regulatory requirements.

9. Government Unique Standard: EPA Method 12 - Inorganic Lead, Stationary Sources (Incorporated: 2000)

Voluntary Standard

ASTM D4358-94 (1999), Standard Test Method for Lead and Chromium in Air Particulate Filter Samples of Lead Chromate Type Pigment Dusts by Atomic Absorption Spectroscopy

Rationale

These ASTM standards do not require the use of glass fiber filters as in EPA Method 12 and require the use of significantly different digestion procedures that appear to be milder than the EPA Method 12 digestion procedure. For these reasons, these ASTM standards cannot be considered equivalent to EPA Method 12. Also, the subject ASTM standards do not require the use of hydrogen fluoride (HF) as in EPA Method 29 and, therefore, they cannot be used for the preparation, digestion, and analysis of Method 29 samples. Additionally, Method 29 requires the use of a glass fiber filter, whereas these three ASTM standards require cellulose filters and other probable nonglass fiber media, which cannot be considered equivalent to EPA Method 29. Voluntary Standard 
ASTM E1741-95 (1995), Standard Practice for Preparation of Airborne Particulate Lead Samples Collected During Abatement and Construction Activities for Subsequent Analysis by Atomic Spectrometry Rationale These ASTM standards do not require the use of glass fiber filters as in EPA Method 12 and require the use of significantly different digestion procedures that appear to be milder than the EPA Method 12 digestion procedure. For these reasons, these ASTM standards cannot be considered equivalent to EPA Method 12. Also, the subject ASTM standards do not require the use of hydrogen fluoride (HF) as in EPA Method 29 and, therefore, they cannot be used for the preparation, digestion, and analysis of Method 29 samples. Additionally, Method 29 requires the use of a glass fiber filter, whereas these three ASTM standards require cellulose filters and other probable nonglass fiber media, which cannot be considered equivalent to EPA Method 29. Voluntary Standard ASTM E1979-98 (1998), Standard Practice for Ultrasonic Extraction of Paint, Dust, Soil, and Air Samples for Subsequent Determination of Lead Rationale These ASTM standards do not require the use of glass fiber filters as in EPA Method 12 and require the use of significantly different digestion procedures that appear to be milder than the EPA Method 12 digestion procedure. For these reasons, these ASTM standards cannot be considered equivalent to EPA Method 12. Also, the subject ASTM standards do not require the use of hydrogen fluoride (HF) as in EPA Method 29 and, therefore, they cannot be used for the preparation, digestion, and analysis of Method 29 samples. Additionally, Method 29 requires the use of a glass fiber filter, whereas these three ASTM standards require cellulose filters and other probable nonglass fiber media, which cannot be considered equivalent to EPA Method 29.

10. Government Unique Standard: EPA Method 15 - Hydrogen Sulfide/Carbon Disulfide/Carbon Sulfide (Incorporated: 1999)

Voluntary Standard

ASME C00031 or PTC 19-10-1981 - Part 10 Flue and Exhaust Gas Analyses Rationale 
Too broad to be useful in regulatory sense. Covers Methods 3, 6, 7, and 15 with variants.

Voluntary Standard

ASTM D4323-84 (1997) - Standard Test Method for Hydrogen Sulfide in the Atmosphere by Rate of Change of Reflectance

Rationale

ASTM D4323 only applies to concentrations of H2S from $1 \mathrm{ppb}$ to $3 \mathrm{ppm}$ without dilution. Many QC items are missing, such as calibration drift and sample line losses. The calibration curve is determined with only one point.

11. Government Unique Standard: EPA Method 1650 - Organic Halides, Absorbable (AOX) (Incorporated: 1998)

Voluntary Standard

ISO, DIN, SCAN, and Standard Methods (SM 5320)

Rationale

EPA decided to use EPA Method 1650. This Method was developed by drawing on various procedures contained in the methods of voluntary consensus standards bodies and other standards developers, such as ISO, DIN, SCAN, and Standard Methods (SM 5320). However, none of these more narrowly focused voluntary consensus standards contained the standardized quality control and quality control compliance criteria that EPA requires for data verification and validation in its water programs. Therefore, EPA found none of these VCS standing alone to meet EPA's needs.

12. Government Unique Standard: EPA Method 17 - Particle Matter (PM) In Stack Filtration (Incorporated: 2001)

Voluntary Standard

ASME C00049

Rationale

EPA looked at this standard for both Pulp and Paper Hazardous Air Pollutant rules and for the Small Municipal Waste Combustion rule. Contains sampling options beyond which would be considered acceptable for Method 5. 
Voluntary Standard

ASTM D3685/3685M-95 - Standard Test method for Sampling and

Determination of Particle Matter in Stack Gases

Rationale

EPA looked at this standard for both Pulp and Paper Hazardous Air Pollutant rules and for the Small Municipal Waste Combustion rule. Contains sampling options beyond which would be considered acceptable for Method 5.

13. Government Unique Standard: EPA Method 18 - VOC/GC (Incorporated: 1999)

Voluntary Standard

ASTM D6060-96 (in review 2000) - Practice for Sampling of Process Vents with a Portable Gas Chromatography

Rationale

This standard lacks key quality control and assurance that is required for EPA Method 18. For example: lacks acceptance criteria for calibration, details on using other collection media (e.g. solid sorbents), and reporting/ documentation requirements.

14. Government Unique Standard: EPA Method 180.1 - Turbidity Nephelometric (Incorporated: 1999)

Voluntary Standard

ISO 7027 - Water Quality Determination of Turbidity

Rationale

EPA has no data upon which to evaluate whether the separate 90 degrees scattered or transmitted light measurement evaluations according to the ISO 7027 method would produce results that are equivalent to results produced by the other methods.

15. Government Unique Standard: EPA Method 2 - Velocity and S-type Pitot (Incorporated: 1999) 
Voluntary Standard

ASTM 3796-90 (1998), Standard Practice for Calibration of Type S Pitot Tubes

Rationale

They are too general, too broad, or not sufficiently detailed to assure compliance with EPA regulatory requirements.

Voluntary Standard

ASTM D3154-00, Standard Method for Average Velocity in a Duct (Pitot Tube Method)

Rationale

1. The standard appears to lack in quality control and quality assurance requirements. It does not include the following: (1) Proof that openings of standard pitot tube have not plugged during the test; $(2)$ if differential pressure gauges other than inclined manometers (e.g., magnehelic gauges) are used, their calibration must be checked after each test series; and (3) the frequency and validity range for calibration of the temperature sensors. 2. They are too general, too broad, or not sufficiently detailed to assure compliance with EPA regulatory requirements.

Voluntary Standard

ASTM D3154-91 (1995), Standard Method for Average Velocity in a Duct (Pitot Tube Method)

Rationale

Is too general, too broad, or not sufficiently detailed to assure compliance with EPA regulatory requirements.

Voluntary Standard

ASTM D3464-96 (2001), Standard Test Method Average Velocity in a Duct Using a Thermal Anemometer

Rationale Applicability specifications are not clearly defined, e.g., range of gas composition, temperature limits. Also, the lack of supporting quality assurance data for the calibration procedures and specifications, and certain variability issues that are not adequately addressed by the standard limit EPA's ability to make a definitive comparison of the method in these areas. Voluntary Standard

ISO 10780:1994, Stationary Source Emissions-- Measurement of Velocity and Volume Flowrate of Gas Streams in Ducts

Rationale 
The standard recommends the use of an L-shaped pitot, which historically has not been recommended by EPA. The EPA specifies the S-type design, which has large openings that are less likely to plug up with dust.

16. Government Unique Standard: EPA Method 21 - Volatile Organic Compound (VOC) Leaks (Incorporated: 2003)

Voluntary Standard ASTM E1211-97 - Standard Practice for Leak Detection and Location Using Surface-Mounted Acoustic Emission Sensors

Rationale

This standard will detect leaks but not classify the leak as VOC, as in EPA Method 21. In addition, in order to detect the VOC concentration of a known VOC leak, the acoustic signal would need to be calibrated against a primary instrument. Background noise interference in some source situations could also make this standard difficult to use effectively.

17. Government Unique Standard: EPA Method 23 - Dioxin and Furan (PCDD and PCDF) (Incorporated: 1999)

Voluntary Standard

European Committee for Standardization (CEN) EN 1948-3 (1997),

Determination of the Mass Concentration of PCDD'S/PCDF'S--Part 3:

Identification and Quantification

Rationale

Is too general, too broad, or not sufficiently detailed to assure compliance with EPA regulatory requirements.

18. Government Unique Standard: EPA Method 24 - Surface Coatings, Volatile Matter Content (Incorporated: 1998)

Voluntary Standard 
ISO 11890-1 (2000) part 1, Paints and Varnishes--Determination of Volatile Organic Compound (VOC) Content-Difference Method

Rationale

Measured nonvolatile matter content can vary with experimental factors such as temperature, length of heating period, size of weighing dish, and size of sample. The standard ISO 11890-1 allows for different dish weights and sample sizes than the one size (58 millimeters in diameter and sample size of 0.5 gram) of EPA Method 24. The standard ISO 11890-1 also allows for different oven temperatures and heating times depending on the type of coating, whereas EPA Method 24 requires 60 minutes heating at 110 degrees Celsius at all times. Because the EPA Method 24 test conditions and procedures define volatile matter, ISO 11890 -1 is unacceptable as an alternative because of its different test conditions.

Voluntary Standard

ISO 11890-2 (2000) Part 2, Paints and Varnishes--Determination of Volatile Organic Compound (VOC) Content-Gas Chromatographic Method Rationale

ISO 11890-2 only measures the VOC added to the coating and would not measure any VOC generated from the curing of the coating. The EPA Method 24 does measure cure VOC, which can be significant in some cases, and, therefore, ISO 11890-2 is not an acceptable alternative to this EPA method.

19. Government Unique Standard: EPA Method 25 - Gaseous Nonmethane Organic Emissions (Incorporated: 2001)

Voluntary Standard

EN 12619:1999 Stationary Source Emissions--Determination of the Mass Concentration of Total Gaseous Organic Carbon at Low Concentrations in Flue Gases--Continuous Flame Ionization Detector Method Rationale

The standards do not apply to solvent process vapors in concentrations greater than 40 ppm (EN 12619) and 10 ppm carbon (ISO 14965). Methods whose upper limits are this low are too limited to be useful in measuring source emissions, which are expected to be much higher.

Voluntary Standard 
ISO 14965:2000(E) Air Quality--Determination of Total Nonmethane Organic Compounds--Cryogenic Preconcentration and Direct Flame lonization Method Rationale

The standards do not apply to solvent process vapors in concentrations greater than 40 ppm (EN 12619) and 10 ppm carbon (ISO 14965). Methods whose upper limits are this low are too limited to be useful in measuring source emissions, which are expected to be much higher.

20. Government Unique Standard: EPA Method 25A - Gaseous Organic Concentration, Flame Ionization (Incorporated: 2001)

Voluntary Standard

EN 12619:1999 Stationary Source Emissions--Determination of the Mass Concentration of Total Gaseous Organic Carbon at Low Concentrations in Flue Gases--Continuous Flame Ionization Detector Method

Rationale

The standards do not apply to solvent process vapors in concentrations greater than 40 ppm (EN 12619) and 10 ppm carbon (ISO 14965). Methods whose upper limits are this low are too limited to be useful in measuring source emissions, which are expected to be much higher.

Voluntary Standard

ISO 14965:2000(E) Air Quality--Determination of Total Nonmethane Organic Compounds--Cryogenic Preconcentration and Direct Flame lonization Method Rationale

The standards do not apply to solvent process vapors in concentrations greater than 40 ppm (EN 12619) and 10 ppm carbon (ISO 14965). Methods whose upper limits are this low are too limited to be useful in measuring source emissions, which are expected to be much higher.

21. Government Unique Standard: EPA Method 26 - Hydrogen Chloride, Halides, Halogens Emissions (Incorporated: 1999)

Voluntary Standard 
EN 1911-1,2,3 (1998), Stationary Source Emissions-- Manual Method of Determination of HCl--Part 1: Sampling of Gases Ratified European Text-Part 2: Gaseous Compounds Absorption Ratified European Text-- Part 3: Adsorption Solutions Analysis and Calculation Rationale Part 3 of this standard cannot be considered equivalent to EPA Method 26 or 26A because the sample absorbing solution (water) would be expected to capture both $\mathrm{HCl}$ and $\mathrm{Cl} 2$ gas, if present, without the ability to distinguish between the two. The EPA Methods 26 and 26A use an acidified absorbing solution to first separate $\mathrm{HCl}$ and $\mathrm{Cl} 2$ gas so that they can be selectively absorbed, analyzed, and reported separately. In addition, in EN 1911 the absorption efficiency for $\mathrm{Cl} 2$ gas would be expected to vary as the $\mathrm{pH}$ of the water changed during sampling.

22. Government Unique Standard: EPA Method 26A - Hydrogen Halide and Halogen, Isokinetic (Incorporated: 1999)

Voluntary Standard

EN 1911-1,2,3 (1998), Stationary Source Emissions-- Manual Method of Determination of HCl--Part 1: Sampling of Gases Ratified European Text-Part 2: Gaseous Compounds Absorption Ratified European Text-- Part 3: Adsorption Solutions Analysis and Calculation

Rationale

Part 3 of this standard cannot be considered equivalent to EPA Method 26 or 26A because the sample absorbing solution (water) would be expected to capture both $\mathrm{HCl}$ and $\mathrm{Cl} 2$ gas, if present, without the ability to distinguish between the two. The EPA Methods 26 and 26A use an acidified absorbing solution to first separate $\mathrm{HCl}$ and $\mathrm{Cl} 2$ gas so that they can be selectively absorbed, analyzed, and reported separately. In addition, in EN 1911 the absorption efficiency for $\mathrm{Cl} 2$ gas would be expected to vary as the $\mathrm{pH}$ of the water changed during sampling. 
23. Government Unique Standard: EPA Method 28 (Section 10.1) - Wood Heaters, Certificate and Auditing (Incorporated: 2003)

Voluntary Standard

ASME Power Test Codes, Supplement on Instruments and Apparatus, part 5, Measurement of Quantity of Materials, Chapter 1, Weighing Scales

Rationale

It does not specify the number of initial calibration weights to be used nor a specific pretest weight procedure.

Voluntary Standard

ASTM E319-85 (Reapproved 1997), Standard Practice for the Evaluation of Single-Pan Mechanical Balances

Rationale

This standard is not a complete weighing procedure because it does not include a pretest procedure.

24. Government Unique Standard: EPA Method 29 - Metals Emissions from Stationary Sources (Incorporated: 2001)

Voluntary Standard

ASTM D4358-94 (1999), Standard Test Method for Lead and Chromium in Air Particulate Filter Samples of Lead Chromate Type Pigment Dusts by Atomic Absorption Spectroscopy

Rationale These ASTM standards do not require the use of glass fiber filters as in EPA Method 12 and require the use of significantly different digestion procedures that appear to be milder than the EPA Method 12 digestion procedure. For these reasons, these ASTM standards cannot be considered equivalent to EPA Method 12. Also, the subject ASTM standards do not require the use of hydrogen fluoride (HF) as in EPA Method 29 and, therefore, they cannot be used for the preparation, digestion, and analysis of Method 29 samples. Additionally, Method 29 requires the use of a glass fiber filter, whereas these three ASTM standards require cellulose filters and other probable nonglass fiber media, which cannot be considered equivalent to EPA Method 29. 
Voluntary Standard

ASTM E1741-95 (1995), Standard Practice for Preparation of Airborne

Particulate Lead Samples Collected During Abatement and Construction

Activities for Subsequent Analysis by Atomic Spectrometry

Rationale

These ASTM standards do not require the use of glass fiber filters as in EPA Method 12 and require the use of significantly different digestion procedures that appear to be milder than the EPA Method 12 digestion procedure. For these reasons, these ASTM standards cannot be considered equivalent to EPA Method 12. Also, the subject ASTM standards do not require the use of hydrogen fluoride (HF) as in EPA Method 29 and, therefore, they cannot be used for the preparation, digestion, and analysis of Method 29 samples. Additionally, Method 29 requires the use of a glass fiber filter, whereas these three ASTM standards require cellulose filters and other probable nonglass fiber media, which cannot be considered equivalent to EPA Method 29. Voluntary Standard ASTM E1979-98 (1998), Standard Practice for Ultrasonic Extraction of Paint, Dust, Soil, and Air Samples for Subsequent Determination of Lead Rationale These ASTM standards do not require the use of glass fiber filters as in EPA Method 12 and require the use of significantly different digestion procedures that appear to be milder than the EPA Method 12 digestion procedure. For these reasons, these ASTM standards cannot be considered equivalent to EPA Method 12. Also, the subject ASTM standards do not require the use of hydrogen fluoride (HF) as in EPA Method 29 and, therefore, they cannot be used for the preparation, digestion, and analysis of Method 29 samples. Additionally, Method 29 requires the use of a glass fiber filter, whereas these three ASTM standards require cellulose filters and other probable nonglass fiber media, which cannot be considered equivalent to EPA Method 29. Voluntary Standard

CAN/CSA Z223.26-M1987, Measurement of Total Mercury in Air Cold Vapour Atomic Absorption Spectrophotometeric Method Rationale It lacks sufficient quality assurance and quality control requirements necessary for EPA compliance assurance requirements. 
25. Government Unique Standard: EPA Method 2C - Velocity and Flow Rate, Standard Pitot (Incorporated: 1999)

Voluntary Standard

ASTM D3154-00, Standard Method for Average Velocity in a Duct (Pitot Tube

Method)

Rationale

1. The standard appears to lack in quality control and quality assurance requirements. It does not include the following: (1) Proof that openings of standard pitot tube have not plugged during the test; $(2)$ if differential pressure gauges other than inclined manometers (e.g., magnehelic gauges) are used, their calibration must be checked after each test series; and (3) the frequency and validity range for calibration of the temperature sensors. 2. They are too general, too broad, or not sufficiently detailed to assure compliance with EPA regulatory requirements.

26. Government Unique Standard: EPA Method 3 - Molecular Weight Carbon Dioxide, Oxygen (Incorporated: 1999)

Voluntary Standard

ASME C00031 or PTC 19-10-1981--part 10, "Flue and Exhaust Gas Analyses" Rationale

Is too general, too broad, or not sufficiently detailed to assure compliance with EPA regulatory requirements.

Voluntary Standard ASTM D3154-00, Standard Method for Average Velocity in a Duct (Pitot Tube Method)

Rationale

1. The standard appears to lack in quality control and quality assurance requirements. It does not include the following: (1) Proof that openings of standard pitot tube have not plugged during the test; $(2)$ if differential pressure gauges other than inclined manometers (e.g., magnehelic gauges) are used, their calibration must be checked after each test series; and (3) the frequency and validity range for calibration of the temperature sensors. 
2. They are too general, too broad, or not sufficiently detailed to assure compliance with EPA regulatory requirements.

27. Government Unique Standard: EPA Method 306 - Chromium Emissions, Electroplating and Anodizing (Incorporated: 2002)

Voluntary Standard

ASTM D4358-94 (1999) - Standard Test Method for Lead and Chromium in Air

Particulate Filter Samples of Lead Chromate Type Pigment Dusts by Atomic Absorption Spectroscopy

Rationale

This MACT standard (Petroleum Refineries) only cites Method 29. Therefore, the following EPA comment is only applicable for Method 29 not Method 12 and 306: Method 29 requires the use of hydrofluoric acid (HF) in its process of digestion of the sample. ASTM D4358-94 (1999) does not require the use of $\mathrm{HF}$; therefore, it cannot be used in the preparation, digestion, and analysis of Method 29 samples. Additionally, Method 29 requires the use of a glass fiber filter, whereas the subject ASTM standard requires cellulose filters and other probable non-glass fiber media, and this further negates their use as Method 29 equivalent methods. (Same comment as provided for ASTM E1741 and ASTM E1979).

28. Government Unique Standard: EPA Method 306a - Chromium Emissions, Electroplating -- Mason Jar (Incorporated: 2002)

Voluntary Standard

ASTM D4358-94 (1999) - Standard Test Method for Lead and Chromium in Air Particulate Filter Samples of Lead Chromate Type Pigment Dusts by Atomic Absorption Spectroscopy

Rationale

This MACT standard (Petroleum Refineries) only cites Method 29. Therefore, the following EPA comment is only applicable for Method 29 not Method 12 and 306: Method 29 requires the use of hydrofluoric acid (HF) in its process 
of digestion of the sample. ASTM D4358-94 (1999) does not require the use of $\mathrm{HF}$; therefore, it cannot be used in the preparation, digestion, and analysis of Method 29 samples. Additionally, Method 29 requires the use of a glass fiber filter, whereas the subject ASTM standard requires cellulose filters and other probable non-glass fiber media, and this further negates their use as Method 29 equivalent methods. (Same comment as provided for ASTM E1741 and ASTM E1979).

29. Government Unique Standard: EPA Method 320 - Vapor Phase Organic and Inorganic Emissions, FTIR (Incorporated: 1999)

Voluntary Standard

ASTM D6348-98, Determination of Gaseous Compounds by Extractive Direct Interface Fourier Transform (FTIR) Spectroscopy

Rationale

Suggested revisions to ASTM D6348-98 were sent to ASTM by the EPA that, would allow the EPA to accept ASTM D6348-98 as an acceptable alternative. The ASTM Subcommittee D22-03 is currently undertaking a revision of ASTM D6348- 98. Because of this, we are not citing this standard as a acceptable alternative for EPA Method 320 in the final rule today. However, upon successful ASTM balloting and demonstration of technical equivalency with the EPA FTIR methods, the revised ASTM standard could be incorporated by reference for EPA regulatory applicability. In the interim, facilities have the option to request ASTM D6348-98 as an alternative test method under 40 CFR 63.7(f) and 63.8(f) on a case-by-case basis.

30. Government Unique Standard: EPA Method 3A - Carbon Dioxide and Oxygen Concentrations, IAP (Incorporated: 1999)

Voluntary Standard ASTM D5835-95, Standard Practice for Sampling Stationary Source Emissions for Automated Determination of Gas Concentration Rationale 
1. They lack in detail and quality assurance/quality control requirements. Specifically, these two standards do not include the following: (1) Sensitivity of the method; (2) acceptable levels of analyzer calibration error; (3) acceptable levels of sampling system bias; (4) zero drift and calibration drift limits, time span, and required testing frequency; (5) a method to test the interference response of the analyzer; (6) procedures to determine the minimum sampling time per run and minimum measurement time; and (7) specifications for data recorders, in terms of resolution (all types) and recording intervals (digital and analog recorders, only). 2. Is too general, too broad, or not sufficiently detailed to assure compliance with EPA regulatory requirements.

Voluntary Standard

CAN/CSA Z223.2-M86(1986), Method for the Continuous Measurement of Oxygen, Carbon Dioxide, Carbon Monoxide, Sulphur Dioxide, and Oxides of Nitrogen in Enclosed Combustion Flue Gas Stream

Rationale

1. It does not include quantitative specifications for measurement system performance, most notably the calibration procedures and instrument performance characteristics. The instrument performance characteristics that are provided are nonmandatory and also do not provide the same level of quality assurance as the EPA methods. For example, the zero and span/calibration drift is only checked weekly, whereas the EPA methods requires drift checks after each run. 2. Is too general, too broad, or not sufficiently detailed to assure compliance with EPA regulatory requirements. Voluntary Standard

ISO 10396:1993, Stationary Source Emissions: Sampling for the Automated Determination of Gas Concentrations

Rationale

1. They lack in detail and quality assurance/quality control requirements. Specifically, these two standards do not include the following: (1) Sensitivity of the method; (2) acceptable levels of analyzer calibration error; (3) acceptable levels of sampling system bias; (4) zero drift and calibration drift limits, time span, and required testing frequency; (5) a method to test the interference response of the analyzer; (6) procedures to determine the minimum sampling time per run and minimum measurement time; and (7) specifications for data recorders, in terms of resolution (all types) and 
recording intervals (digital and analog recorders, only). 2. Is too general, too broad, or not sufficiently detailed to assure compliance with EPA regulatory requirements.

Voluntary Standard

ISO 12039:2001, Stationary Source Emissions-- Determination of Carbon

Monoxide, Carbon Dioxide, and Oxygen--Automated Methods

Rationale

This ISO standard is similar to EPA Method 3A, but is missing some key features. In terms of sampling, the hardware required by ISO 12039:2001 does not include a 3-way calibration valve assembly or equivalent to block the sample gas flow while calibration gases are introduced. In its calibration procedures, ISO 12039:2001 only specifies a two-point calibration while EPA Method 3A specifies a three-point calibration. Also, ISO 12039:2001 does not specify performance criteria for calibration error, calibration drift, or sampling system bias tests as in the EPA method, although checks of these quality control features are required by the ISO standard.

31. Government Unique Standard: EPA Method 3B - Oxygen, Carbon Dioxide, Carbon Monoxide, Emission Rate Correction Factor (Incorporated: 1999)

Voluntary Standard

ASTM D3154-00, Standard Method for Average Velocity in a Duct (Pitot Tube Method)

Rationale

1. The standard appears to lack in quality control and quality assurance requirements. It does not include the following: (1) Proof that openings of standard pitot tube have not plugged during the test; (2) if differential pressure gauges other than inclined manometers (e.g., magnehelic gauges) are used, their calibration must be checked after each test series; and (3) the frequency and validity range for calibration of the temperature sensors. 2. They are too general, too broad, or not sufficiently detailed to assure compliance with EPA regulatory requirements.

Voluntary Standard

ASTM D3154-91 (1995), Standard Method for Average Velocity in a Duct (Pitot Tube Method) 
Rationale

Is too general, too broad, or not sufficiently detailed to assure compliance with EPA regulatory requirements.

32. Government Unique Standard: EPA Method 4 - Moisture Content in Stack Gases (Incorporated: 1999)

Voluntary Standard

ASTM D3154-00, Standard Method for Average Velocity in a Duct (Pitot Tube Method)

Rationale

1. The standard appears to lack in quality control and quality assurance requirements. It does not include the following: (1) Proof that openings of standard pitot tube have not plugged during the test; $(2)$ if differential pressure gauges other than inclined manometers (e.g., magnehelic gauges) are used, their calibration must be checked after each test series; and (3) the frequency and validity range for calibration of the temperature sensors.

2. They are too general, too broad, or not sufficiently detailed to assure compliance with EPA regulatory requirements.

Voluntary Standard

ASTM D3154-91 (1995), Standard Method for Average Velocity in a Duct (Pitot Tube Method)

Rationale Is too general, too broad, or not sufficiently detailed to assure compliance with EPA regulatory requirements.

Voluntary Standard ASTM E337-84 (1996), Standard Test Method for Measuring Humidity with a Psychrometer (the Measurement of Wet- and Dry-Bulb Temperatures) Rationale They are too general, too broad, or not sufficiently detailed to assure compliance with EPA regulatory requirements. 
33. Government Unique Standard: EPA Method 5 - Particulate Matter, Stationary Sources (Incorporated: 1999)

Voluntary Standard

ASME PTC-38-80 R85 or C00049, Determination of the Concentration of

Particulate Matter in Gas Streams

Rationale

It lacks sufficient quality assurance and quality control requirements necessary for EPA compliance assurance requirements.

Voluntary Standard

ASTM D3685/D3685M-98, Test Methods for Sampling and Determination of

Particulate Matter in Stack Gases

Rationale

It lacks sufficient quality assurance and quality control requirements necessary for EPA compliance assurance requirements.

Voluntary Standard

ISO 9096:1992, Determination of Concentration and Mass Flow Rate of Particulate Matter in Gas Carrying Ducts-- Manual Gravimetric Method Rationale

It lacks sufficient quality assurance and quality control requirements necessary for EPA compliance assurance requirements.

34. Government Unique Standard: EPA Method 515.1 - Chlorinated Acids in Water by CC/ECD (Incorporated: 1998)

Voluntary Standard

Standard Methods 6640B

Rationale

Standard Methods 6640B for acid herbicides was tentatively deemed impractical for EPA's needs because its sample preparation and quality control procedures were not similar enough to EPA Method 515.1 to ensure that there would not be underreporting of acid herbicide contamination. EPA plans to offer to work with the Standard Methods committee to resolve this issue prior to the next publication. 
35. Government Unique Standard: EPA Method 515.4 - Chlorinated Acids in DW by LL Fast CG/ECD (Incorporated: 2003)

Voluntary Standard

ASTM D5317-98 -- Standard Test Method For Determination of Chlorinated Organic Acid Compounds in Water by Gas Chromatography With an Electron Capture Detector

Rationale

ASTM D5317-98 specifies acceptance windows for the initial demonstration of proficiency for laboratory fortified blank samples that are as small as 0 percent to as large as 223 percent recovery for picloram, with tighter criteria for other regulated contaminants. Therefore, this method permits unacceptably large control limits, which include 0 percent recovery.

Voluntary Standard

Standard Method 6640 B for the chlorinated acids

Rationale

The use of this voluntary consensus standard would have been impractical due to significant shortcomings in the sample preparation and quality control sections of the method instructions. Section 1b of Method SM 6640 B states that the alkaline wash detailed in section $4 \mathrm{~b} 2$ is optional. The hydrolysis that occurs during this step is essential to the analysis of the esters of many of the analytes. Therefore, this step is necessary and cannot be optional. In addition, the method specifies that the quality control limits for laboratoryfortified blanks are to be based upon plus or minus three times the standard deviation of the mean recovery of the analytes, as determined in each laboratory. Therefore, this method permits unacceptably large control limits, which may include 0 percent recovery.

36. Government Unique Standard: EPA Method 531.2 - NMethylcarbamoylozimes/ates, Aqueous In/HPLC (Incorporated: 2003)

Voluntary Standard

Standard Method 6610, 20th Edition

Rationale 
Standard Method 6610, 20th Edition has recently been approved for compliance monitoring. Standard Method 6610, 20th Supplemental Edition permits the use of a strong acid, hydrochloric acid ( $\mathrm{HCL})$, as a preservative. The preservatives in all of the other approved EPA and Standard Methods procedures for these analytes are weak acids that adjust the $\mathrm{pH}$ to a specific value based upon the pKa of the preservative. The use of HCL would require accurate determinations of the $\mathrm{pH}$ of the sample in the field and could be subject to considerable error and possible changes in $\mathrm{pH}$ upon storage. Although not specifically observed for oxamyl or carbofuran during the development of similar methods, structurally similar pesticides have been shown to degrade over time when kept at pH 3. Therefore, approval of this method is impractical because it specifies the use of a strong acid ( $\mathrm{HCL})$ when positive control of the $\mathrm{pH}$ is critical.

Voluntary Standard

Standard Method 6610, 20th Supplemental Edition

Rationale

Standard Method 6610, 20th Edition has recently been approved for compliance monitoring. Standard Method 6610, 20th Supplemental Edition permits the use of a strong acid, hydrochloric acid ( $\mathrm{HCL})$, as a preservative. The preservatives in all of the other approved EPA and Standard Methods procedures for these analytes are weak acids that adjust the $\mathrm{pH}$ to a specific value based upon the pKa of the preservative. The use of HCL would require accurate determinations of the $\mathrm{pH}$ of the sample in the field and could be subject to considerable error and possible changes in $\mathrm{pH}$ upon storage. Although not specifically observed for oxamyl or carbofuran during the development of similar methods, structurally similar pesticides have been shown to degrade over time when kept at pH 3. Therefore, approval of this method is impractical because it specifies the use of a strong acid ( $\mathrm{HCL})$ when positive control of the $\mathrm{pH}$ is critical.

37. Government Unique Standard: EPA Method 5i - Low Level Particulate Matter, Stationary Sources (Incorporated: 2001)

Voluntary Standard

ASTM D6331-98 
Rationale

This standard does not have paired trains as specified in method 5 and does not include some quality control procedures specified in the EPA method and which are appropriate to use in this rule.

38. Government Unique Standard: EPA Method 6 - Sulphur Dioxide Emissions (Incorporated: 1999)

Voluntary Standard

ASME C00031 or PTC 19-10-1981 - Part 10 Flue and Exhaust Gas Analyses

Rationale

Too broad to be useful in regulatory sense. Covers Methods 3, 6, 7, and 15 with variants.

Voluntary Standard

ISO 11632:1998 - Stationary Source Emissions - Determination of the Mass

Concentration of Sulfur Dioxide - Ion Chromatography

Rationale

ISO 11632:1998 - Stationary Source Emissions - Determination of the Mass

Concentration of Sulfur Dioxide - Ion Chromatography

Voluntary Standard

ISO 7934:1998 - Stationary Source Emissions - Determination of the Mass

Concentration of Sulfur Dioxide - Hydrogen Peroxide/Barium Perchlorate/

Thorin Method

Rationale

This standard is only applicable to sources with $30 \mathrm{mg} / \mathrm{m} 3 \mathrm{SO} 2$ or more. In addition, this method does not separate $\mathrm{SO} 3$ from SO2 as does EPA Method 6; therefore, this method is not valid if more than a negligible amount of SO3 is present. Also, does not address ammonia interferences.

39. Government Unique Standard: EPA Method 6c - Sulphur Dioxide Emissions Stationary by IAP (Incorporated: 1999)

Voluntary Standard 
ASTM D5835-95 - Standard Practice for Sampling Stationary Source Emissions for Automated Determination of Gas Concentration

Rationale

Similar to Methods 3a, 6c, 7e, 10, ALT 004, CTM 022. Lacks in detail and quality assurance and quality control requirements. Very similar to ISO 10396.

Voluntary Standard

CAN/CSA Z223.2-M86 - (1986) Method for the Continuous Measurement of Oxygen, Carbon Dioxide, Carbon Monoxide, Sulphur Dioxide, and Oxides of Nitrogen in Enclosed Combustion Flue Gas Streams

Rationale

Too general. This standard lacks in detail and quality assurance/quality control requirements. Appendices with valid quality control information are not a required part of this method.

Voluntary Standard

ISO 10396:1993 - Stationary Source Emissions: Sampling for the Automated Determination of Gas Concentrations

Rationale

Duplicates Method 3a, 6c, 7e, 10, ALT 004, CTM 022. Lacks in detail and quality assurance plus quality control requirements. Similar to ASTM D5835.

40. Government Unique Standard: EPA Method 7 - Nitrogen Oxide Emissions Stationary Sources (Incorporated: 1999)

Voluntary Standard

ASME C00031 or PTC 19-10-1981 - Part 10 Flue and Exhaust Gas Analyses

Rationale

Too broad to be useful in regulatory sense. Covers Methods 3, 6, 7, and 15 with variants.

41. Government Unique Standard: EPA Method 7e - Nitrogen Oxide, Instrumental (Incorporated: 1999)

Voluntary Standard 
ASTM D5835-95 - Standard Practice for Sampling Stationary Source Emissions for Automated Determination of Gas Concentration

Rationale

Similar to Methods 3a, 6c, 7e, 10, ALT 004, CTM 022. Lacks in detail and quality assurance and quality control requirements. Very similar to ISO 10396.

Voluntary Standard

CAN/CSA Z223.2-M86 - (1986) Method for the Continuous Measurement of Oxygen, Carbon Dioxide, Carbon Monoxide, Sulphur Dioxide, and Oxides of Nitrogen in Enclosed Combustion Flue Gas Streams

Rationale

Too general. This standard lacks in detail and quality assurance/quality control requirements. Appendices with valid quality control information are not a required part of this method.

Voluntary Standard

ISO 10396:1993 - Stationary Source Emissions: Sampling for the Automated Determination of Gas Concentrations

Rationale

Duplicates Method 3a, 6c, 7e, 10, ALT 004, CTM 022. Lacks in detail and quality assurance plus quality control requirements. Similar to ASTM D5835.

42. Government Unique Standard: EPA Method ALT 004 (Incorporated: 2002)

Voluntary Standard

ASTM D5835-95 - Standard Practice for Sampling Stationary Source Emissions for Automated Determination of Gas Concentration

Rationale

Similar to Methods 3a, 6c, 7e, 10, ALT 004, CTM 022. Lacks in detail and quality assurance and quality control requirements. Very similar to ISO 10396.

Voluntary Standard

ISO 10396:1993 - Stationary Source Emissions: Sampling for the Automated Determination of Gas Concentrations

Rationale 
Duplicates Method 3a, 6c, 7e, 10, ALT 004, CTM 022. Lacks in detail and quality assurance plus quality control requirements. Similar to ASTM D5835.

43. Government Unique Standard: EPA Method CTM 022 (Incorporated: 2002)

Voluntary Standard

ASTM D5835-95 - Standard Practice for Sampling Stationary Source Emissions for Automated Determination of Gas Concentration

Rationale

Similar to Methods 3a, 6c, 7e, 10, ALT 004, CTM 022. Lacks in detail and quality assurance and quality control requirements. Very similar to ISO 10396.

Voluntary Standard

ISO 10396:1993 - Stationary Source Emissions: Sampling for the Automated Determination of Gas Concentrations

Rationale

Duplicates Method 3a, 6c, 7e, 10, ALT 004, CTM 022. Lacks in detail and quality assurance plus quality control requirements. Similar to ASTM D5835.

44. Government Unique Standard: EPA Method GG - (Title not found in index) (Incorporated: 2003)

Voluntary Standard

ASTM D3031-81 - Method of Test for Total Sulfur in Natural Gas

(Hydrogenation), Withdrawn

Rationale

This method has been deleted from the final rule because it was discontinued by the ASTM in 1990 with no replacement. If the total sulfur content of the fuel being fired in the turbine is less than 0.4 weight percent, we are adding a provision that the following methods may be used to measure the sulfur content of the fuel: ASTM D4084-82 or 94, D5504-01, D6228-98, or the Gas Processors Association Method 2377-86. This provision is consistent with the provision in 40 CFR 60.13(j)(1) allowing alternatives to 
reference method tests to determine relative accuracy of CEMS for sources with emission rates demonstrated to be less than 50 percent of the applicable standard.

45. Government Unique Standard: EPA Performance Specification 2 (nitrogen oxide portion only) (Incorporated: 2001)

Voluntary Standard

ISO 10849:1996, Determination of the Mass Concentration of Nitrogen Oxides-

-Performance

Rationale

Is too general, too broad, or not sufficiently detailed to assure compliance with EPA regulatory requirements.

46. Government Unique Standard: EPA Performance Specification 2 (sulfur dioxide portion only) (Incorporated: 2001)

Voluntary Standard

ISO 7935:1992, Stationary Source Emissions--Determination of the Mass

Concentration of Sulfur Dioxide--Performance Characteristics of Automated Measuring Methods"

Rationale

Is too general, too broad, or not sufficiently detailed to assure compliance with EPA regulatory requirements.

47. Government Unique Standard: EPA Performance Specifications 11 -

Particulate Matter Continuous Monitoring System (Incorporated: 1999)

Voluntary Standard

ISO 10155:1995 - Stationary source emissions. Automated monitoring of mass concentration of particles - Performance characteristics, test methods and specifications.

Rationale 
This international standard is only applicable on a site specific basis by direct correlation with the manual method ISO 9096 (which does not produce particulate matter measurements like EPA Method 5). This appears to be a PM CEMS performance specification similar to EPA Performance Specification 11 , but does not contain detailed RATA procedures. Also, EPA doesn't have a final performance specification to compare this to.

48. Government Unique Standard: GLI Method 2 (Incorporated: 1999)

Voluntary Standard

ISO 7027 - Water Quality Determination of Turbidity

Rationale

EPA has no data upon which to evaluate whether the separate 90 degrees scattered or transmitted light measurement evaluations according to the ISO 7027 method would produce results that are equivalent to results produced by the other methods.

49. Government Unique Standard: Standard Method 2130B (Incorporated: 1999)

Voluntary Standard

ISO 7027 - Water Quality Determination of Turbidity

Rationale

EPA has no data upon which to evaluate whether the separate 90 degrees scattered or transmitted light measurement evaluations according to the ISO 7027 method would produce results that are equivalent to results produced by the other methods.

50. Government Unique Standard: SW846-6010b (Incorporated: 2002)

Voluntary Standard

ASTM C1111-98 (1998) - Standard Test Method for Determining Elements in Waste Streams by Inductively Coupled Plasma-Atomic Emission Spectrometers 
Rationale

This standard lacks details for instrument operation QA/QC, such as optimizing plasma operating conditions; upper limit of linear dynamic range; spectral interference correction; and calibration procedures, which include initial and continuous calibration verifications. Also lacks internal standard and method of standard addition options for samples with interferences. Voluntary Standard ASTM D6349-99 (1999) - Standard Test Method for Determining Major and Minor Elements in Coal, Coke, and Solid Residues from Combustion of Coal and Coke by Inductively Coupled Plasma-Atomic Emission Spectrometers Rationale

This standard lacks details for instrument operation QA/QC, such as optimizing plasma operating conditions, upper limit of linear dynamic range, spectral interference correction, and calibration procedures, that include initial and continuous calibration verifications. Also lacks details for standard preparation, and internal standard and method of standard addition options for samples with interferences.

3. Please list the Voluntary Consensus Standards (VCS) your agency substituted for Government Unique Standards (GUS) in FY 2005 as a result of review under Section 15(b)(7) of OMB Circular A-119: 0

4. Please provide the total number of Voluntary Consensus Standards your agency used during FY 2005: Optional: If possible, also please provide the total number of Nonconsensus Standards that are developed in the private sector your agency used during FY 2005. In addition, please provide your agency's rationale for using the Nonconsensus Standards that are developed in the private sector counted in this question.

Voluntary Consensus Standards: 1384

Other Technical Standards: 0

Rationale:

5. Please enter the Voluntary Consensus Standards Bodies (VCSB) in which your agency participated in during FY 2005: 26 
Voluntary Consensus Standards Body

Acoustical Society of America

American Architectural Manufacturers Association

American Association of Motor Vehicle

Administrators

American College of Radiology

American Gas Association

American National Standards Institute

American Petroleum Institute

American Society for Testing and Materials

American Society of Heating, Refrigerating, and Air

Conditioning Engineers

American Society of Mechanical Engineers

American Society of Quality Control

American Water Works Association

Building Officials and Code Administrators

International

Electronic Industries Alliance

Illuminating Engineering Society of North America

Institute of Electrical and Electronic Engineers

International Electrotechnical Commission

International Organization for Standardization

National Cooperation for Laboratory Accreditation

NSF International

Organization for Economic Cooperation and

Development

Society of Automotive Engineers

undefined

Underwriters Laboratories

United Nations Economic Commission for Europe WP
Acronym

ASA

AAMA

AAMVA

ACR

AGA

ANSI

API

ASTM

ASHRAE

ASME

ASQC

AWWA

BOCA

EIA

IES

IEEE

IEC

ISO

NACLA

NSFI

OECD

SAE

--SELECT--

UL

UNECE

$.29 /$ GRSP 
6. Please provide the total number of your agency's representatives who participated in voluntary consensus standards activities during FY 2005 and the total number of activities these agency representatives participated in: $\mathbf{5 2}$

7. Please provide any conformity assessment activities (as described in "Guidance on Federal Conformity Assessment Activities" found in the Federal Register, Volume 65, Number 155, dated August 10, 2000) in which your agency was involved in FY 2005.

NACLA, INELA

8. Please provide an evaluation of the effectiveness of Circular A-119 policy and recommendations for any changes:

We need feed-back from the regulated community on use of VCSs since the NTTAA and OMB Circular A119: have they made any difference in facilitating conformance to regulatory requirements? In the last five years there has been only two comments to EPA regulations, published in the Federal Register -- and keep in mind we publish nearly 1000 regulation announcements per year -regarding the technical standards sections of regulations. Comments on our regulations focus on the intent and extent of the what is being regulated not on the test methods used. It is difficult to determine how important or significant the OMB Circular is to the purpose of EPA regulations. This in turn makes it difficult to know how to evaluate the effectiveness of the Circular.

9. Please provide any other comments you would like to share on behalf of your agency.

We had 11 new uses of VCSs in regulations this year.

10. Please use this box to provide any additional comments on how your agency currently reports its use of voluntary consensus standards:

The reporting system currently requires a numerical response to question 10-5. Although the number is meaningless in terms of this Agency's policies and operations, we have included "0" here so that this report is not automatically 
rejected by the system as incomplete.

EPA reviews standards when there is a regulatory issue or problem that requires such a review; in response to public comment on a proposed or final regulation; or in the event that some other reason causes the Agency to re-open a final regulation and there is then an opportunity to review referenced standards. In the broadest sense, EPA does not have a regular schedule for review but does so on an as-needed basis.

NIST is working with EPA and other federal agencies to identify small system glitches such as this and fix them. EPA greatly appreciates all the assistance and friendly help from NIST as we prepare and submit our annual report.

10-1. Removed [This question has been deprecated for 2005]

10-2. Removed [This question has been deprecated for 2005]

10-3. Removed [This question has been deprecated for 2005]

10-4. Does your agency report standards that it uses for guidance purposes (as opposed compliance purposes)? (a) Yes; (b) No; (c) Not applicable; No

10-5. Does your agency report use of standards from non-ANSI accredited standards developers, industry consortia groups, or both? (a) non-ANSI Accredited; (b) Consortia; (c) Both; (d) Neither; or (e) Not applicable; C

10-6. Does your agency have a schedule for periodically reviewing its use of standards for purposes of updating such use? (a) Yes; (b) No; No

10-7. How often does your agency review its standards for purposes of updating such use? [enter the number of years]: 0 


\section{$\underline{\text { Federal Communications Commission }}$}

1. Please describe the importance of standards in the achievement of your agency's mission, how your agency uses standards to deliver its primary services in support of its mission, and provide any examples or case studies of standards success:

FCC standards are based on recommendations from IEEE, ANSI and NCRP.

2. Please list the government-unique standards your agency used in lieu of voluntary consensus standards during FY 2005: 0

3. Please list the Voluntary Consensus Standards (VCS) your agency substituted for Government Unique Standards (GUS) in FY 2005 as a result of review under Section 15(b)(7) of OMB Circular A-119: 0

4. Please provide the total number of Voluntary Consensus Standards your agency used during FY 2005: Optional: If possible, also please provide the total number of Nonconsensus Standards that are developed in the private sector your agency used during FY 2005. In addition, please provide your agency's rationale for using the Nonconsensus Standards that are developed in the private sector counted in this question.

Voluntary Consensus Standards: 0

Other Technical Standards: 0

Rationale:

5. Please enter the Voluntary Consensus Standards Bodies (VCSB) in which your agency participated in during FY 2005: 0

6. Please provide the total number of your agency's representatives who participated in voluntary consensus standards activities during FY 2005 and the total number of activities these agency representatives participated in: 0

7. Please provide any conformity assessment activities (as described in "Guidance on Federal Conformity Assessment Activities" found in the Federal Register, Volume 65, Number 155, dated August 10, 2000) in which your agency was involved in FY 2005. 
N/A

8. Please provide an evaluation of the effectiveness of Circular A-119 policy and recommendations for any changes:

$\mathrm{N} / \mathrm{A}$

9. Please provide any other comments you would like to share on behalf of your agency.

FCC guidelines for RF safety are stated in 47 CFR 1.1307(b)(4) \& (b)(5)

10. Please use this box to provide any additional comments on how your agency currently reports its use of voluntary consensus standards:

10-1. Removed [This question has been deprecated for 2005]

10-2. Removed [This question has been deprecated for 2005]

10-3. Removed [This question has been deprecated for 2005]

10-4. Does your agency report standards that it uses for guidance purposes (as opposed compliance purposes)? (a) Yes; (b) No; (c) Not applicable; No

10-5. Does your agency report use of standards from non-ANSI accredited standards developers, industry consortia groups, or both? (a) non-ANSI Accredited; (b) Consortia; (c) Both; (d) Neither; or (e) Not applicable; D

10-6. Does your agency have a schedule for periodically reviewing its use of standards for purposes of updating such use? (a) Yes; (b) No; No

10-7. How often does your agency review its standards for purposes of updating such use? [enter the number of years]: 10 


\section{Federal Trade Commission}

Title: Federal Trade Commission (FTC) Fiscal Year 2005 Agency Report

1. Please describe the importance of standards in the achievement of your agency's mission, how your agency uses standards to deliver its primary services in support of its mission, and provide any examples or case studies of standards success:

The Federal Trade Commission is an independent agency of the United States Government charged with enforcing competition and consumer protection laws. The Commission's only contact with voluntary consensus standards and the organizations that produce them is in connection with the enforcement of the Federal Trade Commission Act, which prohibits unfair methods of competition and unfair or deceptive acts and practices affecting commmerce. The Commision does not promulgate its own standards or engage in the other standards activities pertinent to OMB Circular A-119.

2. Please list the government-unique standards your agency used in lieu of voluntary consensus standards during FY 2005: 0

3. Please list the Voluntary Consensus Standards (VCS) your agency substituted for Government Unique Standards (GUS) in FY 2005 as a result of review under Section 15(b)(7) of OMB Circular A-119: 0

4. Please provide the total number of Voluntary Consensus Standards your agency used during FY 2005: Optional: If possible, also please provide the total number of Nonconsensus Standards that are developed in the private sector your agency used during FY 2005. In addition, please provide your agency's rationale for using the Nonconsensus Standards that are developed in the private sector counted in this question.

Voluntary Consensus Standards: 0

Other Technical Standards: 0

Rationale: 
5. Please enter the Voluntary Consensus Standards Bodies (VCSB) in which your agency participated in during FY 2005: 0

6. Please provide the total number of your agency's representatives who participated in voluntary consensus standards activities during FY 2005 and the total number of activities these agency representatives participated in: 0

7. Please provide any conformity assessment activities (as described in "Guidance on Federal Conformity Assessment Activities" found in the Federal Register, Volume 65, Number 155, dated August 10, 2000) in which your agency was involved in FY 2005.

See response to question 1 .

8. Please provide an evaluation of the effectiveness of Circular A-119 policy and recommendations for any changes:

See response to question 1 .

9. Please provide any other comments you would like to share on behalf of your agency.

N/A

10. Please use this box to provide any additional comments on how your agency currently reports its use of voluntary consensus standards:

10-1. Removed [This question has been deprecated for 2005]

10-2. Removed [This question has been deprecated for 2005]

10-3. Removed [This question has been deprecated for 2005]

10-4. Does your agency report standards that it uses for guidance purposes (as opposed compliance purposes)? (a) Yes; (b) No; (c) Not applicable; C

10-5. Does your agency report use of standards from non-ANSI accredited standards developers, industry consortia groups, or both? (a) non-ANSI Accredited; (b) Consortia; (c) Both; (d) Neither; or (e) Not applicable; E 
10-5. Does your agency have a schedule for periodically reviewing its use of standards for purposes of updating such use? (a) Yes; (b) No; No

10-5. How often does your agency review its standards for purposes of updating such use? [enter the number of years]: 0 


\section{$\underline{\text { General Services Administration }}$}

Title: General Services Administration (GSA) Fiscal Year 2005 Agency Report

1. Please describe the importance of standards in the achievement of your agency's mission, how your agency uses standards to deliver its primary services in support of its mission, and provide any examples or case studies of standards success:

Standards play a significant role in our program. They are used to establish baselines for product quality, performance and features; allow competitive procurement of functionally equivalent products and; when necessary, ensure interchangeability of products produced under different contracts and across different contract periods.

2. Please list the government-unique standards your agency used in lieu of voluntary consensus standards during FY 2005: 8

1. Government Unique Standard: Federal Specification A-A-1922 - Shield, Expansion (Caulking Anchors, Single Lead) (Incorporated: 2004)

Voluntary Standard

ASTM E488 - Standard Test Methods for Strength of Anchors in Concrete and Masonry Elements

Rationale

This government-unique standard is prepared \& maintained by the Defense Logistics Agency (DLA). Both the GSA \& DLA contract for products that reference A-A-1922. In order to maintain product continuity in the Federal marketplace, we must cite the standard as the DLA.

2. Government Unique Standard: Federal Specification A-A-1923 - Shield Expansion (Lag, Machine and Externally Threaded Wedge Bolt Anchors) (Incorporated: 2004)

Voluntary Standard 
ASTM E488 - Standard Test Methods for Strength of Anchors in Concrete and Masonry Elements

Rationale

This government-unique standard is prepared \& maintained by the Defense Logistics Agency (DLA). Both the GSA \& DLA contract for products that reference A-A-1923. In order to maintain product continuity in the Federal marketplace, we must cite the standard as the DLA.

3. Government Unique Standard: Federal Specification A-A-1924 - Shield, Expansion (Self Drilling Tubular Expansion Shell Bolt Anchors) (Incorporated: 2004)

Voluntary Standard

ASTM E488 - Standard Test Methods for Strength of Anchors in Concrete and Masonry Elements

Rationale

This government-unique standard is prepared \& maintained by the Defense Logistics Agency (DLA). Both the GSA \& DLA contract for products that reference A-A-1924. In order to maintain product continuity in the Federal marketplace, we must cite the standard as the DLA.

4. Government Unique Standard: Federal Specification A-A-1925 - Shield, Expansion (Nail Anchors) (Incorporated: 2000)

Voluntary Standard

ASTM E488 - Standard Test Methods for Strength of Anchors in Concrete and Masonry Elements

Rationale

This government-unique standard is prepared \& maintained by the Defense Logistics Agency (DLA). Both the GSA \& DLA contract for products that reference $A-A-1925$. In order to maintain product continuity in the Federal marketplace, we must cite the standard as the DLA. 
5. Government Unique Standard: Federal Specification A-A-59486 - Padlock Set (Individually Keyed or Keyed Alike) (Incorporated: 2004)

Voluntary Standard

ASTM F883 - Standard Test Methods for Strength of Anchors in Concrete and Masonry Elements

Rationale

Commercial Item Descriptions A-A-59486 contain military specific requirements that are not present in ASTM F883. Military agencies are a primary customer of our agency and they are mandated to use padlocks procured via conformance to the GUS.

6. Government Unique Standard: Federal Specification A-A-59487 - Padlock (Key Operated) (Incorporated: 2004)

Voluntary Standard

ASTM F883 - Standard Test Methods for Strength of Anchors in Concrete and Masonry Elements

Rationale

Commercial Item Descriptions A-A-59487 contain military specific requirements that are not present in ASTM F883. Military agencies are a primary customer of our agency and they are mandated to use padlocks procured via conformance to the GUS.

7. Government Unique Standard: Federal Specification KKK-A-1822E - Federal Specification for Ambulances (Incorporated: 2003)

Voluntary Standard

ASTM F2020 - Standard Practice for Design, Construction, and Procurement of Emergency Medical Services Ambulances

Rationale

The ASTM Standard Practice for Design, Construction, and Procurement of Emergency Medical Services (EMSS) Ambulances (ASTM F2020) is not practical 
for use, and therefore GSA uses the Federal Specification for Ambulances (KKK-A-1822E). GSA has determined the ASTM document is not practical for use for the following reasons:

1) GSA has determined that ASTM F2020 contains specific practices that are technically and economically impractical to use for the acquisition of commercial based vehicles because the document is financially burdensome and technically ineffective. Specifically at issue is the ASTM Standard Specification for Medical Oxygen Delivery Systems for EMS Ground Vehicles, F1949-99 which is inclusive to ASTM F2020.

2) GSA has determined that ASTM F2020 is impractical because it is defined as a standard practice which is ambiguous and an ineffective substitution for specifications or requirements for use in GSA contract documents. ASTM F1949-99, a Standard Specification for Medical Oxygen Delivery Systems for EMS Ground Vehicles is included in ASTM F2020. ASTM F1949-99 is defined as a "standard specification".

3) GSA has determined that ASTM F2020 is impractical because ASTM International does not provide interpretations and written guidance to their publications which is inadequate and less useful. ASTM members may only offer personal opinions. ASTM offers no mechanism to support timely resolution of conflicts between contractor and procurement organizations on technical subject matter. GSA provides interpretations, clarifications and engineering determinations when required. This is one of the most important concerns presented by the Ambulance Manufacturers Division (AMD).

4) The $A M D$ has determined through consensus that it is impractical to replace the Federal Specification for Ambulances, KKK-A-1822E with the ASTM Standard Practice, F2020. GSA initiated a survey to collect public responses from a wide range of constituent users of the Federal Ambulance Specification. The National Association of Emergency Medical Technicians (NAEMT), the International Association of Fire Chiefs (IAFC), the National Association of State EMS Directors (NASEMSD) and the National Association of EMS Physicians universally accept and support the continued use of the 
Federal Specification. The AMD and constituent users have determined that it is impractical to replace the Federal Specification for Ambulances, KKK-A$1822 \mathrm{E}$ with the ASTM Standard Practice, F2020 because rule promulgation is burdensome and costly. Staff and administration resources would need to be diverted in each state EMS office to implement the change in statutes, public health codes, rules and regulations.

5) GSA has determined that ASTM F2020 is impractical because it is burdensome to GSA procurement efforts. While the current ASTM document recites many of the requirements from the Federal Specification, a future ASTM document would likely have diverging requirements unacceptable to the Government. This was verified by a member of the ASTM F2020 subcommittee at the September 4, 2003 meeting of the Federal Interagency Committee on Emergency Medical Services.

8. Government Unique Standard: MIL-G-9954 - Glass Beads for Cleaning and Peening (Incorporated: 2000)

Voluntary Standard

SAE/AMS 2431 - Peening Media, General Requirements

Rationale

This government-unique standard contains specific size \& performance required for Air Force critical applications that are not present in the voluntary standards.

3. Please list the Voluntary Consensus Standards (VCS) your agency substituted for Government Unique Standards (GUS) in FY 2005 as a result of review under Section 15(b)(7) of OMB Circular A-119: 0

4. Please provide the total number of Voluntary Consensus Standards your agency used during FY 2005: Optional: If possible, also please provide the total number of Nonconsensus Standards that are developed in the private sector your agency used during FY 2005. In addition, please provide your agency's rationale for using the Nonconsensus Standards that are developed in the private sector counted in this question. 
Voluntary Consensus Standards: 516

Other Technical Standards: 0

Rationale:

5. Please enter the Voluntary Consensus Standards Bodies (VCSB) in which your agency participated in during FY 2005: 25

\begin{tabular}{|c|c|}
\hline Voluntary Consensus Standards Body & Acronym \\
\hline Aerospace Industries Association of America & AIA \\
\hline Aerospace Material Standards & AMS \\
\hline Ambulance Manufacturers Division & AMD \\
\hline American Gas Association & AGA \\
\hline American National Standards Institute & ANSI \\
\hline American Society for Testing and Materials & ASTM \\
\hline $\begin{array}{l}\text { American Society of Heating, Refrigerating, and Air- } \\
\text { Conditioning Engineers }\end{array}$ & ASHRAE \\
\hline American Society of Mechanical Engineers & ASME \\
\hline Automotive Lift Institute - ALOIM & ALI \\
\hline Builders Hardware Manufacturers Association & BHMA \\
\hline Composite Panel Association & CPA \\
\hline Gas Applicance Manufacturers Association & GAMA \\
\hline International Organization for Standardization & ISO \\
\hline Kitchen Cabinet Manufacturers Association & KCMA \\
\hline National Aerospace and Defence Contractors & NADCAP \\
\hline \multicolumn{2}{|l|}{ Accreditation Program } \\
\hline National Electrical Manufacturers Association & NEMA \\
\hline National Fire Protection Association & NFPA \\
\hline National Truck Equipment Association & NTEA \\
\hline Performance Review Institute & PRI \\
\hline Society of Automotive Engineers & SAE \\
\hline Technical Association of the Pulp an & IPPI \\
\hline
\end{tabular}


The Business and Institutional Furniture

Manufacturer's Association

The Manitenance Council of American Trucking

Association

The Society for Protective Coatings

Underwriters Laboratories
BIFMA

TMC/ATA

SSPC

UL

6. Please provide the total number of your agency's representatives who participated in voluntary consensus standards activities during FY 2005 and the total number of activities these agency representatives participated in: 22

7. Please provide any conformity assessment activities (as described in "Guidance on Federal Conformity Assessment Activities" found in the Federal Register, Volume 65, Number 155, dated August 10, 2000) in which your agency was involved in FY 2005.

A variety of conformity assessment activities were used including direct inspection and testing, supplier and third party testing, and product qualification and listing.

8. Please provide an evaluation of the effectiveness of Circular A-119 policy and recommendations for any changes:

Somewhat effective. Needs to be significantly simplified for ease of response. Needs to contain a more direct and simplified questions to the point.

9. Please provide any other comments you would like to share on behalf of your agency.

No comments.

10. Please use this box to provide any additional comments on how your agency currently reports its use of voluntary consensus standards:

10-1. Removed [This question has been deprecated for 2005]

10-2. Removed [This question has been deprecated for 2005] 
10-3. Removed [This question has been deprecated for 2005]

10-4. Does your agency report standards that it uses for guidance purposes (as opposed compliance purposes)? (a) Yes; (b) No; (c) Not applicable; C

10-5. Does your agency report use of standards from non-ANSI accredited standards developers, industry consortia groups, or both? (a) non-ANSI Accredited; (b) Consortia; (c) Both; (d) Neither; or (e) Not applicable; C

10-5. Does your agency have a schedule for periodically reviewing its use of standards for purposes of updating such use? (a) Yes; (b) No; Yes

10-5. How often does your agency review its standards for purposes of updating such use? [enter the number of years]: 1 


\section{Government Printing Office}

Title: Government Printing Office (GPO) Fiscal Year 2005 Agency Report

1. Please describe the importance of standards in the achievement of your agency's mission, how your agency uses standards to deliver its primary services in support of its mission, and provide any examples or case studies of standards success:

Standards are very important in our acquisition process as well as other services that are provided such as in IT and engineering.

2. Please list the government-unique standards your agency used in lieu of voluntary consensus standards during FY 2005: 1

1. Government Unique Standard: "standard samples" for the procurement of printing paper (Incorporated: 2005)

Voluntary Standard

None

Rationale

Physical samples are required for procurement of printing papers. There is no consensus body to develop such a set.

3. Please list the Voluntary Consensus Standards (VCS) your agency substituted for Government Unique Standards (GUS) in FY 2005 as a result of review under Section 15(b)(7) of OMB Circular A-119: 0

4. Please provide the total number of Voluntary Consensus Standards your agency used during FY 2005: Optional: If possible, also please provide the total number of Nonconsensus Standards that are developed in the private sector your agency used during FY 2005. In addition, please provide your agency's rationale for using the Nonconsensus Standards that are developed in the private sector counted in this question.

Voluntary Consensus Standards: 0 
Other Technical Standards: 0

Rationale:

5. Please enter the Voluntary Consensus Standards Bodies (VCSB) in which your agency participated in during FY 2005: 0

6. Please provide the total number of your agency's representatives who participated in voluntary consensus standards activities during FY 2005 and the total number of activities these agency representatives participated in: 0

7. Please provide any conformity assessment activities (as described in "Guidance on Federal Conformity Assessment Activities" found in the Federal Register, Volume 65, Number 155, dated August 10, 2000) in which your agency was involved in FY 2005.

0

8. Please provide an evaluation of the effectiveness of Circular A-119 policy and recommendations for any changes:

The GPO is a Congressional agency and as such is not required to follow the circular to the letter. However, since the GPO provides services for executive agencies, the Agency acknowledges the definitions set out in the circular. The circular is important to us because of our use of standards in our acquisition programs.

9. Please provide any other comments you would like to share on behalf of your agency.

None

10. Please use this box to provide any additional comments on how your agency currently reports its use of voluntary consensus standards:

We have no set Agency-wide program

10-1. Removed [This question has been deprecated for 2005] 
10-2. Removed [This question has been deprecated for 2005]

10-3. Removed [This question has been deprecated for 2005]

10-4. Does your agency report standards that it uses for guidance purposes (as opposed compliance purposes)? (a) Yes; (b) No; (c) Not applicable; C

10-5. Does your agency report use of standards from non-ANSI accredited standards developers, industry consortia groups, or both? (a) non-ANSI Accredited; (b) Consortia; (c) Both; (d) Neither; or (e) Not applicable; E

10-5. Does your agency have a schedule for periodically reviewing its use of standards for purposes of updating such use? (a) Yes; (b) No; No

10-5. How often does your agency review its standards for purposes of updating such use? [enter the number of years]: $\mathbf{5}$ 
$\underline{\text { National Aeronautics and Space Administration }}$

1. Please describe the importance of standards in the achievement of your agency's mission, how your agency uses standards to deliver its primary services in support of its mission, and provide any examples or case studies of standards success:

The NASA Technical Standards Program is one of the key elements in the achievement of NASA's Mission and serves all of the Agency's Programs, Projects, and Facilities. The Technical Standards Program's Website accessible at http://standards.nasa.gov provides direct access to standards from many sources to NASA personnel for use in research, development, testing, and procurement. Standards not only provide the basis for ensuring the capability and reliability of systems, but are also the basis of cooperative space activities with other organizations. Use of voluntary consensus standards does appear to result in savings in development time and costs, avoiding duplication of private sector activities, improved collaboration and cooperation with the private sector, and increased goodwill for the Federal government. Savings from use of VCS allow NASA to effectively apply resources to other internal activities and provide safe, quality systems and operations.

2. Please list the government-unique standards your agency used in lieu of voluntary consensus standards during FY 2005:

This agency reports voluntary consensus standards usage on a category basis

3. Please list the Voluntary Consensus Standards (VCS) your agency substituted for Government Unique Standards (GUS) in FY 2005 as a result of review under Section 15(b)(7) of OMB Circular A-119: 1

\section{Voluntary Standard}

AIAA Guide 095-2004, Guide to Safety of Hydrogen and Hydrogen System

\section{Government Standard} NASA Safety Standard (NSS) 1740.15, Safety Standard for Hydrogen and Hydrogen Systems 
4. Please provide the total number of Voluntary Consensus Standards your agency used during FY 2005: Optional: If possible, also please provide the total number of Nonconsensus Standards that are developed in the private sector your agency used during FY 2005. In addition, please provide your agency's rationale for using the Nonconsensus Standards that are developed in the private sector counted in this question.

Voluntary Consensus Standards: 195

Other Technical Standards: 0

Rationale: A total of 195 new VCS was added to the NASA Preferred Technical Standards list. Note that NASA uses the "categorical" method of reporting and lists only the number of new standards added each year. NASA also downloaded over 50,000 VCS's from the NASA Technical Standards System for use on Programs and Projects)

5. Please enter the Voluntary Consensus Standards Bodies (VCSB) in which your agency participated in during FY 2005: 31

Voluntary Consensus Standards Body

Acoustical Society of America

Aerospace Industries Association of America

American Institute of Aeronautics and Astronautics

American National Standards Institute

American Society for Nondestructive Testing

American Society For Quality

American Society for Testing and Materials

American Society of Agricultural Engineers

American Society of Mechanical Engineers

American Society of Metals

American Welding Society

Consultative Committee for Space Data Systems

Electronic Industries Alliance

Illuminating Engineering Society of North America

\section{Acronym}

ASA

AIA

AIAA

ANSI

ASNT

ASQ

ASTM

ASAE

ASME

ASM

AWS

CCSDS

EIA

IES 


$\begin{array}{ll}\text { Institute for Interconnecting and Packaging } & \text { IPEC } \\ \text { Electronic Circuits } & \\ \text { Institute of Electrical and Electronic Engineers } & \text { IEEE } \\ \text { Institute of Environmental Sciences \& Technology } & \text { IEST } \\ \text { Interconnection Technology Research Institute } & \text { ITRI } \\ \text { International Astronomical Union } & \text { IAU } \\ \text { International Electrotechnical Commission } & \text { IEC } \\ \text { International Organization for Standardization } & \text { ISO } \\ \text { Internet Society } & \text { ISOC } \\ \text { National Association of Corrosion Engineers } & \text { NACE } \\ \text { International } & \\ \text { National Conference of Standards Laboratories } & \text { NCSL } \\ \text { National Fire Protection Association } & \text { NFPA } \\ \text { National Hydrogen Association } & \text { NHA } \\ \text { Organization for the Advancement of Structured } & \text { OASIS } \\ \text { Information Standards } & \\ \text { Radio Technical Commission for Aeronautics } & \text { RTCA } \\ \text { Society of Automotive Engineers } & \text { SAE } \\ \text { Space Frequency Coordination Group } & \text { SFCG } \\ \text { Telecommunications Industry Association } & \text { TIA }\end{array}$

6. Please provide the total number of your agency's representatives who participated in voluntary consensus standards activities during FY 2005 and the total number of activities these agency representatives participated in: 172

7. Please provide any conformity assessment activities (as described in "Guidance on Federal Conformity Assessment Activities" found in the Federal Register, Volume 65, Number 155, dated August 10, 2000) in which your agency was involved in FY 2005.

NASA's Office of Safety and Mission Assurance conducts conformity assessments internal to NASA at the Agency level via its audits, assessments, and reviews processes according to NASA Procedural Requirements (NPR) 8705.6, "Safety and Mission Assurance Audits, Assessments, and Reviews". Conformity 
assessments of NASA contractors are based on requirements of NASA Policy Directive (NPD) 8730.5 and the NASA Quality Policy. In addition, NASA routinely utilizes other government agencies to assist with Contract Administration Services, including substantial conformity assessment activities. The Defense Contract and Audit Agency, Defense Contract Management Agency, Office of Naval Research, and other activities continue to provide conformity assessment services for NASA Programs.

8. Please provide an evaluation of the effectiveness of Circular A-119 policy and recommendations for any changes:

NASA's efforts to enhance the use of non-government Standards Developing Organizations' Voluntary Consensus Standards continue to be stimulated by the guidance and directives provided in OMB Circular A-119.

9. Please provide any other comments you would like to share on behalf of your agency.

None

10. Please use this box to provide any additional comments on how your agency currently reports its use of voluntary consensus standards:

The Agency reports its usage of non-government Standards Developing Organizations' Voluntary Consensus Standards on a categorical basis. A listing of the 1,564 VCSs endorsed by the Agency as NASA Preferred Technical Standards may be obtained from http://standards.nasa.gov.

10-1. Removed [This question has been deprecated for 2005]

10-2. Removed [This question has been deprecated for 2005]

10-3. Removed [This question has been deprecated for 2005]

10-4. Does your agency report standards that it uses for guidance purposes (as opposed compliance purposes)? (a) Yes; (b) No; (c) Not applicable; Yes 
10-5. Does your agency report use of standards from non-ANSI accredited standards developers, industry consortia groups, or both? (a) non-ANSI Accredited; (b) Consortia; (c) Both; (d) Neither; or (e) Not applicable; C

10-6. Does your agency have a schedule for periodically reviewing its use of standards for purposes of updating such use? (a) Yes; (b) No; No

10-7. How often does your agency review its standards for purposes of updating such use? [enter the number of years]: $\mathbf{5}$ 


\section{National Archives and Records Administration}

1. Please describe the importance of standards in the achievement of your agency's mission, how your agency uses standards to deliver its primary services in support of its mission, and provide any examples or case studies of standards success:

ISO 15489 is used as a framework for much of NARA's Federal Records Management Training. As agencies develop requirements for record series and systems, ISO 15489 provides a systematic strategy for capturing and maintaining records, regardless of media or format. In addition, the standard defines characteristics needed to support a trustworthy recordkeeping system.

2. Please list the government-unique standards your agency used in lieu of voluntary consensus standards during FY 2005: 1

1. Government Unique Standard: NARA data standard (Incorporated: 2000)

Voluntary Standard

Archives, Personal Papers, and Manuscripts (APPM);

General International Standard Archival Description (ISAD $(G))$;

International Standard Archival Authority Record for Corporate Bodies, Persons, and Families (ISAAR(CPF));

Encoded Archival Description (EAD);

Machine Readable Cataloging (MARC)

Rationale

These voluntary standards do not meet the precise needs of the agency.

3. Please list the Voluntary Consensus Standards (VCS) your agency substituted for Government Unique Standards (GUS) in FY 2005 as a result of review under Section 15(b)(7) of OMB Circular A-119: 0

4. Please provide the total number of Voluntary Consensus Standards your agency used during FY 2005: Optional: If possible, also please provide the total number of Nonconsensus Standards that are developed in the private sector your agency used during FY 2005. In addition, please provide your agency's rationale for using the Nonconsensus Standards that are developed in the private sector counted in this question. 
Voluntary Consensus Standards: 89

Other Technical Standards: 0

Rationale:

5. Please enter the Voluntary Consensus Standards Bodies (VCSB) in which your agency participated in during FY 2005: 10

\begin{tabular}{|c|c|}
\hline Voluntary Consensus Standards Body & Acronym \\
\hline American Society for Testing and Materials & ASTM \\
\hline \multicolumn{2}{|c|}{ Association for Information and Image Management AIIM } \\
\hline Consultative Committee for Space Data Systems & CCSDS \\
\hline Federal Geographic Data Committee & FGDC \\
\hline Institute of Electrical and Electronic Engineers & IEEE \\
\hline International Council on Archives & ICA \\
\hline International Organization for Standardization & ISO \\
\hline National Fire Protection Association & NFPA \\
\hline National Information Standards Organization & NISO \\
\hline Society of American Archivists & SAA \\
\hline
\end{tabular}

6. Please provide the total number of your agency's representatives who participated in voluntary consensus standards activities during FY 2005 and the total number of activities these agency representatives participated in: 16

7. Please provide any conformity assessment activities (as described in "Guidance on Federal Conformity Assessment Activities" found in the Federal Register, Volume 65, Number 155, dated August 10, 2000) in which your agency was involved in FY 2005.

NARA did not participate in any conformity assessment activities in FY 2005.

8. Please provide an evaluation of the effectiveness of Circular A-119 policy and recommendations for any changes:

We believe the Circular is working effectively and have no recommendations for changes. 
9. Please provide any other comments you would like to share on behalf of your agency.

Rationale for the use of GUS (question 2):

NARA has combined elements of these standards, because no one standard was designed to meet our descriptive needs, for example:

1. Some of these standards are library standards, not archival standards, and thus were not wholly suitable;

2. Some of these standards dictate a physical design solution that NARA does not find technically sound;

3. Some of these standards focus on personal papers collections, not government records.

It should also be understood that the archival description standard is a standard that NARA is using for description of its own holdings, not a standard imposed on the external world.

10. Please use this box to provide any additional comments on how your agency currently reports its use of voluntary consensus standards:

10-1. Removed [This question has been deprecated for 2005]

10-2. Removed [This question has been deprecated for 2005]

10-3. Removed [This question has been deprecated for 2005]

10-4. Does your agency report standards that it uses for guidance purposes (as opposed compliance purposes)? (a) Yes; (b) No; (c) Not applicable; No

10-5. Does your agency report use of standards from non-ANSI accredited standards developers, industry consortia groups, or both? (a) non-ANSI Accredited; (b) Consortia; (c) Both; (d) Neither; or (e) Not applicable; A

10-6. Does your agency have a schedule for periodically reviewing its use of standards for purposes of updating such use? (a) Yes; (b) No; Yes

10-7. How often does your agency review its standards for purposes of updating such use? [enter the number of years]: 3 


\section{National Science Foundation}

Title: National Science Foundation (NSF) Fiscal Year 2005 Agency Report

1. Please describe the importance of standards in the achievement of your agency's mission, how your agency uses standards to deliver its primary services in support of its mission, and provide any examples or case studies of standards success:

NSF's involvement in standards-related activities is primarily through staff participation in national and international organizations that set voluntary consensus standards for industry.

2. Please list the government-unique standards your agency used in lieu of voluntary consensus standards during FY 2005: 0

3. Please list the Voluntary Consensus Standards (VCS) your agency substituted for Government Unique Standards (GUS) in FY 2005 as a result of review under Section 15(b)(7) of OMB Circular A-119: 0

4. Please provide the total number of Voluntary Consensus Standards your agency used during FY 2005: Optional: If possible, also please provide the total number of Nonconsensus Standards that are developed in the private sector your agency used during FY 2005. In addition, please provide your agency's rationale for using the Nonconsensus Standards that are developed in the private sector counted in this question.

Voluntary Consensus Standards: 0

Other Technical Standards: 0

Rationale: We have not used any Voluntary Consensus Standards.

5. Please enter the Voluntary Consensus Standards Bodies (VCSB) in which your agency participated in during FY 2005: 4

\section{Voluntary Consensus Standards Body $\quad \underline{\text { Acronym }}$}

American Society for Testing and Materials ASTM

IEEE - Bioinformatics Standards Committee BSC/IEEE 
International Telecommunication Union ITU

National Spectrum Managers Association NSMA

6. Please provide the total number of your agency's representatives who participated in voluntary consensus standards activities during FY 2005 and the total number of activities these agency representatives participated in: $\mathbf{4}$

7. Please provide any conformity assessment activities (as described in "Guidance on Federal Conformity Assessment Activities" found in the Federal Register, Volume 65, Number 155, dated August 10, 2000) in which your agency was involved in FY 2005.

None.

8. Please provide an evaluation of the effectiveness of Circular A-119 policy and recommendations for any changes:

Circular A-119 is effective. We do not recommended any change.

9. Please provide any other comments you would like to share on behalf of your agency.

No comments.

10. Please use this box to provide any additional comments on how your agency currently reports its use of voluntary consensus standards:

No comment.

10-1. Removed [This question has been deprecated for 2005]

10-2. Removed [This question has been deprecated for 2005]

10-3. Removed [This question has been deprecated for 2005]

10-4. Does your agency report standards that it uses for guidance purposes (as opposed compliance purposes)? (a) Yes; (b) No; (c) Not applicable; Yes 
10-5. Does your agency report use of standards from non-ANSI accredited standards developers, industry consortia groups, or both? (a) non-ANSI Accredited; (b) Consortia; (c) Both; (d) Neither; or (e) Not applicable; E

10-5. Does your agency have a schedule for periodically reviewing its use of standards for purposes of updating such use? (a) Yes; (b) No; No

10-5. How often does your agency review its standards for purposes of updating such use? [enter the number of years]: 0 
Nuclear Regulatory Commission

1. Please describe the importance of standards in the achievement of your agency's mission, how your agency uses standards to deliver its primary services in support of its mission, and provide any examples or case studies of standards success:

Utilization of consensus codes and standards by the NRC provides effective replacements for NRC-generated regulations. Within the framework of Public Law 104-113, NRC performs reviews of its regulations and regulatory guidance to determine which regulations can be replaced by consensus standards. The NRC participates on many codes and standards development committees to provide staff input and guidance to help assure published codes and standards can be endorsed in the regulatory process. Contributing to the technical bases for national and international codes and standards is an important part of the regulatory process. The outcomes of these efforts significantly increase the assurance that published codes and standards can be endorsed in lieu of using NRC developed technical basis products, such as regulations, regulatory guides, or staff review guidance.

An example of a standards success for NRC involves the endorsement of the Sections III (Construction of Nuclear Facility Components) and XI (In-service Inspection of Nuclear Power Plant Components) of the American Society of Mechanical Engineers (ASME) Boiler and Pressure Vessel Code and the ASME Code for Operation and Maintenance of Nuclear Power Plants (In-service Testing of Nuclear Facility Pumps and Valves) in our regulations and regulatory guidance. These ASME Codes are developed through the consensus process, and endorsement of the ASME Code by the NRC provides a method of incorporating rules into the regulatory process that are acceptable to the NRC and have received industry participation in their development. If the NRC did not take action to endorse the ASME Code, the NRC would either have to independently develop standards for construction, in-service inspection (ISI), and in-service testing (IST) of Nuclear Power Plant Components or establish the acceptable standards and methods for construction, ISI, and IST on a case-by-case basis. 
2. Please list the government-unique standards your agency used in lieu of voluntary consensus standards during FY 2005: 0

3. Please list the Voluntary Consensus Standards (VCS) your agency substituted for Government Unique Standards (GUS) in FY 2005 as a result of review under Section 15(b)(7) of OMB Circular A-119: 0

4. Please provide the total number of Voluntary Consensus Standards your agency used during FY 2005: Optional: If possible, also please provide the total number of Nonconsensus Standards that are developed in the private sector your agency used during FY 2005. In addition, please provide your agency's rationale for using the Nonconsensus Standards that are developed in the private sector counted in this question.

Voluntary Consensus Standards: 1

Other Technical Standards: 0

Rationale:

5. Please enter the Voluntary Consensus Standards Bodies (VCSB) in which your agency participated in during FY 2005: 15

\begin{tabular}{ll} 
Voluntary Consensus Standards Body & Acronym \\
\hline American Concrete Institute & ACI \\
American Institute of Steel Construction & AISC \\
American National Standards Institute & ANSI \\
American Nuclear Society & ANS \\
American Society for Testing and Materials & ASTM \\
American Society of Civil Engineers & ASCE \\
American Society of Mechanical Engineers & ASME \\
Health Physics Society & HPS \\
Institute of Electrical and Electronic Engineers & IEEE \\
Institute of Nuclear Materials Management & INMM \\
Instrumentation Society of America & ISA \\
International Electrotechnical Commission & IEC
\end{tabular}


International Organization for Standardization

National Council of Radiation Protection and

Measurements

National Fire Protection Association
ISO

NCRPM

NFPA

6. Please provide the total number of your agency's representatives who participated in voluntary consensus standards activities during FY 2005 and the total number of activities these agency representatives participated in: 153

7. Please provide any conformity assessment activities (as described in "Guidance on Federal Conformity Assessment Activities" found in the Federal Register, Volume 65, Number 155, dated August 10, 2000) in which your agency was involved in FY 2005.

\section{No Comment}

8. Please provide an evaluation of the effectiveness of Circular A-119 policy and recommendations for any changes:

The NRC believes that the Circular provides appropriate direction and encouragement for federal agencies to develop internal agency-wide guidelines. The circular also provides sufficient and reasonable flexibility for each agency to make an independent determination relative to participation on voluntary consensus bodies and use of developed standards

9. Please provide any other comments you would like to share on behalf of your agency.

No Comment

10. Please use this box to provide any additional comments on how your agency currently reports its use of voluntary consensus standards:

No Comment

10-1. Removed [This question has been deprecated for 2005]

10-2. Removed [This question has been deprecated for 2005] 
10-3. Removed [This question has been deprecated for 2005]

10-4. Does your agency report standards that it uses for guidance purposes (as opposed compliance purposes)? (a) Yes; (b) No; (c) Not applicable; Yes

10-5. Does your agency report use of standards from non-ANSI accredited standards developers, industry consortia groups, or both? (a) non-ANSI Accredited; (b) Consortia; (c) Both; (d) Neither; or (e) Not applicable; D

10-5. Does your agency have a schedule for periodically reviewing its use of standards for purposes of updating such use? (a) Yes; (b) No; No

10-5. How often does your agency review its standards for purposes of updating such use? [enter the number of years]: $\mathbf{0}$ 


\section{Appendix F - Federal Agency Activities Related to Use of Private Sector Standards}

NOTE: The following table lists the various standards organizations in which Federal agencies or their employees participated. The organizations, their names, and their acronyms are listed as they were reported to NIST by the agencies contributing to this year's report. There are 407 individual organizations identified by the agencies, some of which may be duplicated due to differences in the names of the same organization caused by reporting errors of the agencies or by name changes made by the organizations themselves.

\begin{tabular}{|c|c|}
\hline \multicolumn{2}{|c|}{$\begin{array}{c}\text { FY } 2005 \text { Voluntary Consensus Standards Bodies in which Federal Agencies } \\
\text { Participated }\end{array}$} \\
\hline Voluntary Consensus Standards Body & Acronym \\
\hline 3-A Sanitary Standards, Inc & 3-ASS \\
\hline 3rd Generation Partnership Project & 3GPP \\
\hline 3rd Generation Partnership Project 2 & 3GPP2 \\
\hline Accredited Standards Committee X12 & $\mathrm{X} 12$ \\
\hline Acoustical Society of America & ASA \\
\hline Adeno Associated Virus Reference Standard Working Group & AAVSWG \\
\hline Advisory Committee for water Information & ACWI \\
\hline Aerospace Industries Association of America & AIA \\
\hline Aerospace Material Standards & AMS \\
\hline Air Conditioning \& Refrigeration Institute & ACRI \\
\hline Air Movement and Control Association International, Inc. & AMCA \\
\hline Air-Conditioning \& Refrigeration Institute & ARI \\
\hline Alliance for Telecommunications Industry Solutions & ATIS \\
\hline Aluminum Association & AA \\
\hline Ambulance Manufacturers Division & AMD \\
\hline American Academy of Pediatrics & AACP \\
\hline American Architectural Manufacturers Association & AAMA \\
\hline American Association for Budget and Program Analysis & AABPA \\
\hline American Association for Clinical Chemistry & AACC \\
\hline American Association of Blood Banks & AABB \\
\hline American Association of Motor Vehicle Administrators & AAMVA \\
\hline American Association of Physicists in Medicine & AAPM \\
\hline American Association of State Highway and Transportation Officials & AASHTO \\
\hline American Association of Textile Chemists and Colorists & AATCC \\
\hline American Association of Tissue Banks & AATB \\
\hline American Bearing Manufacturers Association & ABMA \\
\hline American Boat and Yacht Council & $\mathrm{ABYC}$ \\
\hline American Bureau of Shipping & $\mathrm{ABS}$ \\
\hline American Chemical Society & ACS \\
\hline American College of Radiology & $\mathrm{ACR}$ \\
\hline American College of Surgeons & ACOS \\
\hline American Concrete Institute & $\mathrm{ACI}$ \\
\hline American Conference of Governmental Industrial Hygienists & ACGIH \\
\hline American Dental Association & $\mathrm{ADA}$ \\
\hline
\end{tabular}


American Gas Association

American Gear Manufacturers Association

AGA

American Hardboard Association

AGMA

American Industrial Hygiene Association

AHA

American Institute of Aeronautics and Astronautics

AIHA

American Institute of Steel Construction

American Institute of Timber Construction

AIAA

AISC

AITC

American Institute of Ultrasound Manufacturers

AIUM

American Iron and Steel Institute

AISI

American Ladder Institute

American Medical Association

American National Metric Council

American National Standards Institute

American Nuclear Society

American Petroleum Institute

American Public Health Association

ALI

AMA

ANMC

ANSI

ANS

API

APHA

American Public Transportation Association

APTA

American Pyrotechnics Association

American Railway Engineering \& Maintenance-of-Way Association

American Red Cross

American Society for Blood and Marrow Transplantation

American Society for Nondestructive Testing

American Society for Photogrammetry and Remote Sensing

APA

AREMA

ARC

ASBMTT

ASNT

ASPRS

American Society for Quality

American Society for Reproductive Medicine

ASQ

American Society for Testing and Materials

American Society of Agricultural and Biological Engineers

American Society of Agricultural Engineers

American Society of Cinematographers

American Society of Civil Engineers

American Society of Heating, Refrigerating, and Air-Conditioning Engineers

ASRM

ASTM

ASABE

ASAE

ASC

ASCE

ASHRAE

American Society of Mechanical Engineers

ASME

American Society of Metals

American Society of Naval Engineers

ASM

American Society of Quality Control

ASNE

American Society of Safety Engineers

American Society of Sanitary Engineering

American Towing Tank Conference

American Trucking Associations

American Vacuum Society

American Water Works Association

American Welding Society

American Wood Preservers Association

APA The Engineering Wood Association

Association for Assessment and Accreditation of Laboratory Animal Care

International

Association for Automatic Identification \& Mobility

Association for Electronic Health Care Transactions

Association for Information and Image Management

ASQC

ASSE

ASSE

ATTC

ATA

AVS

AWWA

AWS

AWPA

APA

AAALAC

AIM

AFEHCT

AIIM 
Association for Machine Technology

Association for the Advancement of Cost Engineering

Association for the Advancement of Medical Instrumentation

Association of American Railroads

Association of Biomolecular Research Facilities

Association of Diving Contractors International

Association of Food and Drug Officials

Association of Official Analytical Chemists International

Association of Public Health Laboratories

Automotive Lift Institute - ALOIM

Baking Industry Sanitary Standards Committee

Basic Linear Algebra Subprograms Technical Forum

Biometrics Application Programming Interface

British Standards Institute

Builders Hardware Manufacturers Association

Building Officials and Code Administrators International

Canadian General Standards Board

Canadian Standards Association

Cast Iron Soil Pipe Institute

Ceilings and Interior Systems Construction Association

Chlorine Institute

Clinical and Laboratory Standards Institute

Clinical Data Interchange Standards Consortium

Codex

Codex Alimentarius

College of American Pathologists

Commercial Vehicle Safety Alliance

Committee on Data for Science and Technology

Common Criteria Management Committee

Composite Panel Association

Compressed Gas Association

Conference for Food Protection

Congress of International Organizations of Medical Sciences

Consolidated Health Informatics

Construction Safety Association of Ontario

Construction Specifications Institute

Consultative Committee for Space Data Systems

Consumer Electronics Association

Convention on International Trade in Endangered Species of Wild Fauna and Flora

Cooling Technology Institute

Cooling Tower Institute

Cordage Institute

Cosmetic Ingredient Review

Cosmetic Toiletry and Fragrance Association

Council on Ionizing Radiation Measurements and Standards

Council on Optical Radiation Measurements

Crane Manufacturing Association of America

Cultural Resources Standards with State Historic Preservation Offices

\begin{tabular}{|l|}
\hline AMT \\
\hline AACE Int. \\
\hline AAMI \\
\hline AAR \\
\hline ABRF \\
\hline ADC \\
\hline AFDO \\
\hline AOACI \\
\hline APHL \\
\hline ALI \\
\hline BISSC \\
\hline BLAS \\
\hline BioAPI \\
\hline BSI \\
\hline BHMA \\
\hline BOCA \\
\hline CGSB \\
\hline CSA \\
\hline CISPI \\
\hline CISCA \\
\hline CI \\
\hline CLSI \\
\hline CDISC \\
\hline CODEX \\
\hline CODEX \\
\hline CAP \\
\hline CVSA \\
\hline CODATA \\
\hline CCMC \\
\hline CPA \\
\hline CGA \\
\hline CFP \\
\hline CIOMS \\
\hline CHI \\
\hline CSAO \\
\hline CSI \\
\hline CCSDS \\
\hline CEA \\
\hline CITES \\
\hline CTI \\
\hline CTI \\
\hline CI \\
\hline CIR \\
\hline CTFA \\
\hline CIRMS \\
\hline \\
\hline SHAA \\
\hline
\end{tabular}




\begin{tabular}{|c|c|}
\hline Data Interchange Standards Association, Inc. & DISAI \\
\hline Deep Foundations Institute & DFI \\
\hline Designated Standards Maintenance Organizations Board & DSMO \\
\hline Deutsches Institut fur Nomung - German Institute for Standardization & DIN \\
\hline Electronic Commerce Code Management Association & ECCMA \\
\hline Electronic Components Assemblies \& Materials Association & ECAMA \\
\hline Electronic Industries Alliance & EIA \\
\hline Electrostatic Discharge Association & EDA \\
\hline Engineering Sciences Data Unit International & ESDU \\
\hline European Directorate for Quality of Medicines & EDQM \\
\hline External RNA Controls Consortium & ERCC \\
\hline Eye Bank Association of America & EBAA \\
\hline Federal Facilities Council & FFC \\
\hline Federal Geographic Data Committee & FGDC \\
\hline FM Global & FMG \\
\hline Foundation for Accreditation of Cellular Therapies & FACS \\
\hline Fresh Produce Association of America & FPA \\
\hline Gas Appliance Manufacturers Association & GAMA \\
\hline Gas Technology Institute & GTI \\
\hline Government Electronics \& Information Technology Association & GEITA \\
\hline Graphic Communications Association & GCA \\
\hline Ground Water Protection Council & GWPC \\
\hline Gypsum Association & GYP \\
\hline Hardwood Plywood \& Veneer Association & HPVA \\
\hline Health Level Seven & HL7 \\
\hline Health Physics Society & HPS \\
\hline Healthcare Information and Management Systems Society & HIMSS \\
\hline High Frequency Industry Association & HFIA \\
\hline Human Factors and Ergonomics Society, Inc. & HFESI \\
\hline Human Factors Society & HFS \\
\hline IEEE - Bioinformatics Standards Committee & BSC/IEEE \\
\hline Illuminating Engineering Society of North America & IES \\
\hline Independent Cosmetic Manufacturers and Distributors & ICMAD \\
\hline Industrial Safety and Equipment Association & ISEA \\
\hline Industrial Truck Association & ITA \\
\hline Industry-wide Cooperative Meat Identification Standards Committee & ICMISC \\
\hline Information Technology Industry Council & ITI \\
\hline Institute for Interconnecting and Packaging Electronic Circuits & IPEC \\
\hline Institute of Clean Air Companies & ICAC \\
\hline Institute of Electrical and Electronic Engineers & IEEE \\
\hline Institute of Environmental Sciences \& Technology & IEST \\
\hline Institute of Makers of Explosives & IME \\
\hline Institute of Nuclear Materials Management & INMM \\
\hline Institute of Transportation Engineers & ITE \\
\hline Instrumentation Society of America & ISA \\
\hline Instrumentation, Systems, and Automation Society & ISA \\
\hline Insulated Cable Engineers Association & ICEA \\
\hline Insulated Steel Door Systems Institute & ISDSI \\
\hline
\end{tabular}




\begin{tabular}{|c|c|}
\hline Intelligent Transportation Society of America & ITS America \\
\hline Inter-American Accreditation Cooperation & IAAC \\
\hline Inter-American Metrology System & SIM \\
\hline Interconnection Technology Research Institute & ITRI \\
\hline International 2-Up ATV Manufacturers Association & I2AMA \\
\hline International Air Transport Association & IATA \\
\hline International Association for Food Protection & IAFP \\
\hline International Association for the Properties of Water and Steam & IAPWS \\
\hline International Association of Cancer Registrars & IACR \\
\hline International Association of Drilling Contractors & IADC \\
\hline International Association of Lighthouse Authorities & IALA \\
\hline International Association of Plumbing and Mechanical Officials & IAPMO \\
\hline International Astronomical Union & IAU \\
\hline International Atomic Energy Agency & IAEA \\
\hline International Blood Group Reference Laboratory & IBRGL \\
\hline International Bureau of Weights and Measures & BIPM \\
\hline International Cartographic Association & ICA \\
\hline International Civil Aviation Organization & ICAO \\
\hline International Code Council & ICC \\
\hline International Commission for Illumination & CIE \\
\hline $\begin{array}{l}\text { International Commission on Harmonization of Technical Requirements for } \\
\text { Registration of Pharmaceuticals for Veterinary Use }\end{array}$ & $\mathrm{VICH}$ \\
\hline International Commission on Occupational Health & $\mathrm{ICOH}$ \\
\hline International Commission on Radiation Protection & ICRP \\
\hline International Commission on Radiation Units and Measurements, Inc. & ICRU \\
\hline International Committee for Cosmetic Harmonization and International Cooperation & CHIC \\
\hline International Committee for Information Technology Standards & INCITS \\
\hline International Committee for Weights and Measures & CIPM \\
\hline International Conference of Building Officials & ICBO \\
\hline $\begin{array}{l}\text { International Conference on the Harmonization of Technical Requirements for } \\
\text { Registration of Pharmaceuticals for Human Use }\end{array}$ & $\mathrm{ICH}$ \\
\hline International Coordinating Committee on the Validation of Alternative Methods & ICCVAM \\
\hline International Council for Science & ICSU \\
\hline International Council on Archives & ICA \\
\hline International Dairy Federation & IDF \\
\hline International Dairy Foods Association & IDFA \\
\hline International Earth Rotation and Reference Systems Service & IERS \\
\hline International Electrotechnical Commission & IEC \\
\hline International Federation on Information Processing & IFIP \\
\hline International Hydrographic Organization & IHO \\
\hline International Imaging Industry Association & IIIA \\
\hline International Maritime Organization & IMO \\
\hline International Organization for Legal Metrology & OIML \\
\hline International Organization for Standardization & ISO \\
\hline International Organization for Standardization in Microbiology & ISOB \\
\hline $\begin{array}{l}\text { International Organization for Standardization/International Electrotechnical } \\
\text { Commission }\end{array}$ & ISO/IEC \\
\hline International Radio Consultative Committee & IRCC \\
\hline International Regulatory Alternatives Group & IRAG \\
\hline
\end{tabular}




\begin{tabular}{|c|c|}
\hline International Seed Testing Association & ISTA \\
\hline International Ship and Offshore Structures Congress & ISOSC \\
\hline International Society for Analytical Cytology & ISAC \\
\hline International Society for Blood Transfusion & ISBT \\
\hline International Society for Cardiovascular Surgery & ISCVS \\
\hline International Society for Cell Therapy & ISCT \\
\hline International Society for Measurement and Control & ISA \\
\hline International Society of Oncology Pharmacy Practitioners & ISOPP \\
\hline International Society on Thrombosis and Homeostasis & ISTH \\
\hline International Telecommunication Union & ITU \\
\hline $\begin{array}{l}\text { International Telecommunication Union - Telecommunication Standardization } \\
\text { Sector }\end{array}$ & ITU-T \\
\hline International Union Against Cancer & UICC \\
\hline $\begin{array}{l}\text { International Union of Laboratories and Experts in Materials, System and } \\
\text { Structures/International Council for Research and Innovation in Building and } \\
\text { Construction }\end{array}$ & RILEM/CIB \\
\hline $\begin{array}{l}\text { International Union of Laboratories and Experts in Materials, Systems and } \\
\text { Structures }\end{array}$ & RILEM \\
\hline International Union of Pure and Applied Chemistry & IUPAC \\
\hline Internet Engineering Task Force & IETF \\
\hline Internet Society & ISOC \\
\hline Internet Software Consortium & ISC \\
\hline Interstate Shellfish Sanitation Conference & ISSC \\
\hline JANNAF - Interagency Propulsion Committee & JANNF \\
\hline Java Grande Forum & JGF \\
\hline Joint Aeronautical Commander's Group & JACG \\
\hline Joint Commission on Accreditation of Healthcare Organizations & JCAHO \\
\hline Joint Electron Device Engineering Council & JEDEC \\
\hline Joint FAO/WHO Expert Committee on Food Additives & JECFA \\
\hline Kitchen Cabinet Manufacturers Association & KCMA \\
\hline Logical Observation Identifier Names and Codes & LOINC \\
\hline Machinery Information Management Open Systems & MIMOSA \\
\hline Magnetic Materials Producers Association & MMPA \\
\hline Manufacturers Standardization Society of the Valve and Fittings Industry & MSSVFI \\
\hline Marine Technology Society & MTS \\
\hline Master Painters Institute & MPI \\
\hline Metal Lath/Steel Framing Association, A Division of NAAMM & MLSFA \\
\hline NAFTA Land Transportation Standards Subcommittee & NAFTA \\
\hline National Academy of Sciences & NAS \\
\hline National Aerospace and Defense Contractors Accreditation Program & NADCAP \\
\hline National Association of Architectural Metal Manufacturers & NAAMM \\
\hline National Association of Corrosion Engineers & NACE \\
\hline National Association of Relay Manufacturers & NARM \\
\hline National Board of Boiler and Pressure Vessel Inspectors & NBBPVI \\
\hline National Cancer Registrar Association & NCRA \\
\hline National Cargo Bureau, Inc & NCB \\
\hline National Center for Vital and Health Statistics & NCVHS \\
\hline National Committee for Information Technology Standards & NCITS \\
\hline National Committee on Uniform Traffic Control Devices & NCUTCD \\
\hline
\end{tabular}




\begin{tabular}{|c|c|}
\hline National Committee on Vital and Health Statistics & NCVHS \\
\hline National Conference for Interstate Milk Shipments & NCIMS \\
\hline National Conference of Standards Laboratories & NCSL \\
\hline National Conference on Weights and Measures & NCWM \\
\hline National Cooperation for Laboratory Accreditation & NACLA \\
\hline National Coordinating Council for Cancer Surveillance & NCCCS \\
\hline National Council for Prescription Drug Program & NCPDP \\
\hline National Council of Radiation Protection and Measurements & NCRPM \\
\hline National Defense Industrial Association & NDIA \\
\hline National Dialog on Cancer & NDC \\
\hline National Electrical Manufacturers Association & NEMA \\
\hline National Electrical Safety Code & NESC \\
\hline National Environmental Health Association & NEHA \\
\hline National Environmental Methods Index & NEMI \\
\hline National Fire Protection Association & NFPA \\
\hline National Fluid Power Association & NFPA \\
\hline National Forum on Education Statistics & NCES Forum \\
\hline National Hydrogen Association & NHA \\
\hline National Information Standards Organization & NISO \\
\hline National Institute for Biological Sciences and Controls & NIBSC \\
\hline National Institute for Occupational Safety and Health & NIOSH \\
\hline National Institute of Building Sciences & NIBS \\
\hline National Marine Electronics Association & NMEA \\
\hline National Marine Manufacturers Association & NMMA \\
\hline National Marrow Donor Program & NMDP \\
\hline National Petroleum Management Association & NPMA \\
\hline National Safety Council & NSC \\
\hline National Sanitation Foundation & NSF \\
\hline National Skill Standards Board & NSSB \\
\hline National Spectrum Managers Association & NSMA \\
\hline National Truck Equipment Association & NTEA \\
\hline National Uniform Billing Committee & NUBC \\
\hline National Uniform Claim Committee & NUCC \\
\hline National Water-Quality Monitoring Council & NWQMC \\
\hline National Window and Door Association & NWDA \\
\hline North American Association of Central Cancer Registries & NAACCR \\
\hline North American Open Math Initiative & NAOMI \\
\hline North American Transport of Dangerous Goods Standards & NATDGS \\
\hline North American Weeds Management Association & NAWMA \\
\hline NSF International & NSFI \\
\hline Open Applications Group & OAGi \\
\hline Open Device Net Vendor Association & ODVA \\
\hline Open Geospatial Consortium & OGC \\
\hline Open Management Group & OMG \\
\hline Optical Internetworking Forum & OIF \\
\hline Optical Society of America & OSA \\
\hline Optical Storage Technology Association & OSTA \\
\hline Optics and Electro-Optics Standards Council & OEOSC \\
\hline
\end{tabular}




\begin{tabular}{|c|c|}
\hline Organization for Economic Cooperation and Development & OECD \\
\hline Organization for the Advancement of Structured Information Systems & OASIS \\
\hline Pan American Health Organization & PAHO \\
\hline Pan-American Standards Commission & COPANT \\
\hline Parachute Industry Association & PIA \\
\hline Pasteurized Milk Ordinance & $\mathrm{PMO}$ \\
\hline Performance Review Institute & PRI \\
\hline Petrotechnical Open Standards Consortium, Inc. & POSC \\
\hline Pipe Fabrication Institute & PFI \\
\hline Plastic Pipe Institute & PPI \\
\hline Plumbing and Draining Institute & PDI \\
\hline Plumbing-Heating-Cooling Contractors Association & PHCCA \\
\hline Portable Sanitation Association International & PSIA \\
\hline Post Secondary Electronic Standards Organization & PESC \\
\hline Post-Tensioning Institute & PTI \\
\hline Precast/Prestressed Concrete Institute & PCI \\
\hline Produce Marketing Association & PMA \\
\hline Project Management Institute & PMI \\
\hline Quarter-Inch Cartridge Drive Standards, Inc. & QCDS \\
\hline Rack Manufacturers Institute & RMI \\
\hline Radio Technical Commission for Aeronautics & RTCA \\
\hline Radio Technical Commission for Maritime Services & RTCM \\
\hline Recreation Vehicle Industry Association & RVIA \\
\hline Rehabilitation Engineering and Assistive Technology Society of North America & RESNA \\
\hline Research Institute for Fragrance Materials & RIFM \\
\hline Resilient Floor Covering Institute & RFCI \\
\hline Resistance Welders Manufacturers Association & RWMA \\
\hline Robotics Industry Association & RIA \\
\hline Rubber Manufacturers Association & RMA \\
\hline Scaffolding, Shoring, and Forming Institute, Inc. & SSFI \\
\hline School Interoperability Framework Association & SIFA \\
\hline Scientific Apparatus Makers Association & SAMA \\
\hline Screen Manufacturers Association & SMA \\
\hline Semantic Interoperability Community of Practice & SICOP \\
\hline Semiconductor Equipment and Materials International & SEMI \\
\hline Sheet Metal and Air Conditioning Contractors' National Association & SMACNA \\
\hline Simulation Interoperability Standards Organization & SISO \\
\hline Single Ply Roofing Institute & SPRI \\
\hline Society for Protective Coatings & SPC \\
\hline Society of Allied Weight Engineers & SAWE \\
\hline Society of American Archivists & SAA \\
\hline Society of Automotive Engineers & SAE \\
\hline Society of Cosmetic Chemists & SCC \\
\hline Society of Fire Protection Engineers & SFPE \\
\hline Society of Motion Picture and Television Engineers & SMPTE \\
\hline Society of Naval Architects and Marine Engineers & SNAME \\
\hline Society of Toxicological Pathologists & STP \\
\hline Southern Building Code Congress International, Inc. & SBCCI \\
\hline
\end{tabular}




\begin{tabular}{|c|c|}
\hline Space Frequency Coordination Group & SFCG \\
\hline Specialty Vehicle Institute of America & SVIA \\
\hline Standard for Exchange of Nonclinical Data & SEND \\
\hline Standards Engineering Society & SES \\
\hline Steel Door Institute & SDI \\
\hline Steel Founders Society of America & SFSA \\
\hline Steel Joist Institute & SJI \\
\hline Steel Window Institute & SWI \\
\hline Strategic National Implementation Process & SNIP \\
\hline Technical Association of the Pulp and Paper Industry & TAPPI \\
\hline Telecommunications Industry Association & TIA \\
\hline Telemanagement Forum & TMF \\
\hline The Business and Institutional Furniture Manufacturer's Association & BIFMA \\
\hline The Instrumentation, Systems, and Automation Society & ISAS \\
\hline The Maintenance Council of American Trucking Association & TMC/ATA \\
\hline The National Digital Orthophoto Program & NDOP \\
\hline The Open Group & TOG \\
\hline The Soap and Detergent Association & SDA \\
\hline The Society for Protective Coatings & SSPC \\
\hline The Tire and Rim Association, Inc. & TRAI \\
\hline Transportation Research Board & TRB \\
\hline Truck Trailer Manufacturers Association & TTMA \\
\hline U.S. Adopted Names Council & USANC \\
\hline U.S. Product Data Association & US PRO \\
\hline UN Centre for Trade Facilitation \& Electronic Business & UCTFEB \\
\hline Underwriters Laboratories & $\mathrm{UL}$ \\
\hline United Fresh Furit and Vegetable Association & UFFVA \\
\hline United Nations Committee on the Transport of Dangerous Goods & UNTDG \\
\hline United Nations Economic Commission for Europe WP .29/GRSP & UNECE \\
\hline United States Adopted Names & USAN \\
\hline United States Pharmacopoeia & USP \\
\hline Urban and Regional Information Systems Association & URISA \\
\hline Versailles Project on Advanced Materials and Standards & VAMAS \\
\hline Video Electronics Standards Association & VESA \\
\hline Water Environment Federation & WEF \\
\hline Window and Door Manufacturers Association & WDMA \\
\hline Workgroup for Electronic Data Interchange & WEDI \\
\hline World Health Organization & WHO \\
\hline World Intellectual Property Organization & WIPO \\
\hline World Meteorological Organization & WMO \\
\hline World Wide Web Consortium & $\mathrm{W} 3 \mathrm{C}$ \\
\hline XML Community of Practice & $\mathrm{xmlCOP}$ \\
\hline
\end{tabular}

There were 407 total Voluntary Consensus Standards Bodies in which Federal Agencies Participated during fiscal year 2005. 


\section{Appendix G - The Interagency Committee on Standards Policy (ICSP)}

The Interagency Committee on Standards Policy, also known as the ICSP, is the primary body responsible for coordinating standards use among agencies of the Federal government. The ICSP seeks to promote effective and consistent standards policies plus foster cooperation between government, industry, and other private organizations involved in standards activities. The Committee reports to the Secretary of the Department of Commerce (DOC) through the Director of the National Institute of Standards and Technology (NIST).

To review the current charter of the ICSP, click here: http://standards.gov/icsp/query/index.cfm?do=Home.ICSPCharter

To see a list of the current ICSP membership, click here: http://standards.gov/icsp/query/index.cfm?do=Home.ICSPExecutives 


\section{Appendix H - Publications Related to the National Technology Transfer and Advancement Act (NTTAA) and Office of Management and Budget (OMB) Circular A-119}

To review a list of publications and reference documents related to Federal agency implementation of the NTTAA as well as OMB Circular A-119, visit the NTTAA Library online at http://ts.nist.gov/ts/htdocs/210/nttaa/pubs.htm.

These documents can be obtained in hardcopy form by sending a written request to:

Standards Coordination and Conformity Group (SCCG)

Standards Services Division (SSD)

National Institute of Standards and Technology (NIST)

Gaithersburg, Maryland 20899-2150

301-975-2490

When making requests, please identify specific documents by title, author, and date wherever possible. 